Notas referentes às tabelas 13 e 14 :

Nota 1: Estrutura protótipo dos derivados 5-nitro-2-tiofilidênicos em estudo<smiles>[R]c1ccc(C(=O)N/N=C/c2ccc([N+](=O)[O-])s2)cc1[R]</smiles>

Nota 2:

(a): Kubinyi, H. QSAR: Hansch Analysis and Related Approaches. New York: VCR, 1993.

(b): Hansch, C., Leo, A. Exploring QSAR: Fundamentals and Applications in Chemistry and Biology. Washington: American Chemical Society, 1995.

(c): Hansch, C., Leo, A., Hoekman, D. Exploring QSAR: Hydrophobic, Electronic and Steric Constants. Washington: American Chemical Society, 1995.

(d): Calculados pelo ClogP Program, versão 4.0

Nota 3:

(*): Sintetizado e avaliado por Nascimento e colaboradores (Nascimento et al., 2003)

(*): Sintetizados e avaliados por Rezende e colaboradores (Rezende et al., 2002)

$\left.{ }^{(\star \star \star}\right)$ : Sintetizado e avaliado por Furlanetto e colaboradores (Furlanetto, Santos, Tavares, 2001)

Nota 4:

(I): Valor não disponível em literatura

(II): Valor não disponível em literatura para derivados dissubstituídos 
TABELA 13. Atividade antimicrobiana e descritores estruturais relacionados aos efeitos eletrônicos de grupos substituintes utilizados na análise de QSAR da série de derivados do 5-nitro-2-tiofilideno

\begin{tabular}{|c|c|c|c|c|c|c|}
\hline $\mathbf{R}_{1}$ & $\mathbf{R}_{\mathbf{2}}$ & $\begin{array}{l}\text { CIM } \\
(\mu \mathrm{M})\end{array}$ & $\begin{array}{l}\text { Potência } \\
\text { Log (1/C) }\end{array}$ & $\sigma^{(\mathrm{a})}$ & $\mathfrak{I}^{(\mathrm{b})}$ & $\Re^{(b)}$ \\
\hline $\mathrm{H}$ & $\mathrm{H}$ & 16,67 & $-1,22$ & 0,00 & 0,00 & 0,00 \\
\hline $\mathrm{Cl}$ & $\mathrm{H}$ & 5,52 & $-0,74$ & 0,23 & 0,42 & $-0,19$ \\
\hline $\mathrm{Cl}$ & $\mathrm{Cl}$ & 2,21 & $-0,34$ & 0,60 & - (II) & -.. (II) \\
\hline 1 & $\mathrm{H}$ & 14,01 & $-1,15$ & 0,18 & 0,42 & $-0,24$ \\
\hline $\mathrm{Br}$ & $\mathrm{H}$ & 2,12 & $-0,32$ & 0,23 & 0,45 & $-0,22$ \\
\hline $\mathrm{n}-\mathrm{C}_{3} \mathrm{H}_{7}$ & $\mathrm{H}$ & 36,55 & $-1,56$ & $-0,13$ & 0,01 & $-0,14$ \\
\hline$i-\mathrm{C}_{3} \mathrm{H}_{7}$ & $\mathrm{H}$ & 28,55 & $-1,46$ & $-0,15$ & 0,04 & $-0,19$ \\
\hline $\mathrm{OC}_{3} \mathrm{H}_{7}$ & $\mathrm{H}$ & 24,29 & $-1,38$ & $-0,25$ & $0,26^{(c)}$ & $-0,51^{\text {(c) }}$ \\
\hline $\mathrm{OC}_{4} \mathrm{H}_{9}$ & $\mathrm{H}$ & 35,41 & $-1,55$ & $-0,32$ & 0,29 & $-0,61$ \\
\hline $\mathrm{NHC}_{4} \mathrm{H}_{9}$ & $\mathrm{H}$ & 22,37 & $-1,35$ & $-0,51$ & $-0,04$ & $-0,57$ \\
\hline $\mathrm{CH}=\mathrm{CH}_{2}$ & $\mathrm{H}$ & 15,66 & $-1,19$ & $-0,02$ & 0,13 & $-0,17$ \\
\hline$n-\mathrm{C}_{4} \mathrm{H}_{9}$ & $\mathrm{H}$ & 40,74 & $-1,61$ & $-0,16$ & $-0,01$ & $-0,15$ \\
\hline $\mathrm{C}_{2} \mathrm{H}_{5}$ & $\mathrm{H}$ & 22,25 & $-1,35$ & $-0,15$ & 0,00 & $-0,15$ \\
\hline $\mathrm{COCH}_{3}$ & $\mathrm{H}$ & 0,44 & 0,36 & 0,50 & 0,33 & 0,17 \\
\hline $\mathrm{CH}_{3}{ }^{*}$ & $\mathrm{H}$ & 13,49 & $-1,13$ & $-0,17$ & 0,01 & $-0,18$ \\
\hline$C N^{* *}$ & $\mathrm{H}$ & 7,02 & $-0,85$ & 0,66 & 0,51 & 0,15 \\
\hline $\mathrm{NO}_{2}$ ** & $\mathrm{H}$ & 5,06 & $-0,70$ & 0,78 & 0,65 & 0,13 \\
\hline $\mathrm{SO}_{2} \mathrm{NH}_{2}{ }^{\star \star \star}$ & $\mathrm{H}$ & 31,75 & $-1,50$ & 0,60 & $0,49^{(c)}$ & $0,11^{\text {(c) }}$ \\
\hline
\end{tabular}


TABELA 14. Descritores estruturais relacionados ao efeito hidrofóbico e volume de grupos substituintes utilizados na análise de QSAR da série de derivados do 5-nitro-2-tiofilideno

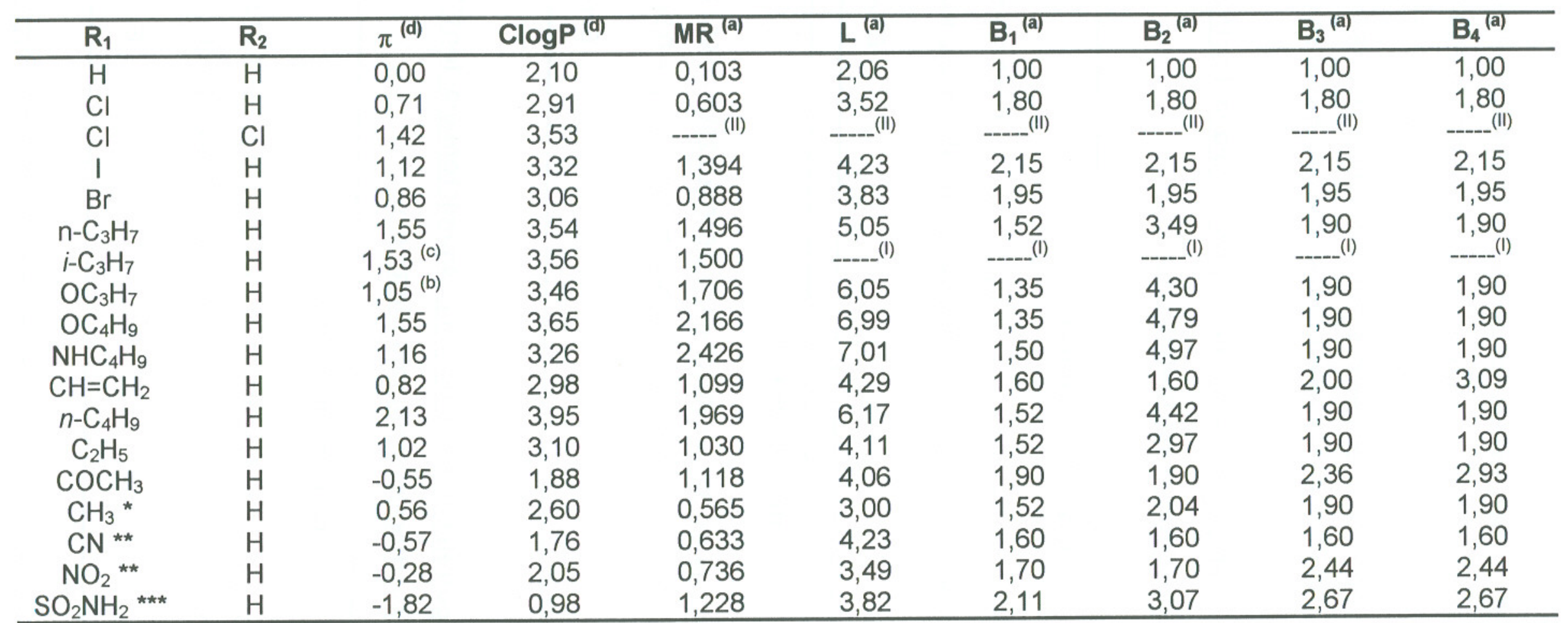


As melhores correlações foram obtidas por aplicação dos modelos parabólico e bilinear e quando associaram-se dois descritores estruturais em cada equação. A saber: $\pi$ e $\sigma, C \log P$ e $\sigma, C l o g P$ e $\mathfrak{I}$. As equações 28, 29, 30, 31, 32, 33 foram consideradas as melhores correlações que expressam a influência de propriedades físico-químicas sobre a atividade antimicrobiana da série de análogos em estudo.

Equacões obtidas pela correlacão entre potência antimicrobiana, log1/C, e os descritores estruturais $\pi$ e $\sigma$

\section{modelo parabólico}

$$
\begin{aligned}
& \log 1 / C=-0,161( \pm 0,055) \pi^{2}+0,112( \pm 0,11) \pi+0,591( \pm 0,29) \sigma-1,119( \pm 0,13) \\
& \left(n=15 ; r=0,935 ; s=0,118 ; F=25,539, Q^{2}=0,781, S_{\text {PRESS }}=0,155\right) \quad \pi_{\text {ótimo }}=0,35
\end{aligned}
$$

Equação 28

\section{modelo bilinear}

$$
\begin{gathered}
\log 1 / C=0,503( \pm 0,19) \pi-0,944( \pm 0,32) \log \left(B .10^{\pi}+1\right)+0,616( \pm 0,29) \sigma-0,951( \pm 0,16) \\
(n=15 ; r=0,943 ; s=0,116 ; F=20,017) \quad \log \beta=-0,330 \pi \pi_{\text {ótimo }}=0,39
\end{gathered}
$$

Equação 29

\section{Equacões obtidas pela correlação entre potência antimicrobiana, $\log 1 / C$, e os} descritores estruturais ClogP e $\sigma$

\section{modelo parabólico}

$\log 1 / C=-0,295( \pm 0,093) C \log P^{2}+1,544( \pm 0,49) C \log P+0,597( \pm 0,27) \sigma-3,084( \pm 0,66)$

$\left(n=15 ; r=0,943 ; s=0,111 ; F=29,211 ; Q^{2}=0,823 ; S_{\text {PRESS }}=0,140\right)$ ClogP ótimo $=2,62$

Equação 30 


\section{modelo bilinear}

$$
\begin{aligned}
\log 1 / C=+0,810( \pm 0,28) C \log P-1,457( \pm 0,47) \log \left(B .10^{C \log P}+1\right)+0,608( \pm 0,28) \sigma \\
-2,633( \pm 0,56) \\
(n=15 ; r=0,946 ; s=0,113 ; F=21,178) \quad \log B=-2,508 \quad C \log P{ }_{\text {otimo }}=2,61
\end{aligned}
$$

Equação 31

Equacões obtidas pela correlação entre potência antimicrobiana, log1/C, e os

\section{descritores estruturais ClogP e I}

\section{modelo parabólico}

$\log 1 / C=-0,297( \pm 0,099) C \log P^{2}+1,453( \pm 0,52) C \log P+0,709( \pm 0,35) \mathfrak{I}-2,929( \pm 0,67)$

$$
\left(n=15 ; r=0,935 ; s=0,117 ; F=25,587 ; Q^{2}=0,640 ; S_{\text {PRESS }}=0,199\right) C \log P_{\text {ótimo }}=2,45
$$

Equação 32

\section{modelo bilinear}

$$
\begin{aligned}
& \log 1 / C=+1,017( \pm 0,34) C \log P-1,599( \pm 0,48) \log \left(B .10^{C \log P}+1\right)+0,719( \pm 0,32) \mathfrak{s} \\
& -2,794( \pm 0,57) \\
& (n=15 ; r=0,951 ; s=0,108 ; F=23,626) \log \beta=-2,098 \quad C^{\prime} \log P{ }_{\text {ótimo }}=2,34
\end{aligned}
$$

Equação 33

\subsubsection{QSAR-3D - APLICAÇÃO DO VOLSURF PROGRAM}

O aplicativo Volsurf é um método computacional que possibilita a produção e exploração das propriedades físico-químicas espaciais de uma molécula ou de um 
conjunto delas, partindo da análise tridimensional de campos de interação molecular gerados entre os probes (moléculas ou átomos prova) e os ligantes (Cruciani et al., 2000, Cruciani, Pastor, Guba, 2000).

Cita-se como principais vantagens desta metodologia a rápida geração de descritores estruturais de caráter físico-químico de fácil entendimento e totalmente independentes do alinhamento das moléculas, sendo importante citar ainda a versatilidade de aplicação de tais descritores tanto em estudos de QSPR (Quantitative Structure-Property Relationships) como de QSAR. Pode-se afirmar assim, que é possível realizar a otimização de estruturas líderes tanto em termos de potência como em termos de propriedades farmacocinéticas (Cruciani et al., 2000, Cruciani, Pastor, Guba, 2000).

Após converter os dezoito derivados 5-nitro-2-tiofilidênicos em estudo em estruturas tridimensionais utilizando o programa CORINA (Sadowski, Rudolph, Gasteiger, 1992; Gasteiger, Rudolph, Sadowski, 1990), foram gerados os mapas de campos de interação molecular por aplicação do programa GRID (Bobbyer et al., 1989, Goodford, 1985), sendo estes posteriormente traduzidos, por aplicação do programa Volsurf, em 48 descritores estruturais de caráter físico-químico.

Procedeu-se a análise de PLS (van de Waterbeemd, 1996, Wold, Johanson, Cocchi, 1993, Geladi, Kowalski, 1986) para relacionar os dados experimentais de atividade antimicrobiana (matriz $Y$ ) com a matriz $X$ de descritores moleculares. Vale ressaltar que as variáveis latentes geradas no PLS nada mais são que uma combinação linear das variáveis $X$ originais, sendo o número de variáveis latentes significativas determinado por validação cruzada. Utilizou-se a opção leave one out, que consiste na construção de modelos que prevêem o valor de atividade biológica dos compostos em estudo, neste caso atividade antimicrobiana, excluindo temporariamente um dos compostos da análise. Este processo foi repetido até que cada um dos dezoito compostos estudados fossem pelo menos uma vez excluídos da construção dos modelos.

Classificou-se como melhor modelo que correlacionou a atividade antimicrobiana com a estrutura tridimensional da série de análogos estudada, o modelo com 48 descritores estruturais de caráter físico-químico e com valores de 
$R^{2}=0,93$ e $Q^{2}=0,87$ para três componentes principais, sendo importante citar que o alto valor do coeficiente de correlação de predição ao quadrado $\left(Q^{2}\right)$ demonstra a excelente capacidade de predição do modelo. Ressalta-se ainda que o baixo valor de SDEP (desvio padrão do erro de predição), em torno de 0,14 , corrobora a capacidade preditiva do modelo final. Apresenta-se, na figura 44, o gráfico dos valores de atividade antimicrobiana experimentais e calculados pelo modelo final obtido no Volsurf para três componentes principais.

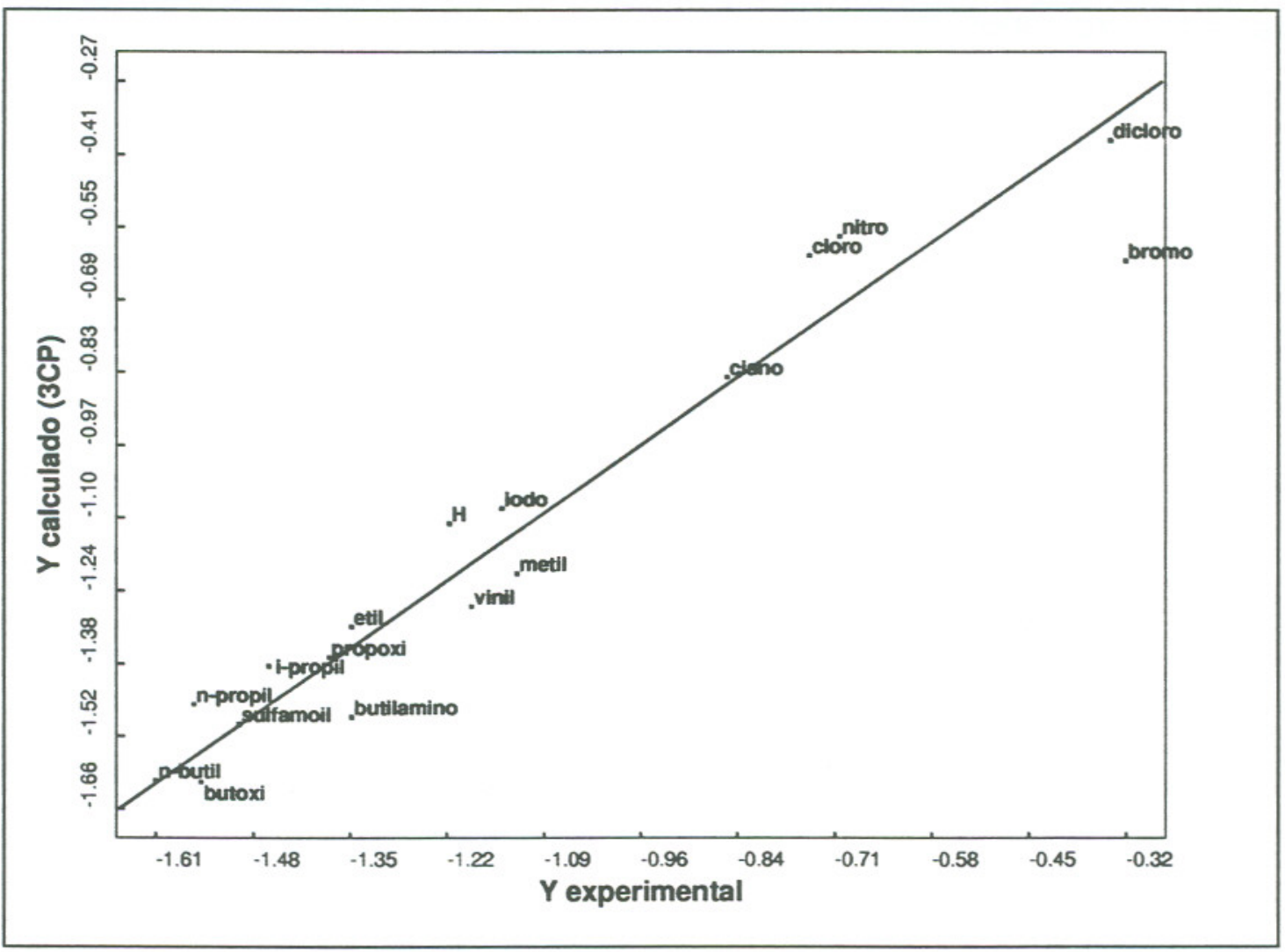

FIGURA 44. Valores de atividade antimicrobiana $(Y)$ calculados pelo modelo final com três componentes principais versus atividade antimicrobiana determinada experimentalmente.

$$
\left(n=17, x=48, y=1, R^{2}=0,93, Q^{2}=0,87\right)
$$

Os 48 descritores gerados pelo modelo são relacionados à distribuição de regiões hidrofílicas e hidrofóbicas na superfície dos ligantes, determinando a magnitude da influência de ambas propriedades na atividade antimicrobiana da série 
em estudo. É considerada ainda, nestes descritores, a capacidade de formação de ligações de hidrogênio, com caráter doador ou aceptor, determinando sua importância no estabelecimento da atividade biológica.

Será apresentado de forma mais detalhada, no item a seguir, "Discussão", o refinamento do modelo bruto inicialmente obtido, até a geração do modelo final. Será abordada ainda a contribuição dos descritores estruturais de maior relevância na análise do modelo final, indicando as características estruturais imprescindíveis para - bom desempenho das 5-nitro-2-tiofilideno benzidrazidas substituídas como agentes antimicrobianos 


\section{DISCUSSÃO}

\subsection{SINNTESE DOS COMPOSTOS}

Prepararam-se quatorze derivados 5-nitro-2-tiofilidênicos, sendo a sintese total composta por três etapas, a saber:

- Obtenção de benzoatos de metila a partir de ácidos benzóicos substituídos;

- Obtenção de benzidrazidas substituídas a partir de benzoatos de metila substituídos;

- Obtenção de 5-nitro-2-tiofilideno benzidrazidas a partir de benzidrazidas substituídas e 5-nitro-2-tiofenocarboxaldeído.

A primeira etapa da obtenção dos compostos planejados consistiu em reação de esterificação de Fischer (Carey, 2000, Solomons, Fryhle, 2000, Morrison, Boyd, 1997), figura 45, na qual se utilizou metanol anidro em excesso e quantidades catalíticas de ácido sulfúrico.

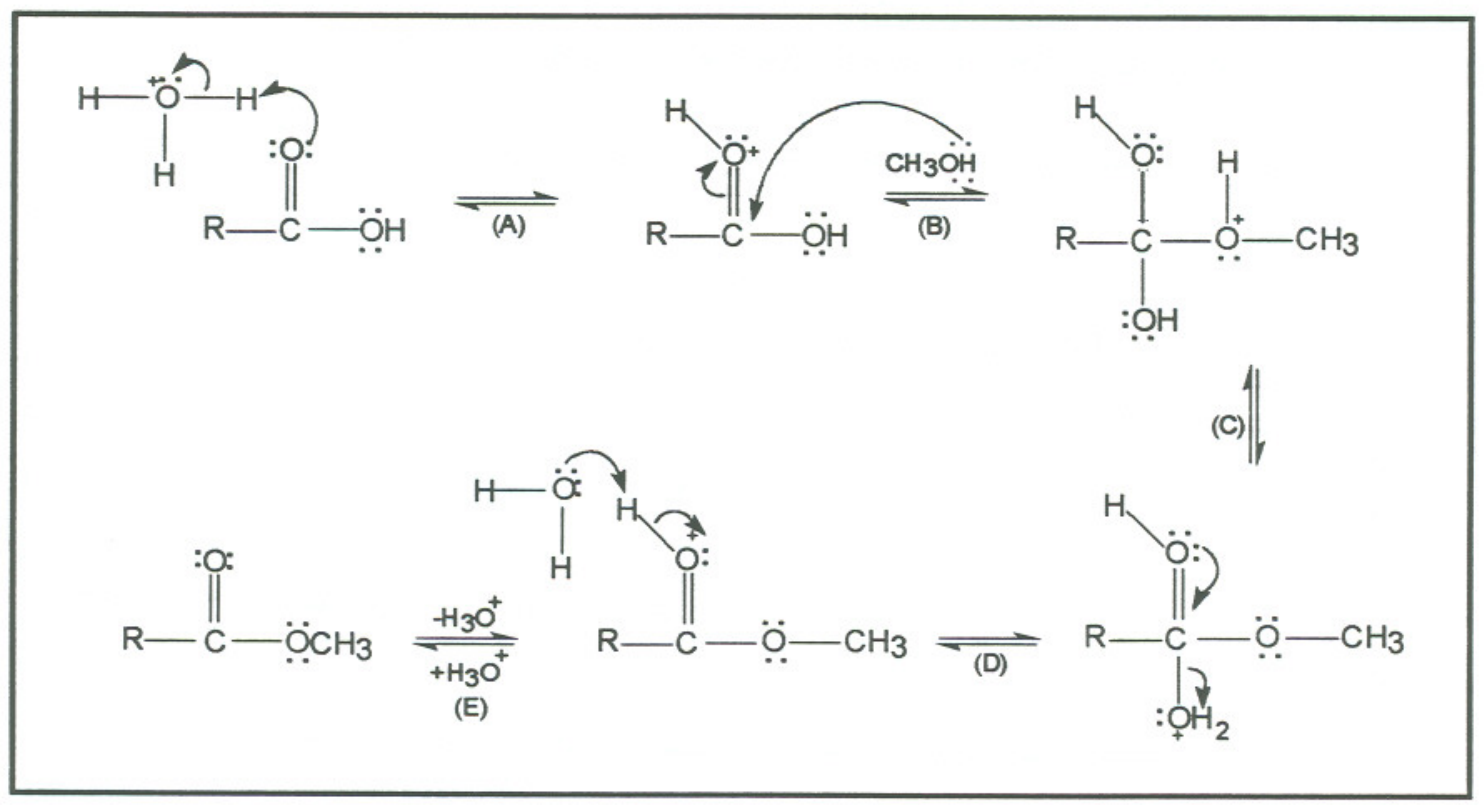

FIGURA 45. Mecanismo de esterificação de Fischer.

A esterificação clássica (Morrison, Boyd, 1997) é uma reação de condensação de caráter reversivel e, geralmente, quando o equilibrio é atingido, encontram-se em 
solução quantidades apreciáveis tanto dos reagentes como dos produtos. Baseado no conceito de equilíbrio foi essencial a utilização de um dos reagentes em excesso, neste caso o metanol, por ser menos dispendioso e de fácil remoção. $\mathrm{O}$ ácido sulfúrico, utilizado como catalisador propicia, inicialmente, a protonação do oxigênio carbonílico do ácido carboxílico tornando o carbono carbonílico mais suscetível ao ataque nucleofílico do metanol. Com isso, ocorre a geração de intermediário tetraédrico que posteriormente perde uma molécula de água originando o produto de interesse (Solomons, Fryhle, 2000, Morrison, Boyd, 1997).

A lavagem dos ésteres benzóicos com porções de água destilada, em nosso trabalho, se fez necessária para a remoção de resíduos ácidos e de metanol. Os ésteres metílicos obtidos foram identificados por comparação das faixas de fusão determinadas experimentalmente com dados encontrados na literatura e por análise espectrométrica de IV. Os rendimentos mostraram-se satisfatórios, apresentando valores de rendimento em torno de $90 \%$.

A segunda etapa da síntese dos compostos planejados, apresentada na figura 46, envolveu a formação de benzidrazidas a partir dos ésteres metílicos substituídos e hidrato de hidrazina $64 \%$ (v/v), empregando-se reação de aminólise (Carey, 2000, Solomons, Fryhle, 2000, Morrison, Boyd, 1997).

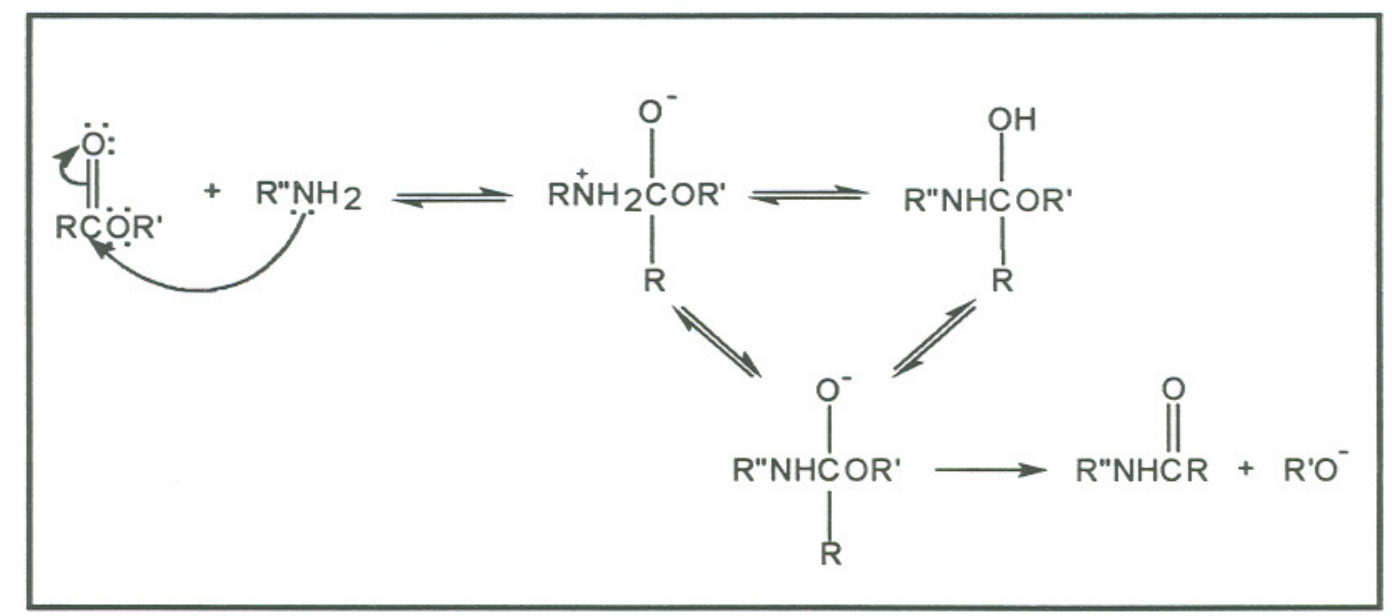

FIGURA 46. Mecanismo de amonólise de ésteres. 
Na reação de amonólise, o carbono carbonílico, deficiente em elétrons, sofre ataque nucleofílico de uma base, neste caso a hidrazina, resultando na eliminação do grupo alcoxila $\left(-\mathrm{OCH}_{3}\right)$ do intermediário tetraédrico (Morrison, Boyd, 1997). As benzidrazidas substituídas obtidas tiveram suas identidades químicas comprovadas por análise espectrométrica de IV e por comparação das faixas de fusão experimental e da literatura. Obteve-se nessa etapa rendimentos em torno de $70 \%$.

A terceira etapa consistiu na obtenção de bases de Schiff (Morrison, Boyd, 1997) por meio da reação entre um composto carbonílico, 5-nitro-2tiofenocarboxaldeído, e uma amina, benzidrazidas substituídas. Apresenta-se, na figura 47, o mecanismo de formação de bases de Schiff.

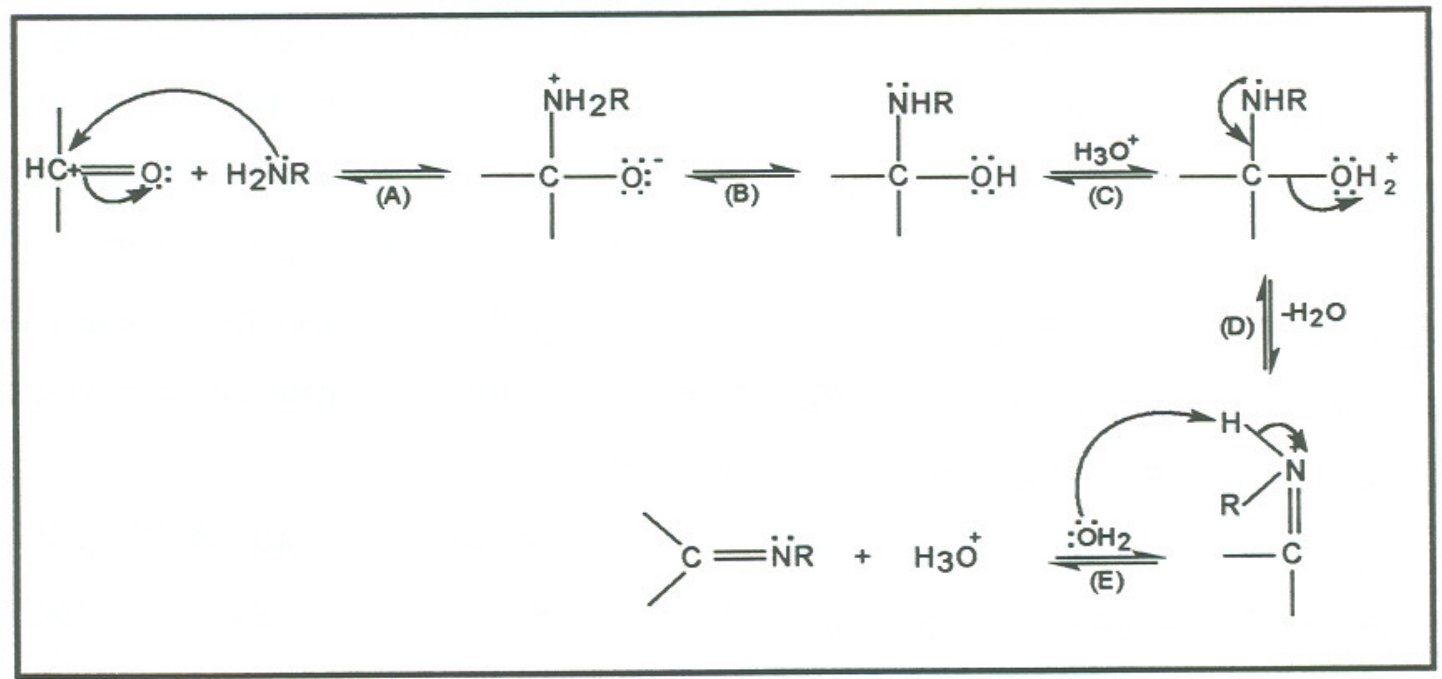

FIGURA 47. Reação de obtenção de bases de Schiff.

A formação de bases de Schiff, última etapa da síntese total dos compostos planejados neste trabalho, é uma reação de adição nucleofilica (Morrison, Boyd, 1997) catalisada por meio ácido. Inicialmente, em decorrência do pH do meio reacional, ocorre a protonação do oxigênio carbonílico do grupamento aldeído tornando-o suscetivel ao ataque nucleofilico da base (benzidrazida). A reação se completa com o ataque do nucleófilo, uma amina primária, ao centro deficiente em elétrons e a liberação de uma molécula de água. Nesta reação o meio deve estar suficientemente ácido para que ocorra a protonação de fração apreciável do 
composto carbonílico, sem, no entanto, permitir decréscimo acentuado da concentração do composto nitrogenado livre. Define-se, portanto, a basicidade da amina e a reatividade da substância carbonílica como as principais condições envolvidas na determinação da velocidade desta reação (Morrison, Boyd, 1997).

As etapas de esterificação e de obtenção de bases de Schiff apresentaram rendimentos altos, todos em torno de $90 \%$. Observou-se, entretanto, na reação de amonólise dos ésteres substituídos, rendimentos consideravelmente menores devido, primeiramente, às diferentes reatividades dos ésteres, por influência dos grupos substituintes, como também pela dificuldade de cristalização e alta solubilidade do sólido obtido em água. No caso do derivado $p$-vinil substituído observou-se na etapa de amonólise o mais baixo dos rendimentos obtidos, equivalente à $38 \%$. Acredita-se que o baixo rendimento deste composto esteja relacionado a um conjunto de fatores como alta solubilidade da benzidrazida em água, provável dificuldade de cristalização da mesma no meio reacional e perdas por filtração. Não é possível afirmar, ao certo, um motivo específico, já que, teoricamente, com a introdução do grupo vinil no anel aromático esperava-se um aumento da hidrofobicidade do composto resultante e, consequentemente, uma menor solubilidade no meio reacional que é aquoso.

Devido à alta solubilidade das benzidrazidas em água, solvente utilizado na remoção de possíveis resíduos de hidrazina não reagida, utilizou-se pequenas porções de água gelada, baixas temperaturas tendem a diminuir a solubilidade do produto nesse solvente, de forma a minimizar perdas de composto durante a lavagem. Recuperou-se ainda, pequenas quantidades de produto reduzindo-se parte do volume da água de lavagem por rotaevaporação e submetendo a solução resultante à banho de gelo.

Apresenta-se, na tabela 15, a seguir, os rendimentos parciais e total das etapas de preparação dos compostos obtidos. 
TABELA 15. Rendimentos parciais e total das etapas de preparação de 5-nitro-2-tiofilideno benzidrazidas substituídas

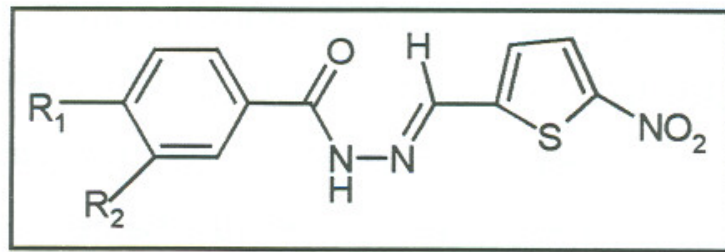

\begin{tabular}{cccccc}
\hline & & \multicolumn{4}{c}{ Rendimento (\%) } \\
\cline { 3 - 6 } $\mathbf{R}_{\mathbf{1}}$ & $\mathbf{R}_{\mathbf{2}}$ & Éster & Benzidrazida & Imina & Total \\
\hline $\mathrm{H}$ & $\mathrm{H}$ & 87 & 62 & 93 & 50 \\
$\mathrm{Cl}$ & $\mathrm{H}$ & 98 & 86 & 96 & 81 \\
$\mathrm{Cl}$ & $\mathrm{Cl}$ & 95 & 78 & 98 & 73 \\
$\mathrm{I}$ & $\mathrm{H}$ & 96 & 76 & 95 & 70 \\
$\mathrm{Br}$ & $\mathrm{H}$ & 98 & 77 & 92 & 69 \\
$n-\mathrm{C}_{3} \mathrm{H}_{7}$ & $\mathrm{H}$ & 89 & 71 & 93 & 59 \\
$i-\mathrm{C}_{3} \mathrm{H}_{7}$ & $\mathrm{H}$ & 65 & 75 & 90 & 44 \\
$\mathrm{OC}_{3} \mathrm{H}_{7}$ & $\mathrm{H}$ & 91 & 76 & 93 & 64 \\
$\mathrm{OC}_{4} \mathrm{H}_{9}$ & $\mathrm{H}$ & 83 & 66 & 97 & 53 \\
$n-\mathrm{C}_{4} \mathrm{H}_{9}$ & $\mathrm{H}$ & 90 & 82 & 98 & 72 \\
$\mathrm{CH}^{-} \mathrm{CH}_{2}$ & $\mathrm{H}$ & 60 & $38 *$ & 90 & 21 \\
$\mathrm{C}_{2} \mathrm{H}_{5}$ & $\mathrm{H}$ & 90 & 75 & 94 & 63 \\
$\mathrm{NHC}_{4} \mathrm{H}_{9}$ & $\mathrm{H}$ & 97 & 69 & 93 & 62 \\
$\mathrm{COCH}_{3}$ & $\mathrm{H}$ & 86 & 73 & 90 & 57 \\
\hline
\end{tabular}

* Rendimento muito abaixo do valor estimado.

\subsection{IDENTIFICAÇÃO DOS COMPOSTOS}

A identificação dos compostos obtidos foi feita por análises espectrométricas de IV, RMN- ${ }^{1} \mathrm{H}$ e $\mathrm{RMN}-{ }^{13} \mathrm{C}$, e seus graus de pureza foram determinados por análise elementar e faixa de fusão. No caso dos compostos 5-nitro-2-tiofilideno-4propoxibenzidrazida (VII) e 5-nitro-2-tiofilideno-4-vinilbenzidrazida $(X)$ foi observado 
um grau de pureza inferior ao constatado para os demais compostos da série, mesmo após submetê-los a recristalizações sucessivas. A faixa de fusão e a análise elementar destes compostos (tabelas 3 e 9) corroboram a afirmação citada. No caso do composto p-propoxi substituído constatou-se uma dificuldade, de certa forma, anormal de solubilização da amostra nos meios líquidos envolvidos nos ensaios biológicos. Acredita-se que as impurezas detectadas neste composto possam ter contribuído nesta dificuldade de solubilização, como também no baixo valor de atividade antimicrobiana constatado. Outro problema a ser citado se refere à baixa solubilidade da 5-nitro-2-tiofilideno-4-iodobenzidrazida (IV) em DMSO-d 6 impossibilitando a obtenção de uma solução suficientemente concentrada para um registro satisfatório do espectro de $\mathrm{RMN}-{ }^{13} \mathrm{C}$.

Os espectros de absorção na região do IV foram registrados em espectrofotômetro Shimadzu IR-470, utilizando-se dispersão em $\mathrm{KBr}$ com a finalidade de se obter espectros livres de bandas de absorção interferentes.

Apresenta-se nas tabelas 16, 17 e 18, a seguir, as principais bandas de absorção (Crews, 1998, Pavia, 1996) de ésteres aromáticos metílicos, benzidrazidas e 5-nitro-2-tiofilideno benzidrazidas substituídas, respectivamente. 
TABELAS 16 e 17. Atribuições para as principais bandas de absorção na região do IV de benzoatos de metila (A) e benzidrazidas substituídas (B)

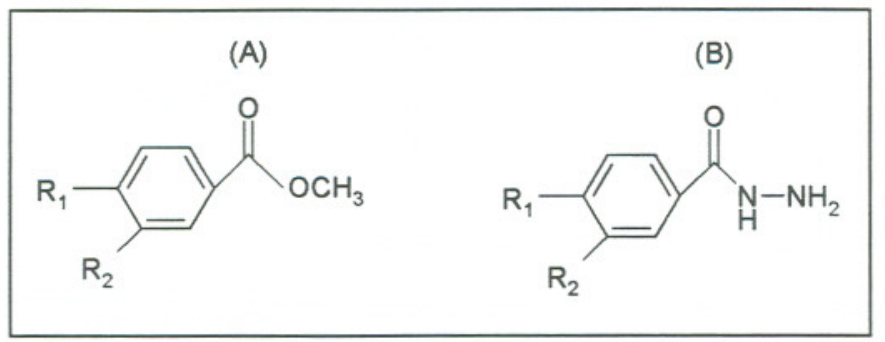

TABELA 16. Benzoatos de metila (A)

\begin{tabular}{cc}
\hline Banda de absorção $\left(\mathrm{cm}^{-1}\right)^{*}$ & Atribuição \\
\hline $3100-3000$ & estiramento $=\mathrm{C}-\mathrm{H} \mathrm{sp}{ }^{2}$ (anel aromático) \\
$2975-2950$ & estiramento C-H sp ${ }^{3}$ (metila) \\
$1740-1705$ & estiramento $\mathrm{C}=\mathrm{O}$ (éster) \\
1600 e 1475 & estiramento $\mathrm{C}=\mathrm{C}$ (anel aromático) \\
$1300-1100$ & estiramento C-O (éster) \\
$900-690$ & deformação =C-H fora do plano (anel aromático) \\
\hline
\end{tabular}

TABELA 17. Benzidrazidas substituídas (B)

\begin{tabular}{|c|c|}
\hline Banda de absorção $\left(\mathrm{cm}^{-1}\right)^{\star}$ & Atribuição \\
\hline$\cong 3300$ & estiramento $\mathrm{N}-\mathrm{H}\left(\right.$ amida $2^{\mathrm{a}}$ ) \\
\hline $3500-3300$ & estiramento $\mathrm{N}-\mathrm{H}\left(\right.$ amina $\left.1^{\mathrm{a}}\right)$ \\
\hline $3100-3000$ & estiramento $\mathrm{C}-\mathrm{H} \mathrm{sp}{ }^{2}$ (anel aromático) \\
\hline $1680-1630$ & estiramento $\mathrm{C}=\mathrm{O}$ (amida) \\
\hline $1650-1590$ & banda II de amida \\
\hline $900-690$ & deformação $=\mathrm{C}-\mathrm{H}$ fora do plano (anel aromático) \\
\hline
\end{tabular}

* Fonte: Pavia, 1996; Crews, 1998. 
TABELA 18. Atribuições para as principais bandas de absorção na região do IV de 5-nitro-2-tiofilideno benzidrazidas substituídas<smiles>[R]c1ccc(C(=O)N/N=C/c2ccc([N+](=O)[O-])s2)cc1[R]</smiles>

\begin{tabular}{cc}
\hline Banda de absorção* $\left(\mathrm{cm}^{-1}\right)$ & Atribuição \\
\hline$\cong 3300$ & estiramento $\mathrm{N}-\mathrm{H}$ (amida 2 ${ }^{\mathrm{a}}$ ) \\
$3100-3000$ & estiramento $\mathrm{C}-\mathrm{H} \mathrm{sp}$ (anel aromático) \\
$1680-1630$ & estiramento $\mathrm{C}=\mathrm{O}$ (amida) \\
1640 e 1555 & deformação $\mathrm{N}-\mathrm{H}$ (banda II de amida) \\
$1690-1650$ & estiramento $-\mathrm{C}=\mathrm{N}$ (imina) \\
$1600-1450$ & estiramento $\mathrm{C}=\mathrm{C}$ (anel aromático) \\
1550 & deformação N-H combinada com estiramento C-N \\
$1550-1490$ & estiramento $\mathrm{NO}_{2}$ assimétrico \\
$1355-1315$ & estiramento $\mathrm{NO}_{2}$ simétrico \\
$900-690$ & deformação $=\mathrm{C}-\mathrm{H}$ fora do plano (anel aromático) \\
$\cong 730$ & estiramento C-NO ${ }_{2}$ \\
\hline
\end{tabular}

* Fonte: Pavia, 1996; Crews, 1998.

São apresentadas também, nas tabelas 19 e 20, os sinais comuns aos espectros de $\mathrm{RMN}-{ }^{1} \mathrm{H}$ e $\mathrm{RMN}-{ }^{13} \mathrm{C}$ das 5-nitro-2-tiofilideno benzidrazidas substituídas (Crews, 1998, Pavia, 1996). 
TABELA 19. Atribuições para os principais sinais observados no espectro de $\mathrm{RMN}-{ }^{1} \mathrm{H}$ de 5-nitro-2-tiofilideno benzidrazidas substituídas

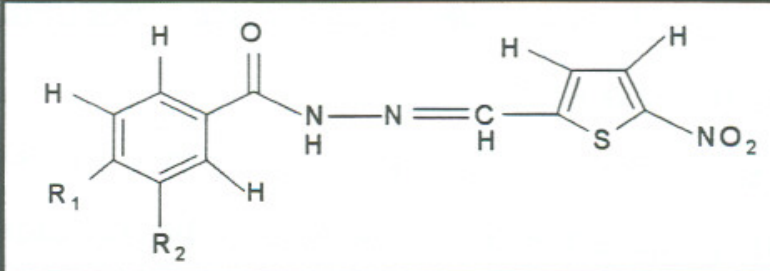

\begin{tabular}{cc}
\hline Posição dos sinais* $(\mathrm{ppm})$ & Atribuição \\
$\cong 12,00$ & $1 \mathrm{H}$, singleto, próton ligado ao nitrogênio benzamídico \\
$\cong 8,50$ & $1 \mathrm{H}$, singleto, próton ligado ao carbono azometínico \\
$\cong 7,60$ e 8,10 & $1 \mathrm{H}$, duplo dupleto, anel heterocíclico aromático \\
$8,17-7,30$ & $4 \mathrm{H}$, dupleto, anel benzênico substituído \\
\hline
\end{tabular}

* Fonte: Pavia, 1996; Crews, 1998.

TABELA 20. Atribuições para os principais sinais observados no espectro de $\mathrm{RMN}-{ }^{13} \mathrm{C}$ de 5-nitro-2-tiofilideno benzidrazidas substituídas

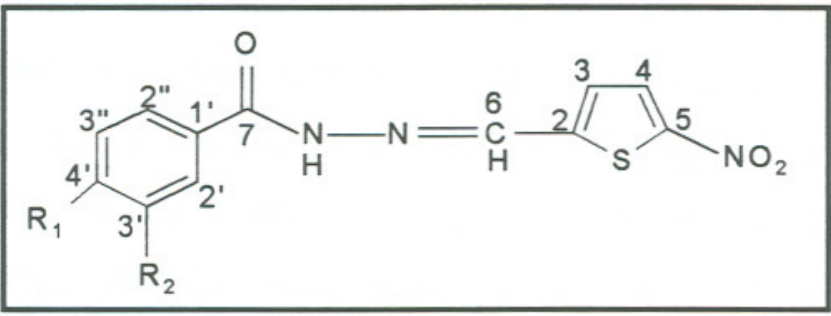

\begin{tabular}{cc}
\hline Posição dos sinais* $(\mathrm{ppm})$ & Atribuição \\
\hline $150-110$ & carbono de anel aromático \\
$185-155$ & carbono do grupo carbonilico de amida \\
$160-155$ & carbono azometínico \\
$140-115$ & carbono insaturado sp ${ }^{2}$ de heteroátomo \\
\hline
\end{tabular}

*Fonte: Pavia, 1996; Crews, 1998.

Com as análises espectrométricas realizadas, comprovou-se as identidades químicas dos compostos planejados que mostraram grau de pureza satisfatório, 
comprovados por determinação das faixas de fusão e análise elementar. Apresentase, no anexo 2 desta tese, a análise espectrométrica específica dos compostos intermediários e finais, ressaltando, em cada caso, peculiaridades estruturais registradas nos espectros de IV e RMN.

Caracterizados os compostos planejados, procedeu-se a avaliação da atividade biológica, mais propriamente, atividade antimicrobiana, por método de determinação da concentração inibitória mínima frente às cepas padrão e multiresistente de Staphylococcus aureus.

\subsection{ENSAIOS MICROBIOLÓGICOS}

\subsubsection{DETERMINAÇÃO DA CONCENTRAÇÃO INIBITÓRIA MÍNIMA FRENTE À CEPA PADRÃO (ATCC 25923) DE Staphylococcus aureus}

A determinação da concentração inibitória mínima é empregada em testes de suscetibilidade microbiana de novos agentes antimicrobianos, como nesse trabalho, no controle terapêutico de fármacos de uso prolongado, em laboratórios clínicos para esclarecer dúvidas remanescentes da aplicação de outros métodos, normalmente de difusão em disco, ou ainda em casos onde há a necessidade de resultados mais precisos (Tortora, Funke, Case, 2000, Collins, Lyne, Grange, 1995).

Neste trabalho, determinou-se a concentração inibitória mínima dos compostos obtidos, empregando o método de macrodiluição sucessiva (NCCLS, 2002, Collins, Lyne, Grange, 1995) adaptado por Tavares e colaboradores (Tavares, Penna, Amaral, 1997) com o objetivo de intensificar a sensibilidade dos resultados obtidos. Este método mostrou-se altamente viável já que permitiu a quantificação de variações de até $0,3 \mu \mathrm{g} / \mathrm{mL}$ (Tavares, Penna, Amaral, 1997) da atividade antimicrobiana dos compostos testados.

Devido à baixa solubilidade dos compostos nos solventes normalmente utilizados neste ensaio, utilizou-se DMSO (dimetilsulfóxido) como solvente padrão. Estudos precedentes, realizados em nosso grupo (Tavares, Penna, Amaral, 1997), determinaram que porcentagens iguais ou maiores a $12,5 \%$ desse solvente inibem o 
crescimento das cepas de Staphylococcus aureus em estudo. Observou-se ainda que, na dependência da crescente hidrofobicidade dos compostos, houve considerável decréscimo da sua solubilidade tanto no DMSO como no meio de cultura, TSB, utilizados nos ensaios.

Apesar da necessidade de busca de possíveis alternativas para a solubilização adequada das amostras em estudo manteve-se como requisito básico, modificar, o mínimo possível, as condições de ensaio. Assim, procedeu-se inicialmente variações mínimas do $\mathrm{pH}$ do meio, de forma a não afetar o pH ótimo de crescimento da cepa utilizada, que se dá em torno da neutralidade. Para isso, foram utilizadas, separadamente, soluções diluídas de ácido clorídrico e hidróxido de sódio, que foram adicionadas de forma sistemática ao meio em estudo com intervalos de tempo pré-estabelecidos e constante acompanhamento das variações de $\mathrm{pH}$. Não foi obtido êxito nesta primeira metodologia adotada, já que a solubilidade dos compostos não se mostrou significativamente alterada em função das variações de $\mathrm{pH}$ empregadas.

Outra possibilidade seria a troca do solvente utilizado nos ensaios. Sabia-se, entretanto, que tal mudança poderia afetar demasiadamente as condições de ensaio adotadas como padrão, optando-se, numa segunda tentativa, pela utilização de cosolvente que auxiliasse no equilibrio lipofílico/hidrofílico envolvido entre o complexo amostra/DMSO/TSB. Durante a seleção de possíveis co-solventes era imprescindível que se identificasse, por meio da literatura e experimentalmente, em que concentrações estes exerceriam efeito tóxico sobre a cepa em estudo.

Baseado nesses fatos escolheu-se em princípio os álcoois, não apenas por serem solventes pouco dispendiosos e de fácil obtenção, como também pela quantidade de informações relacionada à toxicidade dos mesmos em relação a alguns microrganismos (Tortora, Funke, Case, 2000).

Entre os álcoois disponíveis descartou-se o álcool butílico, logo de início, já que $\circ$ aumento da cadeia alifática em álcoois tende a intensificar a atividade antibacteriana (Tortora, Funke, Case, 2000). Procedeu-se alguns testes de solubilidade com álcool etílico e álcool isopropílico, observando, em ambos, estabilização da solução de forma a retardar o tempo de precipitação das amostras, que sem eles, ocorria de imediato. Acredita-se que esses solventes exerçam efeito 
tensoativo temporário sobre o complexo amostra/DMSO/TSB, contrabalançando de certa forma, os efeitos hidrofóbicos e hidrofílicos exercidos por cada componente da mistura.

O retardo no tempo de precipitação detectado foi o suficiente para que se prosseguissem as demais diluições envolvidas no teste. Como o efeito tensoativo detectado em ambos, álcoois etílico e isopropílico, se mostrou praticamente o mesmo, optou-se pela utilização do primeiro por ser menos tóxico. É conhecido que o álcool etílico passa a exercer efeito bactericida em concentrações acima de 40\%, sendo a concentração ótima em torno de 70\% (Tortora, Funke, Case, 2000) mas, como as concentrações a serem utilizadas nos testes de determinação da atividade antimicrobiana dos análogos eram inferiores à 12,5\%, considerou-se este solvente como alternativa viável na co-solubilização das amostras em estudo.

Testes para a verificação da interferência de solvente, DMSO, e co-solvente, álcool etílico, no crescimento da cepa de Staphylococcus aureus ATCC 25923 mostraram que o álcool etílico isolado, nas proporções que seriam utilizadas nos ensaios, não causava qualquer influência no crescimento dos microrganismos, já a mistura etanol/DMSO apresentou interferência sobre o crescimento microbiano em concentrações acima de $25 \%$ (1:1, v/v), ou seja 12,5\% de DMSO e 12,5\% de álcool etílico, confirmando, portanto, os estudos de toxicidade do DMSO isolado, previamente realizados por Tavares e colaboradores (Tavares, Penna, Amaral, 1997). É importante citar que a adição de álcool etílico às soluções-mãe não alterou de forma significativa o $\mathrm{pH}$ das mesmas, mantendo-as durante o teste em torno da neutralidade. A característica citada é considerada fator de extrema importância entre as condições de crescimento do microrganismo teste, já que o pH do meio de cultura utilizado, TSB, é de aproximadamente 7,3.

Determinada a concentração limite do álcool etílico isolado no ensaio, ou seja, a concentração máxima de álcool etílico que não causa qualquer interferência no crescimento bacteriano e a inexistência, pelo menos nas condições do teste, de sinergismo da mistura solvente e co-solvente em possível interferência no crescimento do microrganismo utilizado, procedeu-se a determinação da concentração inibitória mínima dos compostos mais hidrofóbicos utilizando a nova adaptação. 
Todos os ensaios foram realizados em quadruplicata na fase I e em quintuplicata na fase II, com o objetivo de minimizar, ao máximo, os erros experimentais. Foram realizadas pesagens de quatro/cinco alíquotas da amostra em balança analítica, sendo preparadas quatro/cinco soluções de partida. As leituras de inibição/crescimento microbiano foram realizadas com 18 horas de incubação a 35 ${ }^{\circ} \mathrm{C}$. As leituras realizadas com 24 e 48 horas de incubação serviram apenas como simples confirmação de resultados.

Entre os compostos sintetizados e testados frente à cepa padrão de Staphylococcus aureus, constatou-se ser a 5-nitro-2-tiofilideno 4acetilbenzidrazida (XIV) o composto mais ativo ( $\mathrm{CIM}=0,14 \mu \mathrm{g} / \mathrm{mL})$, enquanto que a 5-nitro-2-tiofilideno 4-butilbenzidrazida $(X I)$ se apresentou como composto de mais baixa atividade $(\mathrm{CIM}=13,50 \mu \mathrm{g} / \mathrm{mL})$.

Comparando a atividade antimicrobiana dos compostos analisados em relação à nifuroxazida e à nitrofurantoína frente à cepa padrão, tabela 21 , observouse que todos os compostos testados mostraram-se mais ativos que a nitrofurantoína e que apenas os derivados $p-\mathrm{Cl}$ (II), $m, p-\mathrm{Cl}_{2}$ (III), $p-\mathrm{Br}$ (XIII) e $p-\mathrm{COCH}_{3}$ (XIV) substituídos mostraram-se mais ativos que a nifuroxazida. 
TABELA 21. Concentração inibitória mínima de 5-nitro-2-tiofilideno benzidrazidas substituídas, da nifuroxazida e da nitrofurantoína frente à cepa

ATCC 25923 de Staphylococcus aureus

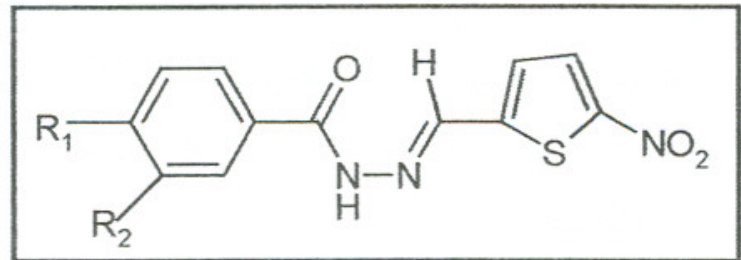

\begin{tabular}{|c|c|c|c|}
\hline$\overline{R_{1}}$ & $\mathrm{R}_{2}$ & $\mathrm{CIM}(\mu \mathrm{g} / \mathrm{mL})$ & $\begin{array}{l}\text { Potência } \\
\log (1 / \mu \mathrm{M})\end{array}$ \\
\hline$n-\mathrm{C}_{4} \mathrm{H}_{9}$ & $\mathrm{H}$ & $\leq 13,50$ & $\leq-1,61$ \\
\hline $\mathrm{OC}_{4} \mathrm{H}_{9}$ & $\mathrm{H}$ & $\leq 12,30$ & $\leq-1,55$ \\
\hline$n-\mathrm{C}_{3} \mathrm{H}_{7}$ & $\mathrm{H}$ & $\leq 11,60$ & $\leq-1,56$ \\
\hline$i-\mathrm{C}_{3} \mathrm{H}_{7}$ & $\mathrm{H}$ & $\leq 9,06$ & $\leq-1,46$ \\
\hline $\mathrm{OC}_{3} \mathrm{H}_{7}$ & $\mathrm{H}$ & $\leq 8,10$ & $\leq-1,38$ \\
\hline $\mathrm{NHC}_{4} \mathrm{H}_{9}$ & $\mathrm{H}$ & $\leq 7,75$ & $\leq-1,35$ \\
\hline $\mathrm{C}_{2} \mathrm{H}_{5}$ & $\mathrm{H}$ & $\leq 6,75$ & $\leq-1,35$ \\
\hline 1 & $\mathrm{H}$ & $\leq 5,62$ & $\leq-1,15$ \\
\hline $\mathrm{CH}=\mathrm{CH}_{2}$ & $\mathrm{H}$ & $\leq 4,72$ & $\leq-1,19$ \\
\hline $\mathrm{H}$ & $\mathrm{H}$ & $\leq 4,59$ & $\leq-1,22$ \\
\hline $\mathrm{Cl}$ & $\mathrm{H}$ & $\leq 1,71$ & $\leq-0,74$ \\
\hline $\mathrm{Cl}$ & $\mathrm{Cl}$ & $\leq 0,76$ & $\leq-0,34$ \\
\hline $\mathrm{Br}$ & $\mathrm{H}$ & $\leq 0,75$ & $\leq-0,32$ \\
\hline $\mathrm{COCH}_{3}$ & $\mathrm{H}$ & $\leq 0,14$ & $\leq 0,36$ \\
\hline \multicolumn{2}{|c|}{ Nifuroxazida } & \multicolumn{2}{|c|}{$3,60^{*}$} \\
\hline \multicolumn{2}{|c|}{ Nitrofurantoína } & \multicolumn{2}{|c|}{16,0 ** } \\
\hline
\end{tabular}

* Tavares, Penna, Amaral, 1997.

** Jones et al.,1993.

Ressalta-se ainda, que todos os compostos testados apresentaram valores de concentração inibitória mínima em região com concentração de DMSO (aproximadamente de $0,7 \%$ à $2,0 \%$ ) muito abaixo de seu limite crítico que é de 
$12,5 \%$, permitindo atribuir a inibição do crescimento microbiano apenas à atividade antibacteriana inerente aos compostos em estudo.

\subsubsection{DETERMINAÇÃO DAS CONCENTRAÇÕES INIBITÓRIA E BACTERICIDA MÍNIMAS FRENTE À CEPA MULTI-RESISTENTE (3SP/R33) de Staphylococcus aureus}

\subsubsection{DETERMINAÇÃO DA CONCENTRAÇÃO INIBITÓRIA MÍNIMA, CIM}

Foram utilizadas cepas de Staphylococcus aureus ATCC 25923 como microrganismo padrão nos testes realizados com a finalidade de validação do método para a cepa multi-resistente (3SP/R33). Entre as mais de cinqüenta cepas caracterizadas pelo Laboratório Referência Nacional de Fagotipagem de Staphylococcus aureus (LRNFSA), sob coordenação da Profa. Dra. Elsa Masae Mamizuka, escolheu-se para este estudo uma cepa resistente a dezenove agentes antimicrobianos utilizados na terapêutica atual. Tabela 11.

Entre os vários compostos testados frente à cepa multi-resistente de Staphylococcus aureus,, observou-se que a 5-nitro-2-tiofilideno 4-acetilbenzidrazida (XIV) se mostrou como $\circ$ análogo mais ativo, $C I M=0,22-0,11 \mu \mathrm{g} / \mathrm{mL}$, enquanto que a 5-nitro-2-tiofilideno 4-butilbenzidrazida (XI) $(\mathrm{CIM}=25,40-12,70$ $\mu \mathrm{g} / \mathrm{mL}$ ) se apresentou como o de mais baixa atividade.

Comparando a atividade antimicrobiana dos compostos sintetizados frente à cepa multi-resistente com os resultados obtidos para a cepa padrão, tabela 22 , observa-se que em todos os casos foi seguida a mesma tendência anteriormente constatada, ou seja, a atividade antimicrobiana aumentou consideravelmente com a hidrofobicidade dos compostos até um limite ótimo, a partir do qual observou-se considerável declínio da mesma. Cita-se ainda, que os valores de CIM em ambos os casos, cepas padrão e multi-resistente, foram praticamente os mesmos, levando-nos a acreditar que provavelmente o alvo da bactéria atingido pelos antimicrobianos analisados é o mesmo em ambas as cepas. Em outras palavras, pode-se sugerir, com base neste estudo, que a bactéria utilizada, com caráter de resistência a 
maioria dos antibióticos empregados na terapêutica atual, não dispõe ainda de mecanismos de resistência aos derivados nitrotiofênicos estudados neste trabalho.

TABELA 22. Potência antimicrobiana de 5-nitro-2-tiofilideno benzidrazidas substituídas, frente às cepas padrão (ATCC 25923) e multi-resistente (3SP/R33) de Staphylococcus aureus<smiles>[R]c1ccc(C(=O)N/N=C/c2ccc([N+](=O)[O-])s2)cc1[R]</smiles>

\begin{tabular}{|c|c|c|c|}
\hline $\mathbf{R}_{1}$ & $\mathbf{R}_{\mathbf{2}}$ & $\begin{array}{c}\text { Potência } \\
\log (1 / \mu \mathrm{M}) \\
\text { cepa ATCC } 25923\end{array}$ & $\begin{array}{c}\text { Potência } \\
\log (1 / \mu M) \\
\text { cepa 3SP/R33 }\end{array}$ \\
\hline$n-\mathrm{C}_{4} \mathrm{H}_{9}$ & $\mathrm{H}$ & $\leq-1,61$ & $\leq-1,88$ \\
\hline $\mathrm{OC}_{4} \mathrm{H}_{9}$ & $\mathrm{H}$ & $\leq-1,55$ & $\leq-1,77$ \\
\hline$n-\mathrm{C}_{3} \mathrm{H}_{7}$ & $\mathrm{H}$ & $\leq-1,56$ & $\leq-1,65$ \\
\hline$i-\mathrm{C}_{3} \mathrm{H}_{7}$ & $\mathrm{H}$ & $\leq-1,46$ & $\leq-1,50$ \\
\hline $\mathrm{OC}_{3} \mathrm{H}_{7}$ & $\mathrm{H}$ & $\leq-1,38$ & --.---* \\
\hline $\mathrm{NHC}_{4} \mathrm{H}_{9}$ & $\mathrm{H}$ & $\leq-1,35$ & $\leq-1,56$ \\
\hline $\mathrm{C}_{2} \mathrm{H}_{5}$ & $\mathrm{H}$ & $\leq-1,35$ & $\leq-1,58$ \\
\hline I & $\mathrm{H}$ & $\leq-1,15$ & $\leq-1,44$ \\
\hline $\mathrm{CH}=\mathrm{CH}_{2}$ & $\mathrm{H}$ & $\leq-1,19$ & $\leq-1,35$ \\
\hline $\mathrm{H}$ & $\mathrm{H}$ & $\leq-1,22$ & $\leq-1,45$ \\
\hline $\mathrm{Cl}$ & $\mathrm{H}$ & $\leq-0,74$ & $\leq-0,84$ \\
\hline $\mathrm{Cl}$ & $\mathrm{Cl}$ & $\leq-0,34$ & $\leq-0,56$ \\
\hline $\mathrm{Br}$ & $\mathrm{H}$ & $\leq-0,32$ & $\leq-0,55$ \\
\hline $\mathrm{COCH}_{3}$ & $\mathrm{H}$ & $\leq 0,36$ & $\leq 0,16$ \\
\hline
\end{tabular}

* não apresentou atividade nos limites de solubilidade impostos pelo teste.

\subsubsection{DETERMINAÇÃO DA CONCENTRAÇÃO BACTERICIDA MÍNIMA}

A determinação da concentração bactericida mínima, CBM, baseou-se nos resultados de inibição/crescimento microbiano obtidos na determinação da 
concentração inibitória mínima, CIM, frente à cepa 3SP/R33. Observou-se que a CBM apresentou diferentes tendências nos compostos testados, permitindo a avaliação dos derivados em questão, quanto às atividades bacteriostática e bactericida exibidas. Tabela 12 .

O composto de menor atividade bacteriostática frente à cepa multi-resistente, a 5-nitro-2-tiofilideno 4-butilbenzidrazida (XI), com valor de CIM situado na faixa entre $25,4 \mu \mathrm{g} / \mathrm{mL}$ e $12,7 \mu \mathrm{g} / \mathrm{mL}$, não apresentou atividade bactericida nos limites de solubilidade impostos pelo ensaio. Em outras palavras, devido a sua alta hidrofobicidade, a concentração máxima obtida durante a realização do teste foi equivalente a $50,80 \mu \mathrm{g} / \mathrm{mL}$. Observou-se a mesma limitação para os derivados $n$ $\mathrm{C}_{3} \mathrm{H}_{7}(\mathrm{~V}), \quad i-\mathrm{C}_{3} \mathrm{H}_{7}$ (VI), I (IV), $\mathrm{OC}_{4} \mathrm{H}_{9}$ (VIII), $\mathrm{NHC}_{4} \mathrm{H}_{9}$ (IX), n- $\mathrm{C}_{4} \mathrm{H}_{9}$ (XI) e $\mathrm{C}_{2} \mathrm{H}_{5}$ (XII) substituídos.

O composto 5-nitro-2-tiofilideno benzidrazida (I), com CIM entre 7,81 $\mu \mathrm{g} / \mathrm{mL}$ e $3,90 \mu \mathrm{g} / \mathrm{mL}$, apresentou atividade bactericida em concentração relativamente elevada $(\mathrm{CBM}=125 \mu \mathrm{g} / \mathrm{mL})$ se comparada à atividade bactericida constatada para os compostos $p-\mathrm{Cl}$ (II) $(\mathrm{CBM}=4,37-2,18 \mu \mathrm{g} / \mathrm{mL}), p-\mathrm{COCH}_{3}(\mathrm{XIV})(\mathrm{CBM}=0,22-0,11 \mu \mathrm{g} / \mathrm{mL}$ ), $p-\operatorname{Br}(\mathrm{XIII})(\mathrm{CBM}=1,25-0,63 \mu \mathrm{g} / \mathrm{mL})$ e $m, p-\mathrm{Cl}_{2}$ (III) $(\mathrm{CBM}=0,63-1,27 \mu \mathrm{g} / \mathrm{mL})$ substituídos, nos quais os valores de $\mathrm{CBM}$ mostraram ser o dobro $\left(p-\mathrm{Cl}, p-\mathrm{COCH}_{3}\right)$ ou iguais $\left(p-\mathrm{Br}, m, p-\mathrm{Cl}_{2}\right)$ à $\mathrm{CIM}$ determinada pelo método de macrodiluição sucessiva.

A partir das informações obtidas, pode-se afirmar que o composto não substituído apresenta primordialmente atividade bacteriostática, já que o valor de CBM determinado para o mesmo mostrou ser muito maior que o de CIM. Por outro lado, os compostos $p-\mathrm{Br}$ (XIII), $p-\mathrm{Cl}$ (II), $m, p-\mathrm{Cl}_{2}$ (III) e $p-\mathrm{COCH}_{3}$ (XIV) substituídos, ao mesmo tempo em que exibiram boa atividade bacteriostática, exerceram efeito bactericida em concentrações significativamente baixas, mostrando serem os análogos mais potentes entre os compostos estudados. A atividade bactericida constatada para os compostos em estudo sinalizam a importância de realização de estudos mais aprofundados desta série de compostos, que tem demonstrado ser muito promissora na identificação de alternativas viáveis para o 
tratamento de infecções causadas por cepas de Staphylococcus aureus com caráter de multi-resistência.

\subsection{ESTUDO DAS RELAÇÕES ENTRE ESTRUTURA QUÍMICA E ATIVIDADE ANTIMICROBIANA DE 5-NITRO-2-TIOFILIDENO BENZIDRAZIDAS SUBSTITUIDAS: ABORDAGEM SEMI-QUANTITATIVA}

Seguindo esquema operacional para substituição aromática proposto por Topliss (1972) constatou-se, por meio da determinação da concentração inibitória mínima dos compostos sintetizados, frente às cepas padrão (ATCC 25923) e multiresistente (3SP/R33) de Staphylococcus aureus, que o ramo da árvore decisória a ser seguido está relacionado ao aumento da hidrofobicidade dos compostos. Figura 48.

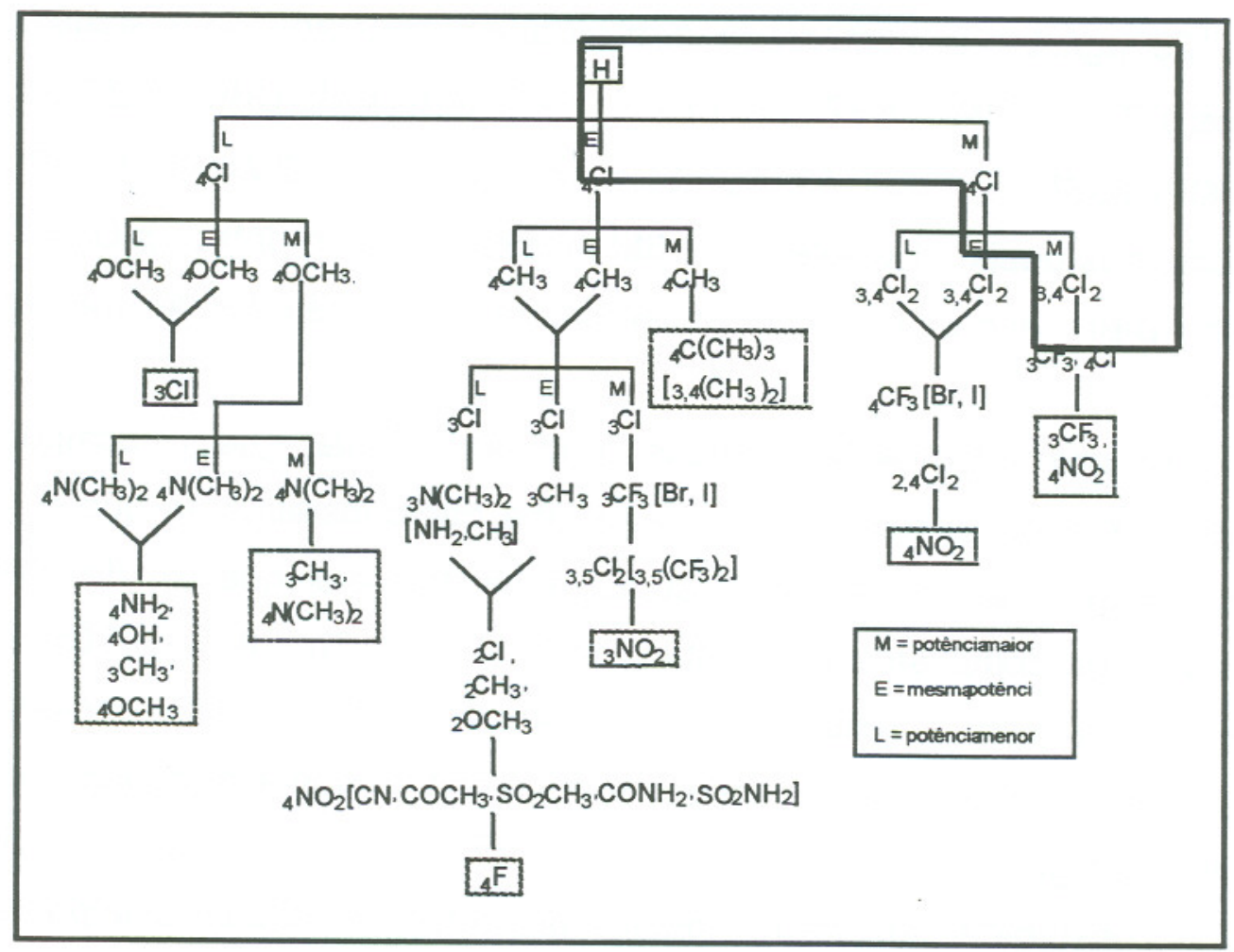

FIGURA 48. Ramo da árvore decisória proposta por Topliss que apresentou acréscimo na atividade antimicrobiana da série de análogos estudados.

(Fonte: Topliss, 1972) 
Estudos de relações quantitativas entre estrutura química e atividade antimicrobiana de quatorze 5-nitro-2-furfurilideno benzidrazidas substituídas realizados por Tavares (1993) mostraram através de Análise de Hansch, considerando modelos lineares e não-lineares, a influência predominante da hidrofobicidade em relação a outras propriedades físico-químicas na determinação da atividade antimicrobiana da série de compostos estudada.

Em outros estudos, também realizados por Tavares e colaboradores (1999a) que consistiram na substituição isostérica do anel furânico da 5-nitro-2-furfurilideno 4-acetil benzidrazida por tiofênico, conferindo maior hidrofobicidade ao análogo resultante, constatou-se que a 5-nitro-2-tiofilideno 4-acetilbenzidrazida apresentou potência antimicrobiana significativamente superior tanto em relação ao análogo furânico, quanto em comparação à nifuroxazida, comprovando ser a hidrofobicidade, propriedade de extrema importância na determinação da atividade antimicrobiana dos análogos em estudo.

Ainda com a finalidade de comprovar a influência da hidrofobicidade na atividade antimicrobiana de derivados 5-nitrofurânicos, Tavares e colaboradores (Rodrigues, 2000, Tavares et al., 1999b) associaram o esquema operacional para substituição em sistemas aromáticos de Topliss (Topliss, 1972) ao diagrama de Craig (Craig, 1971) em série de análogos à nifuroxazida, 5-nitro-2-furfurilideno 4hidroxibenzidrazida, com a finalidade de avaliar a influência de grupos substituintes na referida atividade biológica.

A aplicação do diagrama de Craig com a finalidade de ampliar o número de análogos estudados, permitiu o estabelecimento de modelos matemáticos que explicam quantitativamente a influência da hidrofobicidade na atividade dos análogos em questão. Comprovou-se, mais uma vez, em concordância com os estudos anteriormente realizados, que a hidrofobicidade constitui-se em propriedade físicoquímica de fundamental importância na determinação da atividade antimicrobiana dos derivados 5-nitrofurânicos.

Comprovada a importância da hidrofobicidade no estabelecimento da atividade antimicrobiana de análogos à nifuroxazida em estudos anteriores de nosso grupo (Rezende, 2002, Rodrigues, 2000, Tavares et al., 1999a, Tavares et al., 1999b), efetuou-se, neste trabalho, a substituição isostérica do anel furânico por 
tiofênico, ao mesmo tempo em que se aplicou, em uma primeira etapa, o esquema operacional de Topliss para substituição em sistemas aromáticos, que visa essencialmente a obtenção de compostos com atividade biológica otimizada.

Em concordância com os estudos até o momento realizados, observou-se, por aplicação do esquema operacional de Topliss, que os compostos testados demonstraram considerável acréscimo na atividade antimicrobiana à medida que se aumentou a hidrofobicidade dos análogos por influência dos grupos substituintes.

Por não apresentarem seus respectivos precursores, neste caso ácidos benzóicos dissubstituídos, disponíveis comercialmente, os compostos 5-nitro-2tiofilideno 3-trifluorometil 4-cloro benzidrazida e 5-nitro-2-tiofilideno 3-trifluorometil 4nitro benzidrazida, teriam que ser sintetizados a partir das anilinas correspondentes. Em ambos os casos foram obtidos rendimentos muito baixos na reação de obtenção de nitrilas a partir de anilinas, Reação de Sandmeyer (March, 1992, Carey,1990, Caldwell, 1951), sendo os mesmos equivalentes a $10 \%$ e $6 \%$ para a 4 -cloro-3trifluorometilbenzonitrila e a 4-nitro-3-trifluorometilbenzonitrila, respectivamente.

É provável que os baixos rendimentos obtidos na síntese destes dois compostos estejam relacionados ao caráter desativante dos grupos presentes em posição para do anel anilínico, que promovem, por ressonância, a diminuição da disponibilidade de elétrons livres do grupamento amina, fator fundamental para que ocorra o ataque eletrofílico do íon $\mathrm{NO}^{+}$ao centro com maior disponibilidade de elétrons (March, 1992, Carey, 1990). No caso do composto 3-CF $3 ; 4-\mathrm{NO}_{2}$ dissubstituído o efeito desativante mostrou-se ainda mais pronunciado em decorrência da somatória de fortes características retiradoras de elétrons dos dois grupos substituintes envolvidos. È importante citar ainda que as nitrilas obtidas, que deveriam ser sólidos, foram isoladas em forma de óleo, trazendo provavelmente agregadas consigo, grande concentração de impurezas.

Algumas tentativas de modificação da síntese de nitrilas foram realizadas mas pouco contribuíram para a melhora tanto do rendimento quanto do grau de pureza dos compostos obtidos, observando ainda, no caso da 4-nitro-3trifluorometilbenzonitrila, rápida degradação devido a um breve período de estocagem. Acredita-se que a desativação causada pelos grupos nitro e trifluorometil presentes na estrutura química deste composto provavelmente tenham contribuído 
para tal acontecimento, já que é conhecido, em literatura (March, 1992, Buu-Hoi, 1963, Hayptschein, 1954, Caldwell, Sayin, 1951) que compostos que apresentam o grupo trifluorometil são instáveis e de síntese complicada. Assim, devido às limitações citadas não pôde-se concluir a síntese dos dois últimos análogos dissubstituídos sugeridos pelo esquema operacional de Topliss.

Ressalta-se, entretanto que com base nos demais resultados obtidos, foram selecionados mais dez grupos substituintes de acordo com o Diagrama de Craig (Craig, 1971), considerando intervalo ótimo de valores da contribuição hidrofóbica dos grupos como sendo $0,70 \leq \pi \leq 1,55$, faixa identificada como ótima pela aplicação do diagrama de Topliss. Os valores de $\pi$ considerados como limite foram os correspondentes aos grupos $p-\mathrm{Cl}$ e $m-\mathrm{CF}_{3}, p-\mathrm{Cl}$, respectivamente. Além do intervalo de $\pi$ previamente estabelecido, considerou-se como pré-requisito para escolha dos grupos substituintes, variações significativas no volume dos mesmos, com a finalidade de avaliar o efeito estérico envolvido na determinação da atividade antimicrobiana dos compostos em estudo.

A razão do intervalo de hidrofobicidade situar-se entre valores de $\pi=$ 0,71 e $\pi=1,55$ nada mais é que o resultado prático de estudos relacionados à determinação da atividade antimicrobiana de 5-nitro-2-tiofilideno benzidrazidas substituídas realizados em nosso laboratório, em que os compostos que se mostraram mais ativos foram a 5-nitro-2-tiofilideno-4-bromobenzidrazida (XIII) (CIM < $0,75 \mu \mathrm{g} / \mathrm{mL}$ ) e a 5-nitro-2-tiofilideno-3,4-diclorobenzidrazida (III) (CIM = 0,76 $\mu \mathrm{g} / \mathrm{mL})$, cujos grupos substituintes, neste caso $\mathrm{p}-\mathrm{Br}$ e $m, p-\mathrm{Cl}_{2}$, apresentam valores, ou somatória, de $\pi$ equivalentes a 0,86 e 1,42, respectivamente. Observa-se que a contribuição hidrofóbica inerente a estes dois grupos substituintes, expressa por seus valores de $\pi$, situa-se dentro da faixa por nós estabelecida, de forma a englobar os dois compostos mais ativos obtidos em diferentes trabalhos desenvolvidos no Laboratório de Planejamento e Desenvolvimento de Fármacos sob coordenação do Prof. Assoc. Leoberto Costa Tavares.

Ressalta-se ainda que a seleção de grupos substituintes com constante de hidrofobicidade fora dos limites estabelecidos pelo estudo $\mathrm{como} p-\mathrm{COCH}_{3}(\pi=-$ $0,55), p-\mathrm{CH}_{3}(\pi=0,56), p-\mathrm{CN}(\pi=-0,57), p-\mathrm{NO}_{2}(\pi=-0,28)$ e $p-\mathrm{SO}_{2} \mathrm{NH}_{2}(\pi=-1,82)$ 
foi efetuada para dar maior dispersão no diagrama de Craig e evitar intercorrelação entre parâmetros. Figura 49.

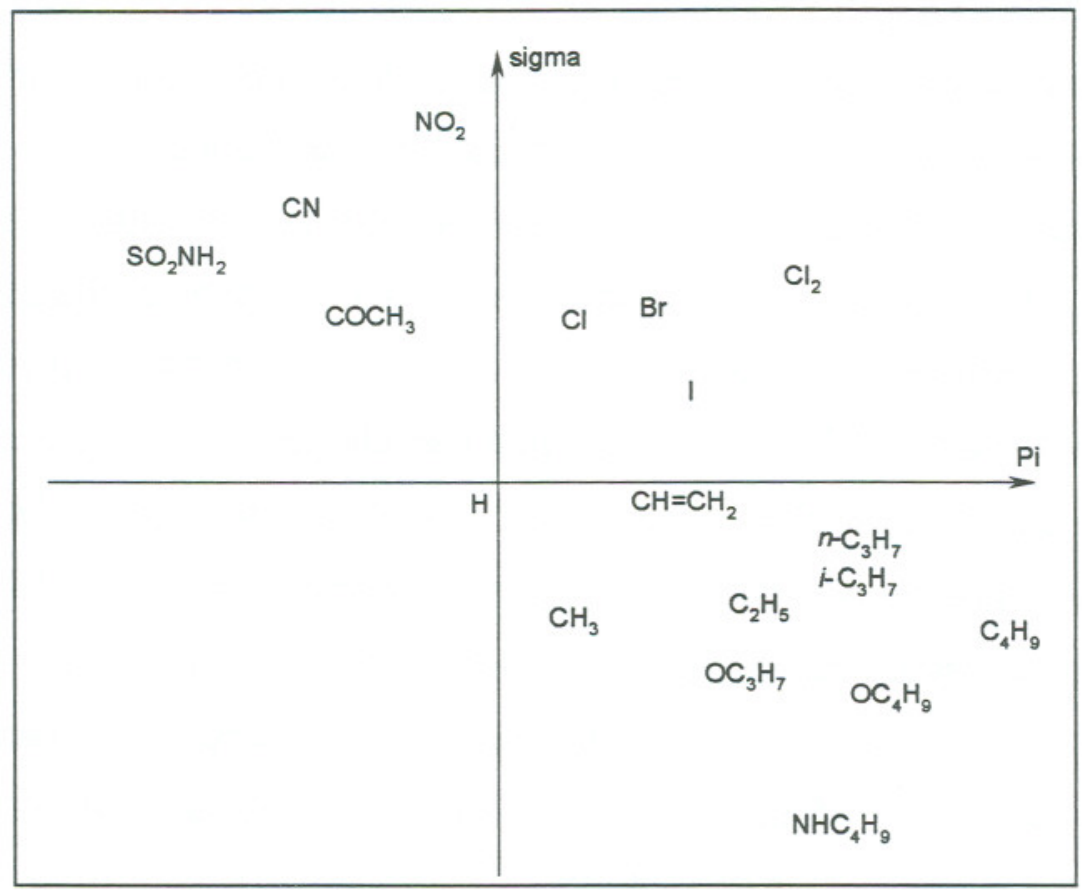

FIGURA 49. Dispersão dos grupos substituintes selecionados para a análise de QSAR-2D considerando seus valores de $\sigma$ e $\pi$

Assim, identificou-se experimentalmente, pela aplicação do diagrama operacional de Topliss, um valor aproximado da contribuição hidrofóbica inerente aos grupos substituintes selecionados $(\pi \cong 0,70 \pm 0,1)$, definido como ótimo. Desta forma, valores de $\pi$ muito acima ou muito abaixo deste valor resultaram em considerável decréscimo da atividade antimicrobiana, com exceção do composto $p$ acetil substituído que exibiu comportamento flagrantemente distinto do observado para toda a série em estudo. Será realizada, no item a seguir, a análise quantitativa da série de análogos 5-nitro-2-tiofilidênicos, na qual serão abordados os fatores que indicam o $p$-acetil derivado como sendo, provavelmente, um outlier. Tabela 23. 
TABELA 23. Potência antimicrobiana frente às cepas padrão e multi-resistente de Staphylococcus aureus e contribuição hidrofóbica inerente aos grupos substituintes de 5-nitro-2-tiofilideno benzidrazidas substituídas<smiles>[R]Cc1ccc(C(=O)N/N=C/c2ccc([N+](=O)[O-])s2)cc1[R]</smiles>

\begin{tabular}{|c|c|c|c|c|}
\hline $\mathbf{R}_{1}$ & $\mathbf{R}_{\mathbf{2}}$ & $\begin{array}{c}\text { Potência } \\
\log (1 / \mu \mathrm{M}) \\
\text { cepa ATCC } 25923\end{array}$ & $\begin{array}{c}\text { Potência } \\
\text { Log }(1 / \mu M) \\
\text { cepa 3SP/R33 }\end{array}$ & $\pi$ \\
\hline$n-\mathrm{C}_{4} \mathrm{H}_{9}$ & $\mathrm{H}$ & $\leq-1,61$ & $\leq-1,88$ & 2,13 \\
\hline $\mathrm{OC}_{4} \mathrm{H}_{9}$ & $\mathrm{H}$ & $\leq-1,55$ & $\leq-1,77$ & 1,55 \\
\hline$n-\mathrm{C}_{3} \mathrm{H}_{7}$ & $\mathrm{H}$ & $\leq-1,56$ & $\leq-1,65$ & 1,55 \\
\hline$i-\mathrm{C}_{3} \mathrm{H}_{7}$ & $\mathrm{H}$ & $\leq-1,46$ & $\leq-1,50$ & 1,53 \\
\hline $\mathrm{OC}_{3} \mathrm{H}_{7}$ & $\mathrm{H}$ & $\leq-1,38$ & --.---* & 1,05 \\
\hline $\mathrm{NHC}_{4} \mathrm{H}_{9}$ & $\mathrm{H}$ & $\leq-1,35$ & $\leq-1,56$ & 1,16 \\
\hline $\mathrm{C}_{2} \mathrm{H}_{5}$ & $\mathrm{H}$ & $\leq-1,35$ & $\leq-1,58$ & 1,02 \\
\hline 1 & $\mathrm{H}$ & $\leq-1,15$ & $\leq-1,44$ & 1,12 \\
\hline $\mathrm{CH}=\mathrm{CH}_{2}$ & $\mathrm{H}$ & $\leq-1,19$ & $\leq-1,35$ & 0,82 \\
\hline $\mathrm{H}$ & $\mathrm{H}$ & $\leq-1,22$ & $\leq-1,45$ & 0,00 \\
\hline $\mathrm{Cl}$ & $\mathrm{H}$ & $\leq-0,74$ & $\leq-0,84$ & 0,71 \\
\hline $\mathrm{Cl}$ & $\mathrm{Cl}$ & $\leq-0,34$ & $\leq-0,56$ & 1,42 \\
\hline $\mathrm{Br}$ & $\mathrm{H}$ & $\leq-0,32$ & $\leq-0,55$ & 0,86 \\
\hline $\mathrm{COCH}_{3}$ & $\mathrm{H}$ & $\leq 0,36$ & $\leq 0,16$ & $-0,55$ \\
\hline
\end{tabular}

* não apresentou atividade nos limites de solubilidade impostos pelo teste.

\subsection{ESTUDOS DAS RELAÇÕES QUANTITATIVAS ESTRUTURA-ATIVIDADE POR APLICAÇÃO DA ANÁLISE DE HANSCH, QSAR-2D}

A Análise de Hansch, QSAR-2D, foi realizada por aplicação do Billin Program, versão 1998, desenvolvido e disponibilizado pelo Prof. Kubinyi (http://home.t- 
online.de/home/kubinyi). Foi aplicado o método de stepwise, em que a atividade biológica expressa na forma de $\mu M$ e potência $(\log 1 / \mu M)$ foi correlacionada a um, dois e três descritores estruturais por vez, sendo estes relacionados à hidrofobicidade e às propriedades eletrônica e estérica de grupos substituintes. Foram obtidas várias correlações entre a atividade antimicrobiana, considerada a variável dependente, e os descritores estruturais, considerados variáveis independentes. As correlações foram representadas por equações e gráficos de dispersão com parâmetros estatísticos que têm por finalidade avaliar o ajuste do modelo obtido aos dados experimentais.

Por aplicação do modelo linear não foram observadas correlações significativas já que os maiores valores de coeficiente de correlação, $r$, se apresentaram em torno de 0,60. Ressalta-se que este comportamento já era esperado uma vez que, ao contrário de estudos que envolvem a análise quantitativa entre estrutura química e propriedades físico-químicas, QSPR (Quantitative Structure-Property Relationships), estudos que englobam dados obtidos in vitro ou in vivo, QSAR, apresentam pouca adequação para este modelo.

Aplicando os modelos parabólico e bilinear observou-se melhora significativa na maioria das correlações obtidas, destacando, em especial, as que consideraram a atividade biológica expressa na forma de potência (log1/C) versus descritores estruturais $\pi$ e $\sigma, C \log P$ e $\sigma, C l o g P$ e $\mathfrak{I}$. Apresenta-se, a seguir, o procedimento adotado na Análise de Hansch.

Inicialmente aplicou-se o modelo parabólico correlacionando a atividade antimicrobiana dos dezoito compostos em estudo com os descritores estruturais $\pi \mathrm{e}$ $\sigma$. Equação 34.

$$
\begin{gathered}
\log 1 / C=-0,205( \pm 0,17) \pi^{2}+0,184( \pm 0,27) \pi+1,036( \pm 0,67) \sigma-1,013( \pm 0,35) \\
\pi \text { ótimo }=0,45(n=18 ; r=0,780 ; s=0,368 ; F=7,227)
\end{gathered}
$$


Os parâmetros estatísticos relativamente ruins apresentados na equação 34 sugerem a possibilidade de que alguns dos dezoito compostos analisados possam estar situados fora da tendência de comportamento da série em estudo, ressaltando que para que uma correlação apresente-se como estatisticamente válida, todos os pontos analisados devem estar dentro da faixa de dois desvios padrão (Kubinyi, 1993). Pela análise do gráfico de dispersão referente a esta equação, figura 50 , evidenciou-se que $\circ$ p-acetil derivado (XIV) situava-se flagrantemente fora da tendência, fato que também pode ser comprovado pelos valores de potência antimicrobiana descritos na tabela 13.

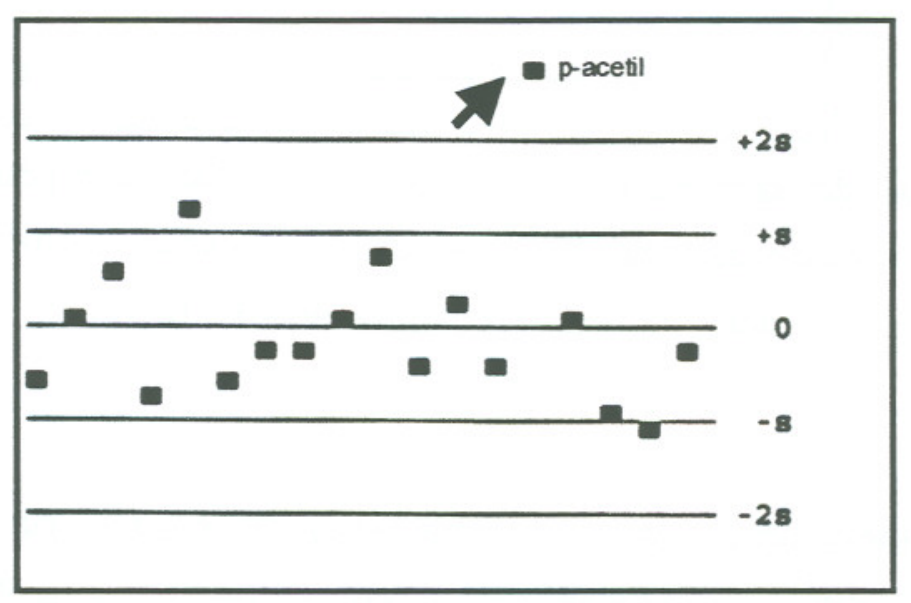

FIGURA 50. Dispersão gerada a partir da equação 34 referente à potência antimicrobiana das 5-nitro-2-tiofilideno benzidrazidas substituidas expressa em log1/C versus constante de hidrofobicidade, $\pi$, e constante de grupo, $\sigma$.

Retirando o derivado $p$-acetil substituído (XIV) da correlação, observou-se um melhor ajuste da equação gerada, equação 35 , aos dados experimentais, sendo este evidenciado pela melhora significativa dos parâmetros estatísticos obtidos.

$$
\begin{gathered}
\log 1 / C=-0,177( \pm 0,10) \pi^{2}+0,246( \pm 0,17) \pi+0,970( \pm 0,41) \sigma-1,154( \pm 0,22) \\
\pi_{\text {ótimo }}=0.70 \quad(n=17 ; r=0,870 ; s=0,225 ; F=13,509)
\end{gathered}
$$


Analisando o gráfico de dispersão gerado a partir da equação 35, entretanto, observou-se outro composto fora da linha de tendência estudada, desta vez, o $p$ bromo derivado (XIII). Figura 51.

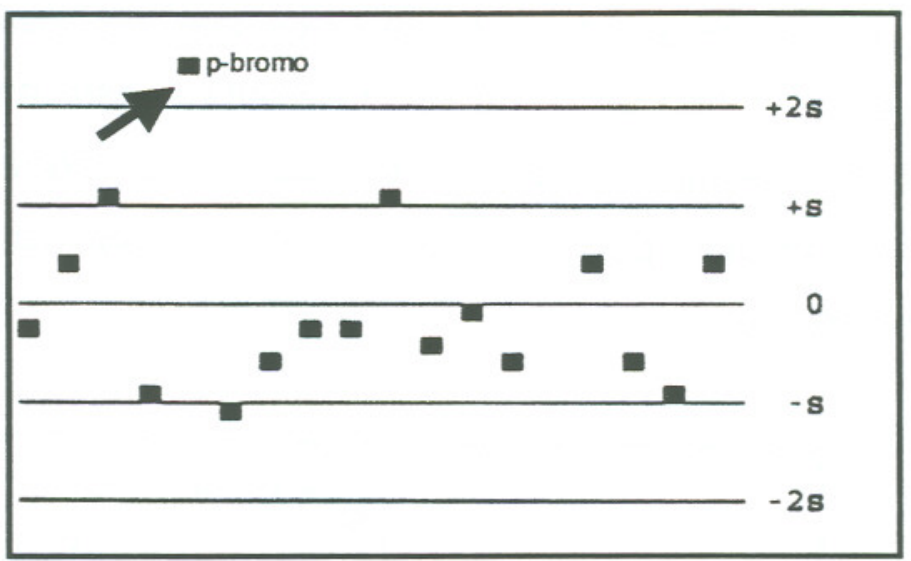

FIGURA 51. Dispersão gerada a partir da equação 35 referente à potência antimicrobiana das 5-nitro-2-tiofilideno benzidrazidas substituídas expressa em log1/C versus constante de hidrofobicidade, $\pi$, e constante de grupo $\sigma$.

Analogamente ao $p$-acetil derivado (XIV), observa-se na tabela 13 , que o $p$ bromo derivado (XIII) é extremamente ativo, situando-se também flagrantemente acima da linha de tendência de correlação dos demais compostos. Assim, retirou-se o p-bromo derivado e refez-se a correlação, o que resultou em equação com parâmetros estatísticos mais adequados. Equação 36.

$$
\begin{gathered}
\log 1 / C=-0.157( \pm 0.079) \quad \pi^{2}+0.215( \pm 0.13) \pi+0.895( \pm 0.32) \sigma-1.187( \pm 0.17) \\
\pi \text { ótimo }=0,68 \quad(n=16 ; r=0.910 ; s=0.169 ; F=19.227)
\end{gathered}
$$

Equação 36

Observou-se ainda, pelo gráfico de dispersão gerado a partir da equação 36 , figura 52, que o único derivado dissubstituído em estudo, o $m, p-\mathrm{Cl}_{2}$ (III), encontravase nos limites de desvio padrão estipulados pela correlação, o que poderia acarretar em possível desvio na equação como um todo. 


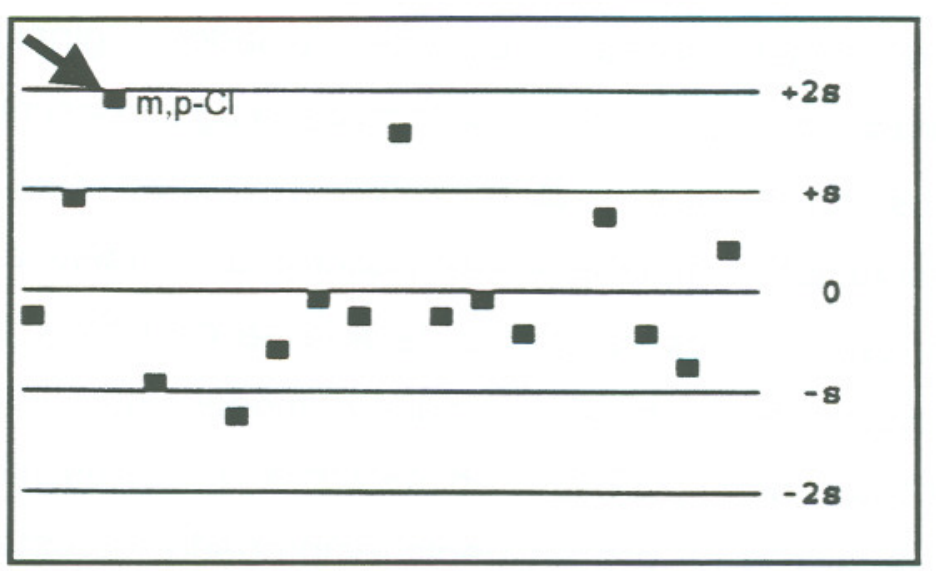

FIGURA 52. Dispersão gerada a partir da equação 36 referente à potência antimicrobiana das 5-nitro-2-tiofilideno benzidrazidas substituídas expressa em log1/C versus constante de hidrofobicidade, $\pi$, e constante de grupo $\sigma$.

Assim, retirou-se também o derivado dissubstituído (III) da correlação, observando um melhor ajuste do modelo ao conjunto de dados, resultando em equação com excelentes parâmetros estatísticos. Apresenta-se, portanto, a equação 28, como a que melhor representa a tendência de comportamento da atividade antimicrobiana da série de compostos em estudo considerando os descritores estruturais $\pi$ e $\sigma$, por aplicação do modelo parabólico.

$$
\begin{gathered}
\log 1 / C=-0.161( \pm 0.055) \pi^{2}+0.112( \pm 0.11) \pi+0.591( \pm 0.29) \sigma \\
-1.119( \pm 0.13) \\
\pi_{\text {ótimo }}=0,35 \quad(n=15 ; r=0.935 ; s=0.118 ; F=25.539)
\end{gathered}
$$

Equação 28

A exclusão do único composto dissubstituído da série, o derivado $m, p-\mathrm{Cl}_{2}$ substituído (III), resultando em melhor ajuste das equações aos dados obtidos, pode ser explicada pelo fato da excelente atividade $(\mathrm{CIM}=0,76 \mu \mathrm{g} / \mathrm{mL}$ ) exibida pelo derivado em questão sofrer provavelmente influência positiva de propriedades relacionadas ao volume dos grupos substituintes envolvidos na atividade antimicrobiana, bem como pelo seu diferente padrão de substituição em relação aos demais derivados. 
A aplicação do modelo bilinear ao conjunto de dados original considerando os descritores estruturais $\pi$ e $\sigma$, evidenciou, de forma análoga à descrita para o modelo parabólico, que os compostos p-acetil (XIV), p-bromo (XIII) e $m, p-\mathrm{Cl}_{2}$ (III) substituídos apresentavam comportamentos distintos da tendência observada para os demais. A exclusão destes derivados da análise de QSAR por aplicação do modelo bilinear, assim como observado para o modelo parabólico, resultou em melhores correlações entre potência antimicrobiana e descritores estruturais. Apresenta-se, no quadro 1, o procedimento empregado na obtenção da melhor equação que correlaciona a potência e os descritores estruturais $\pi$ e $\sigma$ por aplicação do modelo bilinear. 
Equação gerada a partir do conjunto de dados dos compostos em estudo por aplicação do modelo bilinear correlacionando atividade antimicrobiana e os descritores estruturais $\pi$ e $\sigma$.

$$
\begin{gathered}
\log 1 / C=4,625( \pm 3,82) \pi-4,810( \pm 4,04) \quad \log \left(B .10^{\pi}+1\right)+0,902( \pm 0,71) \sigma+7,824( \pm 7,62) \\
\log B=1,820 \quad \pi_{\text {otimo }}=-0,42 \quad(n=18 ; r=0,780 ; s=0,381 ; F=5,051)
\end{gathered}
$$

Equação 37

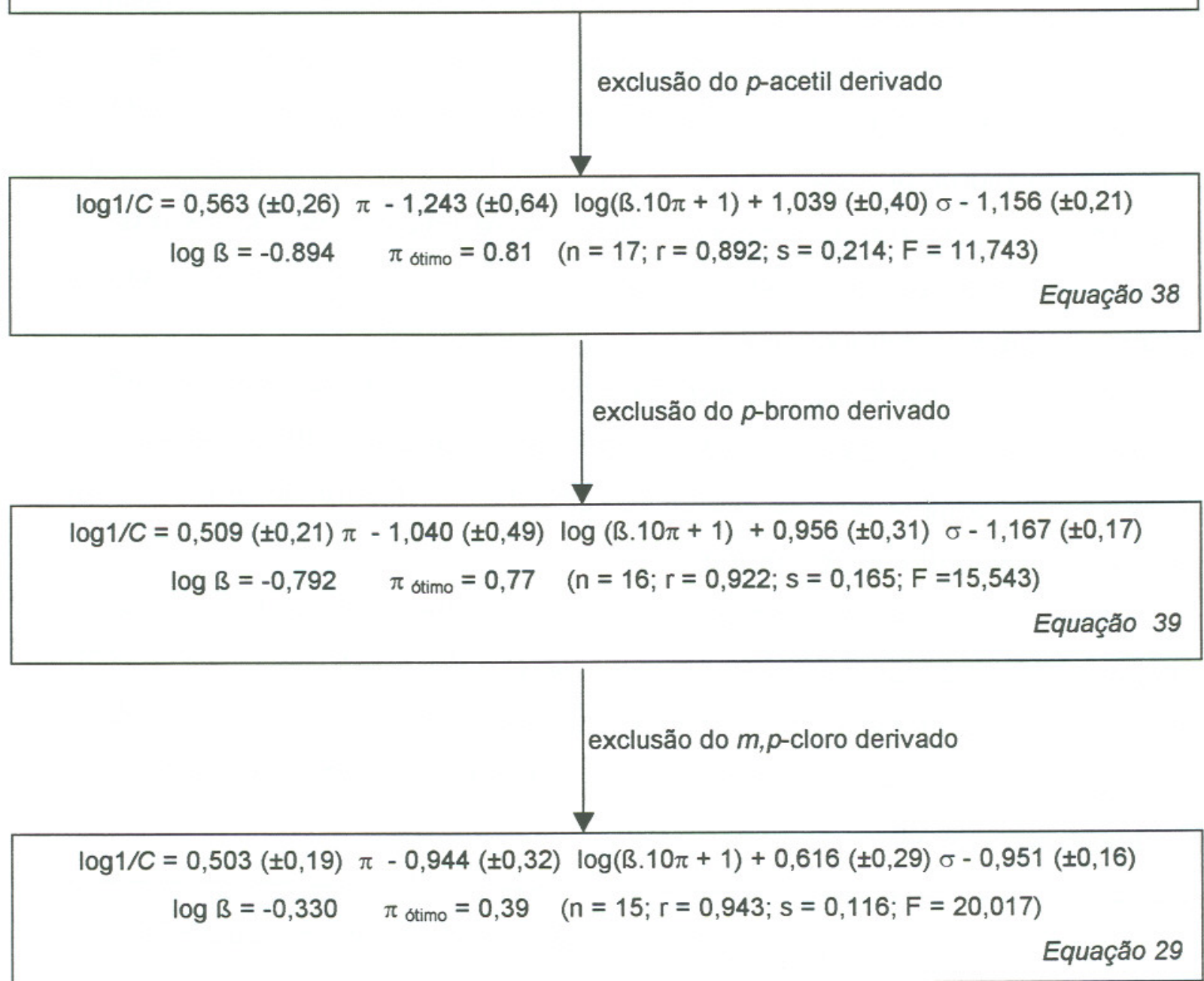

QUADRO 1. Representação esquemática de geração da equação que melhor representa a tendência de comportamento da atividade antimicrobiana das 5-nitro-2-tiofilideno benzidrazidas substituídas em relação aos descritores estruturais $\pi$ e $\sigma$ por aplicação do modelo bilinear. 
Observa-se, pelo quadro 1, que a aplicação do modelo bilinear na correlação entre potência antimicrobiana e os descritores estruturais $\pi$ e $\sigma$ resultou em melhores equações que expressam a dependência não-linear da atividade biológica em relação à hidrofobicidade. Por característica própria, este modelo apresenta termos probabilísticos, que descrevem o deslocamento de compostos químicos no sistema biológico considerando seu caráter multicompartimentar, em que a potência antimicrobiana é altamente dependente das propriedades hidrofóbicas. Assim, dois dados experimentais de extrema importância que podem ser extraídos da equação 29 e aplicados em outros estudos de QSAR devido ao seu caráter preditivo são a constante de hidrofobicidade ótima, $\pi$ ótimo, e o $\log \beta$, sendo o último citado uma constante de ajuste que expressa a relação entre volumes das fases orgânica e aquosa que pode ser aplicada na determinação experimental do coeficiente de partição de ligantes pertencentes a esta série (Kubinyi, 1993).

Aplicando o modelo parabólico na correlação entre a atividade antimicrobiana do conjunto de compostos em estudo com os descritores estruturais ClogP e $\sigma$, evidenciou-se comportamento muito semelhante ao observado nas correlações obtidas considerando os descritores $\pi$ e $\sigma$.

Ressalta-se que esta tendência já era esperada, uma vez que os valores de coeficiente de partição são calculados considerando a somatória dos valores de constante de hidrofobicidade, $\pi$, de grupos substituintes. Sendo assim, obteve-se como primeira correlação, considerando o modelo parabólico, para os descritores citados, a equação 40.

$$
\begin{array}{r}
\log 1 / C=-0,378( \pm 0,29) C \log P^{2}+2,045( \pm 1,52) C \log P+1,069( \pm 0,65) \sigma \\
-3,697( \pm 1,96) \\
C \log P_{\text {ótimo }}=2,71\left(n=18 ; r=0,788 ; s=0,362 ; F=7,623, Q^{2}=0,388, s_{\text {press }}=0,460\right) \\
\text { Equação } 40
\end{array}
$$

A baixa correlação apresentada na equação 41 indica novamente que poderia haver compostos que se situavam fora da linha de comportamento da série em estudo, fato comprovado pela análise do gráfico de dispersão gerado a parir desta 
equação, figura 53, em que o p-acetil derivado (XIV) se mostrou claramente acima da tendência de correlação. Isso se deve provavelmente ao fato da atividade antimicrobiana deste análogo ser muito maior comparativamente aos demais compostos da série estudada. Tabela 13.

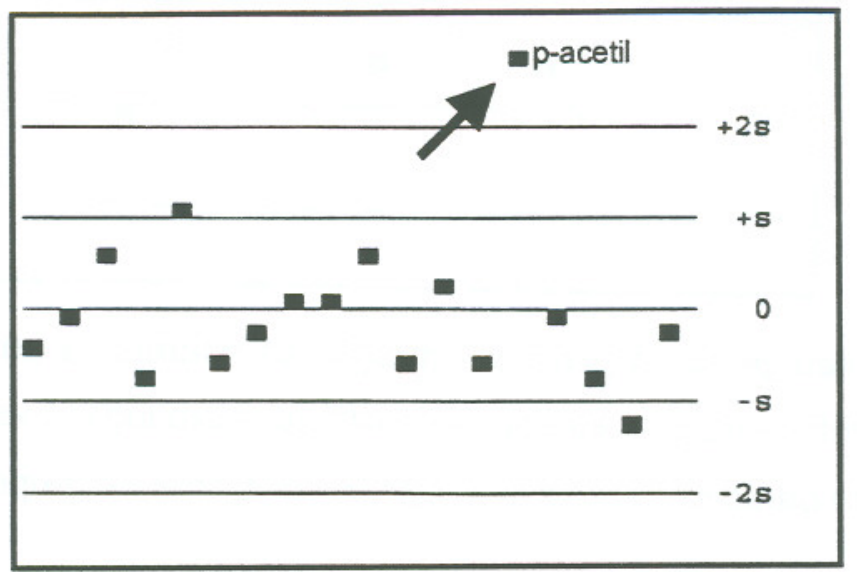

FIGURA 53. Dispersão gerada a partir da equação 40 referente à potência antimicrobiana das 5-nitro-2-tiofilideno benzidrazidas substituídas expressa em $\log 1 / C$ versus coeficiente de partição calculado, ClogP, e constante de grupo $\sigma$.

Retirando o derivado p-acetil substituído (XIV) da correlação, observou-se melhor ajuste da equação gerada aos dados experimentais, equação 41 , sendo este evidenciado pela melhoria dos parâmetros estatísticos obtidos.

$$
\begin{array}{r}
\log 1 / C=-0,330( \pm 0,18) C \log P^{2}+1,886( \pm 0,92) C \log P+0,989( \pm 0,39) \sigma \\
-3,720( \pm 1,18) \\
C \log P{ }_{\text {ótimo }}=2,86 \quad\left(n=17 ; r=0,880 ; s=0,217 ; F=14,811, Q^{2}=0,512, s_{\text {press }}=0,318\right) \\
\text { Equação } 41
\end{array}
$$

Observando o gráfico de dispersão gerado a partir da equação 41, entretanto, evidenciou-se, como esperado, o p-bromo (XIII) derivado situando-se acima da tendência de correlação. Este fato já era esperado, uma vez que este composto, à semelhança do $p$-acetil derivado, também apresenta atividade antimicrobiana muito acima da tendência do conjunto analisado. Figura 54. 


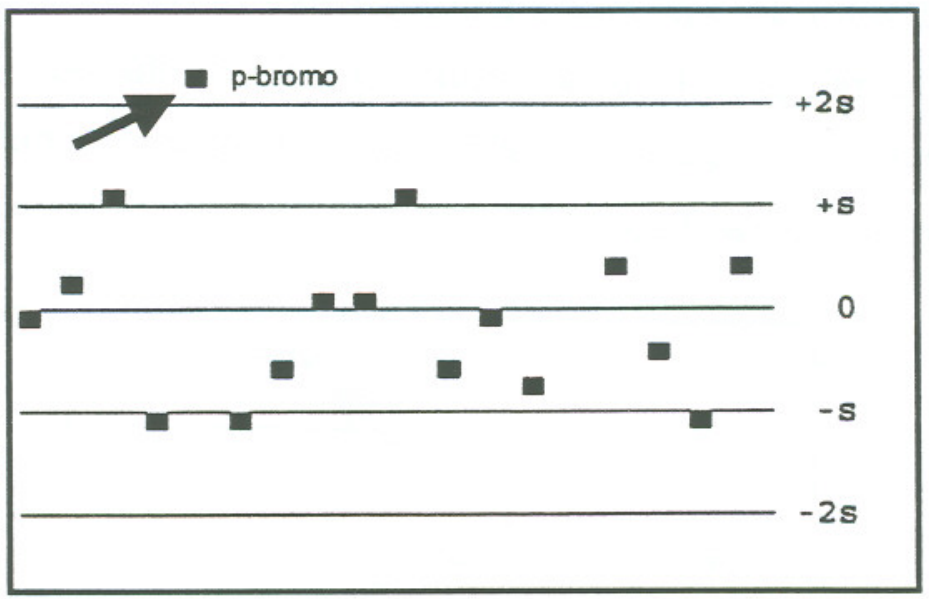

FIGURA 54. Dispersão gerada a partir da equação 41 referente à potência antimicrobiana das 5-nitro-2-tiofilideno benzidrazidas substituídas em log1/C versus coeficiente de partição calculado, $C \log P$, e constante de grupo $\sigma$.

Recalculou-se, com isso, a correlação sem o derivado p-bromo (XIII) substituido, obtendo-se equação com melhores parâmetros estatísticos. Equação 42.

$$
\begin{aligned}
& \log 1 / C=-0,291( \pm 0,14) C \operatorname{Cog} P^{2}+1,654( \pm 0,73) C \log P+0,909( \pm 0,31) \sigma \\
& -3,431( \pm 0,94) \\
& \mathrm{Clog}_{\text {ótimo }}=2,85\left(\mathrm{n}=16 ; r=0,912 ; \mathrm{s}=0,167 ; \mathrm{F}=19,726, \mathrm{Q}^{2}=0,596, \mathrm{~s}_{\text {press }}=0,258\right. \\
& \text { Equação } 42
\end{aligned}
$$

Mais uma vez, observou-se pelo gráfico de dispersão referente à equação 42 , figura 55, que o derivado $m, p-\mathrm{Cl}_{2}$ substituído (III), encontrava-se nos limites de desvio padrão estipulados pela correlação, resultando em diminuição do ajuste do modelo aos dados experimentais. Como citado anteriormente, atribui-se o comportamento diferenciado deste análogo ao efeito estérico introduzido pela presença de um átomo de cloro em posição meta, que apesar de favorecer significativamente a atividade antimicrobiana, foge ao padrão de substituição do conjunto de dados. 


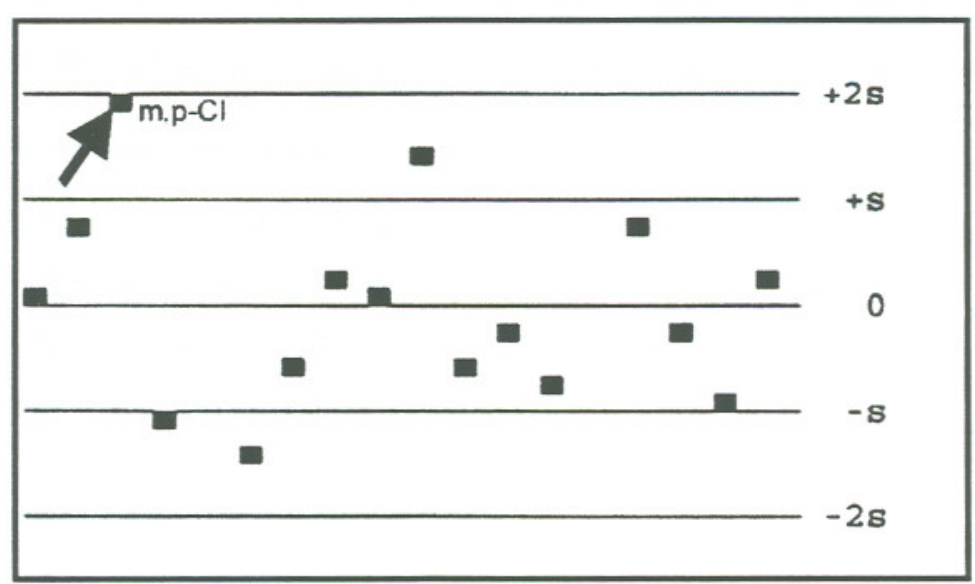

FIGURA 55. Dispersão gerada a partir da equação 42 referente à potência antimicrobiana das 5-nitro-2-tiofilideno benzidrazidas substituidas expressa em log1/C versus coeficiente de partição calculado, ClogP, e constante de grupo $\sigma$.

Com isso, retirou-se também o derivado dissubtituído (III) da correlação, obtendo-se melhor ajuste da equação aos dados, fato evidenciado pelos excelentes parâmetros estatísticos obtidos. Considera-se a equação 30 como a que melhor representa a tendência de comportamento da atividade antimicrobiana da série de compostos em estudo em relação aos descritores estruturais ClogP e $\sigma$ por aplicação do modelo parabólico.

$$
\begin{gathered}
\log 1 / C=-0,295( \pm 0,093) C \log P^{2}+1,544( \pm 0,49) C \log P+0,597( \pm 0,27) \sigma \\
-3,084( \pm 0,66)
\end{gathered}
$$

$C_{\log P}{ }_{\text {ótimo }}=2,62\left(n=15 ; r=0,943 ; s=0,111 ; F=29,211, Q^{2}=0,823, s_{\text {press }}=0,140\right)$ Equação 30

Por aplicação do modelo bilinear na correlação da atividade antimicrobiana dos dezoito compostos em estudo com os descritores estruturais ClogP e $\sigma$, observou-se, de forma análoga à descrita para o modelo parabólico, que os compostos p-acetil (XIV), p-bromo (XIII) e $m, p-\mathrm{Cl}_{2}$ (III) substituídos apresentavam comportamentos distintos da tendência até então observada. A exclusão destes 
derivados da análise de QSAR por aplicação do modelo bilinear, resultou em melhores correlações que se representa no esquema a seguir. Quadro 2.

Equação gerada a partir do conjunto de dados dos compostos em estudo por aplicação do modelo bilinear correlacionando atividade antimicrobiana e os descritores estruturais ClogP e $\sigma$. $\log 1 / C=1,589( \pm 1,23) C \log P-2,065( \pm 1,65) \log \left(B .10^{C \log P}+1\right)+1,040( \pm 0,68) \sigma-3,579( \pm 1,96)$ $\log B=-1,977 \quad C \log P$ ótimo $=2,50 \quad(n=18 ; r=0,788 ; s=0,375 ; F=5,332)$

Equação 43

exclusão do p-acetil derivado
$\log 1 / C=0,840( \pm 0,38) C \log P-1,908( \pm 0,97) \log (B .10 C \log P+1)+1,025( \pm 0,39) \sigma-2,961( \pm 0,84)$ $\log B=-3,028 \quad C \log P_{\text {otimo }}=2,92 \quad(n=17 ; r=0,892 ; s=0,214 ; F=11,720)$

Equação 44

exclusão do p-bromo derivado

$\log 1 / C=0,805( \pm 0,35) C \log P-1,518( \pm 0,74) \log (B .10 C \log P+1)+0,939( \pm 0,32) \sigma-2,849( \pm 0,73)$

$\log B=-2,809 \quad C \log P$ ótimo $=2,86(n=16 ; r=0,916 ; s=0,171 ; F=14,263)$

Equação 45

exclusão do m,p-cloro derivado

$\log 1 / C=0,810( \pm 0,28) C \log P-1,457( \pm 0,47) \log \left(B .10^{C \log P}+1\right)+0,608( \pm 0,28) \sigma-2,633( \pm 0,56)$

$\log B=-2,508 \quad C \log P_{\text {otimo }}=2,61 \quad(n=15 ; r=0,946 ; s=0,113 ; F=21,178)$

Equação 31

QUADRO 2. Representação esquemática de geração da equação que melhor representa a tendência de comportamento da atividade antimicrobiana das 5-nitro-2-tiofilideno

benzidrazidas substituídas em relação aos descritores estruturais

ClogP e $\sigma$ por aplicação do modelo bilinear. 
$\mathrm{Na}$ correlação da potência antimicrobiana com os descritores estruturais ClogP e $\sigma$ por aplicação do modelo bilinear, observou-se que, analogamente ao constatado para os descritores $\pi$ e $\sigma$, foram obtidas as melhores equações que expressam descrição da dependência não-linear da atividade biológica em relação à hidrofobicidade. Ressalta-se, mais uma vez, a importância de dois dados experimentais com caráter preditivo obtidos que são o coeficiente de partição ótimo, Clog $P_{\text {ótimo, }}$ e o $\log \beta$ que podem ser aplicados em estudos futuros de QSAR de séries derivadas do 5-nitro-2-tiofilideno. Quadro 2.

Analisou-se também as correlações que associaram a atividade antimicrobiana expressa na forma de potência com os descritores estruturais de caráter hidrofóbico, ClogP, e eletrônico, representado pela constante $\mathfrak{I}$ de Swain e Lupton Swain, Lupton, 1968).

$\mathrm{O}$ único composto dissubstituído avaliado neste estudo, o derivado $m, p-\mathrm{Cl}_{2}$ (III), foi excluído inicialmente do conjunto de dados pelas razões já citadas e também por não apresentar, em literatura, os valores dos descritores estruturais de caráter eletrônico $\mathfrak{I}$ e $\mathfrak{R}$. Isso se deve ao fato de que, ao contrário dos descritores $\pi$ e $\sigma$, em que se aplica o princípio da aditividade, as constantes $\mathfrak{I}$ e $\mathfrak{R}$ de Swain e Lupton do grupamento cloro nas posições meta e para se simplesmente somadas não representam a influência real deste substituinte em ambas posições citadas em relação à atividade antimicrobiana (Hansch, Leo, 1995, Kubinyi, 1993).

Desta forma, aplicou-se o modelo parabólico correlacionando a atividade antimicrobiana dos dezessete compostos em estudo com os descritores estruturais ClogP e I. Equação 46.

$$
\begin{array}{r}
\log 1 / C=-0,389( \pm 0,32) C \log P^{2}+1,834( \pm 1,64) C \log P+0,880( \pm 1,07) \mathfrak{I} \\
-3,137( \pm 2,10) \\
C \log P_{\text {ótimo }}=2,36\left(n=17 ; r=0,732 ; s=0,391 ; F=4,998, Q^{2}=0,009, s_{\text {press }}=0,571\right) \\
\text { Equação } 46
\end{array}
$$

Evidenciou-se pelos parâmetros estatísticos da equação 46 , baixa correlação entre os dados do conjunto, sugerindo que, provavelmente, haveria compostos que 
fugiam à tendência de comportamento da série em estudo, fato comprovado pela análise do gráfico de dispersão referente a esta equação, figura 56 , em que o $p$ acetil derivado (XIV) se mostrou mais uma vez, totalmente fora da tendência.

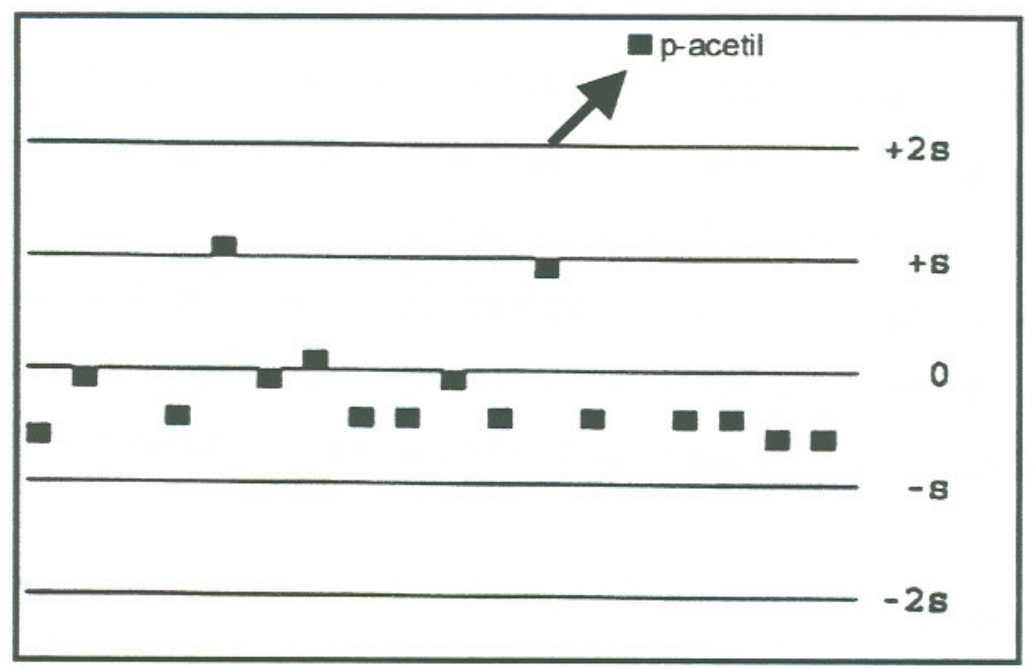

FIGURA 56. Dispersão gerada a partir da equação 46 referente à potência antimicrobiana das 5-nitro-2-tiofilideno benzidrazidas substituídas expressa em log1/C versus coeficiente de partição calculado, ClogP, e constante $\mathfrak{I}$ de Swain e Lupton

Retirando o derivado $p$-acetil substituído (XIV) da correlação, observou-se melhor ajuste da equação gerada aos dados experimentais, equação 47 , sendo este evidenciado pela melhora significativa dos parâmetros estatísticos da correlação.

$$
\begin{array}{r}
\log 1 / C=-0,338( \pm 0,16) C \log P^{2}+1,708( \pm 0,83) C \log P+0,961( \pm 0,55) \mathfrak{I} \\
-3,318( \pm 1,07) \\
C \log P \text { ótimo }=2,53\left(n=16 ; r=0,877 ; s=0,197 ; F=13,293, Q^{2}=0,600, \text { Spress }=0,259\right) \\
\text { Equação } 47
\end{array}
$$

Analisando o gráfico de dispersão relacionado à equação 47 , entretanto, evidenciou-se mais uma vez outro composto fora dos limites impostos pela análise estatística do método, o p-bromo derivado (XIII), confirmando a tendência já observada anteriormente. Figura 57. 


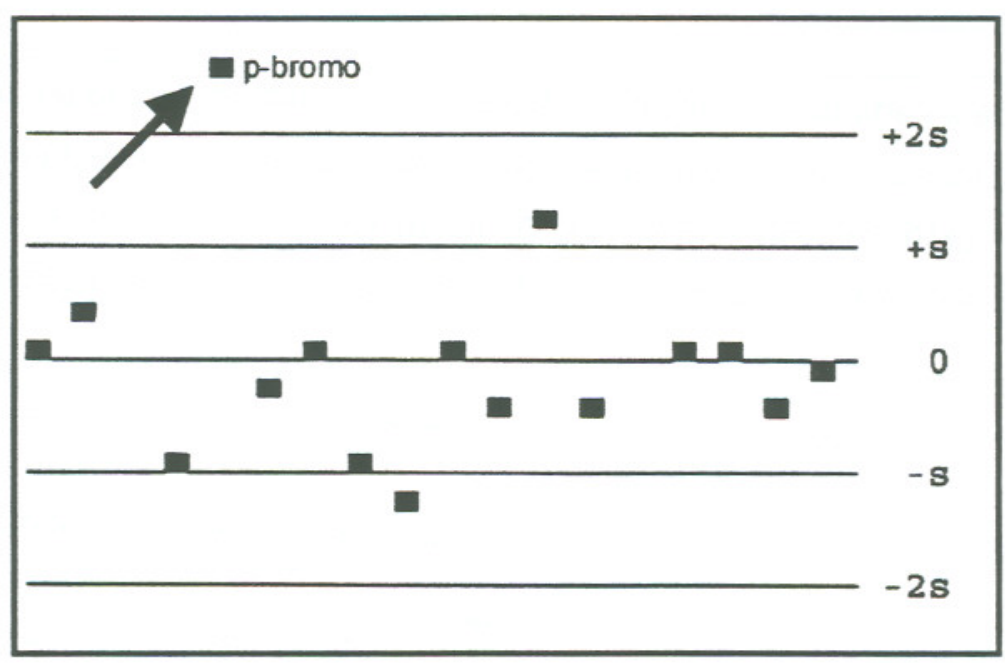

FIGURA 57. Dispersão gerada a partir da equação 47 referente à potência antimicrobiana das 5-nitro-2-tiofilideno benzidrazidas substituídas expressa em log1/C versus coeficiente de partição calculado, ClogP, e constante $\Im$ de Swain e Lupton

Retirou-se o derivado p-bromo substituído (XIII) da correlação, obtendo na equação 33 melhores parâmetros estatísticos. Equação 32.

$$
\begin{array}{r}
\log 1 / C=-0,297( \pm 0,099) C \log P^{2}+1,453( \pm 0,52) C \log P+0,709( \pm 0,35) \mathfrak{I} \\
-2,929( \pm 0,67) \\
C \log P \text { ótimo }=2,45\left(n=15 ; r=0,935 ; s=0,117 ; F=25,587, Q^{2}=0,640, s_{\text {press }}=0,199\right) \\
\text { Equação } 32
\end{array}
$$

Por aplicação do modelo bilinear na correlação da atividade antimicrobiana dos dezessete compostos em estudo com os descritores estruturais ClogP e $\mathfrak{I}$ observou-se, de forma análoga à descrita para o modelo parabólico, que os compostos p-acetil (XIV) e p-bromo (XIII) substituídos apresentavam comportamentos distintos da tendência observada para os demais quinze análogos em estudo, observando-se, mais uma vez, que a exclusão destes análogos da análise de QSAR, por aplicação do modelo bilinear, resultou em melhores correlações como se esquematiza, a seguir, no quadro 3. 
Equação gerada a partir do conjunto de dados dos compostos em estudo por aplicação do modelo

bilinear correlacionando atividade antimicrobiana e os descritores estruturais $\operatorname{Clog} \mathrm{P}$ e $\mathfrak{I}$

$\log 1 / C=14,54( \pm 10,7) C \log P-15,07( \pm 11,0) \log \left(B .10^{c l o g P}+1\right)+0,870( \pm 1,06) \Im-6,766( \pm 4,39)$ $\log \beta=-0,473 \quad C \log P_{\text {otimo }}=1,91 \quad(n=17 ; r=0,768 ; s=0,383 ; F=4,320)$

Equação 48

exclusão do p-acetil derivado

$\log 1 / C=0,895( \pm 0,46) C \log P-1,692( \pm 0,81) \log \left(B .10^{C \log P}+1\right)+0,986( \pm 0,56) \Im-2,841( \pm 0,89)$

$\log B=-2,481 \quad C \log P_{\text {ótimo }}=2,53 \quad(n=16 ; r=0,886 ; s=0,199 ; F=10,039)$

Equação 49

exclusão do p-bromo derivado

$\log 1 / C=1,017( \pm 0,34) C \log P-1,599( \pm 0,48) \log \left(B .10^{C \log P}+1\right)+0,719( \pm 0,32) \Im-2,794( \pm 0,57)$ $\log B=-2,098 \quad C \log P_{\text {ottimo }}=2,34 \quad(n=15 ; r=0,951 ; s=0,108 ; F=23,626)$

Equação 33

QUADRO 3. Representação esquemática de geração da equação que melhor representa a tendência de comportamento da atividade antimicrobiana das 5-nitro-2-tiofilideo benzidrazidas substituídas em relação aos descritores estruturais

ClogP e $\mathfrak{s}$ por aplicação do modelo bilinear.

Observou-se, em todos os casos, que o modelo bilinear foi o que mais se adequou na descrição da influência de propriedades físico-químicas sobre a atividade antimicrobiana da série em estudo. Ressalta-se ainda, que com a exclusão dos compostos p-acetil (XIV), p-bromo (XIII) e $m, p-\mathrm{Cl}_{2}$ (III) substituídos obteve-se melhor ajuste dos modelos gerados aos dados obtidos experimentalmente, evidenciando comportamentos distintos destes compostos em relação aos demais componentes da série. 
Para os compostos $p$-acetil (XIV) (CIM = 0,14 $\mu \mathrm{g} / \mathrm{mL})$ e $p$-bromo (XIII) $(\mathrm{CIM}=$ $0,75 \mu \mathrm{g} / \mathrm{mL}$ ) substituídos foi observado um comportamento diferenciado de atividade antimicrobiana, permitindo-nos classificá-los como super ativos. Ainda não é possivel afirmar, ao certo, quais interações poderiam estar envolvidas ou quais seriam as principais propriedades físico-químicas responsáveis por tão pronunciada atividade.

Correlações com descritores estruturais relacionados com o perfil tridimensional dos substituintes estudados, propostos por Verloop (Verloop, 1987), também foram realizadas, mas resultaram em equações muito pouco significativas. Tal observação corrobora o fato do estudo em questão tratar-se de análise de QSAR em duas dimensões. É importante citar ainda que entre as correlações obtidas com os parâmetros de Sterimol, as que envolveram o descritor $B_{1}$ mostraram-se como as mais significativas. Os resultados obtidos para este descritor de caráter estérico, apesar de não serem muito precisos, constituem ferramenta útil no direcionamento de estudo posterior das relações quantitativas estrutura-atividade em três dimensões.

Foram realizadas ainda correlações considerando três descritores estruturais, mas as equações geradas mostraram-se, em sua maioria, não significativas, impossibilitando a seleção de modelos que quantificassem, com certa margem de segurança, a influência simultânea de três parâmetros na atividade antimicrobiana.

Uma observação de extrema importância está relacionada às interpretações que puderam ser extraídas pela boa significância das equações que envolvem descritores $\sigma$ e $\mathfrak{I}$ na determinação da atividade antimicrobiana. A importância do descritor $\sigma$ estaria relacionada à distribuição eletrônica da estrutura química do derivado, sendo esta resultado da soma dos efeitos indutivo e de ressonância. $A$ relevância descritor $\mathfrak{I}$, entretanto, pode estar relacionada às interações eletrostáticas ligante-receptor propriamente ditas, sendo estas resultado do efeito de campo exercido pelos grupos substituintes. Pode-se depreender, portanto, a partir da alta significância das equações que envolvem estes descritores estruturais, equações 31 e 33, duas conclusões complementares. A saber: $O$ descritor $\sigma$ mede a influência do efeito polar, somatória dos efeitos indutivo e de ressonância, na 
distribuição eletrônica do ligante como um todo, propiciando a interação do mesmo com o sítio receptor por intermédio das duas propriedades citadas. O descritor estrutural $\mathfrak{I}$, por sua vez, considera apenas o efeito indutivo ou de campo dos grupos substituintes ligados ao anel benzênico, o que nos leva a concluir que seria este o principal efeito envolvido na interação entre ligante o sítio receptor na série de compostos estudada, já que não ocorreu diferença significativa nos parâmetros estatísticos das equações 31 e 33. Assim, seria possível supor que o efeito de campo seria predominante em relação ao efeito de ressonância na interação da porção benzênica dos ligantes com o receptor.

Pode-se concluir, deste modo, por meio da análise da relevância dos descritores estruturais de caráter eletrônico, $\sigma$ e $\mathfrak{I}$, na determinação da atividade antimicrobiana, que a distribuição eletrônica estaria influenciando a potência antimicrobiana dos análogos em estudo por dois mecanismos complementares: um deles estaria relacionado à influência dos efeitos indutivo e de ressonância na estrutura química do ligante, e o outro estaria relacionado aos campos moleculares gerados em torno do ligante sugerindo uma possível interação do substituinte com uma área específica do sítio receptor.

A exploração quantitativa da influência dos efeitos de caráter eletrônico sobre a atividade antimicrobiana dos derivados 5-nitro-2-tiofilidênicos realizada neste trabalho, complementa os resultados de outros estudos em que se considerou a análise quantitativa da influência do efeito hidrofóbico sobre a atividade antimicrobiana de compostos com estrutura análoga à nifuroxazida (Masunari, Tavares, 2002, Masunari, Rezende, Tavares, 2001, Tavares et al., 1999, Tavares, Penna, Amaral, 1997, Tavares, Penna, Amaral, 1991), subsidiando fortemente as avaliações e predições relacionadas à série de derivados 5-nitro-2-tiofilidênicos com a atividade antimicrobiana utilizando-se análise de QSAR-2D.

Ressalta-se ainda que os resultados obtidos ao longo dos últimos anos pelo grupo de pesquisa do Laboratório de Planejamento e Desenvolvimento de Fármacos sob coordenação do Prof. Assoc. Leoberto Costa Tavares, orientador desta tese, constituem base teórica substancial acerca destes compostos para estudos futuros e sinalizam a necessidade de complementação do estudo clássico, pela exploração dos aspectos tridimensionais das 5-nitro-2-tiofilideno benzidrazidas p-substituídas. 
Para tal, foi realizado o estudo de QSAR-3D por aplicação do programa Volsurf, item abordado subseqüentemente, com a finalidade de aprofundar e, de certa forma, validar os resultados obtidos no estudo de QSAR-2D.

\subsection{ESTUDOS DAS RELAÇÕES QUANTITATIVAS ESTRUTURA-ATIVIDADE EM TRÊS DIMENSÕES POR APLICAÇÃO DO PROGRAMA VOLSURF, QSAR-3D}

Modelos gerados pelo programa Volsurf são pouco influenciados pela conformação espacial dos compostos e não requerem o alinhamento das moléculas em estudo, duas vantagens que, em conjunto, viabilizam muito a utilização deste programa quando não se conhece exatamente a estrutura do sítio receptor (Cruciani et al., 2000), justificando, desta forma, a escolha deste algoritmo no presente estudo para a análise de QSAR-3D das 5-nitro-2-tifilideno benzidrazidas $p$-substituídas.

Os campos de força gerados entre ligantes e probes, por aplicação do programa GRID, são utilizados para caracterizar prováveis sítios de interação polares e hidrofóbicos presentes ao redor das moléculas em estudo. Nesta metodologia, utiliza-se um potencial baseado na energia total de interação, que nada mais é que a soma do potencial de Lennard-Jones, de termos eletrostáticos e de ligações de hidrogênio (Bobbyer et al., 1989, Goodford, 1985).

O probe "água" é empregado para simular processos de solvatação e dessolvatação dos compostos, enquanto que os probes "DRY" e "oxigênio carbonílico" são utilizados para simular interações entre ligantes e membranas (Cruciani et al., 2000, Goodford, 1985). Para a geração dos campos de interação molecular, no caso deste trabalho, foram utilizados 2, 3 e 4 probes, respectivamente. Constatou-se pouca significância para os modelos gerados com 2 e 3 probes, enquanto que os obtidos com 4 probes mostraram melhor capacidade de predição e boa confiabilidade estatística.

Em análises de QSAR-3D é muito frequente que se tenha número de moléculas muito inferior ao número de variáveis analisadas, tornando a análise clássica de regressão linear múltipla (MLR) praticamente inútil. Para tal, utiliza-se o PLS (Partial Least Squares), um algoritmo que, em linhas gerais, decompõe a matriz 
de variáveis em duas outras, uma delas contém informações das variáveis combinadas linearmente em vetores denominados variáveis latentes (VL's) e a segunda matriz apresenta informações sobre os compostos em estudo. Sendo assim, cada composto é descrito em termos de variáveis latentes (Wold, Johanson, Cocchi, 1993).

As VL's são semelhantes às CP's, componentes principais, numa análise de PCA e são extraídas em ordem decrescente de importância, ou seja, a primeira VL conterá maior número de informações que a segunda, a segunda conterá mais que a terceira e assim subseqüentemente. Para testar a capacidade de predição do modelo de PLS é utilizada a técnica de validação cruzada, sendo os principais parâmetros estatísticos envolvidos $\circ Q^{2}$ (coeficiente de correlação da predição) e o SDEP (desvio padrão do erro de predição). A validação cruzada realiza uma validação interna do modelo e fornece uma estimativa da habilidade preditiva do mesmo, sem a necessidade, portanto, da introdução de um conjunto de dados externos (Wold, Johanson, Cocchi, 1993).

Inicialmente foi gerado um modelo bruto com 88 descritores estruturais e duas CP's. Apesar do valor de $\mathrm{R}^{2}=0,91$ apresentar-se aceitável, indicando boa correlação entre os valores de atividade antimicrobiana determinados experimentalmente e os valores calculados pelo modelo, observou-se valor de $\mathrm{Q}^{2}=$ 0,26, muito baixo, explicitando, assim, sua baixa capacidade de predição.

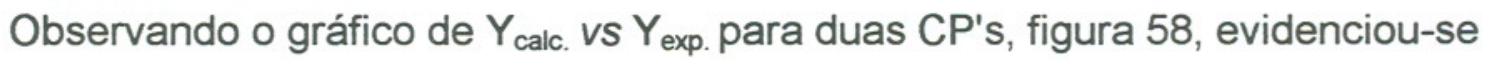
para o $p$-acetil derivado um comportamento fora da linha de tendência dos demais compostos. Ressalta-se que o valor de SDEP, desvio padrão do erro de predição, equivalente a 0,40 , mostrou-se também muito elevado, corroborando o péssimo grau de predição do modelo bruto. 


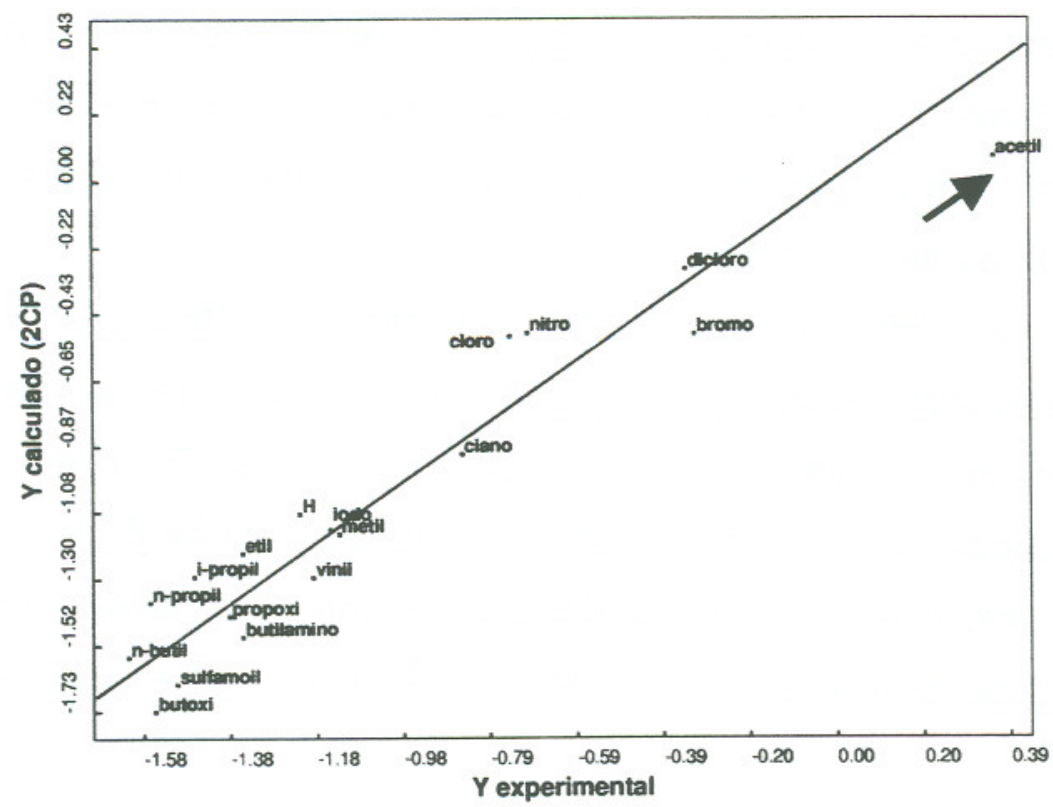

FIGURA 58. Valores de atividade antimicrobiana calculados $\left(Y_{\text {calc }}\right)$ pelo modelo bruto com 2 CP's versus atividade antimicrobiana determinada experimentalmente $\left(Y_{\text {exp }}\right)$.

Apresenta-se, na figura 59, o gráfico dos resíduos, referente ao modelo bruto obtido por aplicação do programa Volsurf $\left(n=18, x=88, Y=1, R^{2}=0,91, Q^{2}=\right.$ $0,26, \operatorname{SDEP}=0,40)$.

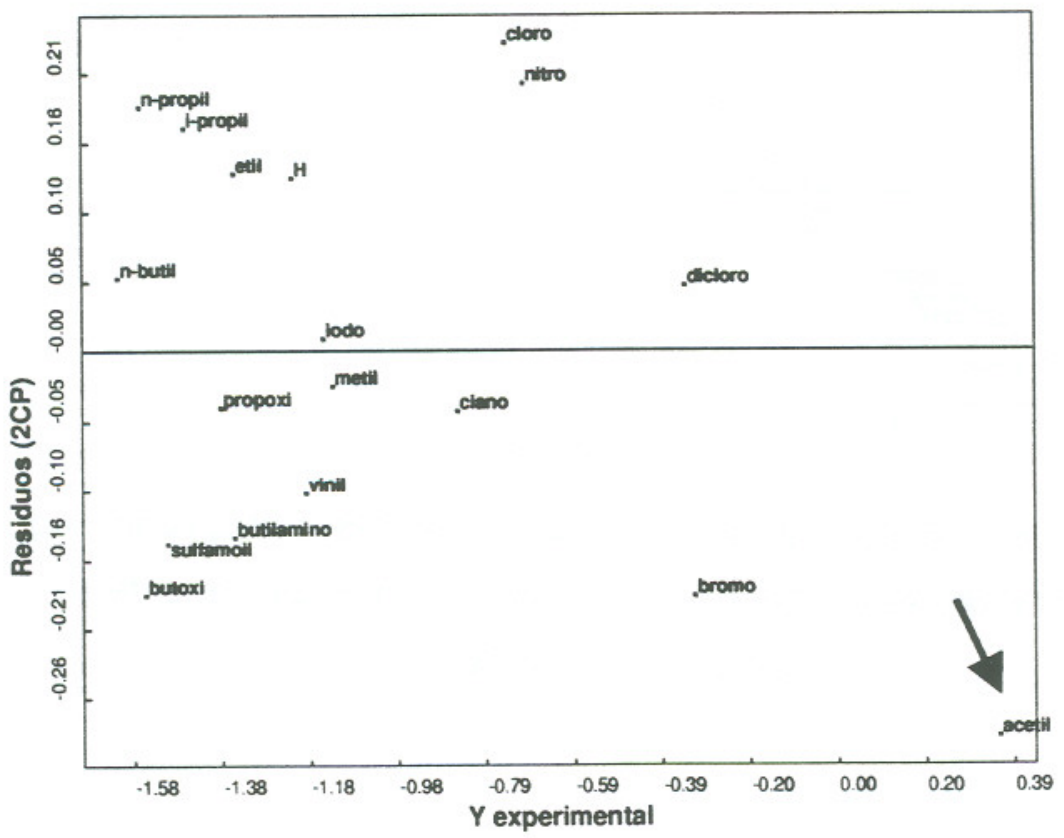

FIGURA 59. Dispersão dos residuos do modelo bruto com 88 descritores estruturais e 2 CP's. 
A classificação do derivado $p$-acetil substituído (XIV) como um provável outlier no estudo em três dimensões corrobora o estudo clássico anteriormente realizado, em que se constatou um padrão de comportamento totalmente diferenciado deste análogo em relação aos demais compostos.

Retirando o p-acetil derivado (XIV) do modelo, observou-se melhora significativa dos parâmetros estatísticos, ressaltando, em especial, os valores de $Q^{2}$ e de SDEP que passaram de 0,26 e 0,40 para 0,80 e 0,17 , respectivamente. Observando os gráficos de $Y_{\text {calc. vs }} Y_{\exp }$ e dos resíduos, figuras 60 e 61, pôde-se observar melhor ajuste dos dezessete análogos restantes ao novo modelo com 6 CP's [ $n=17$ (exclusão do $p$-acetil derivado), $x=88, Y=1, R^{2}=0,97, Q^{2}=0,80$, $\operatorname{SDEP}=0,17]$.

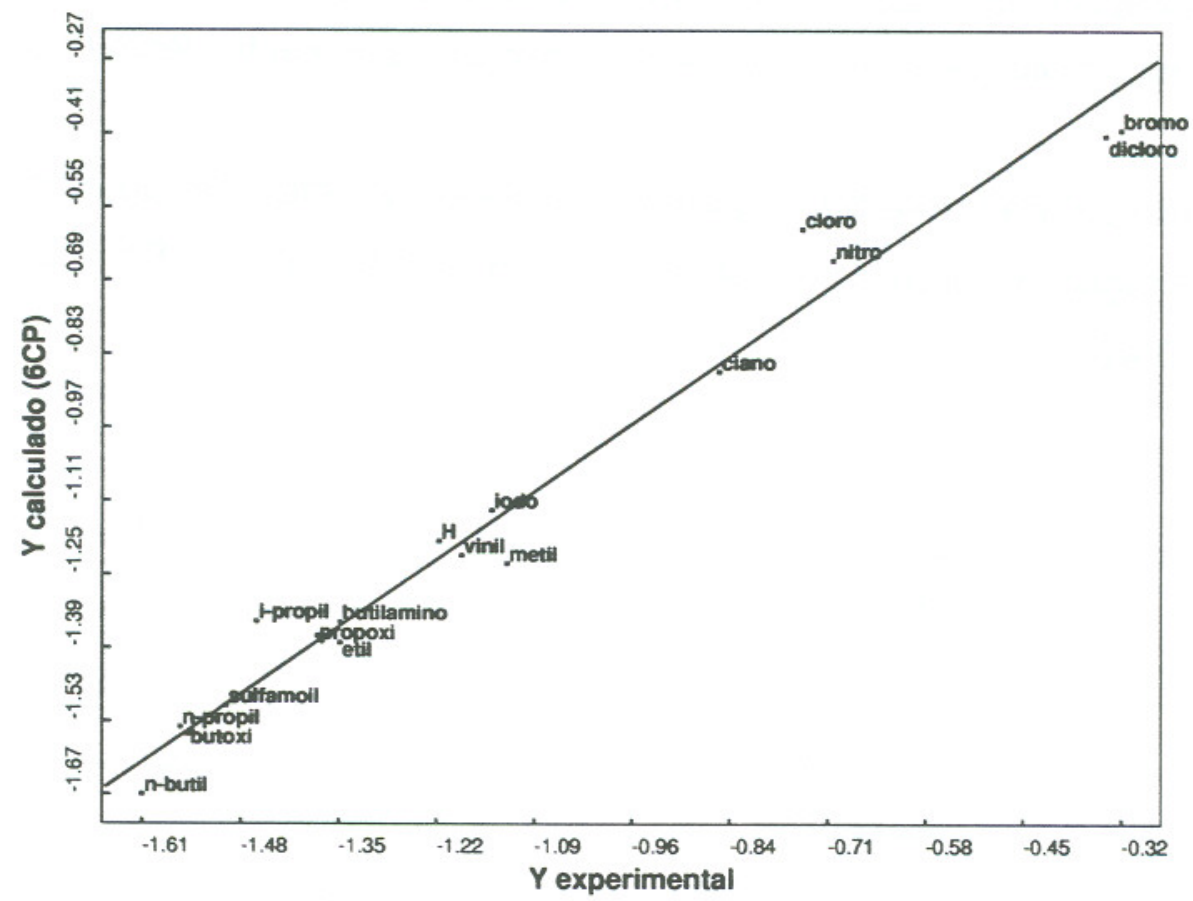

FIGURA 60. Valores de atividade antimicrobiana calculados $\left(Y_{\text {calc }}\right)$ pelo segundo modelo com 88 descritores e 6 CP's versus atividade antimicrobiana determinada experimentalmente $\left(\mathrm{Y}_{\text {exp }}\right)$. 


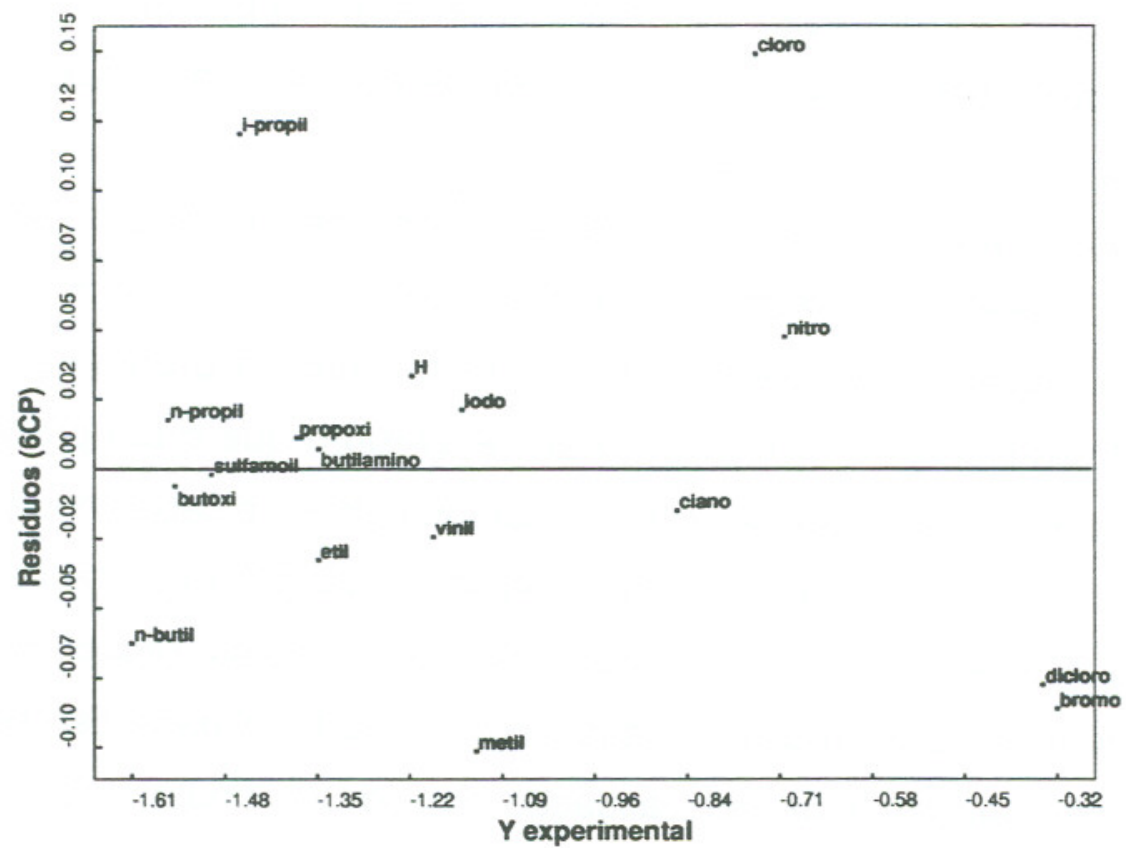

FIGURA 61. Dispersão dos resíduos referente ao segundo modelo com 88 descritores estruturais e 6 CP's.

Apresentou-se como inconveniente, entretanto, o número elevado de componentes principais envolvidas neste segundo modelo, já que os melhores parâmetros estatísticos foram obtidos para 6 CP's. Ressalta-se que um grande número de CP's torna a análise do modelo mais difícil, já que quanto mais se adicionam componentes principais para explicar um modelo, maior será o risco de se resultar em ajuste forçado do modelo aos dados. Como consequência direta do ajuste forçado observa-se baixíssima validade do modelo final.

A dificuldade citada provavelmente se relaciona ao fato da probabilidade de alguns dos descritores gerados no modelo bruto causarem sobreposição de informações, tornando evidente, em alguns casos, a redundância de dados. De fato, de acordo com Cruciani e colaboradores (Cruciani et al., 2000, Cruciani, Pastor, Guba, 2000), numa análise de PLS é muito comum que se obtenha na matriz de descritores (matriz X) um número considerável de variáveis que não apresentam, necessariamente, relação direta com a atividade biológica proporcionando, desta forma, uma descrição inconveniente dos derivados em estudo. Cita-se ainda que é 
praticamente impossível a geração de bons modelos de PLS quando uma única variável significativa possa estar mascarada entre outras, ainda que esta seja altamente relacionada com a atividade.

Para superar esta deficiência, ou melhor, simplificar o modelo gerado pelo PLS, sem prejudicar seu grau de predição e significância, utilizam-se metodologias matemáticas de seleção de variáveis contidas neste mesmo programa. No caso deste estudo utilizou-se o FFD (Fractional Fatorial Design) que é um procedimento no qual são selecionadas apenas as variáveis que aumentam a capacidade preditiva do modelo de PLS. Este método é composto basicamente por três etapas a saber: geração do modelo bruto de PLS; construção de modelos reduzidos para a avaliação individual da contribuição de cada descritor na habilidade de predição do modelo (sendo cada um avaliado por validação cruzada) e, finalmente, a remoção das variáveis da matriz $X$ que podem dificultar a descrição do modelo, gerando novo modelo de PLS.

Algumas recomendações importantes devem ser consideradas antes de se aplicar o FFD num modelo de PLS para que este apresente validade. São elas:

- se o modelo inicial de PLS for pouco preditivo, ou seja, apresentar valores de $\mathrm{Q}^{2}$ muito baixos ou negativos a aplicação do FFD pode gerar correlações pouco confiáveis, seria o mesmo que um ajuste forçado de dados, implicando, portanto, em baixo grau de predição do modelo final;

- deve-se conhecer bem a série em estudo de forma a apontar, antes mesmo da análise de FFD, possíveis outliers que possam comprometer o resultado final, já que sua presença pode resultar no risco de seleção de variáveis mais preditivas para estas exceções do que para o restante dos compostos, resultando, assim, em modelo que não apresenta validade para o conjunto geral de moléculas em estudo.

Ressalta-se mais uma vez a importância da aplicação do estudo em duas dimensões previamente realizado, já que este possibilitou a detecção do derivado $p$ acetil substituído como um provável outlier, fato também evidenciado no estudo de QSAR-3D, resultando em sua eliminação do conjunto total de dados para construção do modelo final de PLS. 
Aplicou-se o FFD na opção fold over design, que consiste na repetição de todas as combinações de variáveis invertendo o padrão de sinais na matriz de combinação de forma a resultar em avaliação muito mais segura do efeito de uma variável ou de um conjunto delas na capacidade de predição do modelo. A aplicação do FFD resultou em redução considerável do número de variáveis, de 88 para 47 , eliminando informações redundantes presentes no modelo bruto.

Obteve-se no modelo final para 3 CP's um bom ajuste dos dados à curva $\left(R^{2}\right.$ $=0,93)$ e um excelente grau de predição $\left(Q^{2}=0,87, \operatorname{SDEP}=0,14\right)$, sendo $\circ$ gráfico de $Y_{\text {calc. vs }} Y_{\text {exp }}$ apresentado na figura 62. Observando o gráfico dos resíduos, figura 63, constata-se bom ajuste dos compostos ao modelo, evidenciando ainda, pelo gráfico de $R^{2} / Q^{2}$ vs número de componentes, figura 64 , que o melhor valor de $Q^{2}$ estaria relacionado a 3 CP's.

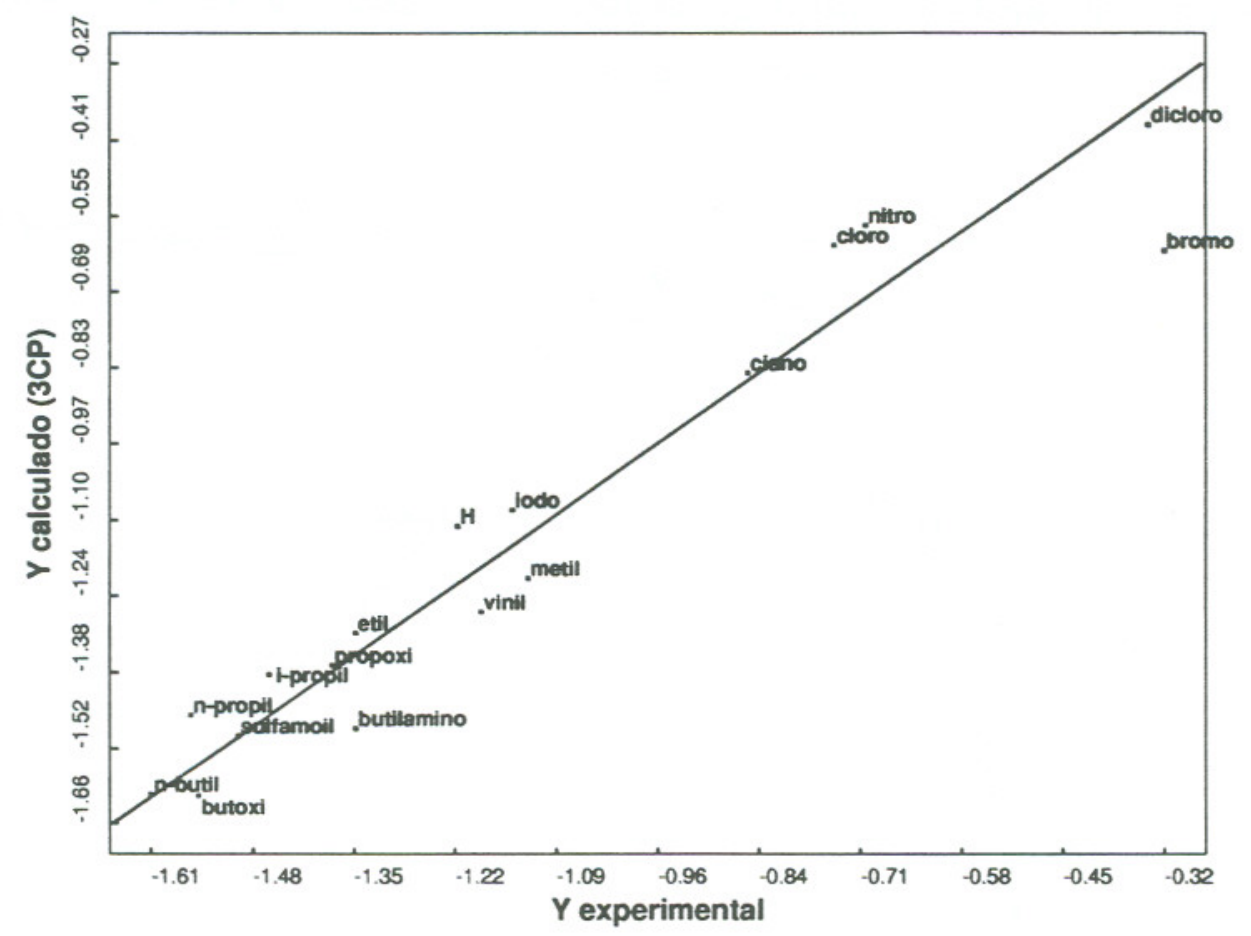

FIGURA 62. Valores de atividade antimicrobiana calculados $\left(Y_{\text {calc }}\right)$ pelo modelo final com 3 CP's versus atividade antimicrobiana determinada experimentalmente $\left(Y_{\text {exp }}\right)$. 


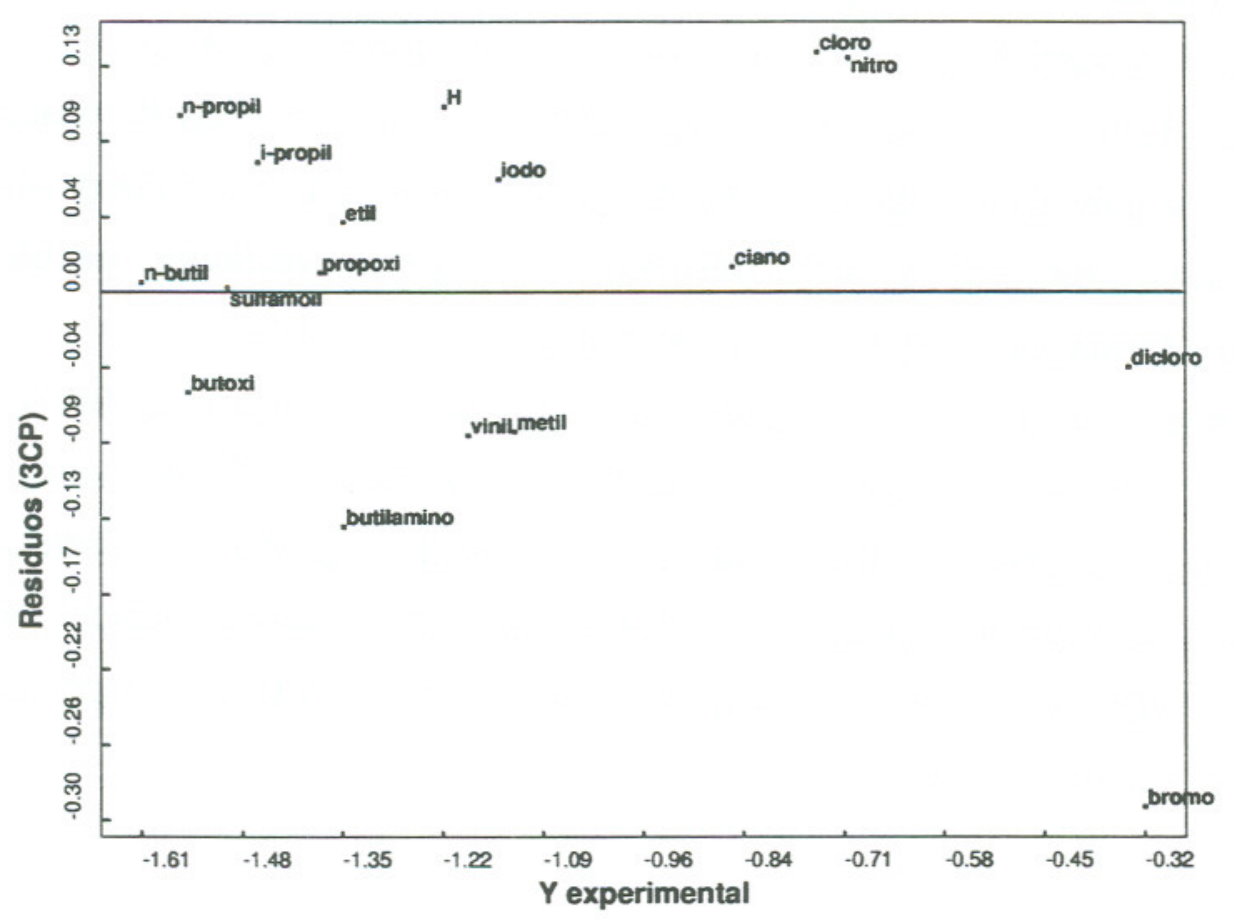

FIGURA 63. Dispersão dos resíduos referente ao modelo final com 47 descritores estruturais e 3 CP's.

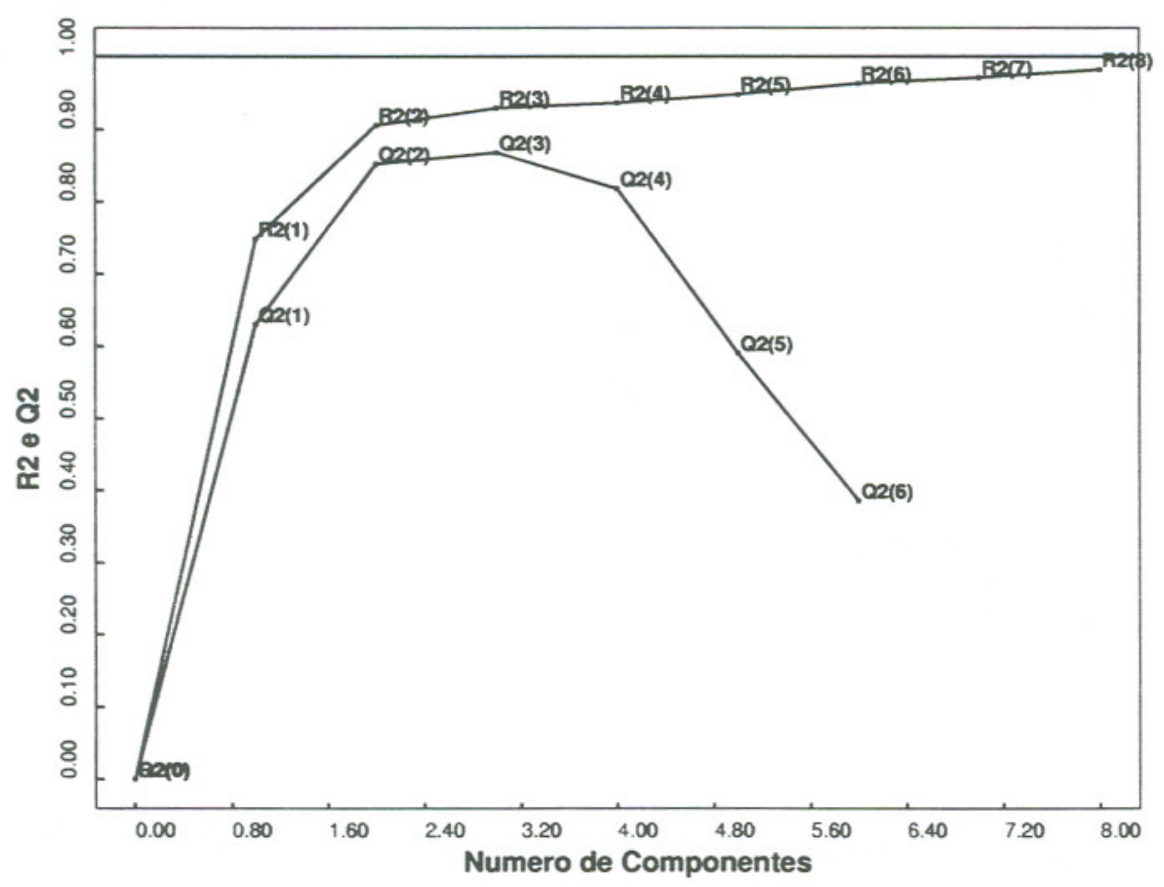

FIGURA 64. Valores de $R^{2} / Q^{2}$ versus número de componentes principais do modelo final. 
Todo o padrão de performance do modelo final gerado por aplicação do algoritmo PLS pôde ser avaliado pelo gráfico de SDEC (desvio padrão de recálculo do ajuste) e SDEP (desvio padrão do erro de predição) em que se observou para 3 CP's o menor desvio padrão do erro de predição (SDEP). Nota-se que a partir de 4 CP's, como indica a curva apresentada na figura 65 , os modelos tornam-se cada vez menos preditivos (altos valores de SDEP).

Ressalta-se ainda que, apesar dos modelos acima de 4 CP's apresentarem teoricamente um melhor ajuste aos dados experimentais (altos valores de SDEC), estes são praticamente sem validade, já que quanto maior o número de componentes para caracterizar um modelo, mais próximo de 1 será o valor de $\mathrm{R}^{2}$ (modelo perfeito), observando um comportamento proporcional dos valores de SDEC.

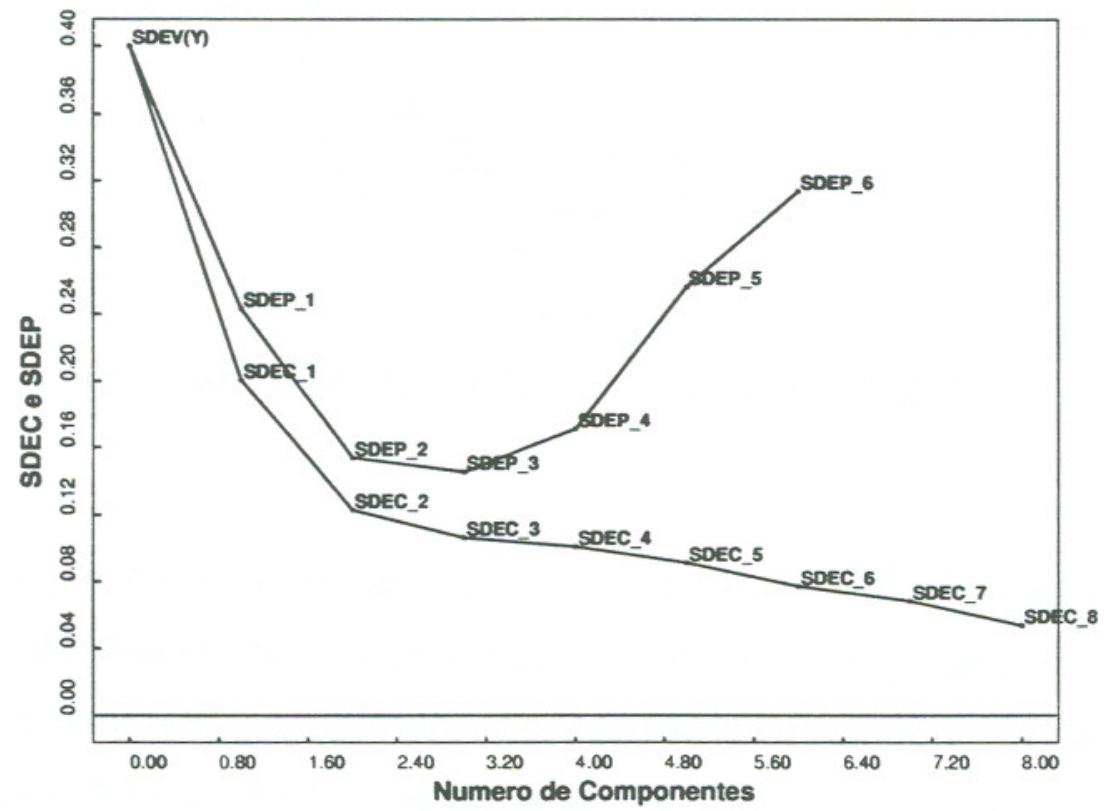

FIGURA 65. Valores de SDEC/SDEP versus número de componentes do modelo final. 
Analisando o gráfico de $\mathrm{CP} 2$ vs $\mathrm{CP} 1$, observou-se que para apenas uma $\mathrm{CP}$ a série 5-nitro-2-tiofilidênica foi dividida em compostos mais ativos (A) e menos ativos (B), já para a CP 2 não foram observadas diferenças significativas. Figura 66.

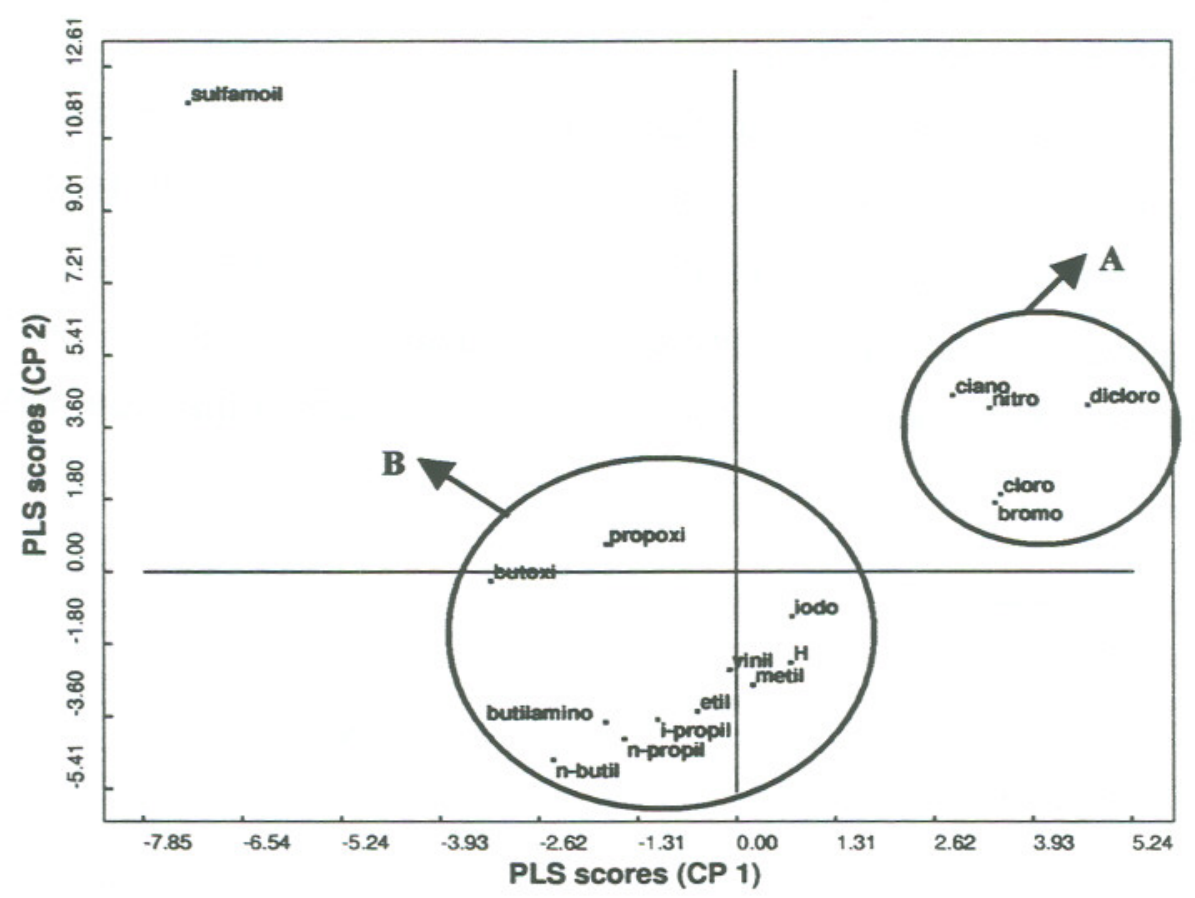

FIGURA 66. CP2 versus CP1 do modelo final.

A aplicação do FFD possibilitou a simplificação do modelo bruto inicialmente obtido, sem, entretanto, comprometer seu significado e capacidade de predição. De acordo com o gráfico dos coeficientes de PLS, figura 67, observou-se a contribuição positiva dos descritores CW1 (fator de capacidade), D1-D8 (distribuição de regiöes hidrofóbicas), CP (Critical Packing), HB2 (doador de ligaçōes de hidrogênio) e W2 (distribuição de regiōes hidrofilicas) sobre a atividade antimicrobiana representada pela potência antimicrobiana. Por outro lado, observou-se contribuição negativa dos descritores W5-W8 (distribuição de regiōes hidrofilicas), IW1-IW3 (Integy-Interaction Energy-Moments Hidrofilicos), CW2-CW7 (fator de capacidade); ID1-ID8 (IntegyInteraction Energy-Moments Hidrofóbicos), HB4-HB8 (doador de ligação de hidrogênio), W3-W8 (distribuição de regiōes hidrofilicas), HB7 (aceptor de ligações de hidrogênio). 


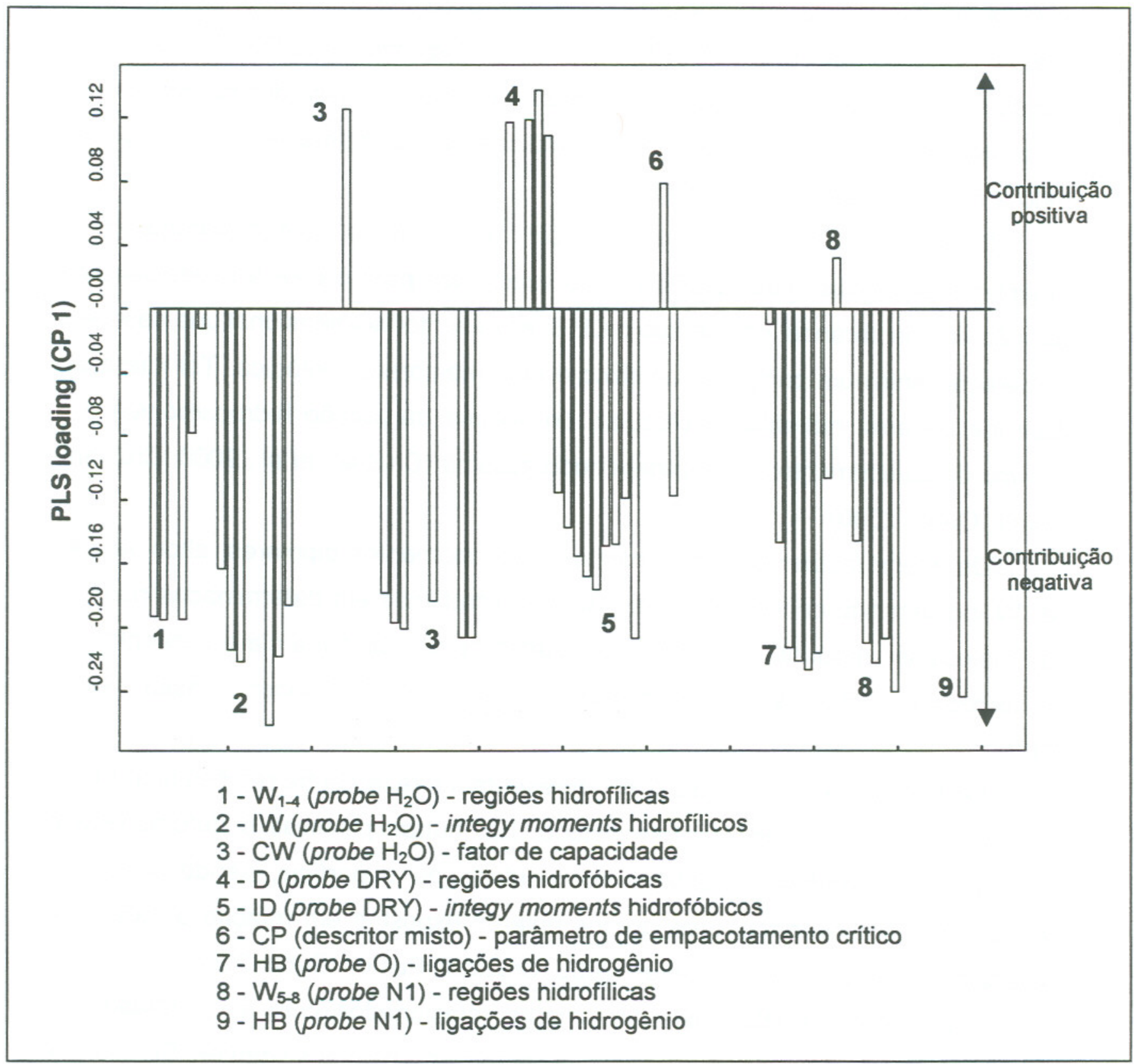

FIGURA 67. Gráfico dos coeficientes de PLS para os descritores gerados no Volsurf considerando uma componente principal.

Os descritores gerados pelo Volsurf apresentam significados claros que se referem tanto à distribuição de regiões hidrofóbicas e hidrofilicas como em relação à formação de ligações de hidrogênio. Os descritores $W$ se referem ao tamanho das regiōes hidrofílicas distribuidas pelos ligantes, enquanto os descritores $D$ se referem 
ao tamanho das regiões hidrofóbicas. O parâmetro de critical packing, CP, se refere à razão entre porções $\mathrm{D}$ e W dos ligantes e os Integy moments hidrofílicos (IW) e hidrofóbicos (ID) medem o desequilíbrio entre o centro de massa dos compostos e o baricentro das regiões hidrofílicas e hidrofóbicas, respectivamente (Cruciani et al., 2000, Cruciani, Pastor, Guba, 2000).

O parâmetro de critical packing, $\mathrm{CP}$, em conjunto com o parâmetro de tamanho das regiões hidrofóbicas, D, são excelentes para prever a capacidade de partição em membranas, cita-se que o CP é um descritor adimensional que descreve a interação entre um composto anfifílico e uma membrana biológica. Tal interação depende da área hidrofílica molecular, do volume da porção hidrocarbônica e o máximo de comprimento que a cadeia pode assumir (Cruciani et al., 2000, Cruciani, Pastor, Guba, 2000).

Os integy moments se assemelham aos momentos dipolares, altos valores de IW indicam alta concentração de regiões hidrofílicas em determinadas porções das moléculas, enquanto que valores elevados de ID indicam a clara concentração de porções hidrofóbicas nos ligantes(Cruciani et al., 2000, Cruciani, Pastor, Guba, 2000).

Os fatores de capacidade, CW, representam a razão entre regiões hidrofílicas e a superfície dos compostos em estudo. Em outras palavras é determinada a quantidade de regiões hidrofílicas por unidade de superfície, sendo a mesma proporcional à concentração de grupos polares expostos em relação a toda área molecular superficial (Cruciani et al., 2000, Cruciani, Pastor, Guba, 2000).

Os descritores HB estão diretamente relacionados com a quantidade de átomos doadores e/ou aceptores de ligações de hidrogênio nos ligantes. Cita-se que os descritores de regiões hidrofílicas incluem um envelope molecular acessivel a moléculas de água, ressaltando ainda o fato de que estes são, em sua maioria, relevantes na determinação da partição em membranas, nas quais processos de solvatação e dessolvatação são críticos (Cruciani et al., 2000, Cruciani, Pastor, Guba, 2000).

A contribuição negativa intensa dos descritores IW e ID indicam que a presença de concentração tanto de regiões hidrofílicas como de regiões hidrofóbicas nos análogos estudados resulta em decréscimo significativo de atividade 
antimicrobiana. Por outro lado, a contribuição positiva do descritor $\mathrm{D}$, que se refere à distribuição de regiões hidrofóbicas nos ligantes, indica que se uniformemente distribuída, esta propriedade tende a aumentar a potência dos compostos em estudo.

De fato, observa-se na figura 68 , que derivados com alto valor de IW (denotado por vetores que apontam do centro de massa do ligante em direção à concentração de regiōes hidrofilicas) apresentaram menores valores de atividade antimicrobiana, enquanto que derivados com distribuição uniforme da hidrofobicidade e baixa concentração de regiões hidrofílicas resultaram em valores maiores de atividade biológica. Figura 69.
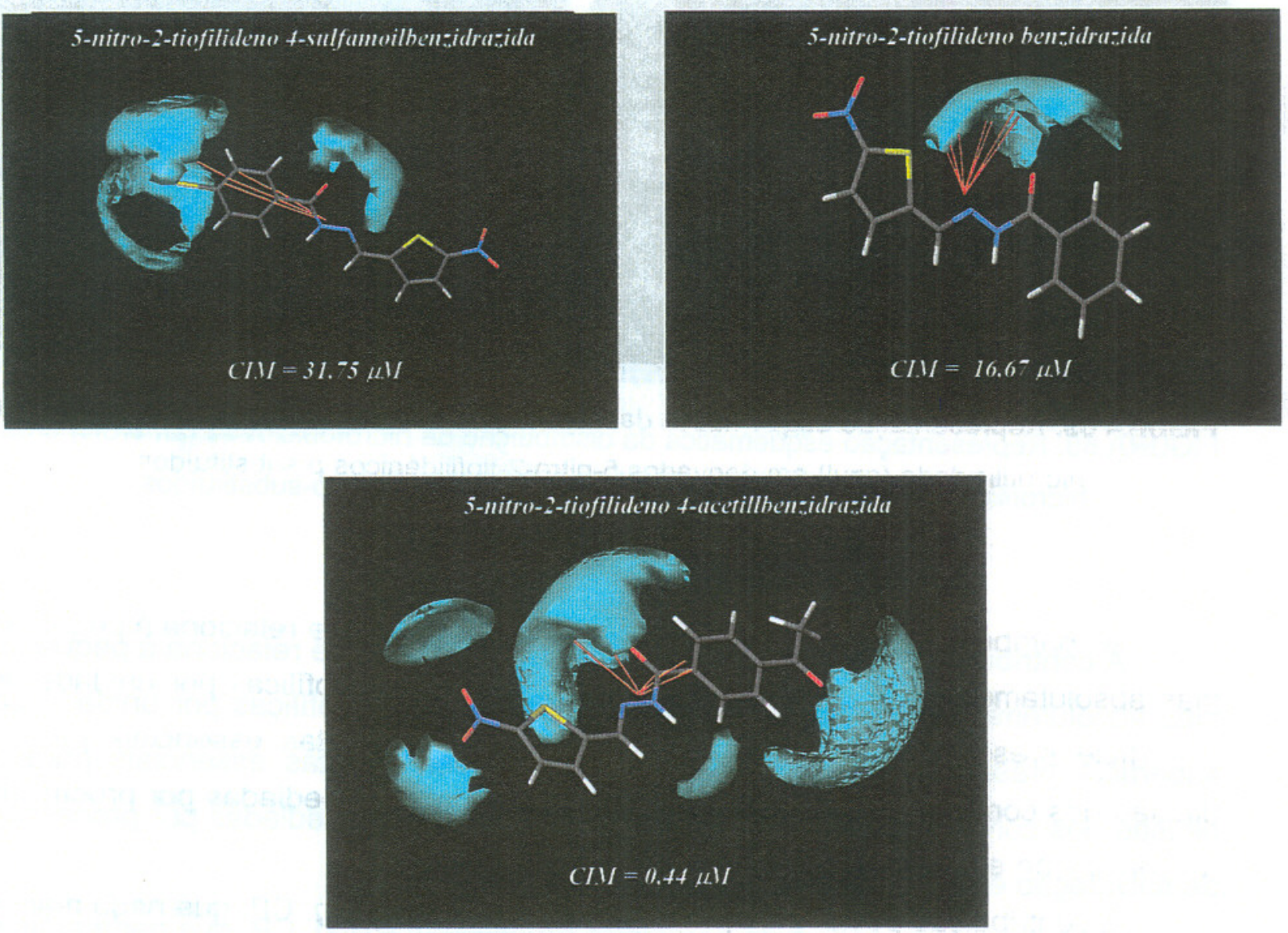

FIGURA 68. Representação esquemática dos integy moments hidrofilicos dos derivados psulfamoil, $p$-acetil substituídos e do composto não substituído 

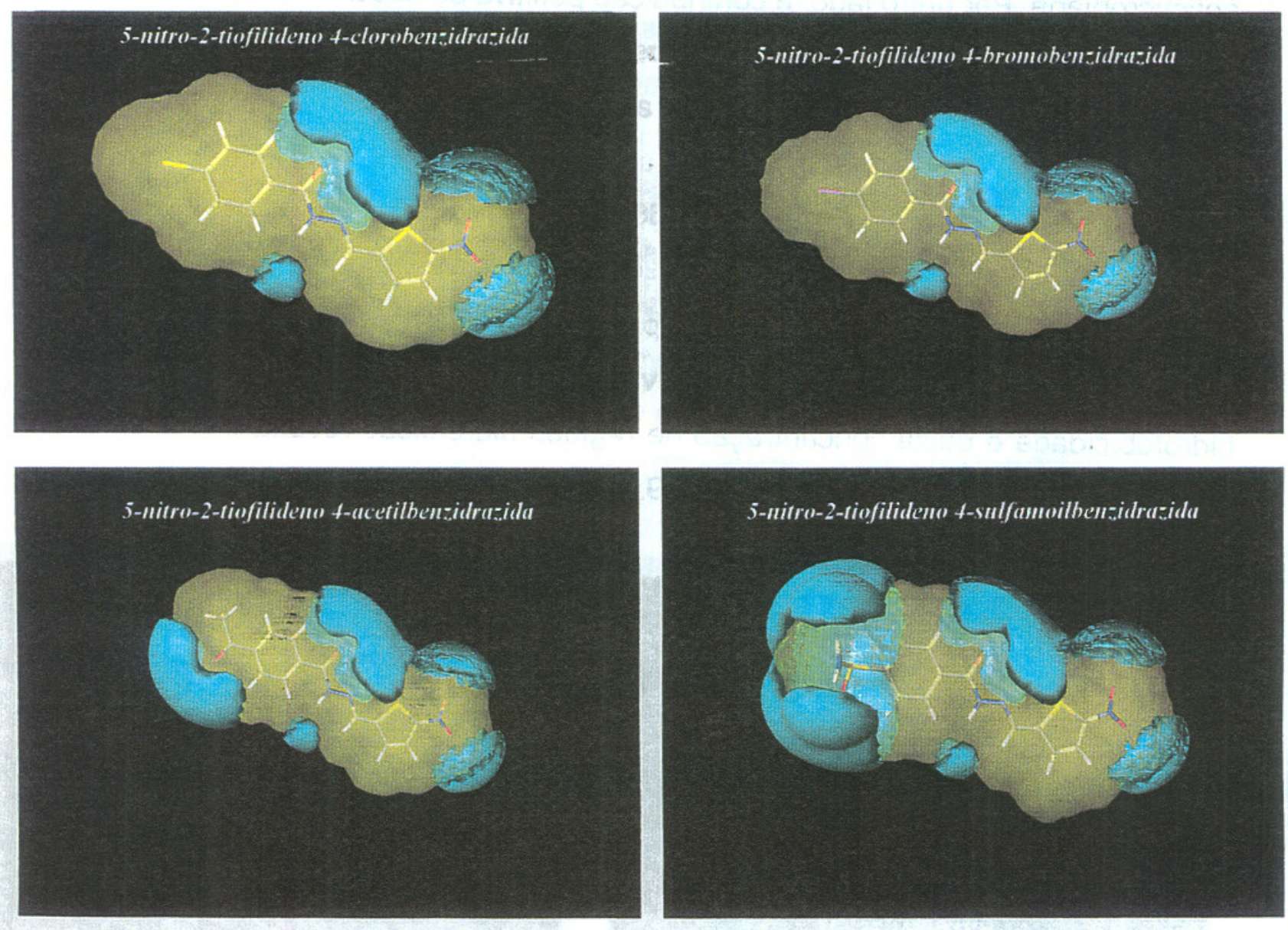

FIGURA 69. Representação esquemática da distribuição da hidrofobicidade (amarelo) e da hidrofilicidade (azul) em derivados 5-nitro-2-tiofilidênicos p-substituídos.

A contribuição positiva de CW1 e W2 provavelmente se relaciona à pequena, mas absolutamente necessária, quantidade de regiões hidrofílicas por unidade de superfície presentes nas moléculas em estudo, sendo estas essenciais para a difusão dos compostos através das membranas biológicas mediadas por processos de solvatação e dessolvatação.

A contribuição positiva do parâmetro de critical packing, $\mathrm{CP}$, que nada mais é do que a razão entre porções hidrofóbicas e hidrofílicas dos ligantes, indica, em conjunto com o descritor D, a importância da distribuição uniforme da hidrofobicidade nos ligantes bem como da presença de alguns pontos hidrofílicos nos derivados para que ocorra o processo de difusão através das membranas bacterianas. 
Vale ressaltar que os dados de atividade biológica utilizados neste trabalho se referem à potência antimicrobiana das 5 -nitro-2-tiofilideno benzidrazidas $p$ substituídas. Este tipo de medida da atividade é amplo não podendo ser atribuído único e individualmente a processos farmacocinéticos ou farmacodinâmicos. De fato, este tipo de medida engloba provavelmente ambos processos, permitindo-nos atribuir a relevância dos descritores gerados no Volsurf à capacidade de dịfusão dos compostos nas membranas biológicas para posterior desencadeamento da atividade farmacológica. Vale lembrar que na discussão do estudo clássico de QSAR, anteriormente realizada, pôde-se sugerir prováveis interações com o sítio receptor (processo farmacodinâmico) a partir da alta relevância do descritor $\mathfrak{I}$ de Swain e Lupton sobre a atividade antimicrobiana.

Como citado anteriormente, os descritores HB estão relacionados a unidades estruturais dos compostos em que existe a possibilidade de formação de ligações de hidrogênio. No caso da série em estudo, observou-se a contribuição positiva dos descritores HB2 (probe 0) e HB7 (probe N), ressaltando a capacidade doadora e aceptora de hidrogênio dos compostos da série em estudo. Observando a estrutura protótipo dos análogos em questão, figura 70 , nota-se que a capacidade aceptora e doadora de ligaçōes de hidrogênio estaria relacionada com as porções A e B da molécula, respectivamente.

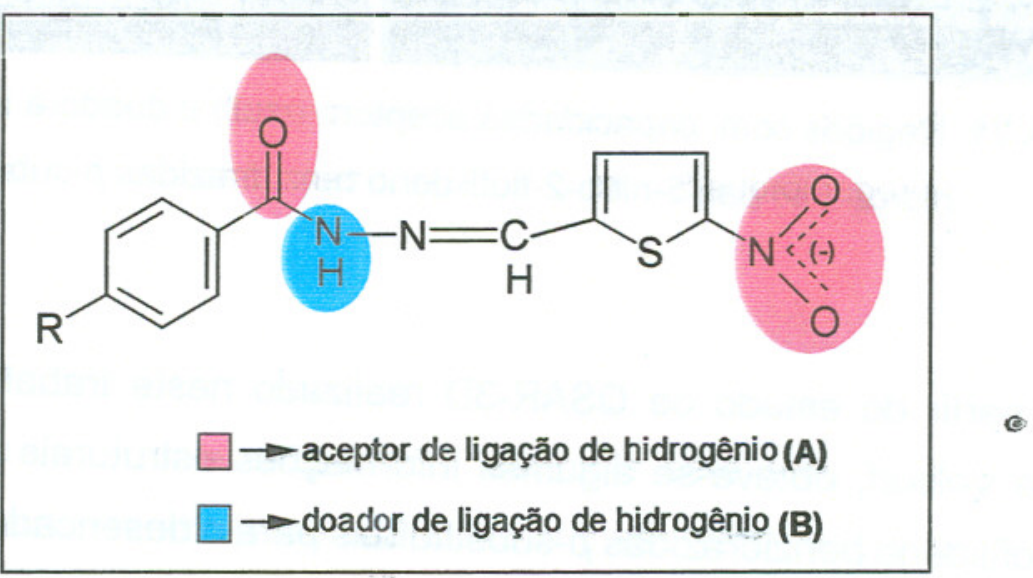

FIGURA 70. Capacidade aceptora (A) e doadora (B) de ligações de hidrogênio das 5-nitro-2-tiofilideno benzidrazidas $p$-substituídas 
Os descritores relacionados ao caráter doador e aceptor de ligações de hidrogênio gerados pelo programa Volsurf apresentaram influência diferenciada sobre a atividade antimicrobiana. No caso do descritor HB2, que se refere ao caráter doador de ligação de hidrogênio, observou-se contribuição positiva para a atividade, enquanto que no caso do descritor HB7, relacionado ao caráter aceptor de ligação de hidrogênio, evidenciou-se contribuição negativa intensa em relação à atividade.

A partir destes resultados pode-se inferir duas informações distintas e de extrema relevância, a primeira delas estaria relacionada à importância da disponibilidade do hidrogênio ligado ao nitrogênio alfa carbonílico para formação de ligações de hidrogênio, enquanto que a contribuição negativa intensa do descritor HB7 sugere que ligações de hidrogênio envolvendo os grupos carbonila e nitro certamente resultaria em queda pronunciada da atividade biológica. Figura 71.
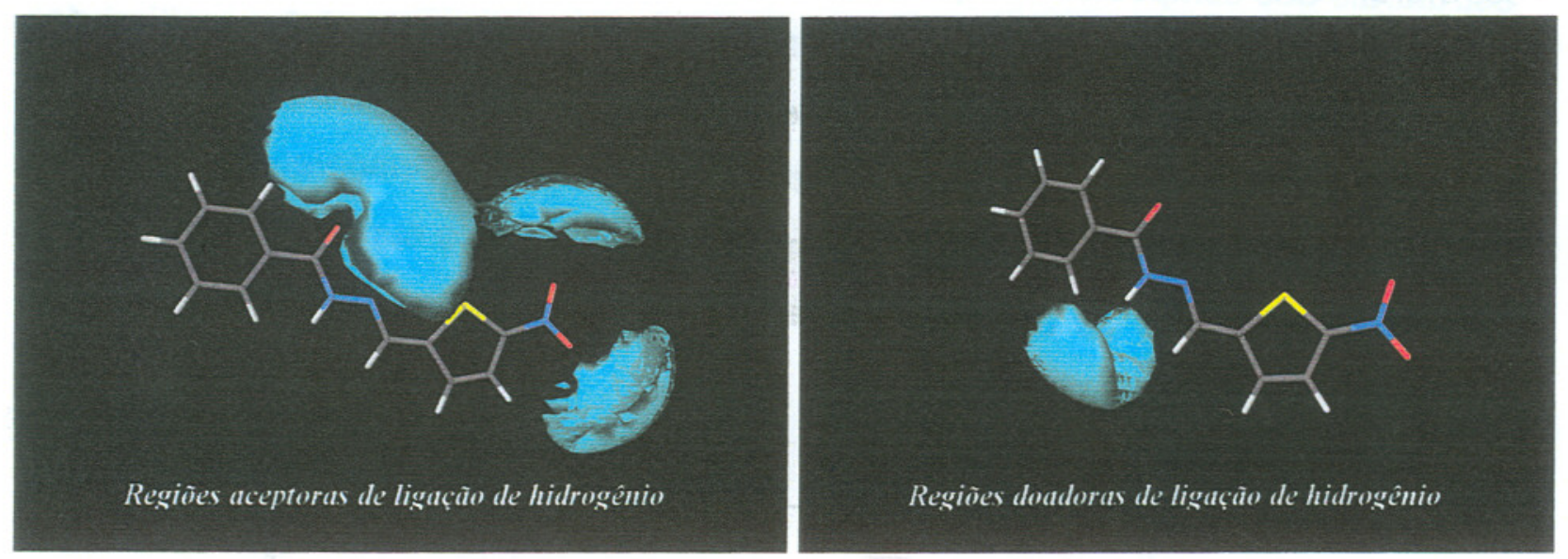

FIGURA 71. Regiöes com capacidades aceptora (azul) e doadora (azul) de ligações de hidrogênio das 5-nitro-2-tiofilideno benzidrazidas $p$-substituídas

A partir do estudo de QSAR-3D realizado neste trabalho por aplicação do programa Volsurf, obteve-se algumas informações estruturais fundamentais das 5nitro-2-tiofilideno benzidrazidas $p$-substituídas para o desencadeamento da atividade antimicrobiana. Em concordância com o estudo clássico, evidenciou-se na última etapa deste trabalho, que considerou os aspectos tridimensionais dos ligantes, ser a hidrofobicidade propriedade fundamental para bons perfis de atividade antimicrobiana dos compostos estudados. 
A grande vantagem da presente abordagem em relação ao estudo de QSAR$2 \mathrm{D}$, entretanto, está relacionada à possibilidade de maior detalhamento da influência da hidrofobicidade sobre a atividade antimicrobiana. Pôde-se especificar, por meio dos descritores gerados pelo Volsurf, que a influência positiva da hidrofobicidade no desempenho dos derivados 5-nitro-2-tiofilidênicos como agentes antimicrobianos estaria relacionada à distribuição uniforme da mesma em torno dos ligantes, já que a presença de regiões hidrofóbicas concentradas influenciam negativamente esta bioatividade.

Verificou-se ainda, que a presença pontual de regiões hidrofílicas é de essencial importância para a bioatividade, uma vez que processos de solvatação e dessolvatação têm importância crítica na difusão dos compostos através das membranas biológicas.

Em linhas gerais, pode-se afirmar que a aplicação do estudo de QSAR-3D evidenciou a importância extrema de um balanço lipofílico-hidrofílico adequado para um bom desempenho das 5-nitro-2-tiofilideno benzidrazidas p-substituídas como agentes antimicrobianos. 


\section{CONCLUSÕES}

Foram sintetizadas, identificadas e testadas, neste trabalho, quatorze 5-nitro2-tiofilideno benzidrazidas substituídas, que apresentaram espectros de IV, RMN- ${ }^{1} \mathrm{H}$ e $\mathrm{RMN}-{ }^{13} \mathrm{C}$ compatíveis com as estruturas químicas planejadas. Os rendimentos envolvidos nas três etapas de obtenção das bases de Schiff mostraram-se satisfatórios e compatíveis com valores descritos em literatura. Por determinação da faixa de fusão e análise elementar comprovou-se alto grau de pureza nos compostos obtidos

Entre os compostos testados frente à cepa padrão de Staphylococcus aureus (ATCC 25923), constatou-se ser a 5-nitro-2-tiofilideno 4-acetilbenzidrazida (XIV) ○ composto de mais alta atividade $(\mathrm{CIM}=0,14 \mu \mathrm{g} / \mathrm{mL})$, enquanto que a 5-nitro-2tiofilideno 4-butilbenzidrazida $(X I)$ apresentou-se como composto menos ativo (CIM = $13,50 \mu \mathrm{g} / \mathrm{mL}$ ). Observou-se, para a série em estudo, o mesmo perfil de atividade frente à cepa multi-resistente de Staphylococcus aureus (3SP/R33), em que novamente o composto 5-nitro-2-tiofilideno 4-acetilbenzidrazida mostrou-se como o mais ativo ( $\mathrm{CIM}=0,22-0,11 \mu \mathrm{g} / \mathrm{mL}$ ), enquanto que a 5-nitro-2-tiofilideno 4butilbenzidrazida (XI) $(\mathrm{CIM}=25,40-12,70 \mu \mathrm{g} / \mathrm{mL})$ se apresentou como $\circ$ de mais baixa atividade

A partir das informações obtidas por determinação da concentração bactericida mínima, CBM, dos derivados em estudo, pode-se afirmar que a 5-nitro-2tiofilideno benzidrazida (I) apresenta primordialmente atividade bacteriostática, já que o valor de CBM determinado para o mesmo demonstrou ser muito maior que o de concentração inibitória mínima, CIM. Por outro lado, os compostos 5-nitro-2tiofilideno 4-bromobenzidrazida, 5-nitro-2-tiofilideno 4-clorobenzidrazida (II), 5-nitro2-tiofilideno 3,4-diclorobenzidrazida (III) e 5-nitro-2-tiofilideno 4-acetilbenzidrazida (XIV), ao mesmo tempo em que mostraram boa atividade bacteriostática, exerceram efeito bactericida em concentrações significativamente baixas, classificando-se como os análogos mais potentes entre os compostos estudados.

Em concordância com estudos anteriores realizados no Laboratório de Planejamento e Desenvolvimento de Fármacos da FCF/USP, sob coordenação do Prof. Assoc. Leoberto Costa Tavares, os resultados de atividade antimicrobiana 
mostraram sofrer influência significativa da hidrofobicidade. Os resultados obtidos para a cepa multi-resistente foram compativeis com os determinados para a cepa padrão sugerindo, inicialmente, que o microrganismo em questão, ainda não dispõe de mecanismos de resistência aos compostos analisados.

$\mathrm{Na}$ abordagem semi-quantitativa deste estudo, por aplicação do diagrama operacional de Topliss, determinou-se um valor aproximado da contribuição hidrofóbica inerente aos grupos substituintes selecionados $(\pi \cong 0,70 \pm 0,1)$, definido como ótimo. Assim, valores de $\pi$ muito acima ou abaixo de 0,70 resultaram em considerável decréscimo da atividade antimicrobiana, com exceção do composto $p$ acetil substituído que exibiu comportamento flagrantemente distinto do observado para toda a série em estudo.

Os estudos de QSAR em duas dimensões demonstraram que a atividade antimicrobiana das 5-nitro-2-tiofilideno benzidrazidas substituidas sofre influência preponderante de duas propriedades físico-químicas que são a hidrofobicidade, expressa pelos descritores estruturais $\pi$ ou ClogP, e a distribuição eletrônica, expressa pelos descritores estruturais $\sigma$ ou $\mathfrak{I}$.

Por aplicação da Análise de Hansch, observou-se que o modelo bilinear foi o que mais se adequou na expressão da influência de propriedades físico-químicas sobre a atividade antimicrobiana da série em estudo, valendo ressaltar que a exclusão dos compostos p-acetil (XIV), p-bromo (XIII) e $m, p-\mathrm{Cl}_{2}$ (III) substituidos na formulação das equações resultou em melhor ajuste do modelo gerado aos dados obtidos experimentalmente.

As equações 31 e 33 que ressaltam a relevância dos descritores estruturais de caráter eletrônico, expressos por $\sigma$ ou $\mathfrak{I}$, na determinação da atividade antimicrobiana, respectivamente, sinalizam que a distribuição eletrônica influencia o aumento da potência antimicrobiana dos análogos em estudo por dois mecanismos complementares; sendo que um deles estaria relacionado à influência dos efeitos indutivo e de ressonância na estrutura química do ligante e o outro estaria relacionado aos campos moleculares gerados em torno do ligante, sugerindo uma possivel interação do substituinte com área específica do sítio receptor.

No estudo de QSAR-3D desenvolvido com aplicação do programa Volsurf, evidenciou-se, em concordância com o estudo de QSAR clássico, que a 
hidrofobicidade prevalece como propriedade fundamental para desencadeamento da atividade antimicrobiana de 5-nitro-2-tiofilideno benzidrazidas $p$-substituídas.

Por meio da abordagem de QSAR-3D foi possivel compreender como a hidrofobicidade estaria influenciando positivamente a bioatividade dos compostos da série estudada, indicando que o acréscimo desta atividade estaria relacionado principalmente à distribuição uniforme da hidrofobicidade na superfície da estrutura química dos ligantes.

Regiões hidrofílicas pontuais apresentaram-se também como de fundamental importância para o desempenho da bioatividade, já que fenômenos de solvatação e dessolvatação são críticos no processo de difusão através das membranas biológicas, condicionando o mecanismo de transferência do ligante até o seu sítio de ação.

Pode-se afirmar, em linhas gerais, que o estudo de QSAR considerando os aspectos tridimensionais dos ligantes evidenciou, primordialmente, a importância de um balanço lipofílico-hidrofílico para um bom desempenho das 5-nitro-2-tiofilideno benzidrazidas $p$-substituídas como agentes antibacterianos.

O composto $p$-acetil substituído (XIV) apresentou comportamento diferenciado de atividade antimicrobiana ( $\mathrm{CIM}=0,14 \mu \mathrm{g} / \mathrm{mL})$, sendo, portanto, classificado como super ativo. Com base em estudos realizados até momento não se pode afirmar, definitivamente, quais seriam as interações envolvidas ou quais seriam as principais propriedades físico-químicas responsáveis por tão pronunciada atividade. Acreditase que o efeito de campo do grupo acetil, somado a um balanço lipofílico-hidrofílico adequado deste composto provavelmente estejam contribuindo para tão pronunciada atividade. Ressalta-se também que para que o $p$-acetil derivado seja classificado como um outlier, ainda são necessárias informações mais aprofundadas referentes a este composto.

Os resultados obtidos no estudo quantitativo das relações entre estrutura química e atividade antimicrobiana, QSAR-2D e QSAR-3D, ressaltam o forte potencial da série de compostos estudada como alternativa viável para o planejamento de novos ligantes, candidatos a fármacos voltados para o tratamento de infecções causadas por Staphylococcus aureus com caráter de multi-resistência. 


\section{REFERÊNCIAS BIBLIOGRÁFICAS}

ABOUL-ENEIN, H., WAINER, I.W. The Impact of Stereochemistry on Drug Development and Use. New York: John Wiley \& Sons, 1997, p. 1-3.

AKIMITSU, N., HAMAMOTO, H., INOUE, R., SHOJI, M., AKAMINE, A., TAKEMORI, K. HAMASAKI, N., SEKIMIZU, K. Increase in resistance of methicillin-resistant Staphylococcus aureus to $\beta$ lactams caused by mutations conferring resistance to benzalkonium chloride, a disinfectant widely used in hospitals. Antimicrob. Agents Chemother., Washington, v. 43, n. 12, p. 3042$3043,1999$.

AKRAM, J. True community-acquired methicillin-resistant Staphylococcus aureus bacterimia. Infect. Control Hosp. Epidemiol., Thorofare, v.19, n.2, p.106-107, 1998.

ALBERT, A. Selective Toxicity. 7 Ed. London: Chapman \& Hall, 1985, p. 206, 398.

ALONSO, R. Outbreak among HIV-Infected patients of Staphylococcus aureus resistant to cotrimoxazole and methicillin. Infect. Control Hosp. Epidemiol., Thorofare, v. 18, n. 9, p. 617$621,1997$.

ALI, S.M., TEDFORD, C.E., GREGORY, R., YATES, S.L., PHILLIPS, J.G. New acetylene based histamine $\mathrm{H}_{3}$ receptor antagonists derived from the marine natural product verongamine. Bioorg. Med. Chem. Lett., Ohio, v. 8, p. 1133-1138, 1998.

ALI, S.M., TEDFORD, C.E., GREGORY, R., HANDLEY, M.K., YATES, S.L., HIRTH, W.W., PHILLIPS, J.G. Design, synthesis and structure-activity relationships of acetylenic-based histamine $\mathrm{H}_{3}$ receptor antagonists. J. Med. Chem., Columbus, v. 42, n. 5, p. 903-909, 1999.

ANDREWS, P.R., CRAIK, D.J., MARTIN, J.L. Functional group contributions to drug-receptor interactions. J. Med. Chem., Columbus, v.27, p. $1648-1657,1984$.

ANDREWS, P.R. 3D QSAR in Drug Design: Theory, Methods and Applications. Leiden: ESCOM, 1993, p. 13.

ANDREWS, J.M. Determination of minimum inhibitory concentrations. J. Antimicrob. Chemother., Oxford, v. 48, suppl. 01, p. 5-16, 2001.

ASNIS, R.E., GOTS, J.S. Studies on the action of nitrofurans on bacterial enzime sistems. I. The inhibition of bacterial respiration by furacin. Arch. Biochem., New York, v. 30, n. 01, p. 25-33, 1951.

AVRIL, J.L., BRIFFORD, J., BEINIS, J.P., DUBRISAY, J. Etude de l'influence de l'antibiothérapie sur les résistances des entérobactéries de l'íntestin. Ann. Microbiol., Paris, v.131B, n.1, p.21-29, 1980.

BAMBURY, R.E. Synthetic antibacterial agents. In: BURGER, A., WOLFF, M. Burger's Medicinal Chemistry. 4.ed., New York: Willey-Interscience, 1980. Part. 2, p.42-81.

BARBOSA, H.R., TORRES, B.B. Microbiologia Básica. São Paulo: Atheneu, 1999. p. 196.

BARREIRO, E.J., FRAGA, C.A.M. Química Medicinal. Porto Alegre: Artmed Editora, 2001.

BARREIRO, E.J, FRAGA, C.A.M., MIRANDA, A.L.P., RODRIGUES, C. R. A química medicinal de $N$ acilidrazonas: novos compostos-protótipos de fármacos analgésicos, antiinflamatórios e antitrombóticos. Quim. Nova, São Paulo, v. 25, n. 01, p. 129-148, 2002. 
BARRETT, F.F. Methicillin-resistant Staphylococcus aureus at Boston city hospital. Bacteriologic and epidemiologic observation. J. Med., New England, v. 279, p. 441-448, 1968.

BAUER, A.W., KIRBY, W.M.M., SHERRIS, J.C., TRUCK, M. Antibiotic susceptibility testing by a standardized single disk method. Am. J. Clin. Pathol., Chicago, v. 45, n. 4, p. 493-\&, 1966.

BEILSTEINS handbuch der organischen chemic. 4 ed. Berlin: Springer-Verlag, 1971, v. 9, suppl. 3, p. 2328. 1983, suppl.4, p. 1008, 1040.

BLANKLEY, C.J. Recent Developments in 3D-QSAR. In: van de Waterbeemd, H. Structure-Property Correlations in Drug Research. San Diego: Academic Press, Inc., 1996, p. 111-126.

BOOBBYER, D.N.A., GOODFORD, P.J., MCWHINNIE, P.M. New hydrogen-bond potential for use in determining energetically favourable binding sites of molecules of known structure. J. Med. Chem., Columbus, v. 32, n. 05, p. 1083-1094, 1989.

BONE, R., SALEMME, F.R. The integration of structure-based design and directed combinatorial chemistry for new pharmaceutical discovery. In: GUBERNATOR, K., BOHM, H.J. Structurebased Ligand Design. Vol. 06. New York: Wiley-VCH, 1998, p. 1-11.

BOYCE, J.M. Environmental contamination due to methicillin-resistant Staphylococcus aureus: possible infection control implications. Infect. Control Hosp. Epidemiol., Thorofare, v.18, n.9, p.622-627, 1997.

BRENWALD, N.P., FRAISE, A.P. Triclosan resistance in methicillin-resistant Staphylococcus aureus (MRSA). J. Hosp. Infect., Londres, v. 55, n. 02, p. 141-144, 2003.

BRYAN, G.T. In: BRYAN, G.T., ed. Carcinogenesis: a comprehensive survey. New York: Raven Press, 1978, p. 1-11.

BUNDGAARD, $\mathrm{H}$. Design and application of prodrugs. In: KROGSGAARD-LARSEN, P., BUNDGAARD, H. A Textbook of Drug Design and Development. Chur: Harwood Academic Publishers, 1991, p. $113-191$.

BURD, M., HUMPHRES, H., GLYN, G., MITCHELL, E., MCDONALD, P., JOHNSON, H., MCDONNELL, B., DOYLE, D., ROSSNEY, A. Control and the prevention of methicillin-resistant Staphylococcus aureus in hospitals in Ireland: North/South study of MRSA in Ireland 1999. J. Hosp. Infect., Londres, v. 53, n. 04, p. 297-303, 2003.

BUU-HOI, P., XUONG, N. D., BAC, N. V. Comptes rendus hebdomadaires des séances de l'académie des sciences. C. R. Hebd. Seances Acad. Sci.; Paris, v. 257, n.19-20, p. 3182-3184, 1963.

CALDWELL, T. W., SAYIN, A. N. The synthesis of some trifluoromethyl derivatives of p-aminobenzoic acid, sulfanilamida and p,p'- diamino diphenyl sulfone. J. Am. Chem. Soc., Washington, v. 73 , p. 5125-51127, 1951.

CANILLAC, N., MOUREY, A. Antibacterial activity of the essential oil of Picea excelsa on Listeria, Staphylococcus aureus and coliform bacteria. Food Microbiology, Amsterdam, v. 18, n. 03, p. 261-268, 2001.

CAREY, F.A. Organic Chemistry. 4 ed. USA: Mc Graw-Hill, 2000, p. 672-677, 790-800.

CAREY, F. A., SUNDBERG, R. J. Advanced Organic Chemistry - part B., 3 ed., New York: Plenum Press, 1990. 
CARRON, M., JULLIEN, M.A., JULIA, M.T., GARCZYNSKA, M. Propriétés antiseptiques de quelques nitro-5furfurilydène benzhydrazides. Etude du (nitro-5'furfurilydène-2) hydroxy-4-benzhydrazide. Ann. Pharm. Fr., Paris, v.21, n.4, p.287-297,1962.

CERECETTO, H., MAIO, R.D, IBARRURI, B, SEONE, G., DENICOLA, A., PELUFLO, G., PAULINO, Q. Synthesis and anti-trypanosomal activity of novel 5-nitro-2-furaldehyde and 5-nitrothiophene-2carboxaldehyde semicarbazone derivatives. Farmaco, Lausanne, v. 53, n. 02, p. 89-94, 1998.

COLLANDER, R. The partition of organic compounds between higher alcohols and water. Acta Chem. Scand., Copenhagen, v. 5, n. 05, p. 774-780, 1951.

COLLINS, C.H., LYNE, P.M., GRANGE, J.M. Collins and Lyne's microbiological methods. 7 ed. Oxford: Butterworth-Heinemann, 1995. p. 493.

CONTERNO, I.O. Risk factors for mortality in Staphylococcus aureus bacterimia. Infect. Control Hosp. Epidemiol., Thorofare, v. 19, n.1, p.32-37, 1998.

CRAIG, P.N. Interdependence between physical parameters and selection of substituent groups for correlation studies. J. Med. Chem., Columbus, v. 14, n. 8, p. 680-684, 1971.

CRAMER, R.D., PATTERSON, D.E., BUNCE, J.D. Comparative molecular field analysis (CoMFA). 1. Effect of shape on binding of steroids to carrier proteins. J. Am. Chem. Soc., Columbus, v. 110, n. 18 , p. $5959-5967,1988$.

CRAMER, R.D. De PRIEST, S.A., PATTERSON, D.E. The developing practice of comparative molecular field analysis. In: KUBINYI, H. 3D QSAR in Drug Design: Theory, Methods and Applications. Leiden: ESCOM, 1993, p. 443-485.

CREWS, P., RODRIGUEZ, J., JASPARS, M. Organic Structure Analysis. New York: Oxford University Press, 1998, 552p.

CRIVORI, P., CRUCIANI, G., CARRUPT, P.A., TESTA, B. Predicting blood-brain barrier permeation from three-dimensional molecular structure. J. Med. Chem., Columbus, v. 43, n. 11, p. 22042216, 2000.

CROWCROFT, N.S. Methicillin-resistant Staphylococcus aureus and antimicrobial use in Belgian hospital. Infect. Control Hosp. Epidemiol., Thorofare, v.20, n. 01, p. 31-36, 1999.

CRUCIANI, G., PASTOR, M., GUBA, W. Volsurf: a new tool for the pharmacokinetic optimization of lead compounds. Eur. J. Pharm. Sci., Paris, v. 11, suppl.2, p. S29-S39, 2000.

CRUCIANI, G., CRIVORI, P., CARRUPT, P.A., TESTA, B. Molecular fields in quantitative structurepermeation relationships: the Volsurf approach. J. Mol. Struc. THEOCHEM, v. 503, n. 01-02, p. $17-30,2000$.

DAILEY, C.F., DILETO-FANG, C.L., BUCHANAN, L.V., ORAMAS-SHIREY, M.P., BATTS, D.H., FORD, C.W., GIBSON, J.K. Efficacy of linezolid in treatment of experimental endocarditis caused by methicillin-resistant Staphylococcus aureus. Antimicrob. Agents Chemother. , Washington, v.45, n. 8, p. 2304-2308, 2001.

DARVAS, F. Application of the sequential simplex method in designing drug analogs. J. Med. Chem. Columbus, v. 17, n. 8, p. 799-804, 1974.

DAUM, T.E., SCHABERG, D.R. TERPENNING, M.S., SOTTILE, W.S., KAUFFMAN, C.A. Increasing resistance of Staphylococcus aureus to ciprofloxacin. Antimicrob. Agents Chemother., Washington, v. 34, n. 09, p. 1862-1863, 1990. 
DAYAN, J., DEGUINGAND, C., TRUZMAN, C. Study of the mutagenic activity of 6 hepatotoxic pharmaceutical drugs in the Salmonella typhimurium microsome test, and the HGPRT Na+/K+ ATPase system in cultured mammalian cells. Mutat. Res., Amsterdam, v.157, n.1, p.1-12, 1985.

DAYAN, J., DEGUINGAND, C., TRUZMAN, C., CHEVRON, M. Application of the SOS chromotest to 10 pharmaceutical agents. Mutat. Res., Amsterdam, v.187, n.2, p.55-66, 1987.

DEBNATH, T., HANSCH, C., KIM, K.H., MARTIN, Y.C. Mechanistic interpretation of the genotoxicity of nitrofuran (antibacterial agents) using quantitative structure-activity relationships and comparative molecular field analysis. J. Med. Chem., Columbus, v. 36, n. 8, p. 1007-1010, 1993.

DELMAS, F., GASQUET, M., TIMON-DAVID, P., MADADI, N., VANELle, P., VAILle, A., MALDONADO, J. Synthesis and in vitro anti-protozoan activity of new 5-nitrothiophene oxime ether derivatives. Eur. J. Med. Chem., Paris, v. 28, n. 01, p. 23- 27, 1993.

DESAI, D., DESAI, N., NIGHTINGALE, P., ElLIOT, T., NEUBERgeR, J. Carriage of methicillinresistant Staphylococcus aureus is associated with an increased risk of infection after liver transplantation. Liver Transplantation, Los Angeles, v.9, n. 7, p. 754-759, 2003.

DODD, M.C., STILLMAN, W.B. The in vivo bacteriostatic action of some simple furan derivatives. J. Pharmacol. Exp. Ther., Bethesda, v.82, n.1, p.11-18, 1944.

EDWARDS, D.I. In: SAMMES, P.G., TAYLOR, J.B., eds. Comprehensive Medicinal Chemistry: the rational design, mechanistic study \& therapeutic application of chemical compounds. Oxford: Pergamon Press, 1990, v.2, p. 725.

EI-OBEID, H.A., ELNIMA, E.I., AL-BADR, A.A. Synthesis and antimicrobial activity of new furan derivatives. Pharm. Res., Stuttgart, v.1, p.42-43, 1985.

ELSOM, G.K.F., HIDE, D. Susceptibillity of methicillin-resistant Staphylococcus aureus to tea tree oil and mupirocin. J. Antimicrob. Chemother., Oxford, v.43, n. 03, p. 427-428, 1999.

ERKER, T. Studies on the chemistry of Thieno-anellated $\mathrm{O}, \mathrm{N}$-and $\mathrm{S}, \mathrm{N}$-containing heterocycles. 2 [1]. Synthesis of Thieno[2,3-b]diazepine derivatives with potential CNS activity. J. Heterocyclic Chem., Austria, v. 30, n. 04, p. 807-809, 1993.

EVANS, M.E., TITLOW, W.B., Selection of fluoroquinolone-resistant methicillin-resistant Staphylococcus aureus with ciprofloxacin and trovafloxacin. Antimicrob. Agents Chemother., Washington, v. 42, n. 03, p. 727, 1998.

FERGUSON, J., Proc. Roy. Soc., Ser. B 127, 387-404 (1939). xx-RICHET, M. C., Compt. Rend. Soc. Biol. (Paris) 45, 775-775 (1893). Apud: KUBINYI, H. QSAR: Hansch analysis and related approaches. New York: VCH, 1993, 4p.

FERNANDES, P.B., MENZEL, R., HARDY, D.J., TSE-DINH, Y., WARREN, A., ELSEMORE, D.A. Microbial resistance: novel screens for a contemporary problem. Med. Res. Rev., New York, v.19, n.6, p.559-568, 1999.

FILIPPONI, E., CRUCIANI, G., TABARRINI, O., CECCHETTI, V., FRAVOLINI, A. QSAR study and Volsurf characterization of anti-HIV quinolone library. J. Comput.-Aided Mol. Des., Netherlands, v. 15, n. 03, p. $203-217,2001$.

FLYNN, B.L., THEESEN, K.A. Pharmacophore management of Alzheimer disease part III: nonsteroidal antiinflammatory drugs-emerging protective evidence? Ann. Pharm. Cincinnati, v. 33. n. 7-8, p. 840-849, 1999. 
FOYE, W.O., LEMKE, T.L., WILLIANS, D.A. Principles of Medicinal Chemistry. 4.ed. Baltimore: Williams \& Wilkins, 1995, p. 995.

FUCHS, P.C., KOOP, J., HAFNER, H., KLEINER, U., PALLUA, N. MRSA - retrospective analysis of an outbreak in the burn centre Aachen. Burns, Wiltshire, v. 28, n. 06, p. 575-578, 2002.

FUJITA, T., IWASA, J., HANSCH, C. A new substituent constant, $\pi$, derived from partition coefficients. J. Am. Chem. Soc., Columbus, v. 86, n. 22, p. 5175-5183, 1964.

FURLANETTO, M., SANTOS, M.G.B., TAVARES, L.C. Avaliação da influência de grupos substituintes sobre a atividade antimicrobiana de derivados 5-nitro-2-tiofilidênicos. RBCF/Braz. J. Pharm. Sci. São Paulo, vol. 37, supl. 1, p. 62, 2001.

GAO, H., DENNY, W.A., GARG, R., HANSCH, C. Quantitative structure-activity relationships (QSAR) for 9-anilinoacridines: a comparative analysis. Chem.-Biol. Interactions, Ireland, v. 116, n. 03, p. 157-180, 1998.

GASTEIGER, J., RUDOLPH, C., SADOWSKI, J. Automatic generation of 3D atomic coordinates for organic molecules. Tethraedron Comp. Method., v. 03, p. 537-547, 1990.

GAUDIO, A.C. Modelos clássicos de estudo quantitativo das relações entre estrutura-química e atividade biológica. Quim. Nova, São Paulo, v. 19, n. 03, p. 278-289, 1996.

GAYRAL, P., RIGOTHIER, M.C., GANTIER, J.C. Comparaison des activités antiparasitaires de deux séries d'aldimines des nitro-5-furane et thiophène. Eur. J. Med. Chem., Toulouse, v. 16, n. 2, p. 151-155, 1981.

GEISEL, R., SCHIMITZ, F.J., THOMAZ, L. Emergence of heterogeneous intermediate vancomycin resistance in Staphylococcus aureus isolates in the Dusseldorf area. J. Antimicrob. Chemother., Oxford, v.43, n. 6,p. 846-848, 1999.

GELADI, P., KOWALSKI, B.R. Partial least-squares regression: a tutorial. Anal. Chim. Acta, Amsterdam, v. 185, p. 1-17, 1986.

GELIN, B.R. Current Approaches in Computer-Aided Molecular Design. In: REYNOLDS, C.H., HOLLOWAY, M.K., COSE, H.K. Computer-Aided Molecular Design: Applications in Agorchemicals, Materials and Pharmaceuticals. Am. Chem. Soc. - ACS Symposium Series, Washington, p. 1-11, 1995.

GIESEN, D.J, STORER, J.W., CRAMER, C.J., TRUHLAR, D.G. General semiempirical quantum mechanical solvation model for nonpolar solvation free energies n-hexadecane. J. Am. Chem. Soc, Columbus, v. 117, n. 03, p. 1057-1068.

GILBERT, D.N., KOHLHEPP, S.J., SLAMA, K.A. Phenotypic resistance of Staphylococcus aureus, selected Enterobacteriaceae and Pseudomona aeruginosa after single and multiple in vitro exposures to ciprofloxacin, levofloxacin and torvalfoxacin. Antimicrob. Agents Chemother., Washington, v. 45, n. 03, p. 883-892, 2001.

GILLESPIE, S.H. Medical microbiology. Oxford: Butterworth Heinemann, 1994. p. 234-247.

GOODFORD, P.J., Computational procedure for determining energetically favourable binding sites on biologically important macromolecules. J. Med. Chem., Columbus, v. 28, n. 07, p. 849-857, 1985.

GREEN, M.N. The effect of furacin (5-Nitro-2-Furaldehyde Semicarbazone) on the metabolism of bacteria. Arch. Biochem., New York, v. 19, n. 1, p. 397-405, 1948. 
HACKSELL, U. Structural and Physicochemical Factors in Drug Action. In: KROGSGAARD-LARSEN, P., LILJEFORS, T., MADSEN, U. A Textbook of Drug Design and Development. 2 ed. Amsterdan: Harwood Academic Publishers, 1996, capitulo, p. 35-48.

HAMILTON-MILLER, J.M.T., SHAH, S. Activity of the tea component epicatechin gallate and analogues against methicillin-resistant Staphylococcus aureus. J. Antimicrob. Chemother., Oxford, v.46, n. 05, p. 852-853, 2000.

HAMMETT, L.P. Physical organic chemistry: reaction rates, equilibria and mechanisms. New York: Mc Graw-Hill, 1940, 404p. (International Chemical Series).

HAMMETT, L.P. The effect of structure upon the reactions of organic compounds. J. Am. Chem. Soc., Columbus, v. 59, n.1, p. 96-103, 1937.

HANSCH, C. A quantitative approach to biochemical structure-activity relationships. Acc. Chem. Res., Columbus, v. 2, n. 08, p. 232-239, 1969.

HANSCH, C., FUJITA, T. $p-\sigma-\pi$ - analysis: a method for the correlation of biological activity and chemical structure. J. Am. Chem. Soc., Columbus, v. 86, n. 08, p. 1616-1626, 1964.

HANSCH, C.; LEO, A., Substituent constants for correlation analysis in chemistry and biology, Wiley, New York, 1976. Apud: KUBINYI, H. QSAR: Hansch analysis and Related Approaches. New York:VCH, 1993, p.35 (Methods and principles in medicinal chemistry, v.1).

HANSCH, C., LEO, A. Exploring QSAR: fundamentals and applications in chemistry and biology. Washington: American Chemical Society, 1995. 557 p.

HANSCH, C., LEO, A., TAFT, R.W. A survey of Hammett substituent constants and resonance and field parameters. Chem. Rev., Columbus, v. 91, n. 1, p. 165-195, 1991.

HANSCH, C., LEO, A., HOEKMAN, D. Exploring QSAR: hydrophobic, electronic, and steric constants. Washington: American Chemical Society, 1995. 348 p.

HANSCH, C., SAMMES, P.G., TAYLOR, J.B. Comprehensive Medicinal Chemistry: the rational design, mechanistic study \& therapeutic application of chemical compounds. Oxford: Pergamon Press, 1990.

HAYPTSCHEIN, M., NODIFF, E. A., SAGGIOMO, A. J. Trifluoromethyl derivatives of hidroxybenzoic acids and related compounds. J. Am. Chem. Soc., Washington, v. 76, p. 1051-1054, 1954.

HIRAMATSU, K., HANAKI, H., INO, T., YABUTA, K., OGURI, T., TENOVER, F.C. Methicillin-resistant Staphylococcus aureus clinical strain with reduced vancomycin susceptibility. J. Antimicrob. Chemother., Oxford, v. 40, n. 01, p. 135-136, 1997.

HIRANO, K., YOSHINA, S., OKAMURA, K., SUZUKA, I. Electronic aspect of the antibacterial activity of nitrofuran derivatives. Bull. Chem. Soc. Jpn., Tokyo, v. 40, n. 10, p. 2229-2233, 1967.

HORII, T., SUZUKI, Y., MONJI, A., MORITA, M., MURAMATSU, H., KONDO, Y., DOI, M., TAKESHITA, A., KANNO, T., MACKAWA, M. Detection of mutations in quinolone resistancedetermining regions in levofloxacin and methicillin-resistant Staphylococcus aureus: effects of the mutations on fluoroquinolone MICs. Diagn. Micr. Infec. Dis., New York, v. 46, n. 02, p. 139-145, 2003.

HOWE. R.A., WOOTTON, M., WALSH, T.R., BENNETT, P.M., MCGOWAN, A.P. Expression and detection of hetero-vancomycin resistance in Staphylococcus aureus. J. Antimicrob. Chemother., Oxford, v.44, n. 01, p. 675-678, 1999. 
HOWE. R.A., WOOTTON, M., WALSH, T.R., BENNETT, P.M., MCGOWAN, A.P. Heterogeneous resistance to vancomycin in Staphylococcus aureus. J. Antimicrob. Chemother., Oxford, v.45, n. 01 , p. 130-131, 2000.

ISHIKAWA, T., MATSUNAGA, N., TAWADA, H., KURODA, N., NAKAYAMA, Y., ISHIBASIH, Y., TOMIMOTO, M., IKEDA, Y., TAGAWA, Y., IIZAWA, Y., OKONOGI, K., HASHIGUCHI, S., MIYAKE, A. TAK-599, a novel N-phosphono type prodrug of anti-MRSA cephalosporin T-91825: synthesis, physicochemical and pharmacological properties. Bioorg. Med. Chem. Lett., Ohio, v. 11, n. 11, p. 2427-2437, 2003.

JAMBHEKAR, S.S. Biopharmaceutical Properties of Drug Substances. In: FOYE, W.O., LEMKE, T.L., WILLIAMS, D.A. Principles of Medicinal Chemistry. 4 ed. London: Williams \& Wilkins, 1995, p. $12-24$

JONES, M.E., BOENINK, N.M., VERHOEF, J., KOHRER, K., SCHIMITZ, F.J. Multiple mutations conferring ciprofloxacin resistance in Staphylococcus aureus demonstrate long-term stability in an antibiotic-free environment. J. Antimicrob. Chemother., Oxford, v.45, n. 03, p. 353-356, 2000.

KANSY, M. Molecular Properties. In: VAN DE WATERBEEMD, H. Structure-Property Correlations in Drug Research. Califórnia: Academic Press, 1996, p. 11-40.

KAPUR, S., SHUSTERMAN, A., VERMA, R.P., HANSCH, C., SELASSIE, C.D. Toxicology of benzyl alcohols: a QSAR analysis. Chemosphere, Oxford, v. 41, n. 10, p. 1623-1649, 2000.

KATAE, H., IWANA, H., TAKASE, Y., SHIMIZU, M. Antitumor activity of nitrofuran and nitrothiophene derivatives on Ehrlich Ascites Carcinoma. Arzneimittel Forschung., Aulendorf, v. 17, n. 08, p. 1030-1034, 1967.

KIM, H.Y., LEE, J.S., CHA, J.H., PAE, A.N., CHO, Y.S., CHANG, M.H., KOH, H.Y. Synthesis and in vitro activity of new methylenepiperidinyl and methylenepyrrolidinyl oxazolidinone antibacterial agents. Bioorg. Med. Chem. Lett., Ohio, v. 13, n. 13, p. 2227-2230, 2003.

KOROLKOVAS, A. Fundamentos de Farmacologia Molecular. São Paulo: EDART, 1970, p. 29-65, 125-166, 197-239.

KOROLKOVAS, A., BURCKHALTER, J. H. Química Farmacêutica. Rio de Janeiro: Guanabara Dois, 1982, 783p.

KOROLKOVAS, A. Essentials of Medicinal Chemistry, 2. ed., New York: John Wiley, 1988, 1204p.

KOROLKOVAS, A., FRANÇA, F.F.C. Dicionário Terapêutico Guanabara. Rio de Janeiro: Guanabara-Koogan, 2001.

KUBINYI, H. Quantitative structure-activity relationships: the bilinear model, a new model for nonlinear dependence of biological activity on hydrophobic character. J. Med. Chem., Columbus, v. 20, p. 625-629, 1977.

KUBINYI, H. Lipophilicity and drug activity. Progr. Drug Res., Basel, v. 23, n. 08, p. 97-198, 1979.

KUBINYI, H. QSAR: Hansch analysis and related approaches, New York: VCH, 1993, 240p.

KUBINYI, H. Strategies and recent technologies in drug discovery. Pharmazie, Eschborn, v. 50, n. 7 , p. $647-662,1995 a$. 
KUBINYI, H. The quantitative analysis of structure-activity relationship. In: WOLFF, M. E., ed. Burger's Medicinal Chemistry and Drug Discovery: principles and practice. 5 ed., New York: John Wiley, 1995b, v. 1, p. 497-572.

KUBINYI, H. QSAR and 3D QSAR in drug design. Part 1: methodology. DDT, Kidlington, v. 02, n. 12, p. 538-546, 1997.

KUBINYI, H. QSAR and 3D QSAR in drug design. Part 2: applications and problems. DDT, Kidlington, v. 02, n. 11, p. $457-467,1997$.

KUO, G.H., PROUTY, C., MURRAY, W.V., PULETO, V., JOLlifFE, L., CHEUNG, P., VARGA, S., EVANGELISTA, M., WANG, J. Design, synthesis and structure-activity relationships of phthalimide-phenylpiperazines: a novel series of potent and selective $\alpha_{1 \mathrm{a}}$-adrenergic receptor antagonists. J. Med. Chem., Columbus, v. 43, n. 11, p. 2183-2195, 2000.

LAMBERT, W.J. Modeling oil-water partitioning and membrane permeation using reversed-phase chromatography. J. Chromatog. A., New York, v. 656, n. 1-2, p. 469-484, 1993.

LEE, V. L., SCOTT, J.H. Antibiotic Resistance versus Small Molecules, the Chemical Evolution. Med. Res. Rev., Hoboken, v.19, n.6, p. 521-542, 1999.

LEITE, L.F.C.C., RAMOS, M.N., SILVA, J.P.B., MIRANDA, A.L.P., FRAGA, C.A.M., BARREIRO, E.J. Synthesis and analgesic profile of novel $\mathrm{N}$-containing heterocycle derivatives: arylidene 3phenyl-1,2,4-oxadiazole-5-carbohydrazide.II Farmaco, Lausanne, v. 54, n.11-12, p. 747-757, 1999.

LIEN, E.J. SAR: Side effects and drug design. In: GRUNEWALD, G.L. Medicinal Research Series, v. 11., New York and Basel:Marcel Dekker Inc., 1987, p. 25-40.

LIM, D. V. Microbiology, 2. ed., Boston: Mc Graw-Hill, 1998. p.720.

LIMONCU, M.H., ERMERTCAN, S., CETIN, C.B., COSAR, G., DINÇ, G. Emergence of phenotypic resistance to ciprofloxacin and levofloxacin in methicillin-resistant and methicillin-sensitive Staphylococcus aureus strains. Int. J. Antimicrob. Ag., Amsterdam, v. 21, n. 5, p. 420-424, 2003.

LUCARINI, M., PEDULLI, G.F., SPINELLI, D., FRASCARI, S. An EPR study of the radicals from 5nitrothiophenecarboxamides: a novel group of direct acting mutagens. Tetrahedron Lett., Bologna, v. 49, n. 33, p. 7317-7324, 1993.

LIZIOLI, A., PRIVITERA, G., ALLIATA, E., BANFI, E.M.A., BOSELLI, L., PANCERI, M.L., PERNA, M.C., PORRETTA, A.D., SANTINI, M.G., CARRERI, V. Prevalence of nosocomial infections in Italy: result from the Lombardy survey in 2000 . J. Hosp. Infect., Londres, v. 54, n. 02, p. 141148, 2003.

MACHADO, T.B., PINTO, A.V., PINTO, M.C.F.R., LEAL, I.C.R., SILVA, M.G., AMARAL, A.C.F., KUSTER, R.M., NETTO-DOS SANTOS, K.R. In vitro activity of brazilian medicinal plants, naturally occurring naphtoquinones and their analogues, against methicillin-resistant Staphylococcus aureus. Int. J. Antimicrob. Ag., Amsterdam, v. 21, n. 03, p. 279-284, 2003.

MACGOWAN, A.P., WISE, R. Establishing MIC breakpoints and the interpretation of in vitro susceptibility tests. J. Antimicrob. Chemother., Oxford, v. 48, suppl. 01, p. 17-28, 2001.

MAGER, P.P. Multivariated Chemometrics in QSAR: A Dialogue. Great Britain: John Wiley \& Sons, 1988, p. $169,170$. 
MANHOLD, R., REKKER, R.F., DROSS, K., BIJLOO, G., DE VRIES, G. The lipophilicity behaviour of organic compounds: 1. An uptading of the hydrophobic fragmental constant approach. QSAR, Weinheim, v. 17, n. 06, p. $517-536,1998$.

MARCH, J. Advanced Organic Chemistry: reactions, mechanisms and structures. 4 ed. New York: John Wiley, 1992.

MARTIN, Y.C. Quantitative Drug Design: A critical introduction. New York, Marcel Dekker, 1978. 425 p. [Medicinal Research Series, v. 8].

MARTIN, Y.C. 3D QSAR: Current State, Scope and Limitations. In: KUBINYI, H., FOLKERS, G., MARTIN, Y.C. 3D QSAR in Drug Design, v. 12-14. Great Britain: Kluwer Academic Publishers, 1998, p.3-23.

MASUNARI, A., REZENDE, P., TAVARES, L.C. Antimicrobial activity optimization of 5-nitro-2thiophylidene derivatives II In: 3rd Congress of Pharmaceutical Sciences, 2001, Águas de Lindóia -SP. Eur. J. Pharm. Sci. ELSEVIER, 2001. v.13. p.S130 - S130.

MASUNARI, A., TAVARES, L.C. Antimicrobial activity optimization of 5-nitro-2-thiophylidene derivatives against multi-resistant strains of Staphylococcus aureus In: XVIlth International Symposium on Medicinal Chemistry, 2002, Barcelona. Drugs of the Future. Barcelona: Prous Science, 2002. v.27. p.183- 183.

MASUNARI, A., VESSONI-PENNA, T.C., MAMIZUKA, E.M., TAVARES, L.C. New 5-nitro-2thiophylidene derivatives with activity against multi-resistant strains of Staphylococcus aureus In: 10th ISSSI- International Symposium on Staphylococci and Staphylococcal Infections, 2002, Tsukuba.10th ISSSI - Abstracts, 2002. p.47-47.

MASUNARI, A., NASCIMENTO, F.L.L., FURLANETTO, M., SANTOS, M.G.B., PENNA, T.C.V., MAMIZUKA, E.M., TAVARES, L.C. Determinação da atividade antimicrobiana de derivados 5nitro-2-tiofilidênicos frente às cepas padrão e multi-resistente de Staphylococcus aureus. In: VII Semana de Ciência e Tecnologia da FCF/USP, São Paulo. RBCF/ Braz. J. Pharm. Sci. São Paulo: FCF-USP, v. 39, supl.3, p. 192-194, 2003.

MASUNARI, A., REZENDE, P., TAVARES, L.C. QSAR studies of nifuroxazide analogs with antimicrobial activity against multidrug-resistant $\mathrm{S}$. aureus. In: The $15^{\text {th }}$ European Symposium on Quantitative Structure-Activity Relationships \& Molecular Modelling, Istanbul. Abstracts, 2004, p.123.

MASUNARI, A., TAVARES, L.C. Propriedades físico-químicas que influenciam a ação de fármacos. In: BARREIRO, E.J., FERREIRA, E. I. Fundamentos de Química Farmacêutica, São Paulo: Editora Atheneu, in press.

MATHISON, I.W., SOLOMONS, W.E., TIDWELL, R.R. Structural Features and Pharmacologic Activity. In: FOYE, W.O., LEMKE, T.L., WILLIAMS, D.A.. Principles of Medicinal Chemistry. 4 ed. London: Williams \& Wilkins, 1995, p. 25 - 49.

MCDONALD, P., MITCHELLI, E., JOHNSON, H., ROSSNEY, A., HUMPHREYS, H., GLYNN, G., BURD, M., DOYLE, D., MCDONNELL, R. Epidemiology of MRSA: the North/South study of MRSA in Ireland 1999. J. Hosp. Infect., Londres, v. 54, n. 02, p. 130-134, 2003.

MENEZES, I.R.A., LOPES, J.C.D., MONTANARI, C.A., OLIVA, G., PAVÃO, F., CASTILHO, M.S., VIEIRA, P.C., PUPO, M.T. J. Comput.-Aided Mol. Des., Netherlands, v. 17, n. 05-06, p. 277$290,2003$. 
MEYER, H., Arch. Exp. Path. Pharm. 42, 109-118 (1899). Apud: KUBINYI, H. QSAR: Hansch analysis and related approaches. New York: VCH, 1993, 4p.

MILLER, G., DOUKOS, P., SEYDEL, J. Sulfonamide structure-activity relationship in a cell free system. Correlation of inhibition of folate synthesis with antibacterial activity and physicochemical parameters. J. Med. Chem., Columbus, v.15, n. 07, p.700 - 706, 1972.

MONNET, D.L. Methicillin-resistant Staphylococcus aureus and its relationships to antimicrobial use: possible implications for control. Infect. Contr. Hosp. Epidem., Thorofare, v.19, n.8, p.552-559, 1998.

MONTANARI, M.L.C., ANDRICOPULO, A.D., MONTANARI, C.A. Calorimetry and structure-activity relationships for a series of antimicrobial hydrazides. Therm. Acta. v. 417, n. 02, p. 283-294, 2004.

MORRISON, R.T., BOYD, R.N. Quimica organica. 5 ed., New York: Addison Wesley Iberoamericana, 1997.

MULLER-SERIEYS, C., DECRE, D., BENOIT, C., BIGOT, C., MAUBERT, B., CARBON, C. Levofloxacin: serum bactericidal activity against methicillin resistant Staphylococcus aureus isolates. J. Antimicrob. Chemother., Washington, v.43, p. 67-70, 1999.

MURRAY, R.J., LIM, T.T., PEARSON, J.C. GRUBB, W.B., LUM, G.D. Community-onset methicillinresistant S. aureus bacteremia in Northern Australia. Int. J. Infect. Dis., v. 8, n. 05, p. 275-283, 2004.

NASCIMENTO, F.L.L., MASUNARI, A., TAVARES, L.C. Síntese e determinação da atividade antimicrobiana de derivados 5-nitro-2-tiofilidênicos frente à cepa padrão de Staphylococcus aureus (ATCC 25923). In: VII Semana de Ciência e Tecnologia da FCF/USP, São Paulo. RBCF/ Braz. J. Pharm. Sci. São Paulo: FCF-USP, v. 39, supl.3, p. 92, 2003.

NCCLS - National Committee for Clinical Laboratory Standards-Performance Standards for Antimicrobial Susceptibility Testing. Wayne, Pa, 2002, suppl. M100-S12 (m2).

NICOLLE, L.E. Regional dissemination and control of epidemic methicillin-resistant Staphylococcus aureus. Infect. Contr. Hosp. Epidem., Thorofare, v.20, n.3, p.202-205, 1999.

NIETO, M.J., ALOVERO, F.L., MANZO, R.H., MAZZIERI, N.R. A new class of fluoroquinolones: benzenesulfonamidefluoroquinolones (BSFQs), antibacterial activity and SAR studies. Eur. J. Med. Chem.., Paris, v. 34, n. 03, p. 209-214, 1999.

NISHI, J. Difference in incidence and transmission mode of methicillin-resistant Staphylococcus aureus among surgery, orthopedics, and pediatrics wards: a prospective study at a university hospital. Infect. Contr. Hosp. Epidem., Thorofare, v.19, n.2., p. 107-109, 1998.

NYS, G.G., REKKER, R.F. Statistical analysis of a series of partition-coefficients with special reference to predictability of folding of drug molecules - introduction of hydrophobic fragmental constants ( $F$ values). Chim. Ther., Netherlands, v. 8, n. 5, p. 521-535, 1973.

O'DONNELL, T.J. Uses a Computer Graphics in Computer-Assisted Drug Design. In: PERUN, T.J., PROPST, C.L. Computer-Aided Drug Design: Methods and Applications. New York: Marcel Dekker, Inc., 1989, p. 31-43.

OLIVEIRA, G.A. Caracterização de cepas de Staphylococcus aureus isoladas de diferentes regiōes do Brasil baseada em métodos genotípicos e fenotípicos. São Paulo, 1998. 164p. (Dissertação de Mestrado-Faculdade de Ciências Farmacêuticas - Universidade de São Paulo). 
OLIVEIRA, G.A., DELL'AQUILA, A.M., MASIERO, R.L., LEVY, C.E., GOMES, M.S., CUI, L., HIRAMATSU, K., MAMIZUKA, E.M. Isolation in Brazil of nosocomial Staphylococcus aureus with reduced susceptibility to vancomicin. Infect. Contr. Hosp. Epidem., Thorofare, v. 22, n. 7, p. 443-448, 2001.

ONORATO, M. Risk factors for colonization or infection due to methicillin-resistant Staphylococcus aureus in HIV-positive patients: a retrospective case-control study. Infect. Contr. Hosp. Epidem., Thorofare, v.20, n.1, p.26-30, 1999.

OSTMAN, B. Orientation in Electrophilic Substitution of I-M Substituted Thiophenes - I. Nitration of Thiophenealdehyde, Thiophenenitrile and Nitrothiophene. Acta Chem. Scand., Sweden, v. 22, n. 9, p. 2754-2764, 1968.

OSTMAN, B. Orientation in Electrophilic Substitution of I-M Substituted Thiophenes - II. Correlations between Localizaton Energy Differences and Reactivity Ratios. Acta Chem. Scand., Sweden, v. 22, n. 9, p. 2765-2772, 1968.

OVERTON, E., Studien uber die Narkose, zugleich ein Beitrag zur allgemeinen. Pharmakologie, G. Fisher, Jena, 1901; English translation by Lipnich, R. L., ed., Studies on Narcosis, Charles Ernest Overton, Chapman and Hall, London, 1991. Apud: KUBINYI, H. QSAR: Hansch analysis and related approaches. New York: VCH, 1993, p. 4 (Methods and principles in medicinal chemistry, v.1).

PATRICK, G.L. An Introduction to Medicinal Chemistry. 2 ed. New York: Oxford University Press, 2001, 620p.

PATT, W.C., EDMONS, J.J., REPINE, J.T., BARRYMAN, K.A., REISDORF, B.R., LEE, C., PLUMMER, M.S., SHALVIRPOUR, A., HALEEL, S.J., KEISER, J.A., FLYMAN, M.A., WELCH, K.M., REINOLDS, E.E., RUIBIN, R., TOBIAS, B., HALLAK, H., DOLVET, A.M. Structure-activity relationships in a series of orally active $\gamma$-hydroxy butenolide endothelin antagonists. J. Med. Chem., Columbus, v. 40, n. 7, p. 1063-1074, 1997.

PANNUTI, C.S., GRINBAUM, R.S. An overview of nosocomial infection control in Brazil. Infect. Contr. Hosp. Epidem., Thorofare, v. 16, p. 170-174, 1995.

PAVIA, D.L., LAMPMAN, G.M., KRIZ, G.S. Introduction to Spectroscopy: a guide for students of organic chemistry. 2 ed., Forth Worth: Harcouth Brace College Publishers, 1996, 511p.

PÉREZ, M.A.C., DÍAZ, H.G., TERUEL, C.F., PLÁ-DELFINA, J.M., SANZ, M.B. A novel approach to determining physocochemical and absorption properties of 6-fluoroquinolone derivatives:experimental assesment. Eur. J. Pharm. Biopharm., Amsterdam, v. 53, n. 3, p. 317325, 2002.

PERIOLI, L., AMBROGI, V., BERNADINI, C., GRANDOLINI, G., RICCI, M., GIOVAGNOLI, S., ROSSI, C. Potential prodrugs of non-steroidal anti-inflammatory agents for targeted drug delivery to the CNS. Eur. J. Med. Chem., Paris, v. 39, n. 08, p. 715-729, 2004.

PETRI JR., W.A. Antimicrobial agents. In: HARDMAN, J.G., LIMBIRD, L.E., GILMAN, A.G. GOODMAN \& GILMAN'S: The Pharmacological Basis of Therapeutics. 10 ed., New York: McGraw-Hill, 2001, p. 1171.

PISCOPO, E., DIURNO, M.V., ALIBERTI, F. Attivitá biologica di nuovi derivati idrazidici e idrazonici variamente sostituiti. Boll. - Soc. Ital. Biol. Sper., Napoli, v.59, n.3, p.344-348, 1983.

PISCOPO, E., DIURNO, M.V., GAGLIARDI, R., MAZZANI, O., FRANCESCO, F.M., PARRILI,C. Structure-activity relationships of hidrazono derivatives of biological interest. Boll. - Chem. Soc. Ital. Biol. Sper., Napoli, v. 55, n. 4, p. 311-316, 1989. 
PLEISS, M.A., UNGER, S.H. The design of test series and the significance of QSAR relationships. In: HANSCH, C., SAMMES, G.P., TAYLOR, J.B., eds. Comprehensive Medicinal Chemistry: the rational design, mechanistic study \& therapeutic application of chemical compounds. v. 4. Oxford: Pergamon Press, 1990, p. 561-569.

PROPST, C.L., PERUN, T.J. Introduction to Computer-Aided Drug In: PERUN, T.J., PROPST, C.L. Computer-Aided Drug Design-Methods and Applications. New York: Marcel Dekker, Inc., 1989, p. 2-15.

RANDO, D.G, SATO, D.N., SIQUEIRA, L., MALVEZZI, A., LEITE, C.Q.F., AMARAL, A.T., FERREIRA, E.I., TAVARES, L.C. Potential tuberculostatic agents. Topliss application on benzoic acid[(5-nitrothiophen-2-yl)-methylene]-hydrazide series. Bioorg. Med. Chem., Ohio, v. 10, n. 03, p. 557-560, 2002.

REKKER, R.F., MANHOLD, R. Calculation of drug lipophylicity: the hydrophobic fragmental constant approaches. New York: VCH, 1993, p. 4.Weinheim: VCH, 1992, 112p.

REZENDE, P., MASUNARI, A., SANTOS, M. G. B., MAMIZUKA, E. M., VESSONI-PENNA, T. C., TAVARES, L. C. Hansch Analysis of nifuroxazide analogues with antimicrobial activity against MRSA In: XVIlth Symposium on Medicinal Chemistry, 2002, Barcelona. Drugs of the Future. Barcelona: Prous Science, 2002. v.27. p.192 - 192

RICHET, M.C. Compt. Rend. Soc. Biol. (Paris) 45, 775-776 (1893). Apud: KUBINYI, H. QSAR: Hansch analysis and related approaches. New York: VCH, 1993, p.4, (Methods and principles in medicinal chemistry, v.1).

RODRIGUES, A.M. Síntese e determinação da concentração inibitória mínima frente a Staphylococcus aureus de 5-nitro-2-furfurilideno benzidrazidas substituídas. São Paulo, 2000. 101p. (Dissertação de Mestrado - Faculdade de Ciências Farmacêuticas - Universidade de São Paulo).

ROHR, U., MUELleR, C., WILHELM, M., MUHR, G., GATERMAN, S. Methicillin-resistant Staphylococcus aureus whole-body decolonization among hospitalized patients with variable site colonization by using mupirocin in combination with octenidine dihydrochloride. J. Hosp. Infect., Londres, v. 54, n. 04, p. 305-309, 2003.

ROBERTS, J.D., MORELAND, W. T. Electrical effects of substituent groups in saturated systems reactivities of 4-substituted bicyclo[2.2.2.] octane-1-carboxylic acids. J. Am. Chem. Soc., Columbus, v. 75, n. 7, p. 2167-2173, 1953.

ROSS, E.M. Pharmacodynamics: Mechanisms of Drug Action and the Relationship Between Drug Concentration and Effect. In: In: HARDMAN, J.G., LIMBIRD, L.E., GILMAN, A.G. GOODMAN \& GILMAN'S: The Pharmacological Basis of Therapeutics. 9 ed., New York: McGraw-Hill, 2001, p. 29-42.

RUBIN, R.J., HARRINGTON, C.A., POON, A., DIETRICH, K., GREENE, J.A., MOIDUDDIN, A. The economic impact of Staphylococcus aureus infection in New York city hospitals. Emerging. Infect. Dis., Atlanta, v.5, n.1, p.1-14, 1999.

SADER, H.S., PIGNATARI, A.C., HOLLIS, R.J., JONES, R.N. Evaluation of interhospital spread of methilicillin-resistant Staphylococcus aureus in São Paulo, Brazil, using pulsed-field gel electrophoresis of chromosomal DNA. Infect. Contr. Hosp. Epidem., Thorofare, v.15, n.5, p.320323, 1994.

SADOWSKI, J., RUDOPLH, C., GASTEIGER, J. The generation of 3D models of host-guest complexes. Anal. Chim. Acta, Amsterdam, v. 265, n. 02, 1992. 
SCHMITZ, F.J., VERHOEF, J., FLUIT, A.C. Prevalence of resistance to MLS antibiotics in 20 European university hospitals participating in the European SENTRY surveillance program. J. Antimicrob. Chemother., Oxford, v.43, n.06, p. 783-792, 1999.

SEILER, P. Interconversion of lipophilicities from hydrocarbon/water system into the octanol/water system. Eur. J. Med. Chem., Paris, v. 49, n. 5, p. 473-479, 1974.

SHETTY, N., WILSON, P.R. Sitafloxacin in the treatment of patients with infections caused by vancomycin-resistant enterococci and methicillin-resistant Staphylococcus aureus. J. Antimicrob. Chemother., Oxford, v.46, n.04, p. 633-637, 2000.

SIERADZKI, K., TOMASZ, A. Gradual alterations in cell wall structure and metabolism in vancomycinresistant mutants of Staphylococcus aureus. J. Bacteriol., Washington, v. 181, n. 24, p 7566$7570,1999$.

SILIPO, C., VITTORIA, A. Three-dimensional Structure of Drugs. In: HANSCH, C., SAMMES, P.G., TAYLOR, J.B. Comprehensive Medicinal Chemistry. the rational design, mechanistic study \& therapeutic application of chemical compounds. v. 4. Oxford: Pergamon Press, 1990, p. 154 204.

SILVA, C.H.P.M. Bacteriologia - um estudo ilustrado. Rio de Janeiro: Editora Eventos, 1999, p.386394.

SILVA, P., RESENDE, A. Farmacologia, 5. ed., Rio de Janeiro: Guanabara Koogan, 1998. 1034 p.

SILVERMAN, R.B. The Organic Chemistry of Drug Design and Drug Action. Califórnia: Academic Press, 1992. 422p.

SIMONYI, M., MAKSAY, G. Stereochemical aspects of drug action ii: optical isomerism. In: WERMUTH, C.G. The practice of medicinal chemistry. London: Academic Press, 2000, p. 414432.

SMITH, R.M. Retention prediction of analytes in reversed-phase high-performance liquid chromatography based on molecular structure. J. Chromat., Amsterdam., v. 475, n. 57-74., p. 75-83, 1989.

SOLOMONS, G., FRYHLE, C. Organic Chemistry. 7 ed. New York : John Wiley \& Sons, 2000, p, 738.

SQUELLA, J.A., LETELIER, M.E., LINDERMEYER, L., NUNES VERGARA, L.J. Redox behaviour of nifuroxazide: generation of one-electron reduction product. Chem.-Biol. Interact., Amsterdam, v. 99, n. 1-3, p. 227-238, 1996.

SREIDER, C.M.; GRINBLAT, T.; STOPPANI, A.O.M. Catalysis of nitrofuran redox-cycling and superoxide anion production by heart lipoamide dehydrogenase. Biochem. Pharmacol.; Oxford, v. 40, n. 08, p. $1849-1857,1990$.

STEINBAUGH, B.A., HAMILTON, H.W., PRASAD, V., PARA, K.S., TUMMINO, P.J., FERGUSON, D., LUNNEY, A., BLANKLEY, C. J. A. Topliss Tree Analysis of the HIV-protease Inhibitory Activity of 6-phenil-4-hidroxi-pyran-2-ones. Bioorg. Med. Chem. Lett., Kidlington, v. 6, n. 10, p. 1099-1104, 1996.

STOUCH, T.R. Computer-Aided Drug Design. In: WELLING, P.G., LASAGNA, L., BANAKAR, U.V. The Drug Development Process. vol. 76. New York: Marcel Dekker, Inc., 1996, p. 204-215. 
STRAUSBAUGH, L.J. Vancomicin-intermediate Staphylococcus epidermidis: curio or omen? Emerging Infect. Dis., Atlanta, v.20, n.3. p.163-165, 1999.

SUGAYA, K., UZ, T., KUMAR, V., MANEV, H. New anti-inflammatory treatment strategy in Alzheimer's disease. Jpn. J. Pharmacol., Kyoto, v. 82, n. 2, p. 85-94, 2000.

SULLER, M.T.E., RUSSEL, A.D. Triclosan and antibiotic resistance in Staphylococcus aureus. J. Antimicrob. Chemother., Oxford, v.46, n. 01, p. 11-18, 2000.

SUN-YOUNG, J., YOUNG, H.H., SEUNG, W.K., WONKU, L., JONGKOOK, L., SUNGHOON, K., YONG, W.K., WON, K.L., HYUN-JOON, H. Synthesis and antibacterial acivity of arylpiperazinyl oxazolidinones with diversification of the $\mathrm{N}$-substituents. Bioorg. Med. Chem. Lett., Kidlington, v. 14, p. 3881-3885, 2004.

SWAIN, C.G, LUPTON Jr., E.C. Field and ressonance components of substituent effects. J. Am. Chem. Soc., Columbus, v. 90, n. 15, p. 4328-4337, 1968.

TAFT, R.W. Polar and sterics substituents constant for aliphatic and o-benzoate groups from esterification and hydrolysis of esters. J. Am. Chem. Soc., Columbus, v. 74, n. 12, p. 3120-3128, 1952.

TAFT, R.W., LEWIS, I.C. The general applicability of a fixed scale of inductive effects. II. Inductive effect of dipolar substituents in the reactivities of $\mathrm{m}$ and $\mathrm{p}$-substituted derivatives of benzene. $\mathrm{J}$. Am. Chem. Soc., Columbus, v. 80, n. 10, p. 2436 - 2443, 1958.

TAVARES, L.C. Relações quantitativas entre a estrutura química e a atividade antimicrobiana de análogos a nifuroxazida. São Paulo, 1993. 186p (Tese de Doutorado - Faculdade de Ciências Farmacêuticas - Universidade de São Paulo).

TAVARES, L.C., AMARAL, A.T. Partition coefficient determination of nitrofurans derivatives for a QSAR study. In: WORKSHOP ON CHEMICAL STRUCTURE-BIOLOGICAL ACTIVITY, São Paulo, 1991. Resumos de Trabalhos. São Paulo: I.Q./USP. 1991. p. 8.

TAVARES, L.C., AMARAL, A.T. Efeito eletrônico de substituintes sobre a polaridade do grupo carbonila e a avaliação da atividade anestésica local de N-[(Dimetilamino)metil]benzamidas 4substituídas. Rev. Farm. Bioquím., São Paulo, v. 33, n. 2, p. 123-129, 1997.

TAVARES, L.C., CHISTÉ, J.J., SANTOS, M.G.B., PENNA, T.C.V. Synthesis and biological activity of nifuroxazide and analogs II. Boll. Chim. Farm., Milano, v. 138, n. 8, p. 432-436, 1999 a.

TAVARES, L.C.; MILANI, S.R.; RODRIGUES, A.M.; SANTOS, M.G.B.; PENNA, T.C.V. Síntese e determinação da atividade antimicrobiana de derivados do 5-nitro-2-furfurilideno. Rev. Farm. Quim., São Paulo, v.32, n.1, p.44-48, 1999 b.

TAVARES, L.C., PENNA, T.C.V., AMARAL, A.T. Synthesis and biological activity of nifuroxazide and analogs. Boll. Quim. Farm., Milano, v.136, n.3, p.244-9, 1997.

TAVARES, L.C., VESSONI-PENNA, T.C., AMARAL, A.T. A QSAR study of nitrofurans derivatives with antimicrobial activity. In: WORKSHOP ON CHEMICAL STRUCTURE-BIOLOGICAL ACTIVITY., São Paulo, 1991. Resumos de Trabalhos. São Paulo: I.Q./USP. 1991. p. 2.

TAVARES, L.C., FERREIRA, E.I., Relações quantitativas estrutura-atividade: fundamentos e aplicações da Análise de Hansch. In: PRADO, M.A., BARREIRO, E.J. Prácticas de Química Farmacêutica y Medicinal. Pamplona, SYTED-Red Iberoamericana para la Investigación, Diseño, y Desarrollo de Medicamentos, 2002, p. 36-66. 
TAYLOR, P.J. Hydrophobic properties of drugs. In: HANSCH, C., SAMMES, P. G., TAYLOR, J. B. Comprehensive Medicinal Chemistry: the rational design, mechanistic study \& therapeutic application of chemical compounds. v. 4. Oxford: Pergamon Press, 1990, p. 241-294.

TEDLAOUTI, F., GASQUET, M. Evaluation of the antimalarial activity of new compounds against Plasmodium falciparum in vitro, and Plasmodium berghei in vivo. J. Pharm. Belg. Marseille, v. 45 , n. 5 , p. 306-310, 1990.

TEDLAOUTI, F., GASQUET, M., DELMAS, F., MAJESTER, B., TIMON-DAVID, P. Synthesis and study of antiprotozoal activity of some 5-nitrothiophene aldimines. Farmaco., France, v. 46, n. 10, p. 1195-1201, 1991.

TENOVER, F.C., SCHABERG, D.R. Molecular biology resistance. In: BRACHMAN, P.S., BENNETT, J.V. Hosp. Infect. 4 ed. Philadelphia, New York: Lippincott-Raven Publishers, 1998, p. 237 247.

THEUS, P.M., WEUFFEN, W., TIEDT, H. Untersuchungen uber Nitrothiohen- und Nitofuranderivate.II. Arch. Pharmaz., Greifswald, v.301, n. 2, p.139-161, 1968a.

THEUS, P.M., WEUFFEN, W., TIEDT, H. Untersuchungen uber Nitrothiohen- und Nitofuranderivate. III. Arch. Pharmaz., Greifswald, v.301, n. 6, p.401-412, 1968 b.

THREADGILL, M.D. Synthesis of a series of nitrothiophenes with basic or electrophilic substituents and evaluation as radiosensitizers and as bioreductively activated cytotoxins. J. Med. Chem., Columbus, v. 34, n. 07, p. 2112-2120, 1991.

TISIODRAS, S., GOLD, H.S., SAKOULAS, G., ELIOPOULOS, G.M, WENNEISTEN, C., VENKATARAMAN, L., MOELLERING, R.C. FERRARO, M.J. Linezolid resistance in a clinical isolate of S. aureus. The Lancet, v. 358, p. 207-208, 2001.

TOCHER, J.H. Reductive activation of nitroheterocyclic compounds. Gen. Pharmacol., Oxford, v. 28, n. 4, p. 485-487, 1997.

TOPLISS, J.G., Utilization of operational scheme for analog synthesis in drug design J. Med. Chem., Columbus, v. 15, n. 10, p. 1006-1010, 1972.

TOPLISS, J.G. A manual method for applying the Hansch approach to drug design. J. Med. Chem., Columbus, v. 20, n. 04, p.463-469, 1977.

TORTORA, G.J., FUNKE, B.R., CASE, C.L. Microbiologia, 6 ed., Porto Alegre: Artmed Editora, 2000.

TORVALDSEN, S. The continuing evolution of methicillin-resistant Staphylococcus aureus in western Australia. Infect. Contr. Hosp. Epidem., v. 20, n. 02, p.133-135, 1999.

TOTSUKA, K., SHISEK, M., KIKUCHI, K., MATSUI, K. Combined effects of vancomycin and imipenem against methicillin-resistant Staphylococcus aureus (MRSA) in vitro and in vivo. J. Antimicrob. Chemother., Oxford, v.44, n. 04, p. 455-460, 1999.

TRABULSI, L.R., ALTERTHIEM, F., GOMPERTZ, O.F., CANDEIAS, J.A.N. Microbiologia, 3 ed., São Paulo: Editora Atheneu, 1999, p. 149.

TROILLET, N., CARMELI, Y., SAMORE, M.H., DAKOS, J., EICHELBERGER, K., DEGIROLAMI. P.C., KARCHMER, A.W., Carriage of methicillin-resistant Staphylococcus aureus at hospital admission. Infect. Contr. Hosp. Epidem., v. 19, n.3, p.181-185, 1998. 
TRZCINSKI, K., COOPER, B.S., HRYNIECWICZ, W., DOWSON, C.G. Expression of resistance to tetracyclines in strains of methicillin-resistant Staphylococcus aureus. J. Antimicrob. Chemother., Oxford, v.45, n.6, p. 763-770, 2000.

TUTE, M.S. Principles and practice of Hansch analysis: a guide to structure-activity correlation for medicinal chemistry, Adv. Drug Res., London, v. 6, p. 1-77, 1971.

TUTE, M.S. History and objectives of quantitative drug design. In: HANSCH, C., SAMMES, G.P., TAYLOR, J.B. Comprehensive medicinal chemistry: the rational design, mechanistic study \& therapeutic application of chemical compounds. vol. 4. Oxford: Pergamon Press, 1990, p. 1-31.

ULMAR, T.M., MITCHARD, M. The competitive inhibition of nitroredutase by some analogues of nitrofurantoin. Biochem. Pharmacol., New York, v.17, p.2057-2060, 1968.

UNGER, S.H. Octanol-physiological buffer distribution coefficients of lipophilic amines by reversedphase high-performance liquid chromatography and these correlation with biological activity. J. Med. Chem., Columbus, v. 24, n. 1, p. 262-270, 1981.

VAN DE WATERBEEMD, H. The history of drug research: from Hansch to the present, QSAR Weinheim, v. 11, n. 02, p. 200-204, 1992.

VAN DE WATERBEEMD, H. 3D QSAR. In: MANHOLD, R., KROGSGAARD-LARSEN, P., TIMMERMAN, H. Advanced Computer-Assited Techniques in Drug Discovery. Vol 3. Weinheim: $\mathrm{VCH}, 1995$, p.1-7.

VAN DE WATERBEEMD, H Chemometric Methods used in Drug Design. In: VAN DE WATERBEEMD, H. Structure-Property Correlations in Drug Research. San Diego: Academic Press, Inc., 1996, p. 55-80.

VANelle, P., GHezAli, S., MALdonAdo, J., CROZET, M. P., DELMAS, F., GASQuet, M., TIMON-DAVID, P. New 2-alkylidenemethyl-5-nitrothiophenes:preparation via $S_{R N} 1$ reactions and in vitro antiprotozoan activity. Eur. J. Med. Chem., Paris, v. 29, n. 01, p. 41-44, 1994.

VÉGH, D., KOVÁC, J., DANDÁROVÁ, M. Nucleophilic substitution on 2-(2-Bromovinyl)-5nitrothiophene, new one step method for preparation of new biologically active ethylenic derivatives of 5-nitro-2-thiophene. Tetrahedron Lett., Czechoslovakia, v. 21, p. 969-970, 1980.

VENKATACHALAM, T.K., SUDBECK, E.A., MAO, C., VCKUN, F. M. Stereochemistry of halopyridyl and thiazolyl thiourea compounds is a major determinant of their potency as nonnucleoside inhibitors of $\mathrm{HIH}-1$ reverse transcriptase. Bioorg. Med. Chem. Lett., Oxford, v. 10, n. 18, p. 20712074, 2000.

VENUTI, M.C. The role of recombinant DNA technology in medicinal chemistry and discovery. In: WOLFF, M.E., ed. Burger's medicinal chemistry and drug discovery: principles and practice. 5 ed., New York: John Wiley \& Sons, 1995, v.1, cap. 16, p. 661-696.

VERLOOP, A. The sterimol approach to drug design. New York: Marcel Dekker, 1987, 112p.

VIODÉ, C.; BETTACHE, N.; CENAS, N.; KRAUTH-SIEGEL, R.L.; CHAVIÉRE, G.; BALAKARA, N.; PÉRIE, J. Enzymatic reduction studies of nitroheterocycles. Biochem. Pharmacol., Oxford, v. 57 , n. 5 , p. 549-557, 1999.

VOSS, A., MILATOVIC, D., WALHAUCH-SCHWARZ, C., ROSDHAL, V.T., BRAVENY, I. Methicillinresitant Staphylococcus aureus in Europe. Eur. J. Clin. Microbiol. Infect. Dis., Wiesbaden, v. 13, n. 01, p. 50-55, 1994. 
VOZYAKOVA, T.I., OLEINIK, A.F., NOVITSKII, K.Y. Synthesis and reactions of arylfuran derivatives, V. Nauchn Konf. Khim. Teknol. Furanovykh Soedin (1978) 100-101: Chem. Abstr. 92 (1980) 180897.

WAINER, I.W. Drug stereochemistry. New York: Marcel Dekker, 1993, p. 245-337.

WALLER, C.L. A three dimensional technique for the calculation of octanol-water prtition coefficients. QSAR, Weinheim, v. 13, p. 172-176, 1994.

WEINSTEIN, R.A., HAYDEN, M.K. Mutiply drug-resistant pathogens: epidemiology and control. In: BRACHMAN, P.S., BENNETT, J.V. Hospital infection, 4 ed. Philadephia, New York: LippincoutRaven Publishers, 1998, p. 215-236.

WENZEL, R.P. The emergence of methicillin-resitant Staphylococcus aureus. Ann. Intern. Med., Philadelphia, v.97, n. 3, p. 440-442, 1982.

WERMUTH, C.G. The Practice of Medicinal Chemistry. London: Academic Press, 2003, 768p.

WILSON, P., ANDREWS, J.A., CHARLESWORTH, R., WALESBY, R., SINGER, M., FARREL, D.J., ROBBINS, M. Linezolide resistance in clinical isolates of S. aureus. J. Antimicrob. Chemother., Oxford, v. 51, n. 01, p. 186-188, 2003.

WOLD, S., JOHANSON, E., COCCHI, M., PLS-Partial least squares projections to latent structures. In: KUBINYI, H. 3D QSAR in Drug Design: Theory, Methods and Applications. Leiden: ESCOM, 1993, p. 523-563.

WU, J. Y. Preparation of push-pull type chromophores via nitrothiophene induced Michael type reaction of alkynes. Tetrahedron, Oxford, v. 55, p. 13973-13982, 1999.

ZAMORA, I, OPREA, T., CRUCIANI, G., PASTOR, M., UNGEL, A.L. Surface descriptors for proteinligand affinity prediction. J. Med. Chem., Columbus, v. 46, n. 01, p. 25-33, 2003. 


\section{Anexo 1.}

\section{Procedimento experimental para o preparo de 5-nitro-2-tiofilideno benzidrazidas substituídas}

Como citado anteriormente, as 5-nitro-2-tiofilideno benzidrazidas substituídas foram obtidas em três etapas a saber: síntese de benzoatos de metila a partir de ácidos benzóicos; síntese de benzidrazidas substituídas a partir de benzoatos de metila e síntese de bases de Schiff a partir de benzidrazidas e 5-nitro-2-tiofenocarboxaldeído.

Procedeu-se a identificação dos benzoatos de metila e benzidrazidas através de comparação das faixas de fusão experimental com a da literatura e por espectrometria de absorção na região do Infravermelho (IV). A identificação das 5-nitro-2-tiofilideno benzidrazidas substituídas foi realizada por análises espectrométricas de IV, RMN- ${ }^{1} \mathrm{H}$ e $\mathrm{RMN}-{ }^{13} \mathrm{C}$. Todos os espectros dos compostos finais encontram-se no item ANEXO 2 dessa tese. Apresenta-se, a seguir, o procedimento experimental completo para a obtenção dos quatorze derivados em estudo.

\section{SÍNTESE DA 5-NITRO-2-TIOFILIDENO BENZIDRAZIDA}

\section{$>$ OBTENÇÃO DO BENZOATO DE METILA}

Sob agitação magnética constante, adicionou-se 5,00 g (0,04 mol) de ácido benzóico em 50,0 mL $(1,23 \mathrm{~mol})$ de metanol anidro e 1,0 $\mathrm{mL}(0,02 \mathrm{~mol})$ de ácido sulfúrico concentrado. Manteve-se o meio reacional sob refluxo por 4 horas. Rotaevaporou-se o metanol, procedendo a lavagem do éster resultante com duas porções de $10 \mathrm{~mL}$ de água destilada gelada. Obteve-se óleo de aspecto incolor.

\section{$>$ OBTENÇÃO DA BENZIDRAZIDA}

Aqueceu-se, sob agitação constante, $50,0 \mathrm{~mL}(0,55 \mathrm{~mol})$ de hidrato de hidrazina $64 \%(\mathrm{v} / \mathrm{v})$ até 50 -

$60{ }^{\circ} \mathrm{C}$. Atingida a temperatura de interesse, adicionou-se, de maneira constante, 4,82g (0,03 mol) do benzoato de metila e manteve-se a mistura reacional sob refluxo por dez minutos. Procedeu-se o resfriamento da massa reacional sequencialmente em banho de água, banho de gelo e banho de gelo seco e etanol. Observou-se a formação de cristais aciculares de coloração branca, que foram filtrados sob pressão reduzida, lavados com água destilada gelada e secos. 
> OBTENÇÃO DA 5-NITRO-2-TIOFILIDENO BENZIDRAZIDA

Adicionou-se 2,46 g (0,02 mol) de 5-nitro-2-tiofenocarboxaldeído sobre mistura contendo água destilada, ácido sulfúrico concentrado, ácido acético glacial e metanol na proporção de 8:7:8:20, respectivamente. Aqueceu-se o meio reacional até a temperatura de refluxo, adicionando-se lentamente, sob agitação magnética constante, $2,13 \mathrm{~g}(0,02 \mathrm{~mol})$ de benzidrazida. Observou-se a formação de sólido que foi filtrado sob pressão reduzida, lavado com água desionizada gelada e recristalizado de DMF/água. Obteve-se sólido de aspecto amorfo e coloração amarelo-intenso que foi novamente filtrado sob pressão reduzida, lavado com água destilada gelada e seco.

\section{SÍNTESE DA 5-NITRO-2-TIOFILIDENO 4-CLOROBENZIDRAZIDA}

\section{> OBTENÇÃO DO 4-CLOROBENZOATO DE METILA}

Sob agitação magnética constante, adicionou-se 5,00 g (0,03mol) de ácido 4-clorobenzóico em 50,0 $\mathrm{mL}(1,23 \mathrm{~mol})$ de metanol anidro e 1,0 $\mathrm{mL}(0,02 \mathrm{~mol})$ de ácido sulfúrico concentrado. Manteve-se o meio reacional sob refluxo por 4 horas. Reduziu-se cerca de metade do volume de metanol em rotaevaporador, procedendo o resfriamento da massa reacional em banho de gelo. Obtiveram-se cristais aciculares de coloração branca que foram filtrados, lavados com água destilada gelada e secos.

\section{$>$ OBTENÇÃO DA 4-CLOROBENZIDRAZIDA}

Aqueceu-se, sob agitação constante, $60,0 \mathrm{~mL}(0,66 \mathrm{~mol})$ de hidrato de hidrazina $64 \%(\mathrm{v} / \mathrm{v})$ até 50 $60{ }^{\circ} \mathrm{C}$. Atingida a temperatura de interesse, adicionou-se, de maneira constante, $5,34 \mathrm{~g}(0,03 \mathrm{~mol})$ do 4-clorobenzoato de metila e manteve-se a mistura reacional em refluxo por dez minutos. Procedeu-se o resfriamento da massa reacional sequencialmente em banho de água, banho de gelo e banho de gelo seco e etanol. Observou-se a formação de cristais aciculares de coloração branca, que foram filtrados sob pressão reduzida, lavados com água destilada gelada e secos.

\section{> OBTENÇÃO DA 5-NITRO-2-TIOFILIDENO 4-CLOROBENZIDRAZIDA}

Adicionou-se $1,84 \mathrm{~g}(0,01 \mathrm{~mol})$ de 5-nitro-2-tiofenocarboxaldeído sobre mistura contendo água destilada, ácido sulfúrico concentrado, ácido acético glacial e metanol na proporção de 8:7:8:20, respectivamente. Aqueceu-se o meio reacional até a temperatura de refluxo, adicionando-se lentamente, sob agitação magnética constante, $2,00 \mathrm{~g}(0,01 \mathrm{~mol})$ de 4-clorobenzidrazida. Observou-se a formação de sólido que foi filtrado sob pressão reduzida, lavado com água destilada gelada e 
recristalizado de DMF/água. Obteve-se sólido de aspecto amorfo e coloração alaranjada, que foi novamente filtrado sob pressão reduzida, lavado com água destilada gelada e seco.

\section{SÍNTESE DA 5-NITRO-2-TIOFILIDENO 3,4-DICLOROBENZIDRAZIDA}

\section{$>$ OBTENÇÃO E IDENTIFICAÇÃO DO 3,4-DICLOROBENZOATO DE METILA}

Sob agitação magnética constante, adicionou-se 5,00 g (0,03 mol) de ácido 3,4-diclorobenzóico em $50,0 \mathrm{~mL}(1,23 \mathrm{~mol})$ de metanol anidro e 1,0 mL (0,02 mol) de ácido sulfúrico concentrado. Manteve-se o meio reacional sob refluxo por 4 horas. Reduziu-se cerca de metade do volume de metanol em rotaevaporador, procedendo o resfriamento da massa reacional em banho de gelo. Obtiveram-se cristais aciculares de coloração branca que foram filtrados, lavados com água destilada gelada e secos.

\section{> OBTENÇÃO DA 3,4-DICLOROBENZIDRAZIDA}

Aqueceu-se, sob agitação constante, $60,0 \mathrm{~mL}(0,66 \mathrm{~mol})$ de hidrato de hidrazina $64 \%(\mathrm{v} / \mathrm{v})$ até 50 $60{ }^{\circ} \mathrm{C}$. Atingida a temperatura de interesse, adicionou-se de maneira constante, $5,08 \mathrm{~g}(0,03 \mathrm{~mol})$ do 3,4-diclorobenzoato de metila e manteve-se a mistura reacional refluxo por dez minutos. Procedeu-se o resfriamento da massa reacional sequencialmente em banho de água, banho de gelo e banho de gelo seco e etanol. Observou-se a formação de cristais aciculares de coloração branca, que foram filtrados sob pressão reduzida, lavados com água destilada gelada e secos.

\section{> OBTENÇÃO DA 5-NITRO-2-TIOFILIDENO 3,4-DICLOROBENZIDRAZIDA}

Adicionou-se 1,83g $(0,01 \mathrm{~mol})$ de 5-nitro-2-tiofenocarboxaldeído sobre mistura contendo água destilada, ácido sulfúrico concentrado, ácido acético glacial e metanol na proporção de 8:7:8:20, respectivamente. Aqueceu-se o meio reacional até a temperatura de refluxo, adicionando-se lentamente, sob agitação magnética constante, $2,38 \mathrm{~g}(0,01 \mathrm{~mol})$ de 3,4-diclorobenzidrazida. Observou-se a formação de sólido que foi filtrado sob pressão reduzida, lavado com água destilada gelada e recristalizado de DMF/água. Obteve-se sólido de aspecto amorfo e coloração alaranjada que foi novamente filtrado sob pressão reduzida, lavado com água destilada gelada e seco.

\section{SÍNTESE DA 5-NITRO-2-TIOFILIDENO 4-IODOBENZIDRAZIDA}

\section{> OBTENÇÃO E IDENTIFICAÇÃO DO 4-IODOBENZOATO DE METILA}

Sob agitação magnética constante, adicionou-se 5,00 g (0,02 mol) de ácido 4-iodobenzóico em 50,0 $\mathrm{mL}(1,23 \mathrm{~mol})$ de metanol anidro e $1,0 \mathrm{~mL}(0,02 \mathrm{~mol})$ de ácido sulfúrico concentrado. Manteve-se 0 
meio reacional sob refluxo por 4 horas. Reduziu-se cerca de metade do volume de metanol em rotaevaporador, procedendo o resfriamento da massa reacional em banho de gelo. Obtiveram-se cristais aciculares de coloração branca que foram filtrados, lavados com água destilada gelada e secos.

\section{$>$ OBTENÇÃO DA 4-IODOBENZIDRAZIDA}

Aqueceu-se, sob agitação constante, $60,0 \mathrm{~mL}(0,66 \mathrm{~mol})$ de hidrato de hidrazina $64 \%(\mathrm{v} / \mathrm{v})$ até 50 $60{ }^{\circ} \mathrm{C}$. Atingida a temperatura de interesse, adicionou-se de maneira constante, $5,07 \mathrm{~g}(0,02 \mathrm{~mol})$ do 4-iodobenzoato de metila e manteve-se a mistura reacional refluxo por dez minutos. Procedeu-se o resfriamento da massa reacional sequencialmente em banho de água, banho de gelo e banho de gelo seco e etanol. Observou-se a formação de cristais aciculares de coloração branca, que foram filtrados sob pressão reduzida, lavados com água destilada gelada e secos.

\section{> OBTENÇÃO DA 5-NITRO-2-TIOFILIDENO 4-IODOBENZIDRAZIDA}

Adicionou-se 1,50g (0,01 mol) de 5-nitro-2-tiofenocarboxaldeído sobre mistura contendo água destilada, ácido sulfúrico concentrado, ácido acético glacial e metanol na proporção de 8:7:8:20, respectivamente. Aqueceu-se o meio reacional até a temperatura de refluxo, adicionando-se lentamente, sob agitação magnética constante, $2,50 \mathrm{~g}$ (0,01 mol) de 4-iodobenzidrazida. Observou-se a formação de sólido que foi filtrado sob pressão reduzida, lavado com água destilada gelada e recristalizado de DMF/água. Obteve-se sólido de aspecto amorfo e coloração amarela que foi novamente filtrado sob pressão reduzida, lavado com água destilada gelada e seco.

\section{SÍNTESE DA 5-NITRO-2-TIOFILIDENO 4-PROPILBENZIDRAZIDA}

\section{> OBTENÇÃO DO 4-PROPILBENZOATO DE METILA}

Sob agitação magnética constante, adicionou-se 2,00 g (0,01 mol) de ácido 4-propilbenzóico em 30,0 $\mathrm{mL}(0,74 \mathrm{~mol})$ de metanol anidro e $0,5 \mathrm{~mL}(0,01 \mathrm{~mol})$ de ácido sulfúrico concentrado. Manteve-se o meio reacional sob refluxo por 4 horas. Rotaevaporou-se o metanol, procedendo a lavagem do éster resultante, dissolvido em $10 \mathrm{~mL}$ de clorofórmio, com duas porções de $10 \mathrm{~mL}$ de água destilada gelada. Rotaevaporou-se o clorofórmio e obteve-se óleo de aspecto incolor. 


\section{$>$ OBTENÇÃO DA 4-PROPILBENZIDRAZIDA}

Aqueceu-se, sob agitação constante, $30,0 \mathrm{~mL}(0,33 \mathrm{~mol})$ de hidrato de hidrazina $64 \%(\mathrm{v} / \mathrm{v})$ até 50 $60{ }^{\circ} \mathrm{C}$. Atingida a temperatura de interesse, adicionou-se, de maneira constante, $2,80 \mathrm{~g}(0,01 \mathrm{~mol})$ do 4-propilbenzoato de metila e manteve-se a mistura reacional sob refluxo por dez minutos. Procedeuse o resfriamento da massa reacional sequencialmente em banho de água, banho de gelo e banho de gelo seco e etanol. Observou-se a formação de cristais aciculares de coloração branca, que foram filtrados pressão reduzida, lavados com água destilada gelada e secos.

\section{> OBTENÇÃO DA 5-NITRO-2-TIOFILIDENO 4-PROPILBENZIDRAZIDA}

Adicionou-se 1,76 g (0,01 mol) de 5-nitro-2-tiofenocarboxaldeído sobre mistura contendo água destilada, ácido sulfúrico concentrado, ácido acético glacial e metanol na proporção de 8:7:8:20, respectivamente. Aqueceu-se o meio reacional até a temperatura de refluxo, adicionando-se

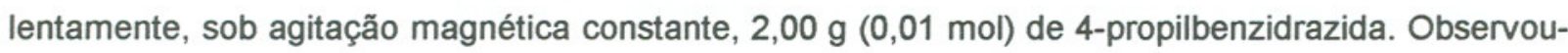
se a formação de sólido que foi filtrado sob pressão reduzida, lavado com água destilada gelada e recristalizado de DMF/água. Obteve-se sólido de aspecto amorfo e coloração amarelo-intenso, que foi novamente filtrado sob pressão reduzida, lavado com água destilada gelada e seco.

\section{SÍNTESE DA 5-NITRO-2-TIOFILIDENO 4-ISOPROPILBENZIDRAZIDA}

\section{$>$ OBTENÇÃO DO 4-ISOPROPILBENZOATO DE METILA}

Sob agitação magnética constante, adicionou-se 2,00 g (0,01 mol) de ácido 4-isopropilbenzóico em $30,0 \mathrm{~mL}(0,74 \mathrm{~mol})$ de metanol anidro e $0,5 \mathrm{~mL}(0,01 \mathrm{~mol})$ de ácido sulfúrico concentrado. Manteve-se o meio reacional sob refluxo por 4 horas. Rotaevaporou-se o metanol, procedendo a lavagem do éster resultante, dissolvido em $10 \mathrm{~mL}$ de clorofórmio, com duas porções de $10 \mathrm{~mL}$ de água destilada gelada. Rotaevaporou-se o clorofórmio e obteve-se óleo de aspecto incolor.

\section{$>$ OBTENÇÃO DA 4-ISOPROPILBENZIDRAZIDA}

Aqueceu-se, sob agitação constante, $25,0 \mathrm{~mL}(0,28 \mathrm{~mol})$ de hidrato de hidrazina $64 \%(\mathrm{v} / \mathrm{v})$ até 50 -

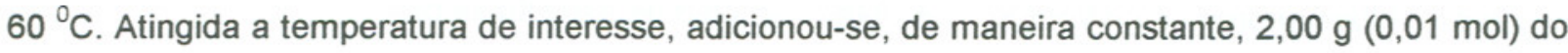
4-isopropilbenzoato de metila e manteve-se a mistura reacional sob refluxo por dez minutos. Procedeu-se o resfriamento da massa reacional sequencialmente em banho de água, banho de gelo e banho de gelo seco e etanol. Observou-se a formação de cristais aciculares de coloração branca, que foram filtrados pressão reduzida, lavados com água destilada gelada e secos. 
> OBTENÇÃO DA 5-NITRO-2-TIOFILIDENO 4-ISOPROPILBENZIDRAZIDA

Adicionou-se $1,00 \mathrm{~g}(0,006 \mathrm{~mol})$ de 5-nitro-2-tiofenocarboxaldeído sobre mistura contendo água destilada, ácido sulfúrico concentrado, ácido acético glacial e metanol na proporção de 8: 7: 8: 20, respectivamente. Aqueceu-se o meio reacional até a temperatura de refluxo, adicionando-se lentamente, sob agitação magnética constante, $0,88 \mathrm{~g}(0,006 \mathrm{~mol})$ de 4-isopropilbenzidrazida. Observou-se a formação de sólido que foi filtrado sob pressão reduzida, lavado com água destilada gelada e recristalizado de DMF/água. Obteve-se sólido de aspecto amorfo e coloração amarelointenso, que foi novamente filtrado sob pressão reduzida, lavado com água destilada gelada e seco.

\section{SÍNTESE DA 5-NITRO-2-TIOFILIDENO 4-PROPOXIBENZIDRAZIDA}

\section{$>$ OBTENÇÃO DO 4-PROPOXIBENZOATO DE METILA}

Sob agitação magnética constante, adicionou-se 5,00 g (0,03 mol) de ácido 4-propoxibenzóico em $50,0 \mathrm{~mL}(1,23 \mathrm{~mol})$ de metanol anidro e 1,0 mL (0,02 mol) de ácido sulfúrico concentrado. Manteve-se o meio reacional sob refluxo por 4 horas. Rotaevaporou-se o metanol, procedendo a lavagem do éster resultante, dissolvido em $10 \mathrm{~mL}$ de clorofórmio, com duas porções de $10 \mathrm{~mL}$ de água destilada gelada. Rotaevaporou-se o clorofórmio e obteve-se óleo de coloração amarelada.

\section{$>$ OBTENÇÃO DA 4-PROPOXIBENZIDRAZIDA}

Aqueceu-se, sob agitação constante, $50,0 \mathrm{~mL}(0,55 \mathrm{~mol})$ de hidrato de hidrazina $64 \%(\mathrm{v} / \mathrm{v})$ até 50 -

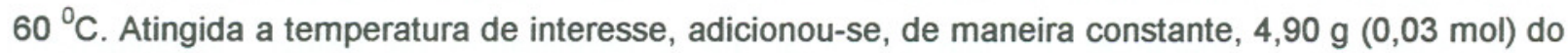
4-propoxibenzoato de metila e manteve-se a mistura reacional sob refluxo por dez minutos. Procedeu-se o resfriamento da massa reacional sequencialmente em banho de água, banho de gelo e banho de gelo seco e etanol. Observou-se a formação de cristais aciculares de coloração branca, que foram filtrados pressão reduzida, lavados com água destilada gelada e secos.

\section{> OBTENÇÃO DA 5-NITRO-2-TIOFILIDENO 4-PROPOXIBENZIDRAZIDA}

Adicionou-se $1,50 \mathrm{~g}(0,009 \mathrm{~mol})$ de 5-nitro-2-tiofenocarboxaldeído sobre mistura contendo água destilada, ácido sulfúrico concentrado, ácido acético glacial e metanol na proporção de 8:7:8:20, respectivamente. Aqueceu-se o meio reacional até a temperatura de refluxo, adicionando-se lentamente, sob agitação magnética constante, $1,86 \mathrm{~g}(0,009 \mathrm{~mol})$ de 4-propoxibenzidrazida. Observou-se a formação de sólido que foi filtrado sob pressão reduzida, lavado com água destilada gelada e recristalizado de DMF/água. Obteve-se sólido de aspecto amorfo e coloração amarelointenso, que foi novamente filtrado sob pressão reduzida, lavado com água destilada gelada e seco. 


\section{SÍNTESE DA 5-NITRO-2-TIOFILIDENO 4-BUTOXIBENZIDRAZIDA}

\section{> OBTENÇÃO DO 4-BUTOXIBENZOATO DE METILA}

Sob agitação magnética constante, adicionou-se 2,50 g (0,01 mol) de ácido 4-butoxibenzóico em 30,0 $\mathrm{mL}(0,74 \mathrm{~mol})$ de metanol anidro e $0,5 \mathrm{~mL}(0,01 \mathrm{~mol})$ de ácido sulfúrico concentrado. Manteve-se o meio reacional sob refluxo por 4 horas. Rotaevaporou-se o metanol, procedendo a lavagem do éster resultante, dissolvido em $10 \mathrm{~mL}$ de clorofórmio, com duas porções de $10 \mathrm{~mL}$ de água destilada gelada. Rotaevaporou-se o clorofórmio e obteve-se óleo de aspecto incolor.

\section{$>$ OBTENÇÃO DA 4-BUTOXIBENZIDRAZIDA}

Aqueceu-se, sob agitação constante, $30,0 \mathrm{~mL}(0,33 \mathrm{~mol})$ de hidrato de hidrazina $64 \%(\mathrm{v} / \mathrm{v})$ até 50 -

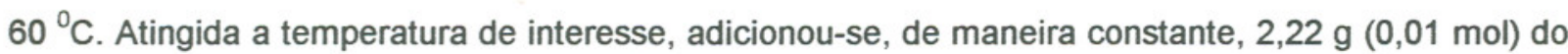
4-butoxibenzoato de metila e manteve-se a mistura reacional sob refluxo por dez minutos. Procedeuse o resfriamento da massa reacional sequencialmente em banho de água, banho de gelo e banho de gelo seco e etanol. Observou-se a formação de cristais aciculares de coloração branca, que foram filtrados pressão reduzida, lavados com água destilada gelada e secos.

\section{$>$ OBTENÇÃO DA 5-NITRO-2-TIOFILIDENO 4-BUTOXIBENZIDRAZIDA}

Adicionou-se 1,50 g (0,009 mol) de 5-nitro-2-tiofenocarboxaldeído sobre mistura contendo água destilada, ácido sulfúrico concentrado, ácido acético glacial e metanol na proporção de 8:7:8:20, respectivamente. Aqueceu-se o meio reacional até a temperatura de refluxo, adicionando-se lentamente, sob agitação magnética constante, $1,97 \mathrm{~g}(0,009 \mathrm{~mol})$ de 4-butoxibenzidrazida. Observou-se a formação de sólido que foi filtrado sob pressão reduzida, lavado com água destilada gelada e recristalizado de DMF/água. Obteve-se sólido de aspecto amorfo e coloração amarelointenso, que foi novamente filtrado sob pressão reduzida, lavado com água destilada gelada e seco.

\section{SÍNTESE DA 5-NITRO-2-TIOFILIDENO 4-BUTILAMINOBENZIDRAZIDA}

\section{$>$ OBTENÇÃO DO 4-BUTILAMINOBENZOATO DE METILA}

Sob agitação magnética constante, adicionou-se 2,50 g (0,01 mol) de ácido 4-butilamonibenzóico em $30,0 \mathrm{~mL}(0,74 \mathrm{~mol})$ de metanol anidro e $0,5 \mathrm{~mL}(0,01 \mathrm{~mol})$ de ácido sulfúrico concentrado. Manteve-se o meio reacional sob refluxo por 4 horas. Rotaevaporou-se o metanol, procedendo a lavagem do 
éster resultante com duas porções de $10 \mathrm{~mL}$ de água destilada gelada. Obteve-se sólido amorfo de coloração amarela que foi seco em presença de pentóxido de fósforo.

\section{$>$ OBTENÇÃO DA 4-BUTILAMINOBENZIDRAZIDA}

Aqueceu-se, sob agitação constante, $30,0 \mathrm{~mL}(0,33 \mathrm{~mol})$ de hidrato de hidrazina $64 \%(\mathrm{v} / \mathrm{v})$ até 50 -

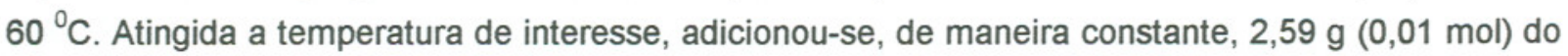
4-butilaminobenzoato de metila e manteve-se a mistura reacional sob refluxo por dez minutos. Procedeu-se o resfriamento da massa reacional sequencialmente em banho de água, banho de gelo e banho de gelo seco e etanol. Observou-se a formação de cristais aciculares de coloração branca, que foram filtrados pressão reduzida, lavados com água destilada gelada e secos.

\section{> OBTENÇÃO DA 5-NITRO-2-TIOFILIDENO 4-BUTILAMINOBENZIDRAZIDA}

Adicionou-se $0,80 \mathrm{~g}(0,005 \mathrm{~mol})$ de 5-nitro-2-tiofenocarboxaldeído sobre mistura contendo água destilada, ácido sulfúrico concentrado, ácido acético glacial e metanol na proporção de 8:7:8:20, respectivamente. Aqueceu-se o meio reacional até a temperatura de refluxo, adicionando-se lentamente, sob agitação magnética constante, $1,00 \mathrm{~g}(0,005 \mathrm{~mol})$ de 4-butilaminobenzidrazida. Observou-se a formação de sólido que foi filtrado sob pressão reduzida, lavado com água destilada gelada e recristalizado de DMF/água. Obteve-se sólido de aspecto amorfo e coloração vermelhointenso, que foi novamente filtrado sob pressão reduzida, lavado com água destilada gelada e seco.

\section{SÍNTESE DA 5-NITRO-2-TIOFILIDENO 4-VINILBENZIDRAZIDA}

\section{$>$ OBTENÇÃO DO 4-VINILBENZOATO DE METILA}

Sob agitação magnética constante, adicionou-se 2,00 g (0,01 mol) de ácido 4-vinilbenzóico em 30,0 $\mathrm{mL}(0,74 \mathrm{~mol})$ de metanol anidro e $0,5 \mathrm{~mL}(0,01 \mathrm{~mol})$ de ácido sulfúrico concentrado. Manteve-se o meio reacional sob refluxo por 4 horas. Rotaevaporou-se o metanol, procedendo a lavagem do éster com duas porções de $10 \mathrm{~mL}$ de água destilada gelada. Obteve-se sólido amorfo de coloração branca que foi seco em presença de pentóxido de fósforo.

\section{$>$ OBTENÇÃO DA 4-VINILBENZIDRAZIDA}

Aqueceu-se, sob agitação constante, $10,0 \mathrm{~mL}(0,11 \mathrm{~mol})$ de hidrato de hidrazina $64 \%(\mathrm{v} / \mathrm{v})$ até 50 -

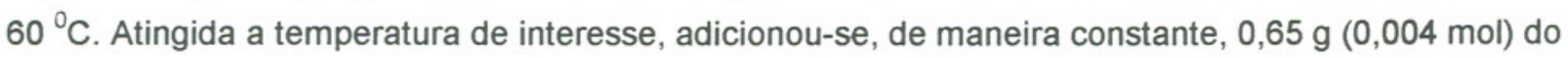
4-vinilbenzoato de metila e manteve-se a mistura reacional sob refluxo por dez minutos. Procedeu-se 
o resfriamento da massa reacional sequencialmente em banho de água, banho de gelo e banho de gelo seco e etanol. Observou-se a formação de cristais aciculares de coloração branca, que foram filtrados pressão reduzida, lavados com água destilada gelada e secos.

\section{> OBTENÇÃO DA 5-NITRO-2-TIOFILIDENO 4-VINILBENZIDRAZIDA}

Adicionou-se $0,24 \mathrm{~g}(0,001 \mathrm{~mol})$ de 5-nitro-2-tiofenocarboxaldeído sobre mistura contendo água destilada, ácido sulfúrico concentrado, ácido acético glacial e metanol na proporção de 8:7:8:20, respectivamente. Aqueceu-se o meio reacional até a temperatura de refluxo, adicionando-se

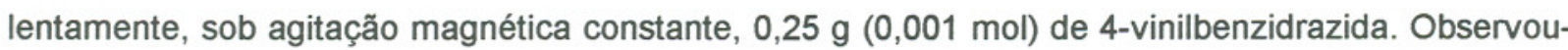
se a formação de sólido que foi filtrado sob pressão reduzida, lavado com água destilada gelada e recristalizado de DMF/água. Obteve-se sólido de aspecto amorfo e coloração amarelo-intenso, que foi novamente filtrado sob pressão reduzida, lavado com água destilada gelada e seco.

\section{SÍNTESE DA 5-NITRO-2-TIOFILIDENO 4-BUTILBENZIDRAZIDA}

\section{> OBTENÇÃO DO 4-BUTILBENZOATO DE METILA}

Sob agitação magnética constante, adicionou-se 5,00 g (0,02 mol) de ácido 4-butilbenzóico em 50,0 $\mathrm{mL}(1,23 \mathrm{~mol})$ de metanol anidro e 1,0 mL (0,02 mol) de ácido sulfúrico concentrado. Manteve-se o meio reacional sob refluxo por 4 horas. Rotaevaporou-se o metanol, procedendo a lavagem do éster resultante, dissolvido em 10,0 mL de clorofórmio, com duas porções de $10 \mathrm{~mL}$ de água destilada gelada. Rotaevaporou-se o clorofórmio e obteve-se óleo de aspecto incolor.

\section{$>$ OBTENÇÃO DA 4-BUTILBENZIDRAZIDA}

Aqueceu-se, sob agitação constante, $50,0 \mathrm{~mL}(0,55 \mathrm{~mol})$ de hidrato de hidrazina $64 \%(\mathrm{v} / \mathrm{v})$ até 50 $60{ }^{\circ} \mathrm{C}$. Atingida a temperatura de interesse, adicionou-se, de maneira constante, $4,87 \mathrm{~g}(0,03 \mathrm{~mol})$ do 4-butilbenzoato de metila e manteve-se a mistura reacional sob refluxo por dez minutos. Procedeu-se o resfriamento da massa reacional sequencialmente em banho de água, banho de gelo e banho de gelo seco e etanol. Observou-se a formação de cristais aciculares de coloração branca, que foram filtrados pressão reduzida, lavados com água destilada gelada e secos.

\section{> OBTENÇÃO DA 5-NITRO-2-TIOFILIDENO 4-BUTILBENZIDRAZIDA}

Adicionou-se $3,00 \mathrm{~g}(0,01 \mathrm{~mol})$ de 5-nitro-2-tiofenocarboxaldeído sobre mistura contendo água destilada, ácido sulfúrico concentrado, ácido acético glacial e metanol na proporção de 8:7:8:20, respectivamente. Aqueceu-se o meio reacional até a temperatura de refluxo, adicionando-se lentamente, sob agitação magnética constante, $2,03 \mathrm{~g}$ (0,01 mol) de 4-butilbenzidrazida. Observou-se 
a formação de sólido que foi filtrado sob pressão reduzida, lavado com água destilada gelada e recristalizado de DMF/água. Obteve-se sólido de aspecto amorfo e coloração amarelo-intenso, que foi novamente filtrado sob pressão reduzida, lavado com água destilada gelada e seco.

\section{SÍNTESE DA 5-NITRO-2-TIOFILIDENO 4-ETILBENZIDRAZIDA}

\section{> OBTENÇÃO DO 4-ETILBENZOATO DE METILA}

Sob agitação magnética constante, adicionou-se 5,00 g (0,03 mol) de ácido 4-etilbenzóico em 50,0 $\mathrm{mL}(1,23 \mathrm{~mol})$ de metanol anidro e 1,0 $\mathrm{mL}(0,02 \mathrm{~mol})$ de ácido sulfúrico concentrado. Manteve-se o meio reacional sob refluxo por 4 horas. Rotaevaporou-se o metanol, procedendo a lavagem do éster resultante, dissolvido em $10,0 \mathrm{~mL}$ de clorofórmio, com duas porções de $10 \mathrm{~mL}$ de água destilada gelada. Rotaevaporou-se o clorofórmio e obteve-se óleo de aspecto incolor.

\section{$>$ OBTENÇÃO DA 4-ETILBENZIDRAZIDA}

Aqueceu-se, sob agitação constante, $50,0 \mathrm{~mL}(0,55 \mathrm{~mol})$ de hidrato de hidrazina $64 \%(\mathrm{v} / \mathrm{v})$ até 50 $60{ }^{\circ} \mathrm{C}$. Atingida a temperatura de interesse, adicionou-se, de maneira constante, $4,90 \mathrm{~g}(0,03 \mathrm{~mol})$ do 4-etilbenzoato de metila e manteve-se a mistura reacional sob refluxo por dez minutos. Procedeu-se o resfriamento da massa reacional sequencialmente em banho de água, banho de gelo e banho de gelo seco e etanol. Observou-se a formação de cristais aciculares de coloração branca, que foram filtrados pressão reduzida, lavados com água destilada gelada e secos.

\section{> OBTENÇÃO DA 5-NITRO-2-TIOFILIDENO 4-ETILBENZIDRAZIDA}

Adicionou-se $1,50 \mathrm{~g}(0,01 \mathrm{~mol})$ de 5-nitro-2-tiofenocarboxaldeído sobre mistura contendo água destilada, ácido sulfúrico concentrado, ácido acético glacial e metanol na proporção de 8:7:8:20, respectivamente. Aqueceu-se o meio reacional até a temperatura de refluxo, adicionando-se

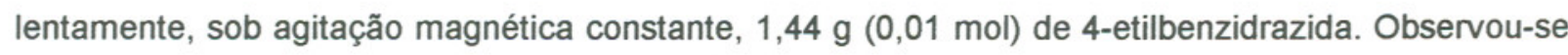
a formação de sólido que foi filtrado sob pressão reduzida, lavado com água destilada gelada e recristalizado em $\mathrm{N}, \mathrm{N}$-dimetilformamida/água. Obteve-se sólido de aspecto amorfo e coloração amarelo-intenso, que foi novamente filtrado sob pressão reduzida, lavado com água destilada gelada e seco. 


\section{SÍNTESE DA 5-NITRO-2-TIOFILIDENO 4-BROMOBENZIDRAZIDA}

\section{> OBTENÇÃO DO 4-BROMOBENZOATO DE METILA}

Sob agitação magnética constante, adicionou-se 2,50 g (0,01 mol) de ácido 4-bromobenzóico em $30,0 \mathrm{~mL}(0,74 \mathrm{~mol})$ de metanol anidro e $0,5 \mathrm{~mL}(0,01 \mathrm{~mol})$ de ácido sulfúrico concentrado. Manteve-se o meio reacional sob refluxo por 4 horas. Rotaevaporou-se o metanol, procedendo a lavagem do éster com duas porções de $10 \mathrm{~mL}$ de água destilada gelada. Obteve-se sólido amorfo de coloração branca que foi seco em presença de pentóxido de fósforo.

\section{> OBTENÇÃO DA 4-BROMOBENZIDRAZIDA}

Aqueceu-se, sob agitação constante, $30,0 \mathrm{~mL}(0,33 \mathrm{~mol})$ de hidrato de hidrazina $64 \%(\mathrm{v} / \mathrm{v})$ até 50 $60{ }^{\circ} \mathrm{C}$. Atingida a temperatura de interesse, adicionou-se, de maneira constante, $2,61 \mathrm{~g}(0,01 \mathrm{~mol})$ do 4-bromobenzoato de metila e manteve-se a mistura reacional sob refluxo por dez minutos. Procedeuse o resfriamento da massa reacional sequencialmente em banho de água, banho de gelo e banho de gelo seco e etanol. Observou-se a formação de cristais aciculares de coloração branca, que foram filtrados pressão reduzida, lavados com água destilada gelada e secos.

\section{> OBTENÇÃO DA 5-NITRO-2-TIOFILIDENO 4-BROMOBENZIDRAZIDA}

Adicionou-se 1,46 g (0,009 mol) de 5-nitro-2-tiofenocarboxaldeído sobre mistura contendo água destilada, ácido sulfúrico concentrado, ácido acético glacial e metanol na proporção de 8:7:8:20, respectivamente. Aqueceu-se o meio reacional até a temperatura de refluxo, adicionando-se lentamente, sob agitação magnética constante, 2,00 g (0,009 mol) de 4-bromobenzidrazida. Observou-se a formação de sólido que foi filtrado sob pressão reduzida, lavado com água destilada gelada e recristalizado de DMF/água. Obteve-se sólido de aspecto amorfo e coloração amarelointenso, que foi novamente filtrado sob pressão reduzida, lavado com água destilada gelada e seco.

\section{SÍNTESE DA 5-NITRO-2-TIOFILIDENO 4-ACETILBENZIDRAZIDA}

\section{> OBTENÇÃO DO 4-ACETILBENZOATO DE METILA}

Sob agitação magnética constante, adicionou-se 2,00 g (0,01 mol) de ácido 4-acetilbenzóico em 30,0 $\mathrm{mL}(0,74 \mathrm{~mol})$ de metanol anidro e $0,5 \mathrm{~mL}(0,01 \mathrm{~mol})$ de ácido sulfúrico concentrado. Manteve-se o meio reacional sob refluxo por 4 horas. Rotaevaporou-se o metanol, procedendo a lavagem do éster 
com duas porções de $10 \mathrm{~mL}$ de água destilada gelada. Obteve-se sólido amorfo de coloração branca que foi seco em presença de pentóxido de fósforo.

\section{> OBTENÇÃO DA 4-ACETILBENZIDRAZIDA}

Aqueceu-se, sob agitação constante, $25,0 \mathrm{~mL}(0,28 \mathrm{~mol})$ de hidrato de hidrazina $64 \%(\mathrm{v} / \mathrm{v})$ até 50 -

$60{ }^{\circ} \mathrm{C}$. Atingida a temperatura de interesse, adicionou-se, de maneira constante, $1,98 \mathrm{~g}(0,01 \mathrm{~mol})$ do 4-bromobenzoato de metila e manteve-se a mistura reacional sob refluxo por dez minutos. Procedeuse o resfriamento da massa reacional sequencialmente em banho de água, banho de gelo e banho de gelo seco e etanol. Observou-se a formação de cristais aciculares de coloração branca, que foram filtrados pressão reduzida, lavados com água destilada gelada e secos.

\section{$>$ OBTENÇÃO DA 5-NITRO-2-TIOFILIDENO 4-ACETILBENZIDRAZIDA}

Adicionou-se $0,89 \mathrm{~g}(0,006 \mathrm{~mol})$ de 5-nitro-2-tiofenocarboxaldeído sobre mistura contendo água destilada, ácido sulfúrico concentrado, ácido acético glacial e metanol na proporção de 8:7:8:20, respectivamente. Aqueceu-se o meio reacional até a temperatura de refluxo, adicionando-se lentamente, sob agitação magnética constante, $1,00 \mathrm{~g}(0,006 \mathrm{~mol})$ de 4-acetilbenzidrazida. Observouse a formação de sólido que foi filtrado sob pressão reduzida, lavado com água destilada gelada e recristalizado de DMF/água. Obteve-se sólido de aspecto amorfo e coloração amarelo-intenso, que foi novamente filtrado sob pressão reduzida, lavado com água destilada gelada e seco. 


\section{Anexo 2.}

\section{Análise espectrométrica especifica dos derivados 5-nitro-2-tiofilidênicos}

Apresenta-se, a seguir, a análise espectrométrica na região do IV dos compostos intermediários de reação e as análises espectrométricas na região do IV, de $\mathrm{RMN}-{ }^{1} \mathrm{H}$ e $\mathrm{RMN}-{ }^{13} \mathrm{C}$ dos compostos finais, com o objetivo de ressaltar características estruturais particulares de cada composto. São apresentados também, os espectros de IV, de RMN- ${ }^{1} \mathrm{H}$ e de RMN $-{ }^{13} \mathrm{C}$ dos compostos finais.

\section{formacăo do benzoato de metila}

Desaparecimento de banda larga em $2875 \mathrm{~cm}^{-1}$ referente ao estiramento O-H do ácido carboxílico e aparecimento de banda fina e intensa em $2950 \mathrm{~cm}^{-1}$ atribuída a estiramento $\mathrm{C}-\mathrm{H} \mathrm{sp}{ }^{3}$ do grupo metílico.

\section{formação da benzidrazida}

Bandas largas em $3295 \mathrm{~cm}^{-1}$ e $3150 \mathrm{~cm}^{-1}$ referentes aos estiramentos $\mathrm{N}-\mathrm{H}$ de amida secundária e amina primária, respectivamente;

Banda em $1559 \mathrm{~cm}^{-1}$ referente à deformação $\mathrm{N}-\mathrm{H}$ fora do plano de amida secundária

\section{formação da base de Schiff 5-nitro-2-tiofilideno benzidrazida}

Bandas em $1521 \mathrm{~cm}^{-1}$ e $1330 \mathrm{~cm}^{-1}$ referentes aos estiramentos assimétrico e simétrico do grupo $\mathrm{NO}_{2}$, respectivamente, e banda em $638 \mathrm{~cm}^{-1}$ referente ao estiramento C-S;

Multipleto na região de 7,69 - 7,59 ppm referente aos cinco prótons do anel benzênico e duplo dupleto em 7,98 ppm relacionado aos dois prótons do anel tiofênico.

\section{formaçăo do 4-clorobenzoato de metila}

Desaparecimento de banda larga em $2830 \mathrm{~cm}^{-1}$ referente ao estiramento O-H do ácido carboxílico e aparecimento de banda fina e intensa em $2950 \mathrm{~cm}^{-1}$ atribuída a estiramento $\mathrm{C}-\mathrm{H} \mathrm{sp}$ do grupo metílico;

Banda em $1085 \mathrm{~cm}^{-1}$ referente ao estiramento Cl-Ar.

\section{formaçăo da 4-clorobenzidrazida}

Bandas largas em $3305 \mathrm{~cm}^{-1}$ e $3190 \mathrm{~cm}^{-1}$ referentes aos estiramentos $\mathrm{N}-\mathrm{H}$ de amida secundária e amina primária, respectivamente;

Banda em $1553 \mathrm{~cm}^{-1}$ referente à deformação $\mathrm{N}-\mathrm{H}$ fora do plano de amida secundária.

Banda em $1110 \mathrm{~cm}^{-1}$ referente ao estiramento $\mathrm{Cl}-\mathrm{Ar}$. 
formação da 5-nitro-2-tiofilideno 4-clorobenzidrazida

Bandas intensas em $1523 \mathrm{~cm}^{-1}$ e $1331 \mathrm{~cm}^{-1}$ referentes aos estiramentos assimétrico e simétrico do grupo $\mathrm{NO}_{2}$, respectivamente, e banda em $632 \mathrm{~cm}^{-1}$ referente ao estiramento C-S;

Banda em $1110 \mathrm{~cm}^{-1}$ referente ao estiramento $\mathrm{Cl}-\mathrm{Ar}$.

Singleto em 8,68 ppm referente ao próton do carbono azometínico.

\section{formação do 3,4-diclorobenzoato de metila}

Desaparecimento de banda larga em $2820 \mathrm{~cm}^{-1}$ referente ao estiramento $\mathrm{O}-\mathrm{H}$ do ácido carboxílico e surgimento de banda fina e intensa em $2955 \mathrm{~cm}^{-1}$ atribuída a estiramento $\mathrm{C}-\mathrm{H} \mathrm{sp}{ }^{3}$ do grupo metílico; Banda em $1108 \mathrm{~cm}^{-1}$ referente ao estiramento $\mathrm{Cl}-\mathrm{Ar}$.

\section{formação da 3,4-diclorobenzidrazida}

Banda larga em $3275 \mathrm{~cm}^{-1}$ referente ao estiramento $\mathrm{N}-\mathrm{H}$ de amida secundária. Como o estiramento $\mathrm{N}-\mathrm{H}$ relativo à amina primária é muito próximo às bandas relativas ao estiramento $\mathrm{C}-\mathrm{H} \mathrm{sp}^{2}$ do anel aromático e o acima citado ( $\mathrm{N}-\mathrm{H}$ amida), provavelmente houve sobreposição de bandas não permitindo sua definição;

Banda em $1545 \mathrm{~cm}^{-1}$ referente à banda II de amida secundária;

Banda em $1027 \mathrm{~cm}^{-1}$ referente ao estiramento $\mathrm{Cl}-\mathrm{Ar}$.

\section{formação da 5-nitro-2-tiofilideno 3,4-diclorobenzidrazida}

Bandas intensas em $1521 \mathrm{~cm}^{-1}$ e $1330 \mathrm{~cm}^{-1}$ referentes aos estiramentos assimétrico e simétrico do grupo $\mathrm{NO}_{2}$, respectivamente;

Banda em 638 referente ao estiramento C-S;

Banda em $1069 \mathrm{~cm}^{-1}$ referente ao estiramento $\mathrm{Cl}-\mathrm{Ar}$;

Multipleto em 7,91 - 7,83 ppm com integração para dois prótons do anel benzênico;

Singleto em 7,61 ppm referente a um próton do anel benzênico em posição orto.

\section{formação do 4-iodobenzoato de metila}

Desaparecimento de banda larga em $2830 \mathrm{~cm}^{-1}$ referente ao estiramento O-H do ácido carboxílico e aparecimento de banda fina e intensa em $2865 \mathrm{~cm}^{-1}$ atribuída a estiramento $\mathrm{C}-\mathrm{H} \mathrm{sp}$ do grupo metílico;

Banda em $1004 \mathrm{~cm}^{-1}$ referente ao estiramento I-Ar.

\section{formação da 4-iodobenzidrazida}

Bandas largas em $3290 \mathrm{~cm}^{-1}$ e $3185 \mathrm{~cm}^{-1}$ referentes aos estiramentos $\mathrm{N}-\mathrm{H}$ de amida secundária e amina primária, respectivamente;

Banda em $1528 \mathrm{~cm}^{-1}$ referente à deformação $\mathrm{N}-\mathrm{H}$ fora do plano de amida secundária;

Banda em $1002 \mathrm{~cm}^{-1}$ referente ao estiramento I-Ar. 
formação da 5-nitro-2-tiofilideno 4-iodobenzidrazida

Bandas intensas em $1530 \mathrm{~cm}^{-1}$ e $1320 \mathrm{~cm}^{-1}$ referentes aos estiramentos assimétrico e simétrico do grupo $\mathrm{NO}_{2}$, respectivamente, e banda em $680 \mathrm{~cm}^{-1}$ referente ao estiramento C-S;

Dois dupletos em 7,80 ppm e 7,59 ppm referentes aos quatro prótons do anel benzênico.

Singleto em 8,59 ppm referente ao próton do carbono azometínico;

Banda em $1005 \mathrm{~cm}^{-1}$ referente ao estiramento I-Ar.

\section{formação do 4-bromobenzoato de metila}

Desaparecimento de banda larga em $3085 \mathrm{~cm}^{-1}$ referente ao estiramento O-H do ácido carboxílico e aparecimento de banda fina e intensa em $3035 \mathrm{~cm}^{-1}$ atribuída a estiramento $\mathrm{C}-\mathrm{H} \mathrm{sp}{ }^{3}$ do grupo metílico;

Banda em $1048 \mathrm{~cm}^{-1}$ referente ao estiramento $\mathrm{Br}-\mathrm{Ar}$.

\section{formação da 4-bromobenzidrazida}

Bandas largas em $3305 \mathrm{~cm}^{-1}$ e $3195 \mathrm{~cm}^{-1}$ referentes aos estiramentos $\mathrm{N}-\mathrm{H}$ de amida secundária e amina primária, respectivamente;

Banda em $1617 \mathrm{~cm}^{-1}$ referente à deformação $\mathrm{N}-\mathrm{H}$ fora do plano de amida secundária;

Banda em $1040 \mathrm{~cm}^{-1}$ referente ao estiramento $\mathrm{Br}-\mathrm{Ar}$.

\section{formação da 5-nitro-2-tiofilideno 4-bromobenzidrazida}

Bandas intensas em $1528 \mathrm{~cm}^{-1}$ e $1333 \mathrm{~cm}^{-1}$ referentes aos estiramentos assimétrico e simétrico do grupo $\mathrm{NO}_{2}$, respectivamente, e banda em $630 \mathrm{~cm}^{-1}$ referente ao estiramento C-S;

Singleto em 8,67 ppm referente ao próton do carbono azometínico;

Banda em $1037 \mathrm{~cm}^{-1}$ referente ao estiramento $\mathrm{Br}-\mathrm{Ar}$.

\section{formação do 4-propilbenzoato de metila}

Desaparecimento de banda larga em $3065 \mathrm{~cm}^{-1}$ referente ao estiramento O-H do ácido carboxílico e aparecimento de banda fina e intensa em $3025 \mathrm{~cm}^{-1}$ atribuída a estiramento $\mathrm{C}-\mathrm{H} \mathrm{sp}{ }^{3}$ do grupo metílico;

Banda de intensidade média em $1460 \mathrm{~cm}^{-1}$ referente à deformação dos grupos metilênicos;

Banda de intensidade média em $1380 \mathrm{~cm}^{-1}$ referente à deformação do grupo metílico.

\section{formação da 4-propilbenzidrazida}

Bandas largas em $3370 \mathrm{~cm}^{-1}$ referente aos estiramentos $\mathrm{N}-\mathrm{H}$, neste caso sobrepostos, de amida secundária e amina primária.

Banda em $1559 \mathrm{~cm}^{-1}$ referente à deformação $\mathrm{N}-\mathrm{H}$ fora do plano de amida secundária;

Banda de intensidade média em $1459 \mathrm{~cm}^{-1}$ referente à deformação dos grupos metilênicos;

Banda de intensidade média em $1377 \mathrm{~cm}^{-1}$ referente à deformação do grupo metílico. 
formação da 5-nitro-2-tiofilideno 4-propilbenzidrazida

Bandas intensas em $1534 \mathrm{~cm}^{-1}$ e $1341 \mathrm{~cm}^{-1}$ referentes aos estiramentos assimétrico e simétrico do grupo $\mathrm{NO}_{2}$, respectivamente, e banda em $690 \mathrm{~cm}^{-1}$ referente ao estiramento C-S;

Banda de intensidade média em $1466 \mathrm{~cm}^{-1}$ referente à deformação dos grupos metilênicos;

Banda de intensidade média em $1375 \mathrm{~cm}^{-1}$ referente à deformação do grupo metílico;

Dois dupletos em 7,80 ppm e 7,32 ppm referentes aos quatro prótons do anel benzênico;

Tripleto em 2,59 ppm referente ao grupo metileno ligado ao anel benzênico;

Sexteto em 1,60 ppm referente ao grupo metileno ligado à metila;

Tripleto em 0,87 ppm referente ao grupo metílico.

\section{formação do 4-isopropilbenzoato de metila}

Desaparecimento de banda larga em $3070 \mathrm{~cm}^{-1}$ referente ao estiramento O-H do ácido carboxílico e aparecimento de banda fina e intensa em $2955 \mathrm{~cm}^{-1}$ atribuída a estiramento $\mathrm{C}-\mathrm{H} \mathrm{sp}{ }^{3}$ do grupo metílico;

Desdobramento da banda de média intensidade referente à deformação do grupo metila em dois picos de igual intensidade em $1377 \mathrm{~cm}^{-1}$, caracterizando o grupo isopropil.

\section{formação 4-isopropilbenzidrazida}

Bandas largas em $3295 \mathrm{~cm}^{-1}$ e $3130 \mathrm{~cm}^{-1}$ referentes aos estiramentos $\mathrm{N}-\mathrm{H}$ de amida secundária e amina primária, respectivamente;

Banda em $1545 \mathrm{~cm}^{-1}$ referente à deformação $\mathrm{N}-\mathrm{H}$ fora do plano de amida secundária; Desdobramento da banda de média intensidade referente à deformação do grupo metila em dois picos de igual intensidade em $1378 \mathrm{~cm}^{-1}$, caracterizando o grupo isopropil.

\section{formação 5-nitro-2-tiofilideno 4-isopropilbenzidrazida}

Bandas intensas em $1524 \mathrm{~cm}^{-1}$ e $1331 \mathrm{~cm}^{-1}$ referentes aos estiramentos assimétrico e simétrico do grupo $\mathrm{NO}_{2}$, respectivamente, e banda em $670 \mathrm{~cm}^{-1}$ referente ao estiramento C-S;

Desdobramento da banda de deformação do grupo metila em dois picos de igual intensidade em $1381 \mathrm{~cm}^{-1}$, caracterizando o grupo isopropil;

Dois dupletos em 7,50 pm e 7,32 ppm referentes aos quatro prótons do anel benzênico.

Quarteto em 2,88 ppm referente ao grupo $\mathrm{CH}$ ligado à duas metilas.

Dupleto em 1,14 ppm referente aos grupos metílicos.

\section{formação do 4-propoxibenzoato de metila}

Desaparecimento de banda larga em $2840 \mathrm{~cm}^{-1}$ referente ao estiramento $\mathrm{O}-\mathrm{H}$ do ácido carboxílico e aparecimento de banda fina e larga em $2955 \mathrm{~cm}^{-1}$ atribuída a estiramento $\mathrm{C}-\mathrm{H} \mathrm{sp}{ }^{3}$ do grupo metílico; Banda fina e intensa em $1254 \mathrm{~cm}^{-1}$ referente ao estiramento C-O referente ao grupamento éter; Banda de intensidade média em $1462 \mathrm{~cm}^{-1}$ referente à deformação dos grupos metilênicos; 
Banda de intensidade média em $1388 \mathrm{~cm}^{-1}$ referente à deformação do grupo metílico.

\section{formação da 4-propoxibenzidrazida}

Bandas largas em $3300 \mathrm{~cm}^{-1}$ e $3150 \mathrm{~cm}^{-1}$ referentes ao estiramento $\mathrm{N}-\mathrm{H}$ de amida secundária; Banda em $1567 \mathrm{~cm}^{-1}$ referente à deformação $\mathrm{N}-\mathrm{H}$ fora do plano de amida secundária.

Banda intensa em $1253 \mathrm{~cm}^{-1}$ referente ao estiramento C-O referente ao grupamento éter; Banda de intensidade média em $1466 \mathrm{~cm}^{-1}$ referente à deformação dos grupos metilênicos;

Banda de intensidade média em $1389 \mathrm{~cm}^{-1}$ referente à deformação do grupo metílico.

\section{formação da 5-nitro-2-tiofilideno 4-propoxibenzidrazida}

Bandas intensas em $1528 \mathrm{~cm}^{-1}$ e $1337 \mathrm{~cm}^{-1}$ referentes aos estiramentos assimétrico e simétrico do grupo $\mathrm{NO}_{2}$, respectivamente, e banda em $680 \mathrm{~cm}^{-1}$ referente ao estiramento C-S;

Banda intensa em $1256 \mathrm{~cm}^{-1}$ referente ao estiramento C-O referente ao grupamento éter; Banda de intensidade média ensidade em $1470 \mathrm{~cm}^{-1}$ referente à deformação dos grupos metilênicos; Banda de intensidade média em $1391 \mathrm{~cm}^{-1}$ referente à deformação do grupo metílico;

Dois dupletos em 7,89 ppm e 7,10 ppm referentes aos quatro prótons do anel benzênico;

Tripleto em 4,02 ppm referente ao grupo metileno ligado ao oxigênio;

Sexteto em 1,76 ppm referente ao grupo metileno ligado à metila;

Tripleto em $0,99 \mathrm{ppm}$ referente ao grupo metílico.

\section{formação do 4-butoxibenzoato de metila}

Desaparecimento de banda larga em $3015 \mathrm{~cm}^{-1}$ referente ao estiramento $\mathrm{O}-\mathrm{H}$ do ácido carboxílico e aparecimento de banda fina e intensa em $2955 \mathrm{~cm}^{-1}$ atribuída a estiramento $\mathrm{C}-\mathrm{H} \mathrm{sp}{ }^{3}$ do grupo metílico;

Banda intensa em $1276 \mathrm{~cm}^{-1}$ referente ao estiramento C-O referente ao grupamento éter;

Banda de intensidade média em $1462 \mathrm{~cm}^{-1}$ referente à deformação dos grupos metilênicos;

Banda de intensidade média em $1380 \mathrm{~cm}^{-1}$ referente à deformação do grupo metílico;

\section{formação da 4-butoxibenzidrazida}

Bandas largas em $3295 \mathrm{~cm}^{-1}$ referente ao estiramento $\mathrm{N}-\mathrm{H}$ de amida secundária;

Banda em $1567 \mathrm{~cm}^{-1}$ referente à deformação $\mathrm{N}-\mathrm{H}$ fora do plano de amida secundária;

Banda intensa em $1251 \mathrm{~cm}^{-1}$ referente ao estiramento C-O referente ao grupamento éter;

Banda de intensidade média em $1464 \mathrm{~cm}^{-1}$ referente à deformação dos grupos metilênicos;

Banda de intensidade média em $1385 \mathrm{~cm}^{-1}$ referente à deformação do grupo metílico.

\section{formação da 5-nitro-2-tiofilideno 4-butoxibenzidrazida}

Bandas intensas em $1529 \mathrm{~cm}^{-1}$ e $1339 \mathrm{~cm}^{-1}$ referentes aos estiramentos assimétrico e simétrico do grupo $\mathrm{NO}_{2}$, respectivamente, e banda em $679 \mathrm{~cm}^{-1}$ referente ao estiramento C-S; 
Banda intensa em $1256 \mathrm{~cm}^{-1}$ referente ao estiramento C-O referente ao grupamento éter;

Banda de intensidade média em $1466 \mathrm{~cm}^{-1}$ referente à deformação dos grupos metilênicos;

Banda de intensidade média em $1384 \mathrm{~cm}^{-1}$ referente à deformação do grupo metílico;

Dois dupletos em 7,87 ppm e 7,05 ppm referentes aos quatro prótons do anel benzênico;

Tripleto em 4,03 ppm referente ao grupo metileno ligado ao oxigênio;

Quinteto em 1,70 ppm referente ao grupo metileno ligado à outros dois grupos metilênicos;

Sexteto em 1,40 ppm referente ao grupo metileno ligado à metila;

Tripleto em 0,92 ppm referente ao grupo metílico.

\section{formação do 4-butilaminobenzoato de metila}

Desaparecimento de banda larga em $3045 \mathrm{~cm}^{-1}$ referente ao estiramento O-H do ácido carboxílico e aparecimento de banda fina e intensa em $2930 \mathrm{~cm}^{-1}$ atribuída a estiramento $\mathrm{C}-\mathrm{H} \mathrm{sp}{ }^{3}$ do Banda em $1463 \mathrm{~cm}^{-1}$ referente à deformação dos grupos metilênicos;

Banda de intensidade média em $1393 \mathrm{~cm}^{-1}$ referente à deformação do grupo metílico.

\section{formação da 4-butilaminobenzidrazida}

Bandas largas em $3285 \mathrm{~cm}^{-1}$ referente ao estiramento $\mathrm{N}-\mathrm{H}$ de amida secundária;

Banda em $1610 \mathrm{~cm}^{-1}$ referente à deformação $\mathrm{N}-\mathrm{H}$ fora do plano de amida secundária;

Banda de intensidade média em $1458 \mathrm{~cm}^{-1}$ referente à deformação dos grupos metilênicos;

Banda de intensidade média em $1380 \mathrm{~cm}^{-1}$ referente à deformação do grupo metílico.

\section{formação da 5-nitro-2-tiofilideno 4-butilaminobenzidrazida}

Bandas intensas em $1542 \mathrm{~cm}^{-1}$ e $1340 \mathrm{~cm}^{-1}$ referentes aos estiramentos assimétrico e simétrico do grupo $\mathrm{NO}_{2}$, respectivamente, e banda em $645 \mathrm{~cm}^{-1}$ referente ao estiramento C-S;

Banda de de intensidade média em $1453 \mathrm{~cm}^{-1}$ referente à deformação dos grupos metilênicos;

Banda de de intensidade média em $1373 \mathrm{~cm}^{-1}$ referente à deformação do grupo metílico;

Dois dupletos em 7,51 ppm e 6,41 ppm referentes aos quatro prótons do anel benzênico;

Tripleto em 6,41 ppm referente ao grupo $\mathrm{NH}$ ligado ao anel benzênico;

Quarteto em 3,07 ppm referente ao grupo metileno ligado ao nitrogênio;

Quinteto em 1,54 ppm referente ao grupo metileno ligado a outros dois grupos metilenos;

Sexteto em 1,39 ppm referente ao grupo metileno ligado à metila;

Tripleto em 0,91 ppm referente ao grupo metílico.

\section{formação do 4-acetilbenzoato de metila}

Desaparecimento de banda larga em $3050 \mathrm{~cm}^{-1}$ referente ao estiramento O-H do ácido carboxílico e aparecimento de banda fina e intensa em $2957 \mathrm{~cm}^{-1}$ atribuída a estiramento $\mathrm{C}-\mathrm{H} \mathrm{sp}{ }^{3}$ do grupo metílico. 


\section{formação da 4-acetilbenzidrazida}

Bandas largas em $3320 \mathrm{~cm}^{-1}$ referente ao estiramento $\mathrm{N}-\mathrm{H}$ de amida secundária;

Banda em $1557 \mathrm{~cm}^{-1}$ referente à deformação $\mathrm{N}-\mathrm{H}$ fora do plano de amida secundária.

\section{formação da 5-nitro-2-tiofilideno 4-acetilbenzidrazida}

Bandas intensas em $1522 \mathrm{~cm}^{-1}$ e $1329 \mathrm{~cm}^{-1}$ referentes aos estiramentos assimétrico e simétrico do grupo $\mathrm{NO}_{2}$, respectivamente, e banda em $672 \mathrm{~cm}^{-1}$ referente ao estiramento C-S;

Dois dupletos em 7,71 ppm e 7,01 ppm referentes aos quatro prótons do anel benzênico;

Tripleto em 6,41 ppm referente ao grupo NH ligado ao anel benzênico;

Singleto em 3,26 ppm referente à metila.

\section{formação do 4-butilbenzoato de metila}

Desaparecimento de banda larga em $2870 \mathrm{~cm}^{-1}$ referente ao estiramento O-H do ácido carboxílico e surgimento de banda fina e intensa em $2855 \mathrm{~cm}^{-1}$ atribuída a estiramento $\mathrm{C}-\mathrm{H} \mathrm{sp}{ }^{3}$ do grupo metílico; Banda de intensidade média em $1452 \mathrm{~cm}^{-1}$ referente à deformação dos grupos metilênicos; Banda de intensidade média de em $1390 \mathrm{~cm}^{-1}$ referente à deformação do grupo metílico.

\section{formação da 4-butillbenzidrazida}

Banda larga em $3300 \mathrm{~cm}^{-1}$ referente ao estiramento $\mathrm{N}-\mathrm{H}$ de amida secundária. Como o estiramento $\mathrm{N}-\mathrm{H}$ relativo à amina primária é muito próximo às bandas relativas ao estiramento $\mathrm{C}-\mathrm{H} \mathrm{sp} \mathrm{sp}^{2}$ do anel aromático e o acima citado ( $\mathrm{N}-\mathrm{H}$ amida), provavelmente houve sobreposição de bandas não permitindo sua definição;

Banda em $1612 \mathrm{~cm}^{-1}$ referente à deformação $\mathrm{N}-\mathrm{H}$ de amina primária;

Banda de intensidade média em $1457 \mathrm{~cm}^{-1}$ referente à deformação dos grupos metilênicos;

Banda de intensidade média em $1391 \mathrm{~cm}^{-1}$ referente à deformação do grupo metílico.

\section{formação da 5-nitro-2-tiofilideno 4-butilbenzidrazida}

Bandas intensas em $1534 \mathrm{~cm}^{-1}$ e $1339 \mathrm{~cm}^{-1}$ referentes aos estiramentos assimétrico e simétrico do grupo $\mathrm{NO}_{2}$, respectivamente;

Banda de intensidade média em $1465 \mathrm{~cm}^{-1}$ referente à deformação dos grupos metilênicos;

Banda de intensidade média em $1393 \mathrm{~cm}^{-1}$ referente à deformação do grupo metílico;

Banda em $656 \mathrm{~cm}^{-1}$ referente ao estiramento C-S;

Singleto em 8,67 ppm referente ao próton do carbono azometínico.

\section{formação do 4-vinilbenzoato de metila}

Desaparecimento de banda larga em $3080 \mathrm{~cm}^{-1}$ referente ao estiramento O-H do ácido carboxílico e aparecimento de banda fina e intensa em $2945 \mathrm{~cm}^{-1}$ atribuída a estiramento $\mathrm{C}-\mathrm{H} \mathrm{sp}{ }^{3}$ do grupo metílico; 
Bandas em $1029 \mathrm{~cm}^{-1}$ e $902 \mathrm{~cm}^{-1}$ referentes à deformação =C-H fora do plano do grupo vinílico.

\section{formação da 4-vinilbenzidrazida}

Bandas largas em $3380 \mathrm{~cm}^{-1}$ referente aos estiramentos $\mathrm{N}-\mathrm{H}$, neste caso sobrepostos, de amida secundária e amina primária.

Banda em $1558 \mathrm{~cm}^{-1}$ referente à deformação $\mathrm{N}-\mathrm{H}$ fora do plano de amida secundária;

Bandas em $1029 \mathrm{~cm}^{-1}$ e $906 \mathrm{~cm}^{-1}$ referentes à deformação =C-H fora do plano do grupo vinílico.

\section{formação da 5-nitro-2-tiofilideno 4-vinilbenzidrazida}

Bandas intensas em $1529 \mathrm{~cm}^{-1}$ e $1328 \mathrm{~cm}^{-1}$ referentes aos estiramentos assimétrico e simétrico do grupo $\mathrm{NO}_{2}$, respectivamente, e banda em $690 \mathrm{~cm}^{-1}$ referente ao estiramento C-S;

Bandas em $1030 \mathrm{~cm}^{-1}$ e $903 \mathrm{~cm}^{-1}$ referentes à deformação =C-H fora do plano do grupo vinílico;

Singleto em 12,18 ppm referente ao próton amídico.

\section{formação do 4-etilbenzoato de metila}

Desaparecimento de banda larga em $2950 \mathrm{~cm}^{-1}$ referente ao estiramento O-H do ácido carboxílico e surgimento de banda fina e intensa em $2870 \mathrm{~cm}^{-1}$ atribuída a estiramento $\mathrm{C}-\mathrm{H} \mathrm{sp}{ }^{3}$ do grupo metílico; Banda de intensidade média em $1465 \mathrm{~cm}^{-1}$ referente à deformação dos grupos metilênicos; Banda de intensidade média em $1385 \mathrm{~cm}^{-1}$ referente à deformação do grupo metílico.

\section{formação da 4-etilbenzidrazida}

Banda larga em $3310 \mathrm{~cm}^{-1}$ referente ao estiramento $\mathrm{N}-\mathrm{H}$ de amida secundária. Como o estiramento $\mathrm{N}-\mathrm{H}$ relativo à amina primária é muito próximo às bandas relativas ao estiramento $\mathrm{C}-\mathrm{H} \mathrm{sp}^{2}$ do anel aromático e o acima citado ( $\mathrm{N}-\mathrm{H}$ amida), provavelmente houve sobreposição de bandas não permitindo sua definição;

Banda em $1611 \mathrm{~cm}^{-1}$ referente à deformação N-H de amina primária;

Banda de intensidade média em $1465 \mathrm{~cm}^{-1}$ referente à deformação dos grupos metilênicos;

Banda de intensidade média em $1396 \mathrm{~cm}^{-1}$ referente à deformação do grupo metílico.

\section{formação da 5-nitro-2-tiofilideno 4-etillbenzidrazida}

Bandas em $1550 \mathrm{~cm}^{-1}$ e $1342 \mathrm{~cm}^{-1}$ referentes aos estiramentos assimétrico e simétrico do grupo $\mathrm{NO}_{2}$, respectivamente;

Banda de intensidade média em $1462 \mathrm{~cm}^{-1}$ referente à deformação dos grupos metilênicos;

Banda de intensidade média em $1376 \mathrm{~cm}^{-1}$ referente à deformação do grupo metílico;

Banda em $654 \mathrm{~cm}^{-1}$ referente ao estiramento C-S;

Quarteto em 2,67 ppm referente aos prótons metilênicos que acoplam com os prótons metílicos. 


\section{Anexo 3.}

Estruturas químicas dos derivados 5-nitro-2-tiofilidênicos p-substituídos em estudo<smiles>O=C(N/N=C/c1ccc([N+](=O)[O-])s1)c1ccccc1</smiles>

5-nitro-2-tiofilideno benzidrazida (I)<smiles>O=C(N/N=C/c1ccc([N+](=O)[O-])s1)c1ccc(Cl)c(Cl)c1</smiles>

5-nitro-2-tiofilideno 3,4-diclorobenzidrazida (III)<smiles>CCCCCCc1ccc(C(=O)N/N=C/c2ccc([N+](=O)[O-])s2)cc1</smiles>

5-nitro-2-tiofilideno 4-propilbenzidrazida (V)<smiles>CCCCCOc1ccc(C(=O)N/N=C/c2ccc([N+](=O)[O-])s2)cc1</smiles>

5-nitro-2-tiofilideno 4-propoxibenzidrazida (VII)<smiles>O=C(N/N=C/c1ccc([N+](=O)[O-])s1)c1ccc(Cl)cc1</smiles>

5-nitro-2-tiofilideno 4-clorobenzidrazida (II)<smiles>O=C(N/N=C/c1ccc([N+](=O)[O-])s1)c1ccc(I)cc1</smiles>

5-nitro-2-tiofilideno 4-iodobenzidrazida (IV)<smiles>CCc1ccc(C(=O)N/N=C/c2ccc([N+](=O)[O-])s2)cc1</smiles>

5-nitro-2-tiofilideno 4-isopropilbenzidrazida (VI)<smiles>COc1ccc(C(=O)N/N=C/c2ccc([N+](=O)[O-])s2)cc1</smiles>

5-nitro-2-tiofilideno 4-butoxibenzidrazida (VIII) 
<smiles>CCNc1ccc(C(=O)N/N=C/c2ccc([N+](=O)[O-])s2)cc1</smiles>

5-nitro-2-tiofilideno 4-butilaminobenzidrazida (IX)<smiles>Cc1ccc(C(=O)N/N=C/c2ccc([N+](=O)[O-])s2)cc1</smiles>

5-nitro-2-tiofilideno 4-butilbenzidrazida (XI)<smiles>O=C(N/N=C/c1ccc([N+](=O)[O-])s1)c1ccc(Br)cc1</smiles>

5-nitro-2-tiofilideno 4-bromobenzidrazida (XIII)<smiles>C=Cc1ccc(C(=O)N/N=C/c2ccc([N+](=O)[O-])s2)cc1</smiles>

5-nitro-2-tiofilideno 4-vinilbenzidrazida (X)<smiles>Cc1ccc(C(=O)N/N=C/c2ccc([N+](=O)[O-])s2)cc1</smiles>

5-nitro-2-tiofilideno 4-etilbenzidrazida (XII)<smiles>CC(=O)c1ccc(C(=O)N/N=C/c2ccc([N+](=O)[O-])s2)cc1</smiles>

5-nitro-2-tiofilideno 4-butilbenzidrazida (XI) 


\section{5-nitro-2-tiofilideno 4-iodobenzidrazida}
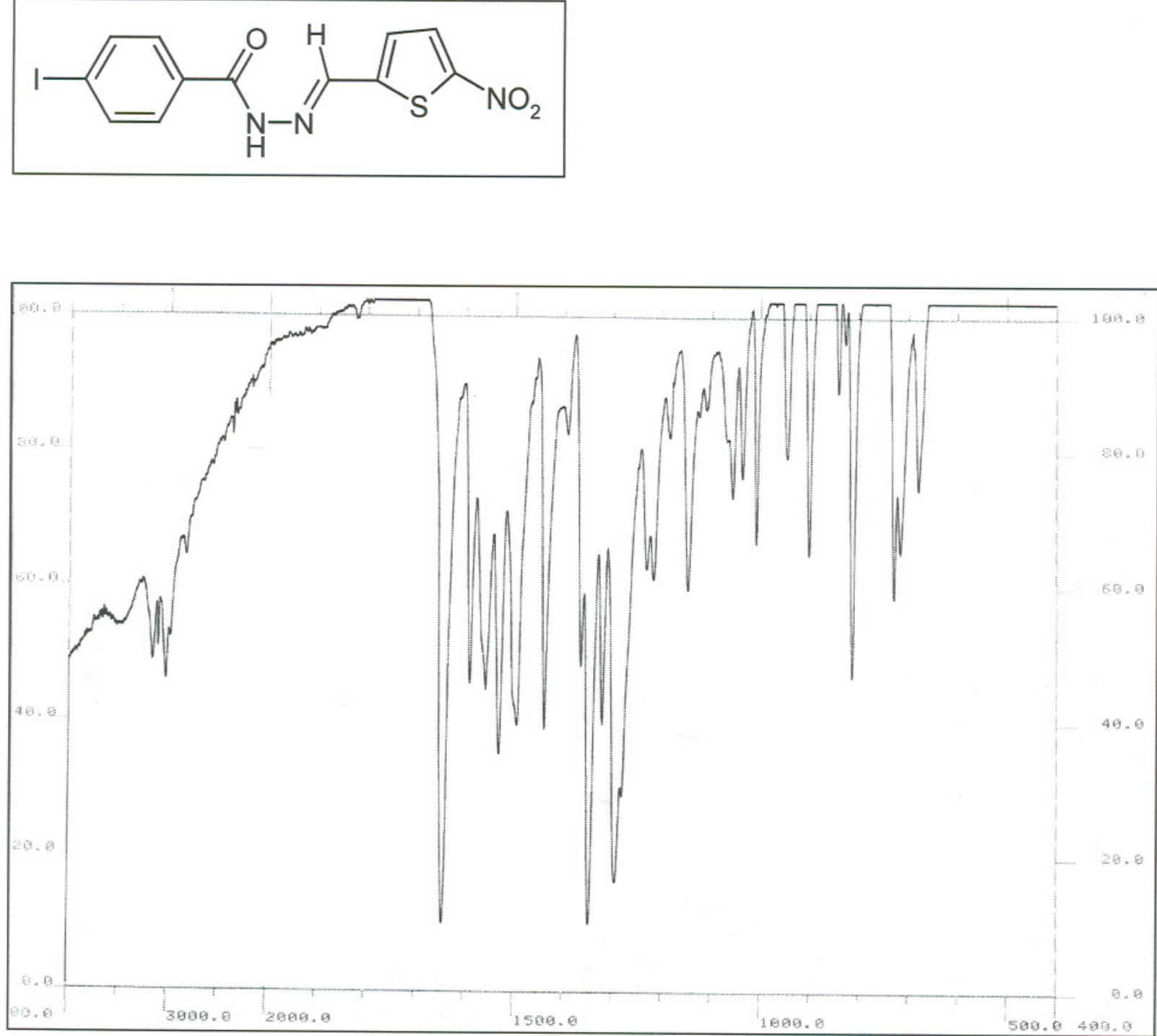

Espectro de absorção na região do IV da 5-nitro-2-tiofilideno 4-iodobenzidrazida. 


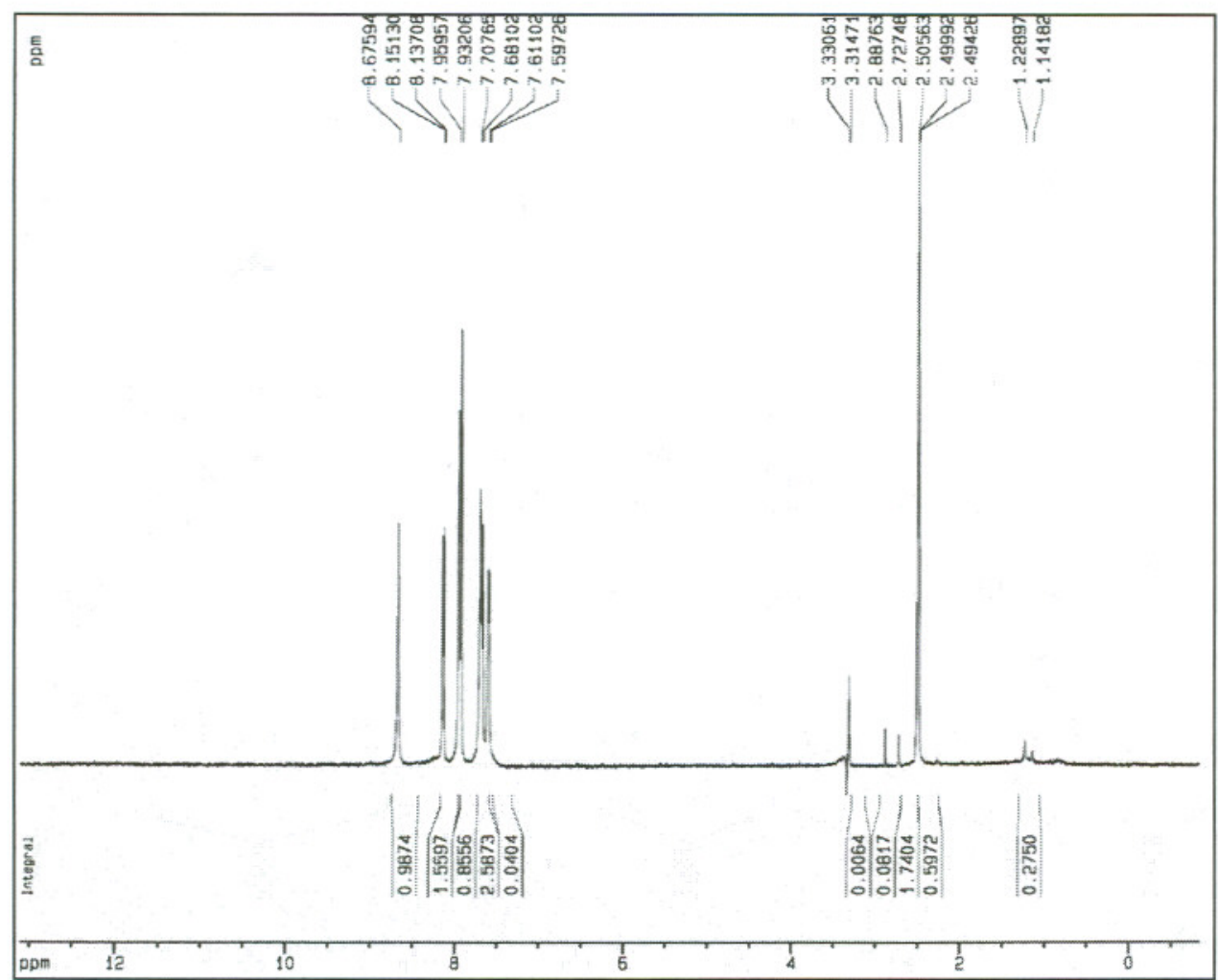

Espectro de $\mathrm{RMN}-{ }^{1} \mathrm{H}$ da 5-nitro-2-tiofilideno 4-iodobenzidrazida.

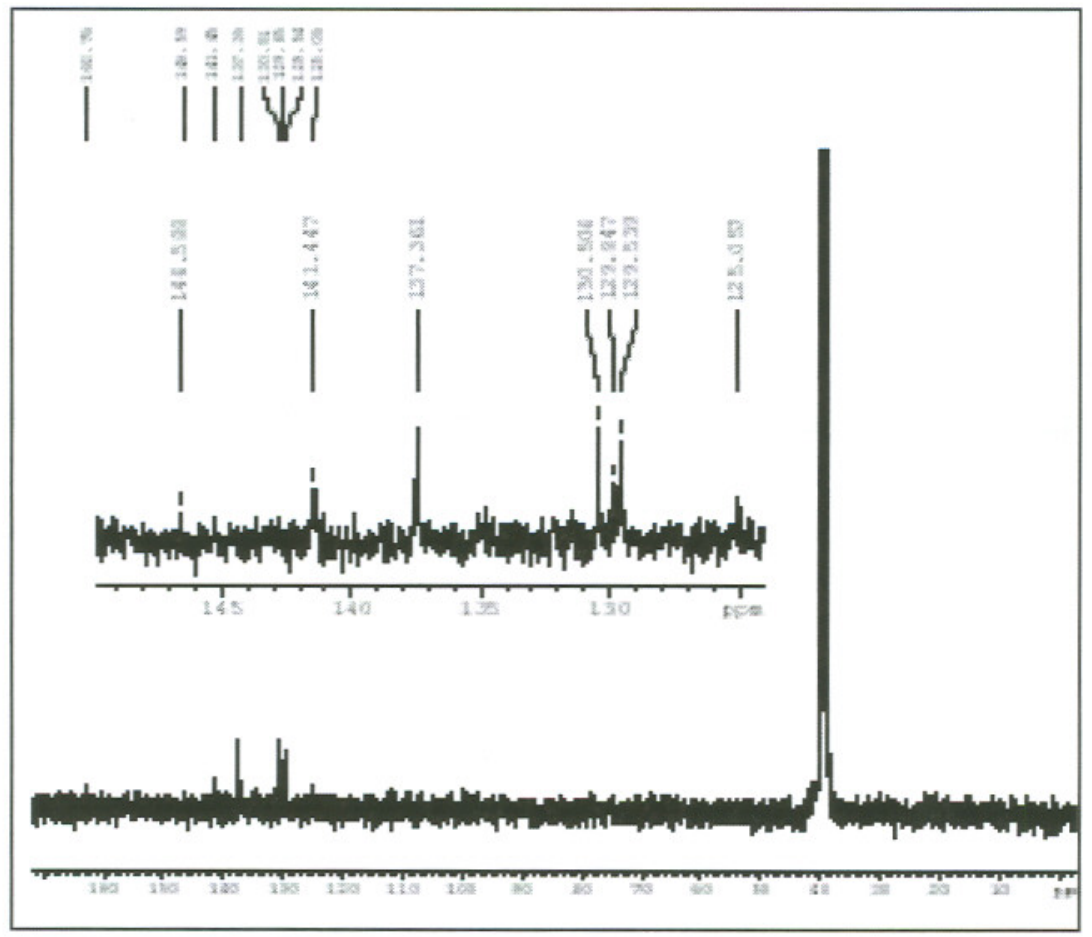

Espectro de $\mathrm{RMN}-{ }^{13} \mathrm{C}$ da 5-nitro-2-tiofilideno 4-iodobenzidrazida. 


\section{5-nitro-2-tiofilideno 4-propilbenzidrazida}
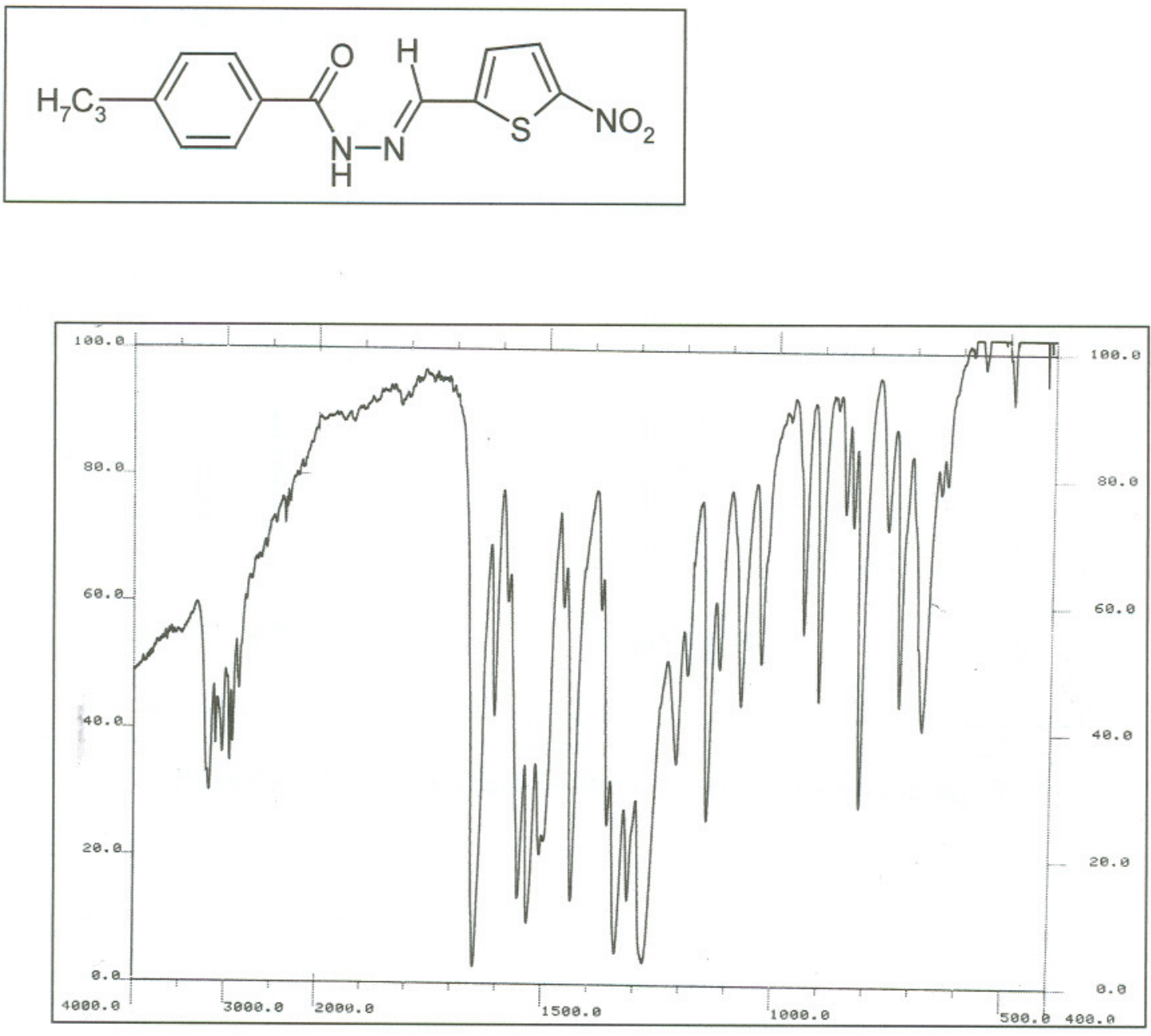

Espectro de absorção na região do IV da 5-nitro-2-tiofilideno 4-propilbenzidrazida. 


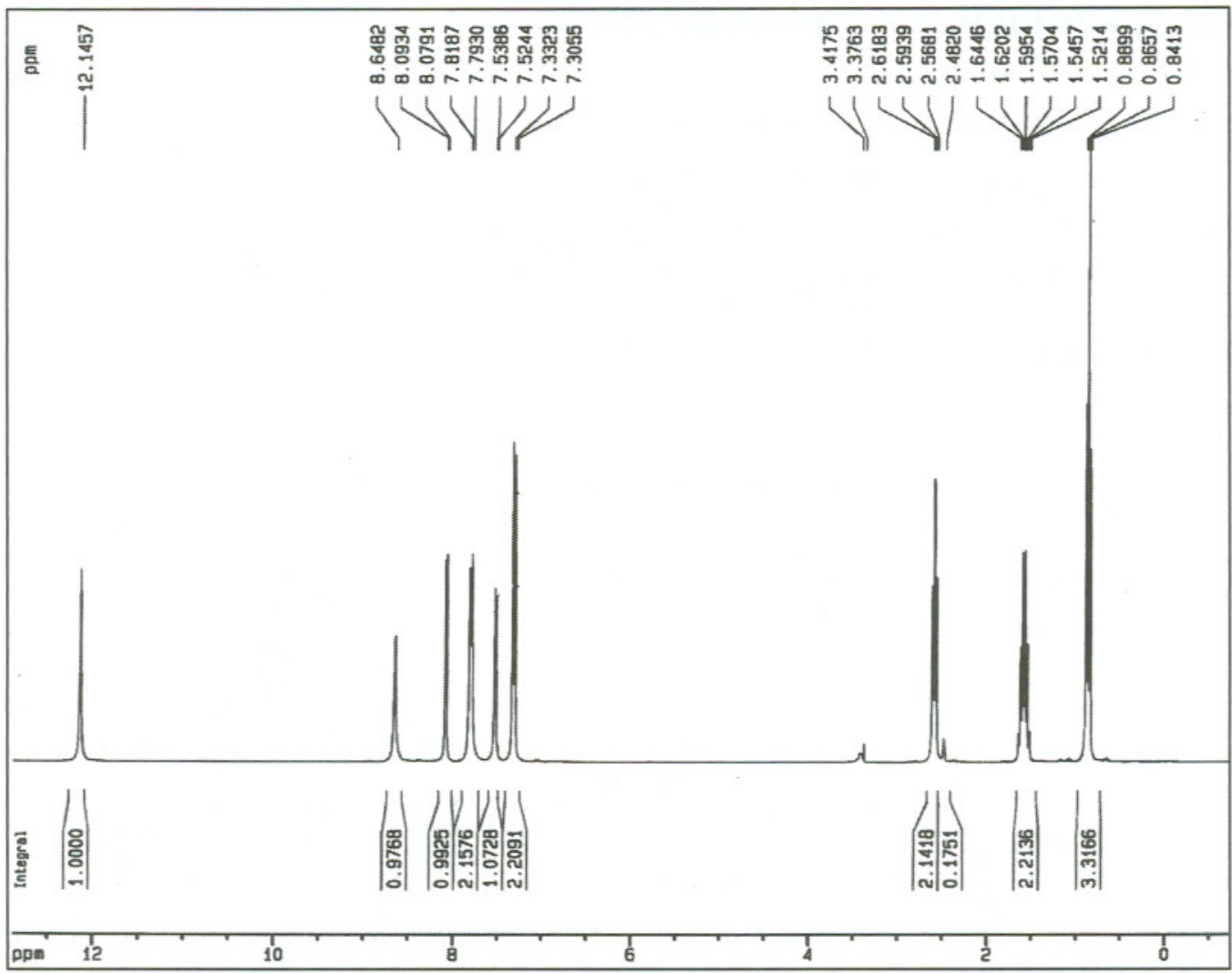

Espectro de $\mathrm{RMN}-{ }^{1} \mathrm{H}$ da 5-nitro-2-tiofilideno 4-propilbenzidrazida.

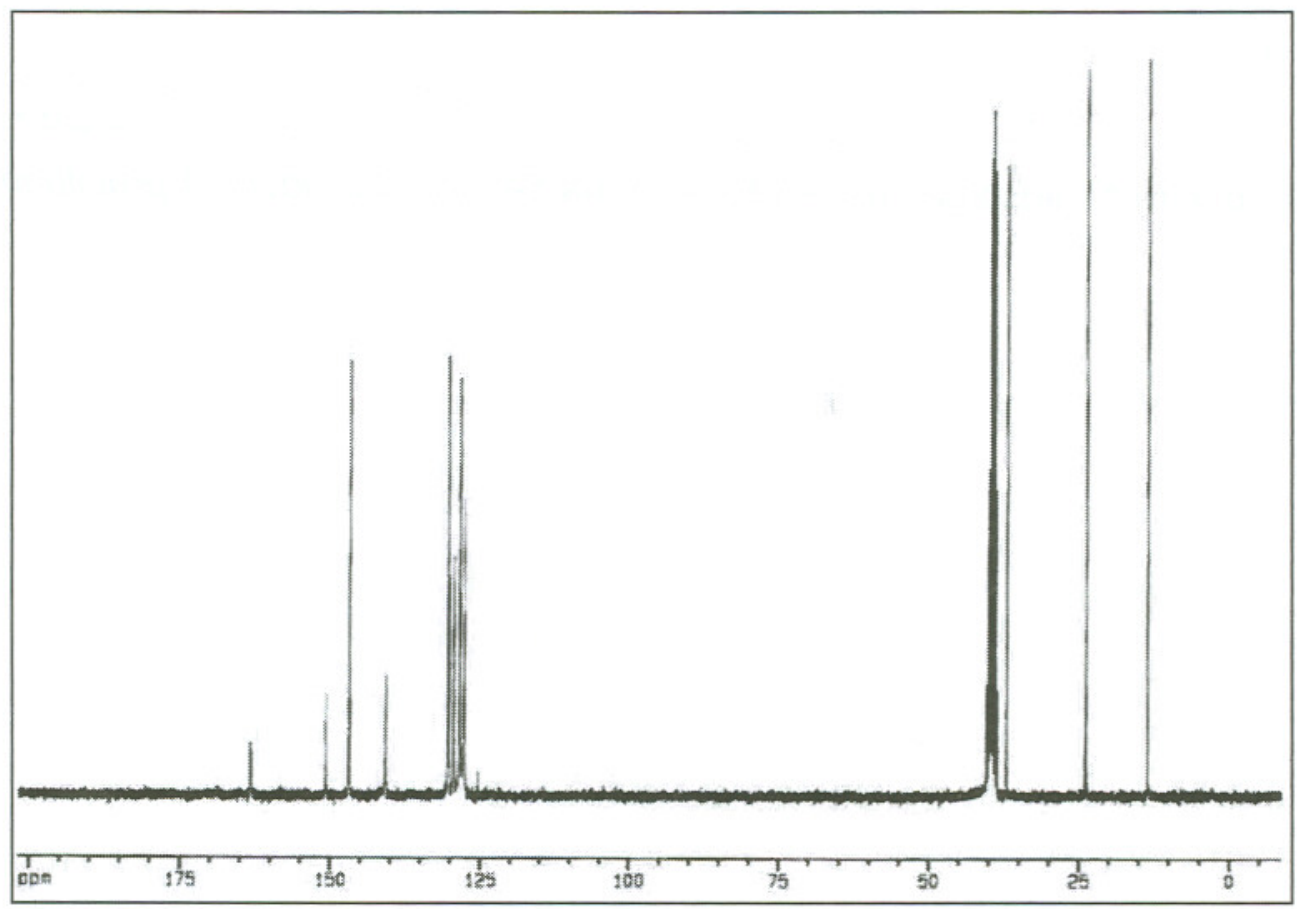

Espectro de $\mathrm{RMN}-{ }^{13} \mathrm{C}$ da 5-nitro-2-tiofilideno 4-propilbenzidrazida. 


\section{5-nitro-2-tiofilideno 4-propoxibenzidrazida}<smiles>CCCCCOc1ccc(C(=O)N/N=C/c2ccc([N+](=O)[O-])s2)cc1</smiles>

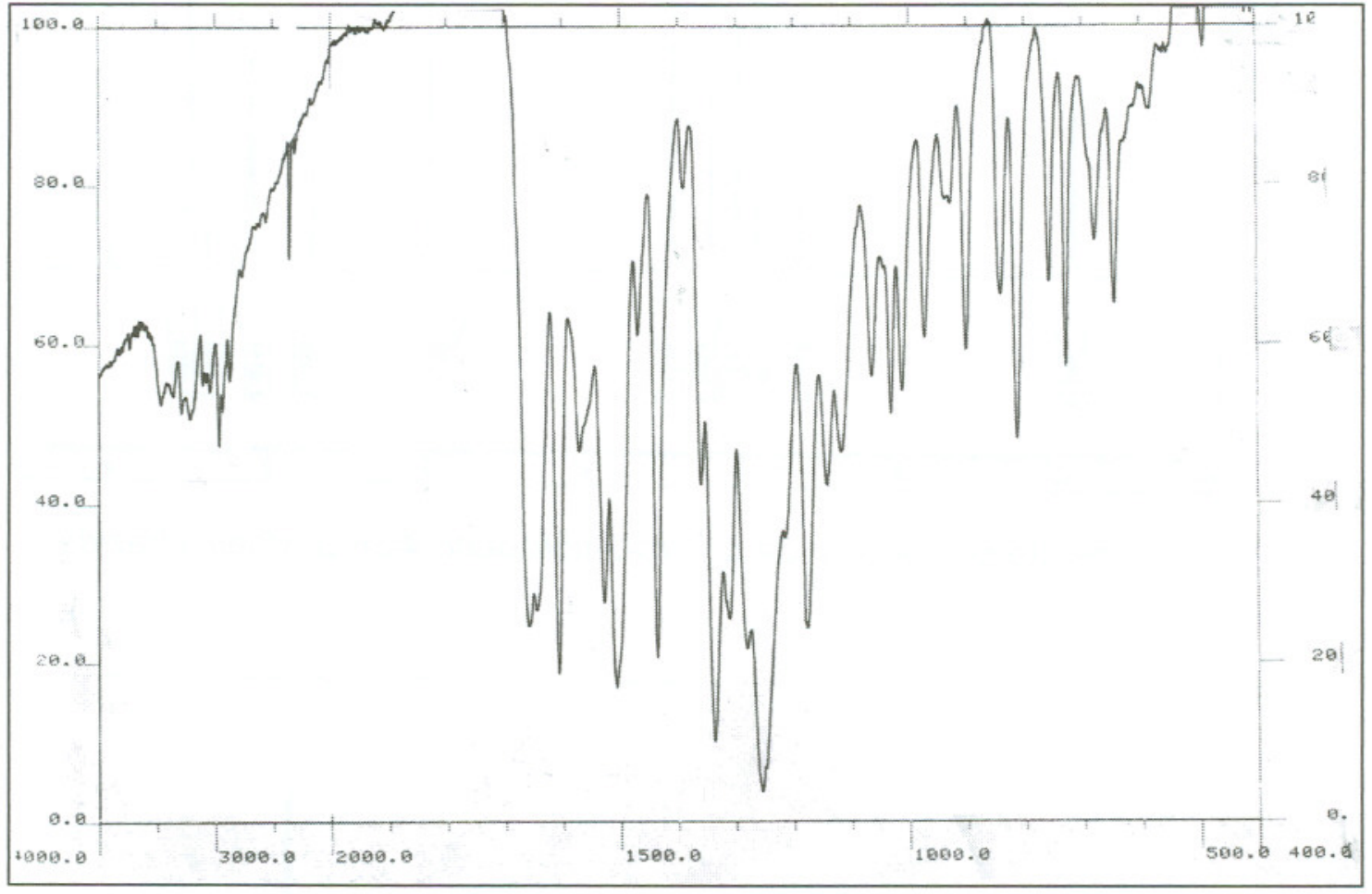

Espectro de absorção na região do IV da 5-nitro-tiofilideno 4-propoxibenzidrazida. 


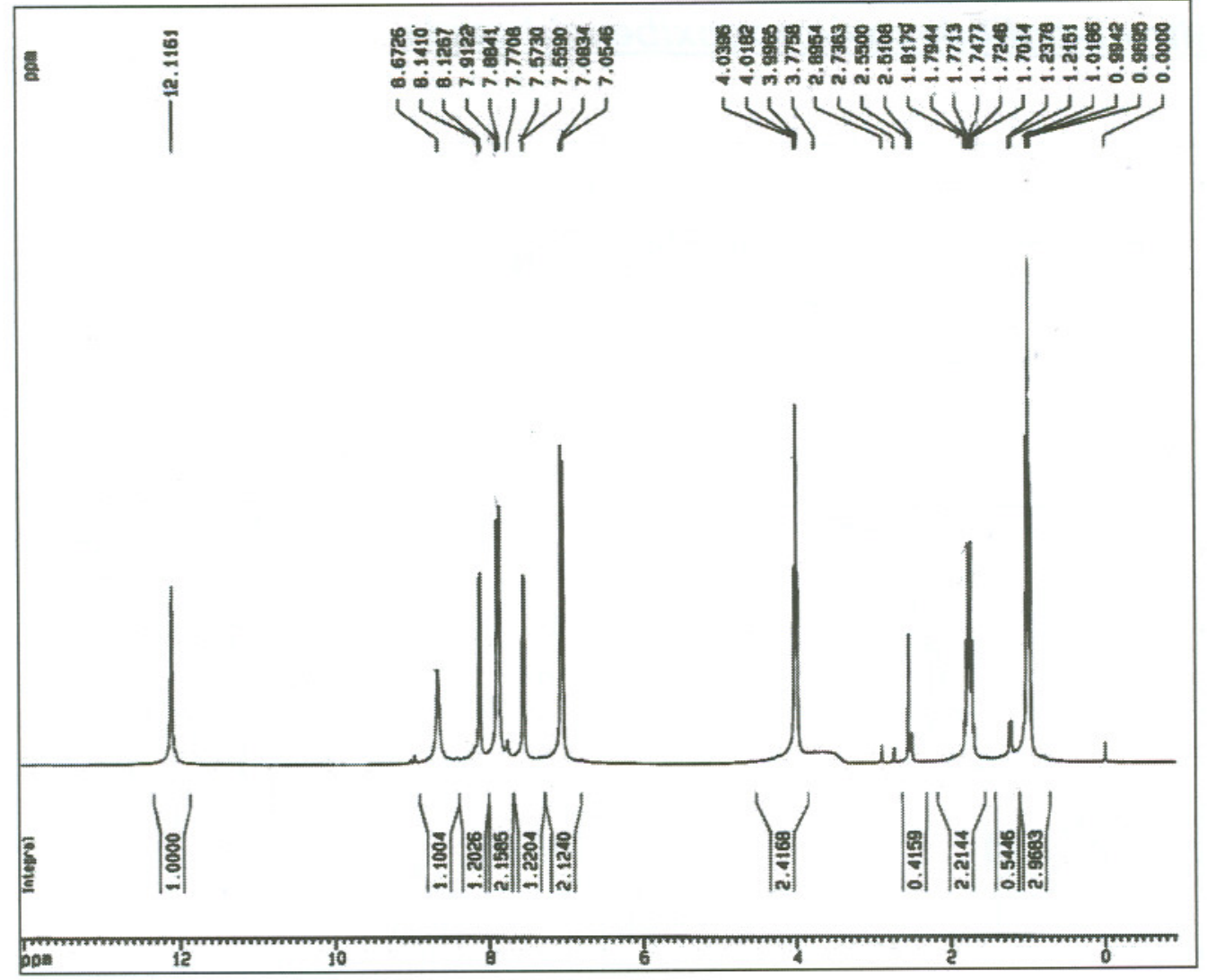

Espectro de $\mathrm{RMN}-{ }^{1} \mathrm{H}$ da 5-nitro-2-tiofilideno 4-propoxibenzidrazida.

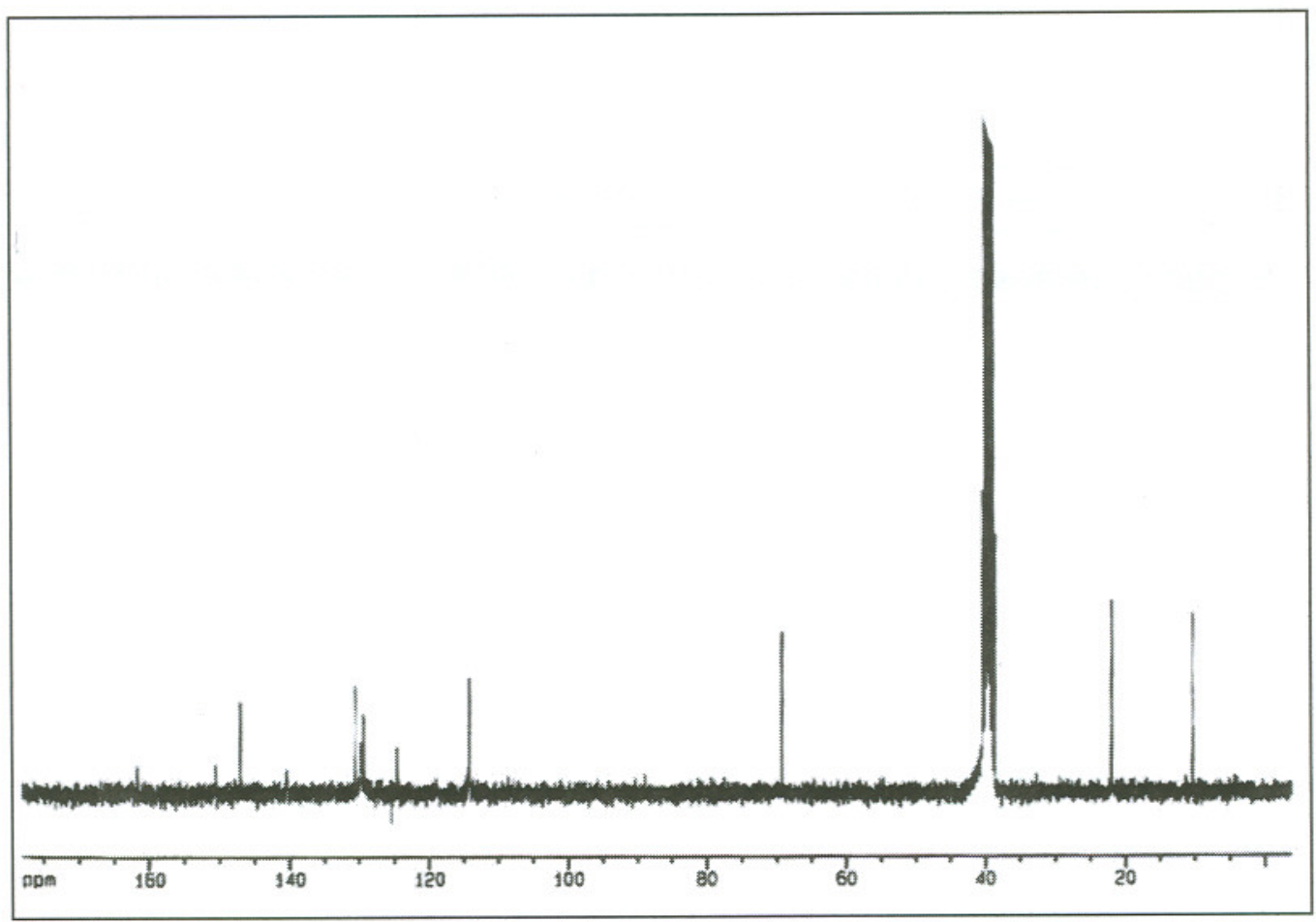

Espectro de $\mathrm{RMN}-{ }^{13} \mathrm{C}$ da 5-nitro-2-tiofilideno 4-propoxibenzidrazida. 


\section{5-nitro-2-tiofilideno 4-vinilbenzidrazida}
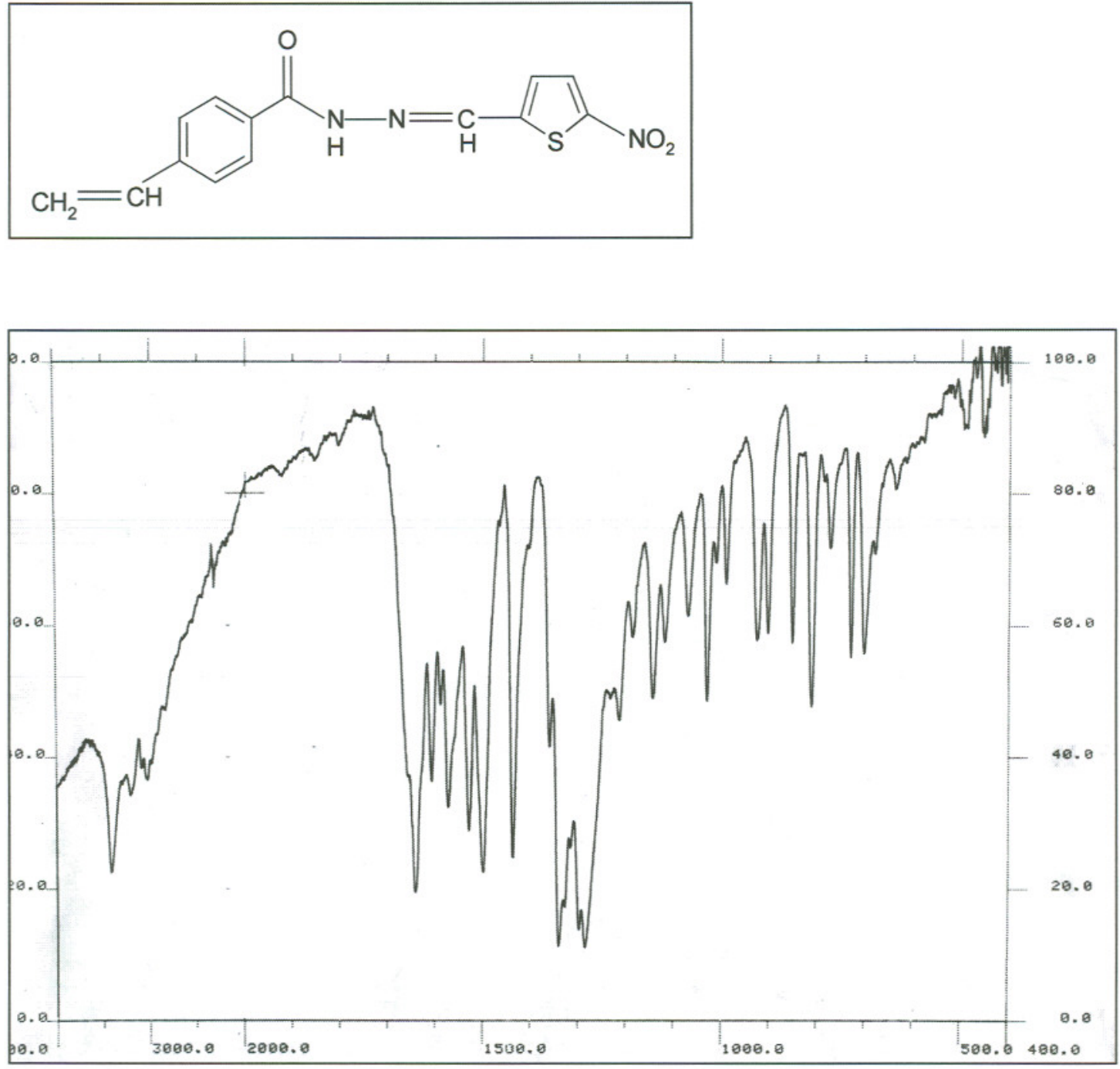

Espectro de absorção na região do IV da 5-nitro-tiofilideno 4-vinilbenzidrazida. 


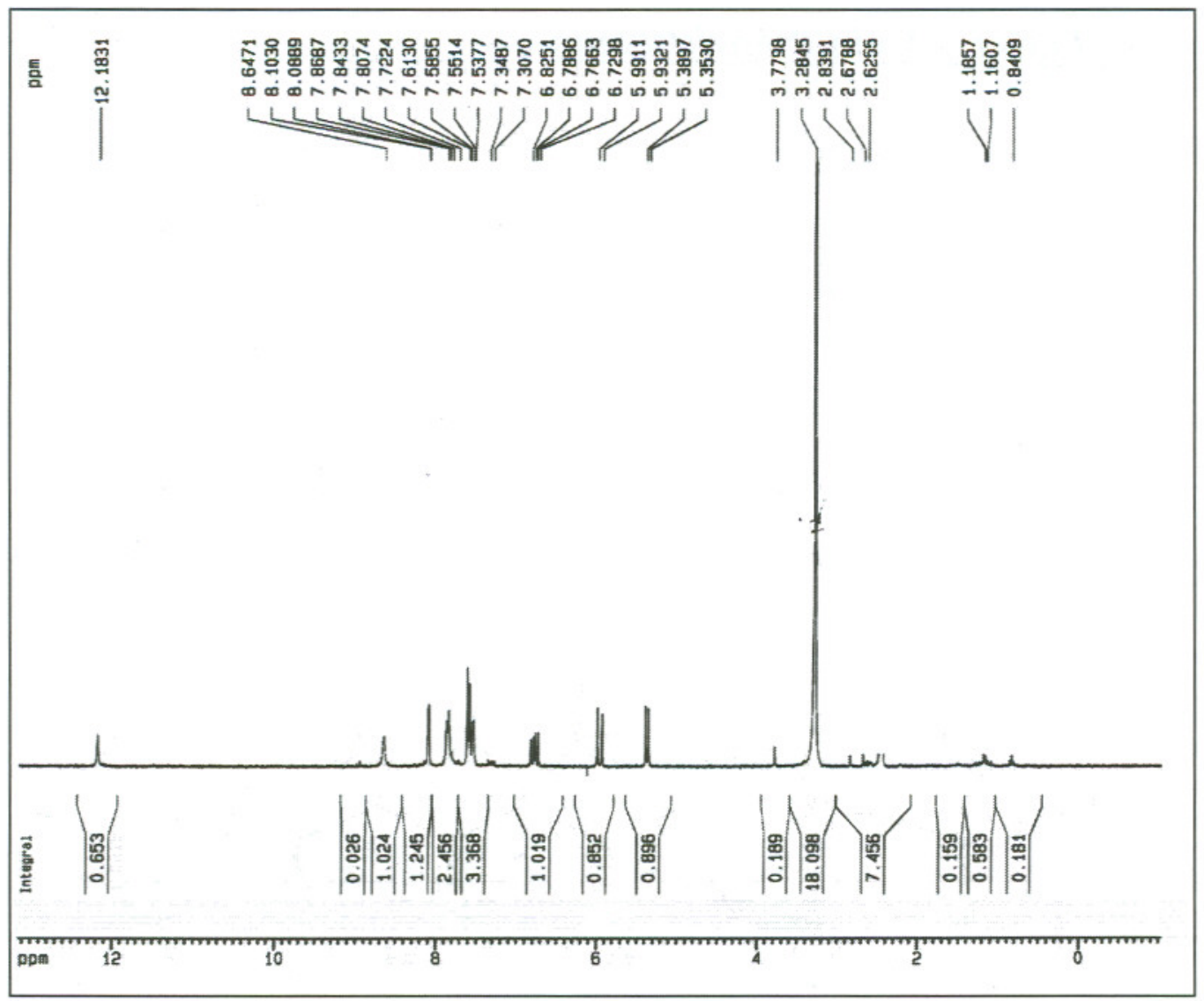

Espectro de RMN- ${ }^{1} \mathrm{H}$ da 5-nitro-2-tiofilideno 4-vinilbenzidrazida.

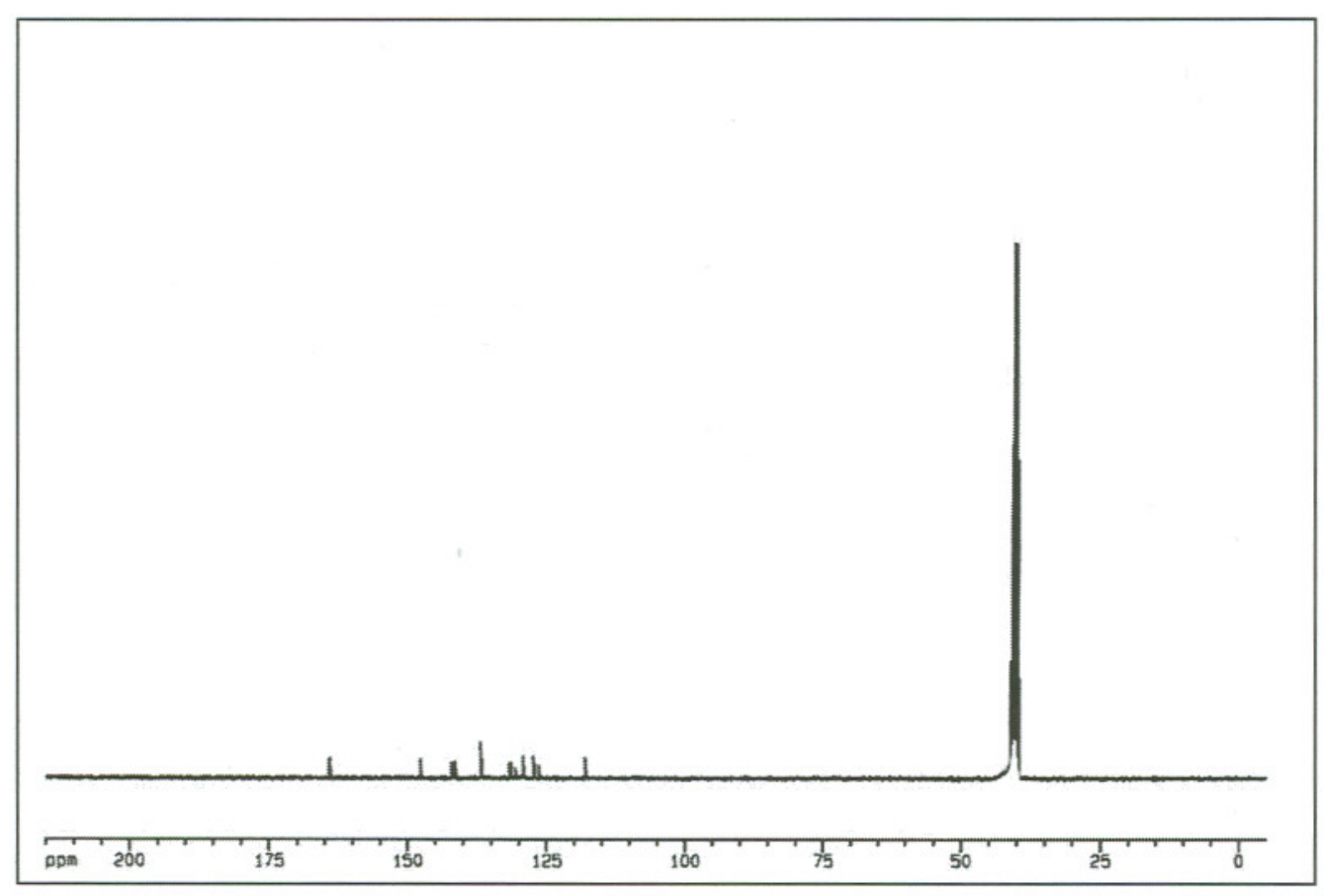

Espectro de $\mathrm{RMN}-{ }^{13} \mathrm{C}$ da 5-nitro-2-tiofilideno 4-vinilbenzidrazida. 


\section{5-nitro-2-tiofilideno 4-clorobenzidrazida}
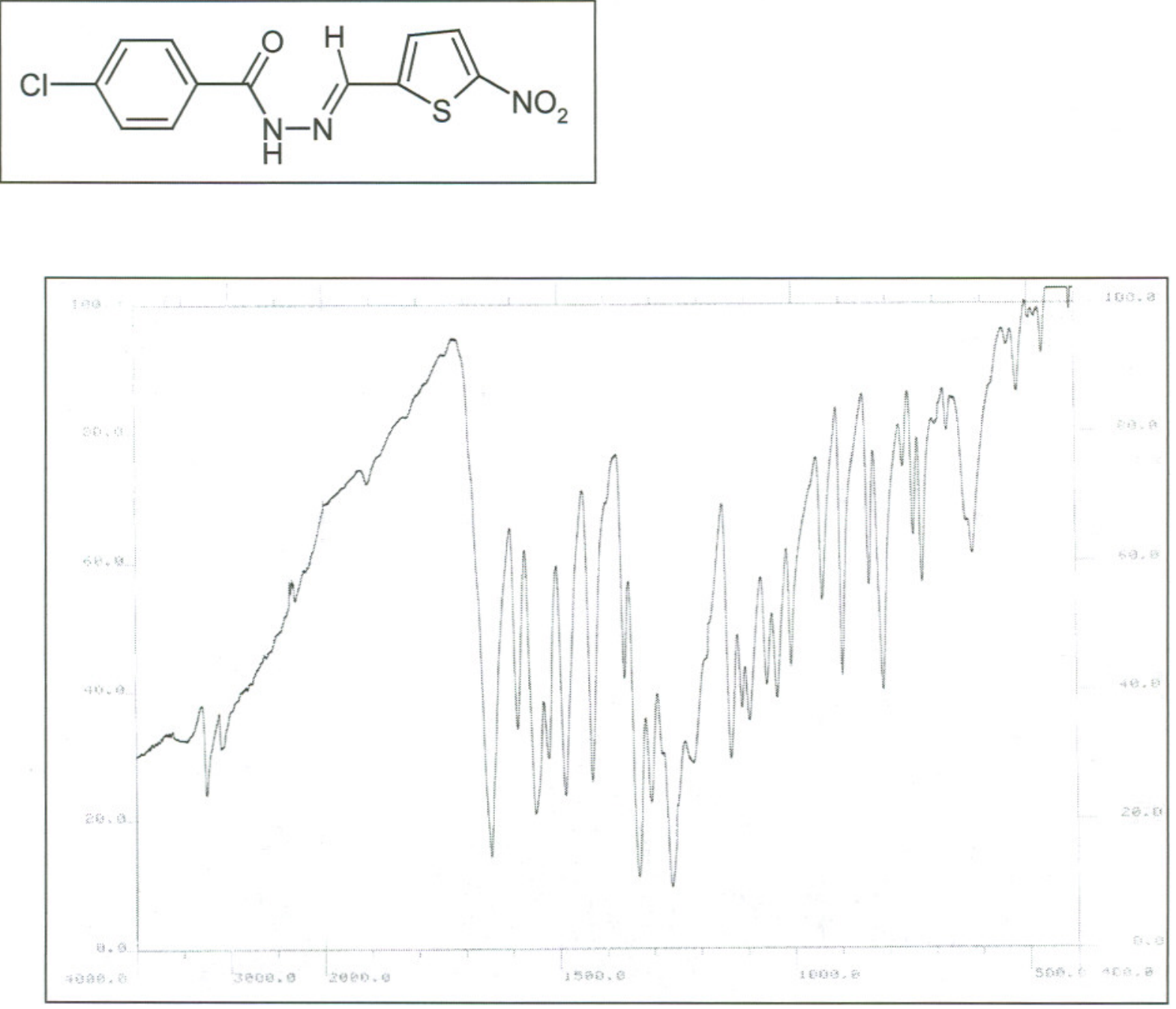

Espectro de absorção na região do IV da 5-nitro-2-tiofilideno-4-clorobenzidrazida. 


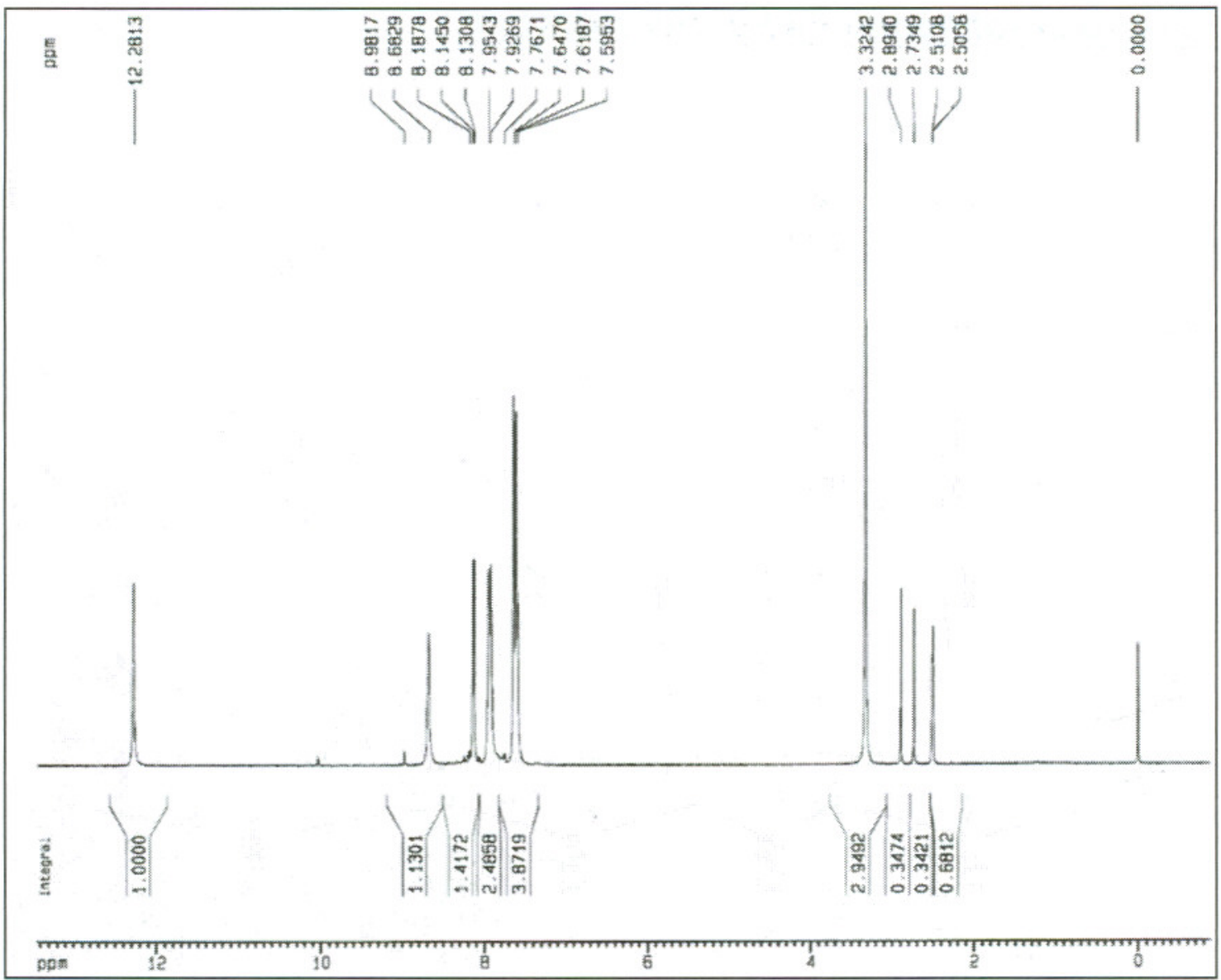

Espectro de RMN- ${ }^{1} \mathrm{H}$ da 5-nitro-2-tiofilideno 4-clorobenzidrazida.

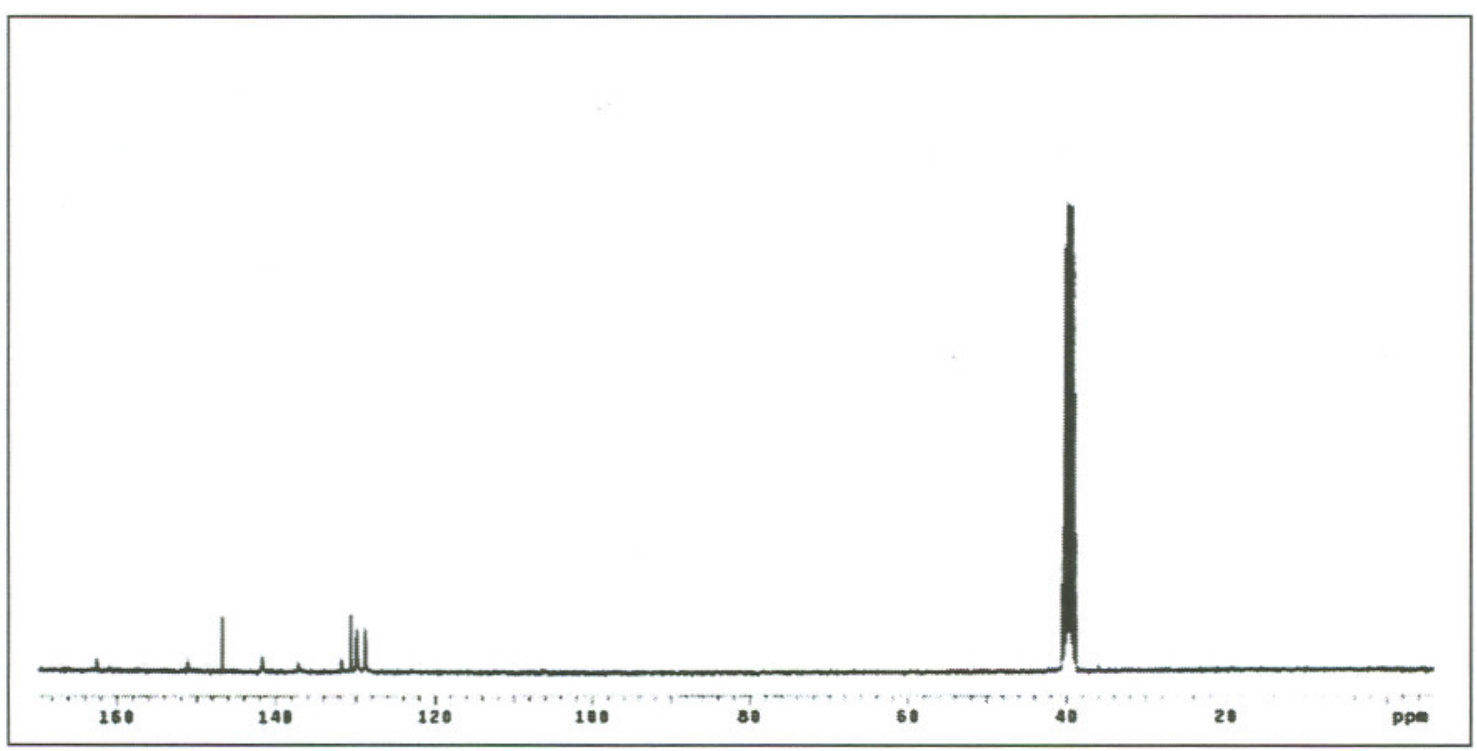

Espectro de $\mathrm{RMN}-{ }^{13} \mathrm{C}$ da 5-nitro-2-tiofilideno 4-clorobenzidrazida. 


\section{5-nitro-2-tiofilideno 4-acetilbenzidrazida}
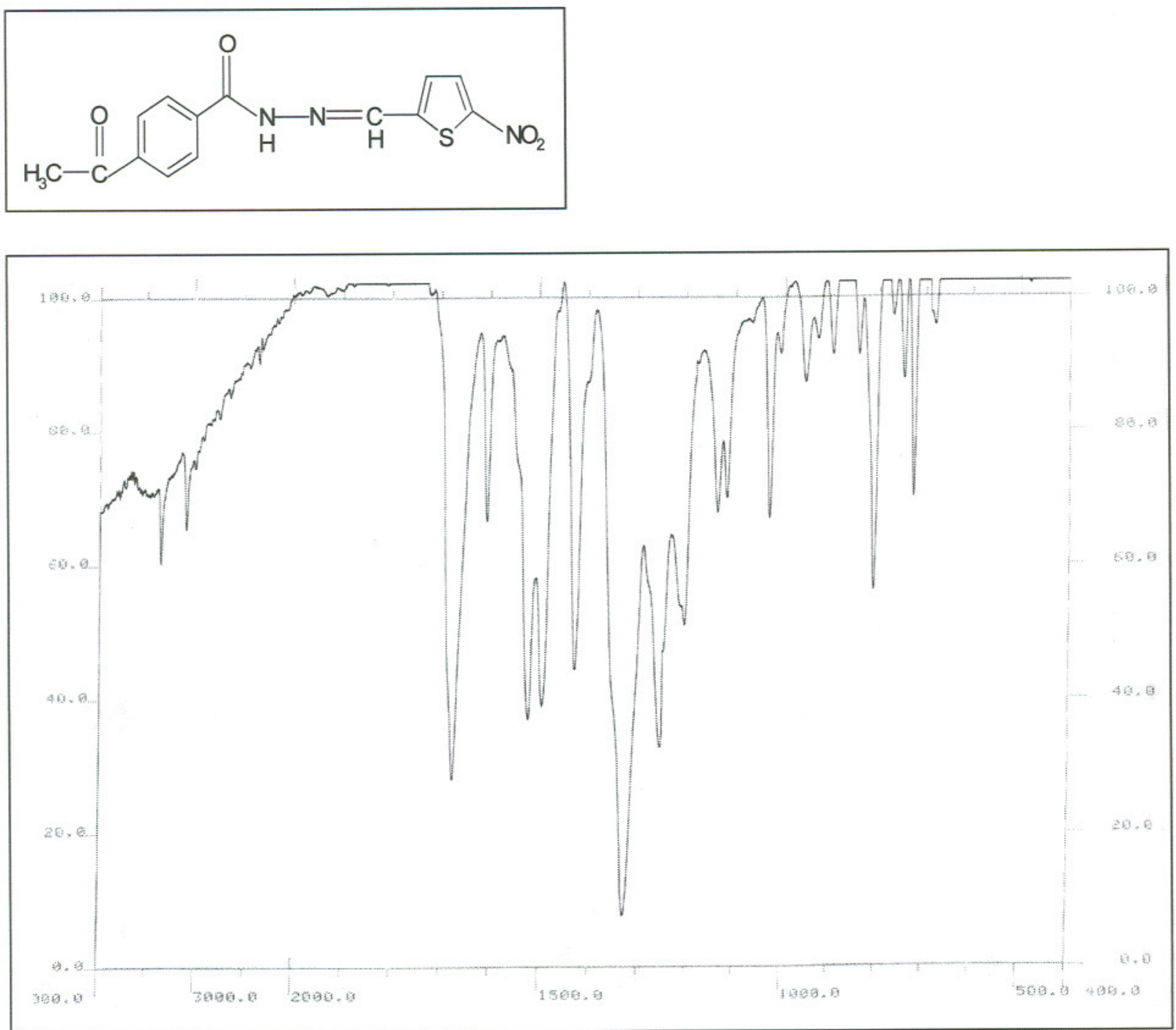

Espectro de absorção na região do IV da 5-nitro-2-tiofilideno 4-acetilbenzidrazida 


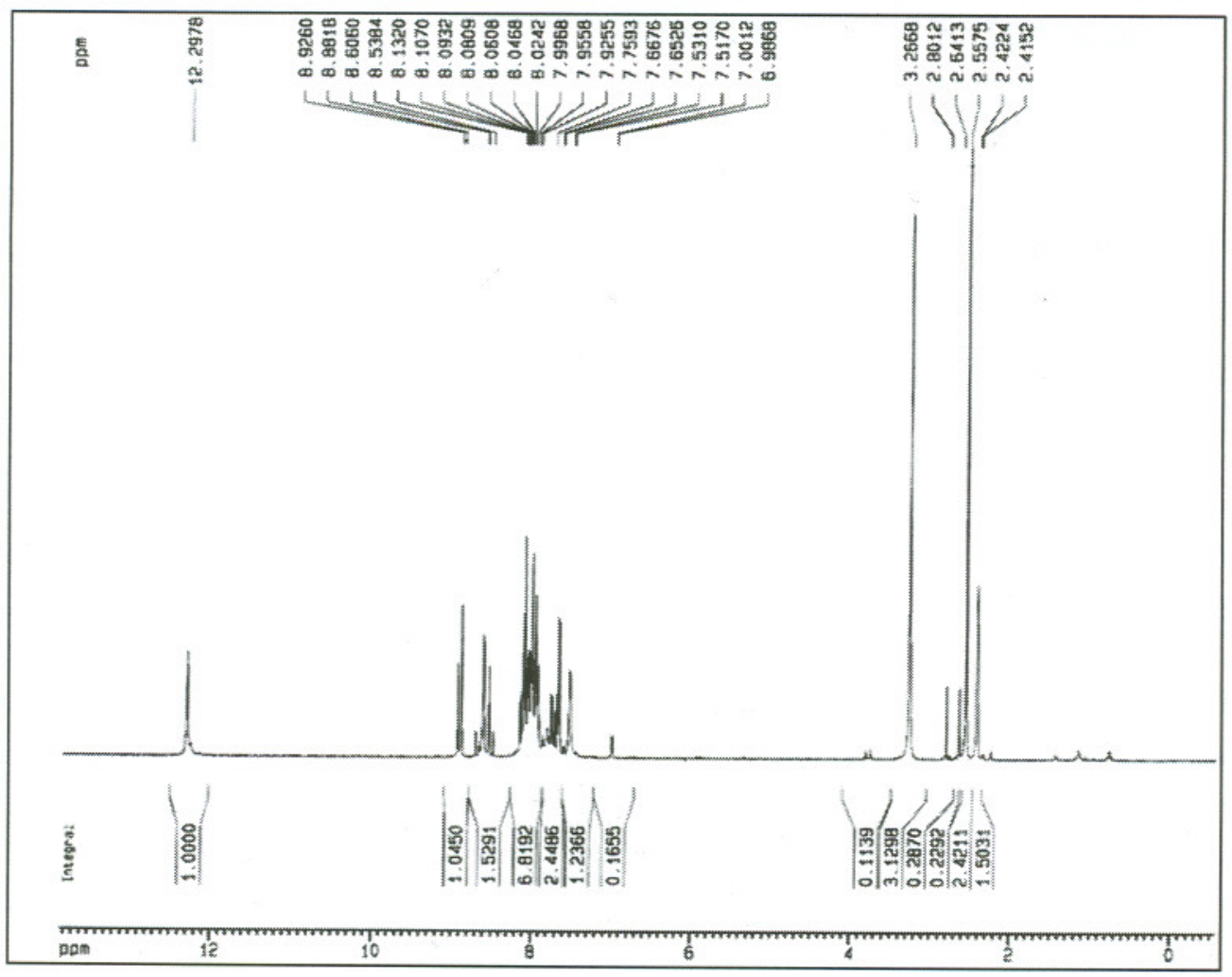

Espectro de RMN- ${ }^{1} \mathrm{H}$ da 5-nitro-2-tiofilideno 4-acetilbenzidrazida

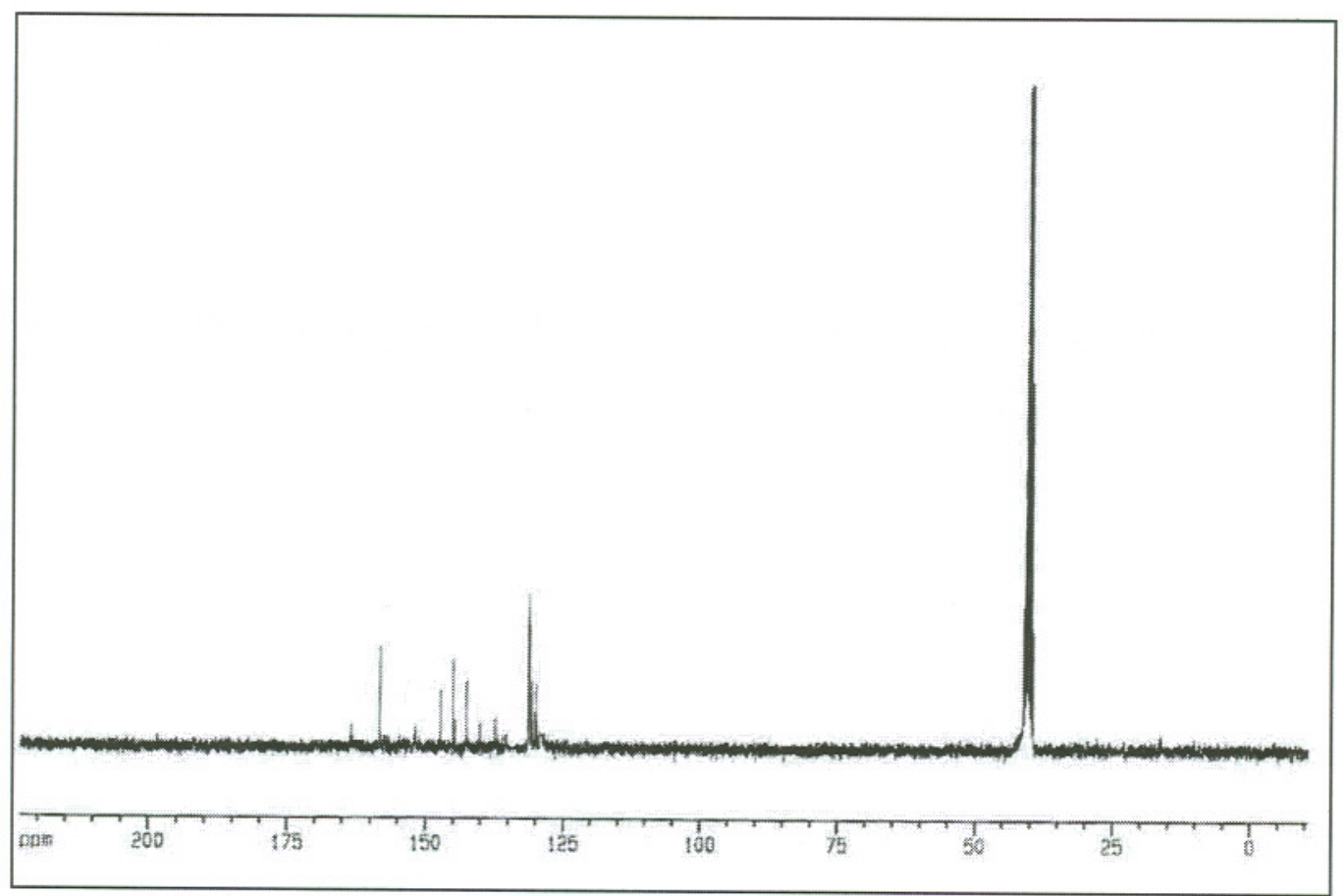

Espectro de $\mathrm{RMN}-{ }^{13} \mathrm{C}$ da 5-nitro-2-tiofilideno 4-acetilbenzidrazida 
FBT/FCF/USP

5-nitro-2-tiofilideno 4-butilaminobenzidrazida<smiles>CCNc1ccc(C(=O)N/N=C/c2ccc([N+](=O)[O-])s2)cc1</smiles>

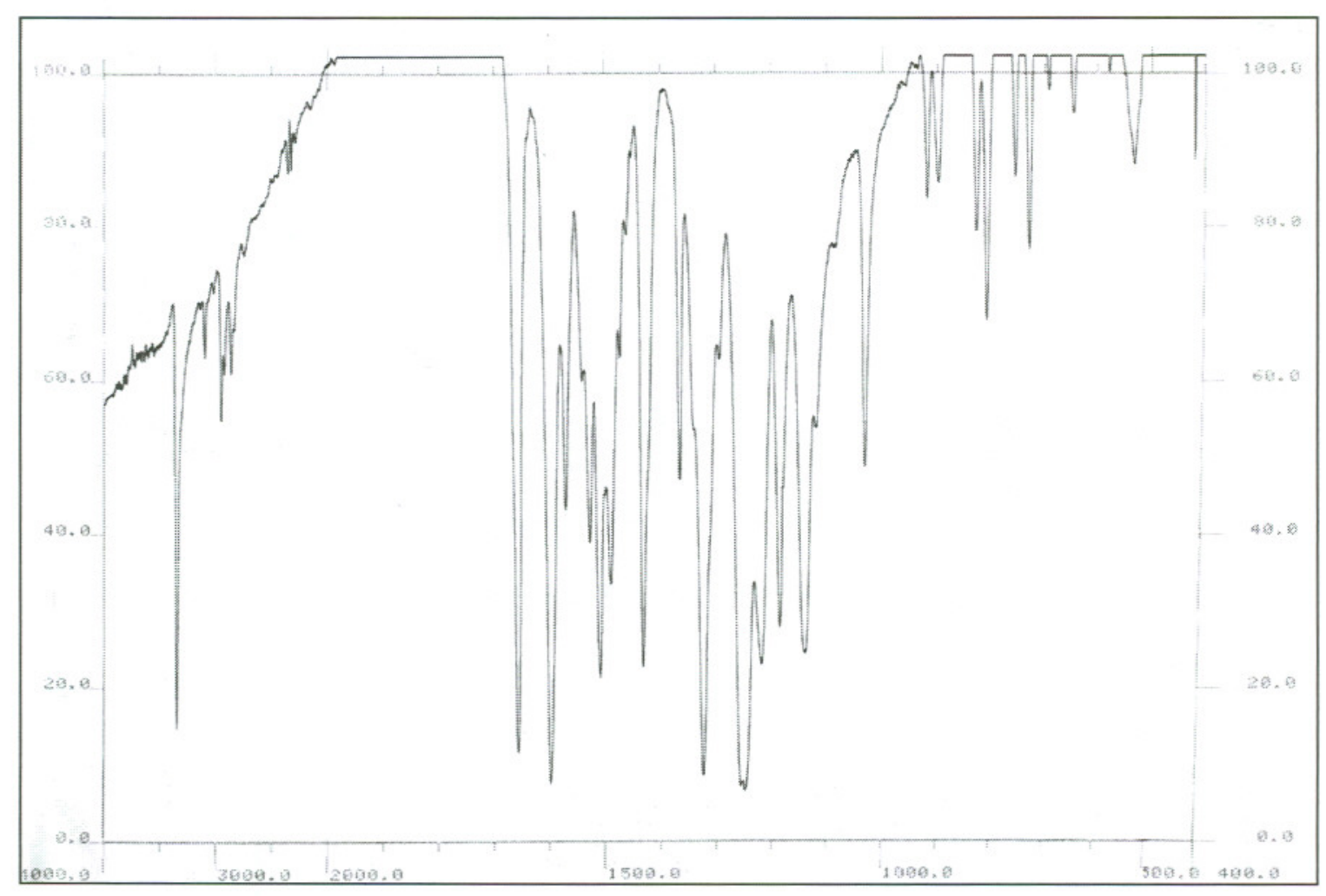

Espectro de absorção na região do IV da 5-nitro-2-tiofilideno 4-butilaminobenzidrazida.

Andrea Masunari 


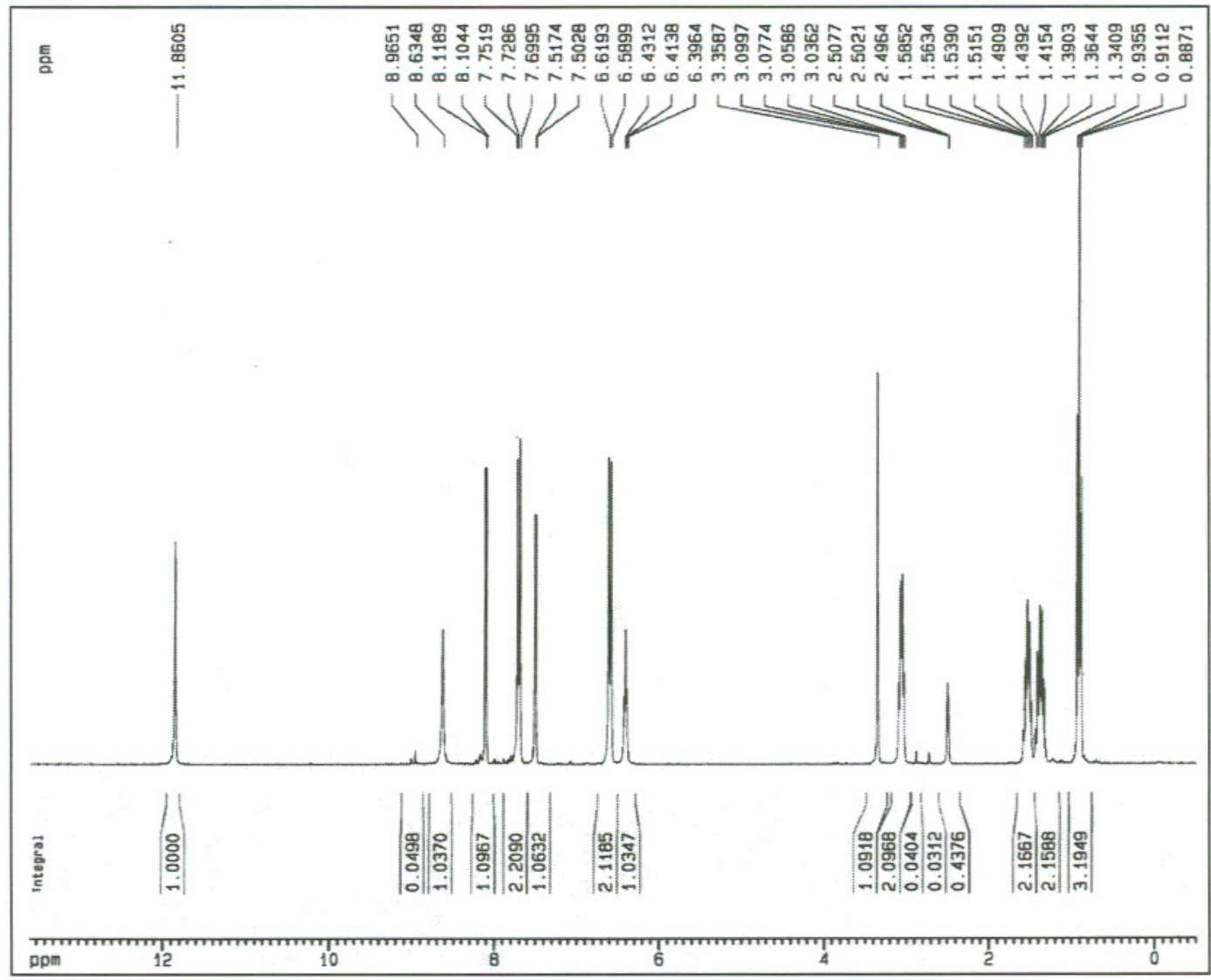

Espectro de $\mathrm{RMN}-{ }^{1} \mathrm{H}$ da 5-nitro-2-tiofilideno 4-butilaminobenzidrazida.

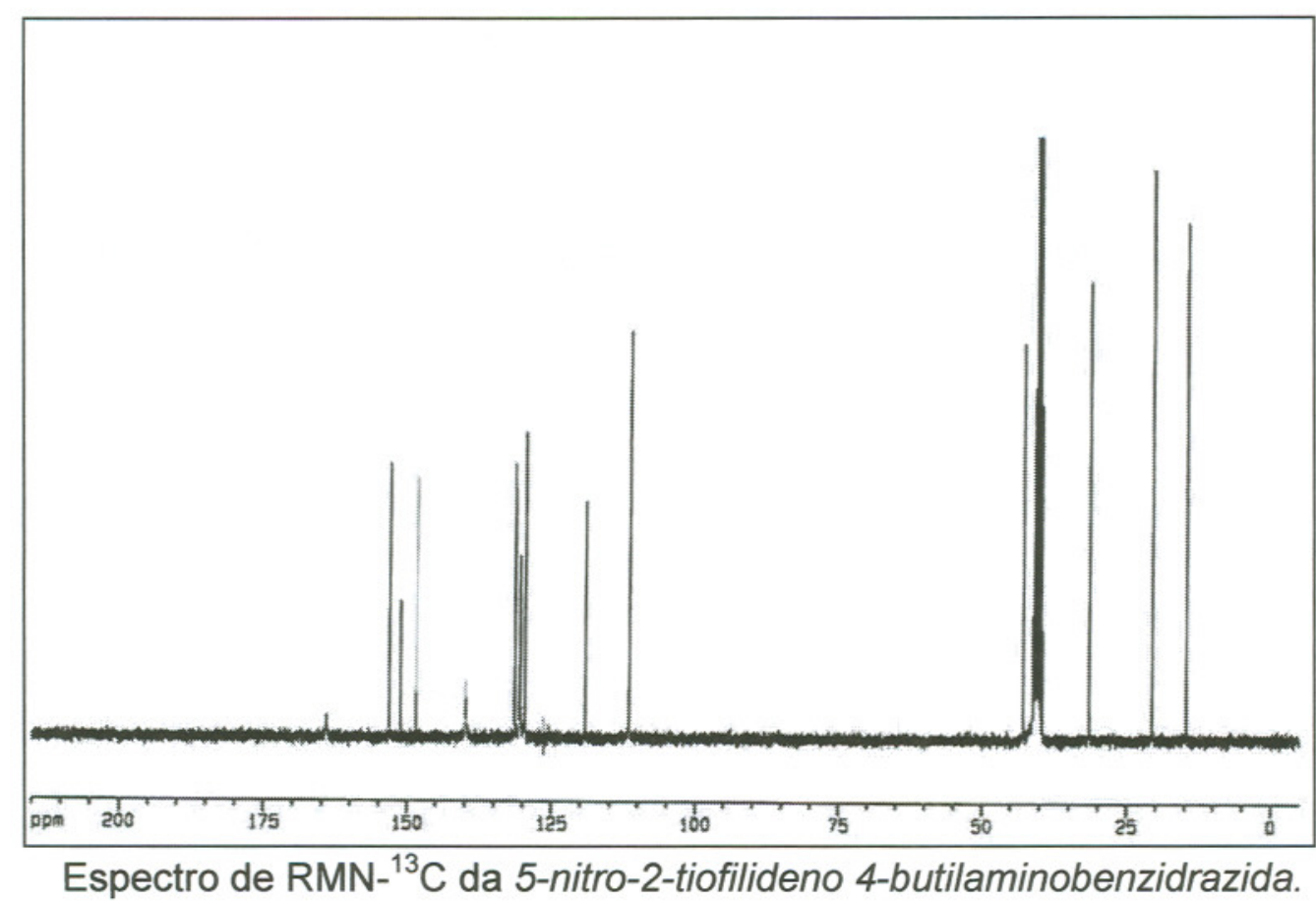




\section{5-nitro-2-tiofilideno 4-butoxibenzidrazida}<smiles>COc1ccc(C(=O)N/N=C/c2ccc([N+](=O)[O-])s2)cc1</smiles>

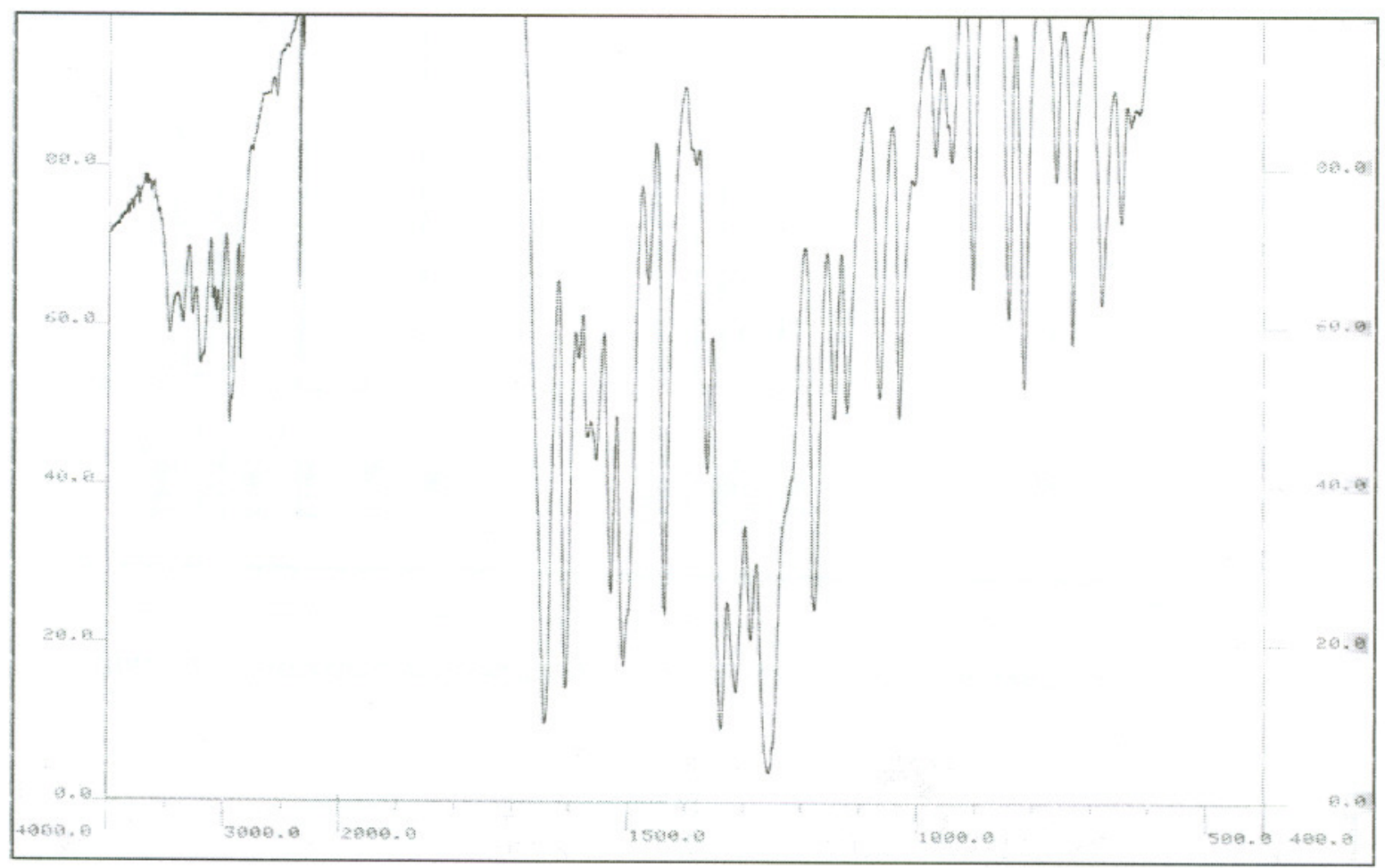

Espectro de absorção na região do IV da 5-nitro-2-tiofilideno 4-butoxibenzidrazida. 


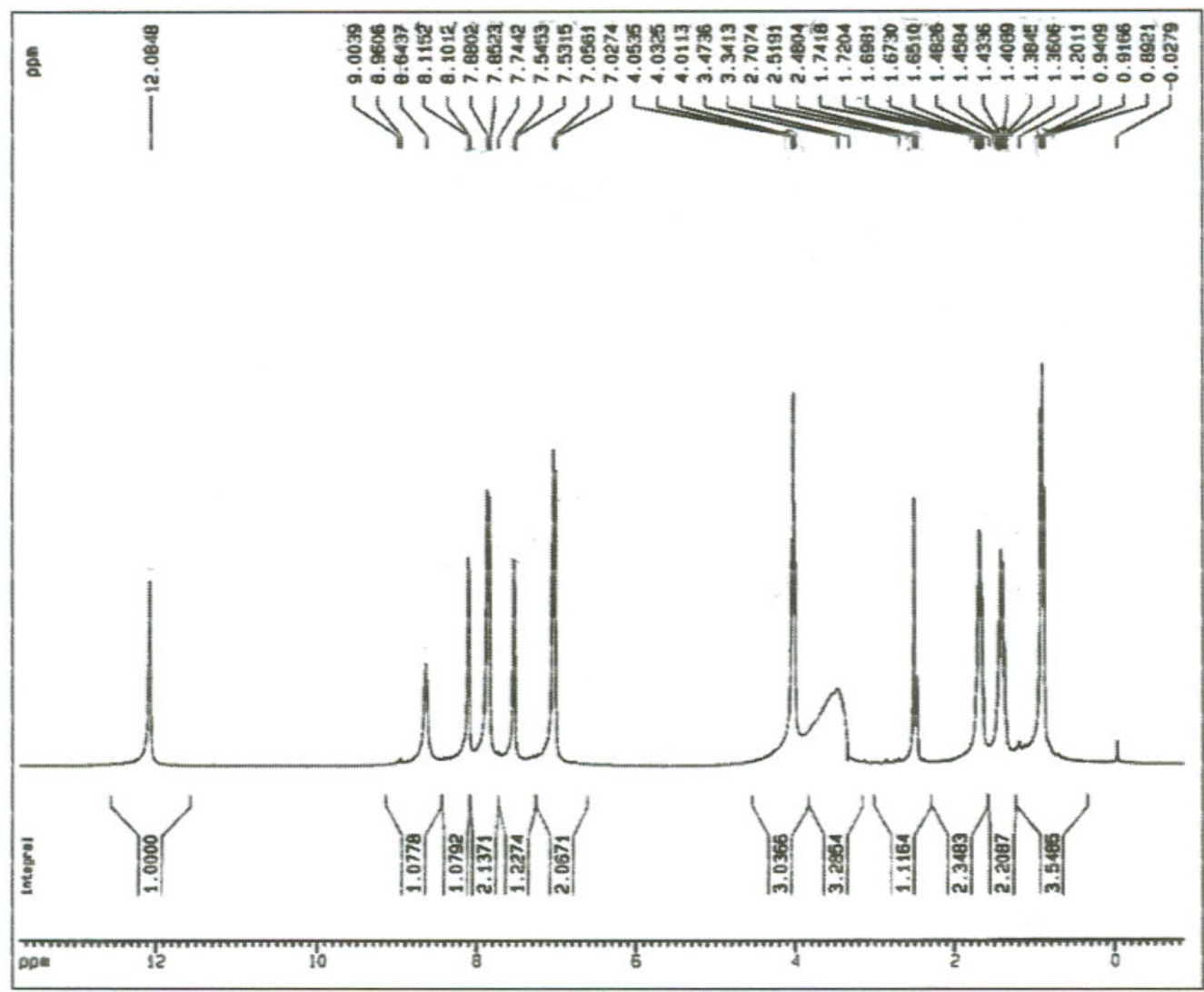

Espectro de RMN- ${ }^{1} \mathrm{H}$ da 5-nitro-2-tiofilideno 4-butoxibenzidrazida.

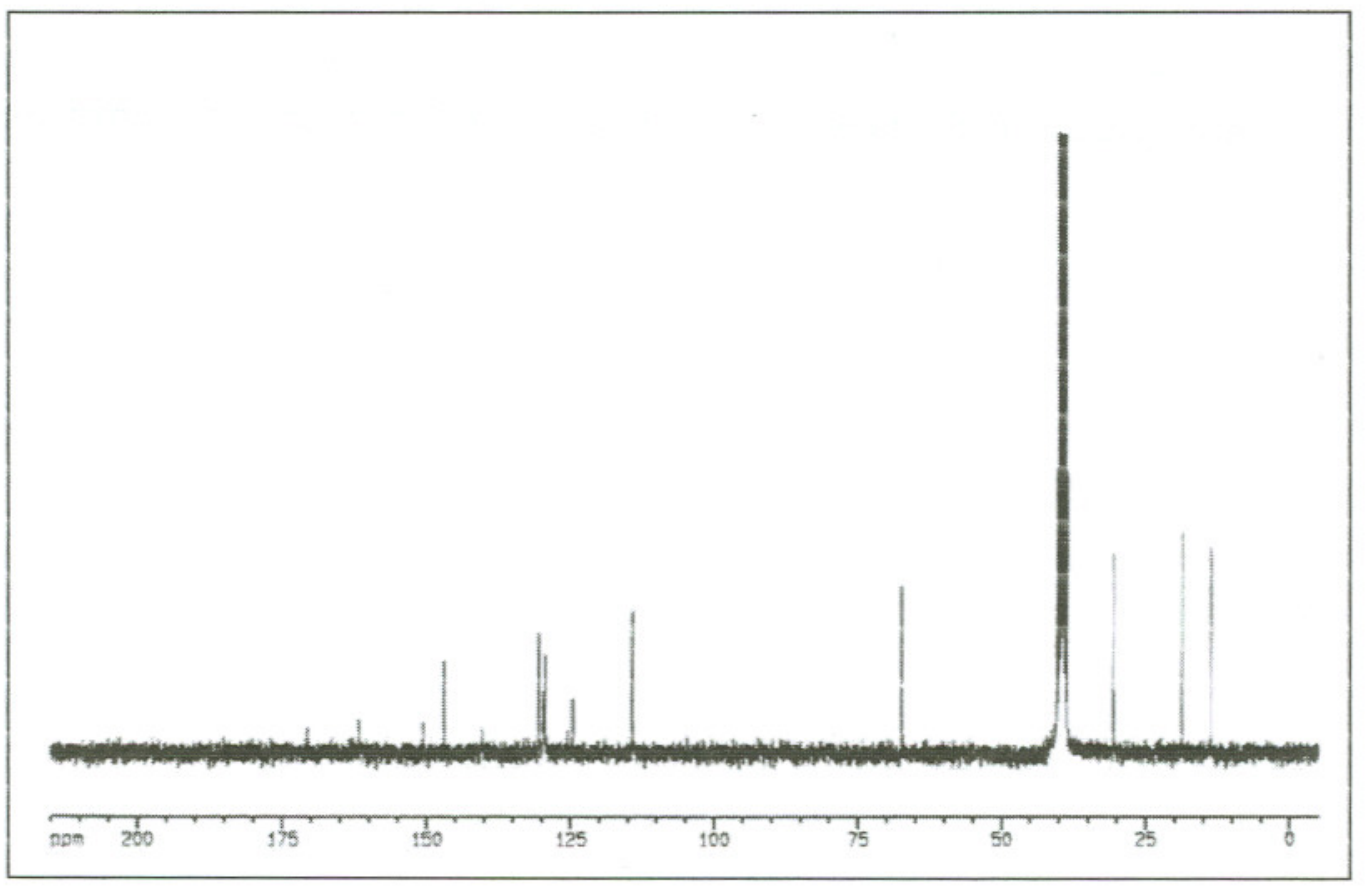

Espectro de $\mathrm{RMN}-{ }^{13} \mathrm{C}$ da 5-nitro-2-tiofilideno 4-butoxibenzidrazida. 


\section{5-nitro-2-tiofilideno 4-bromobenzidrazida}
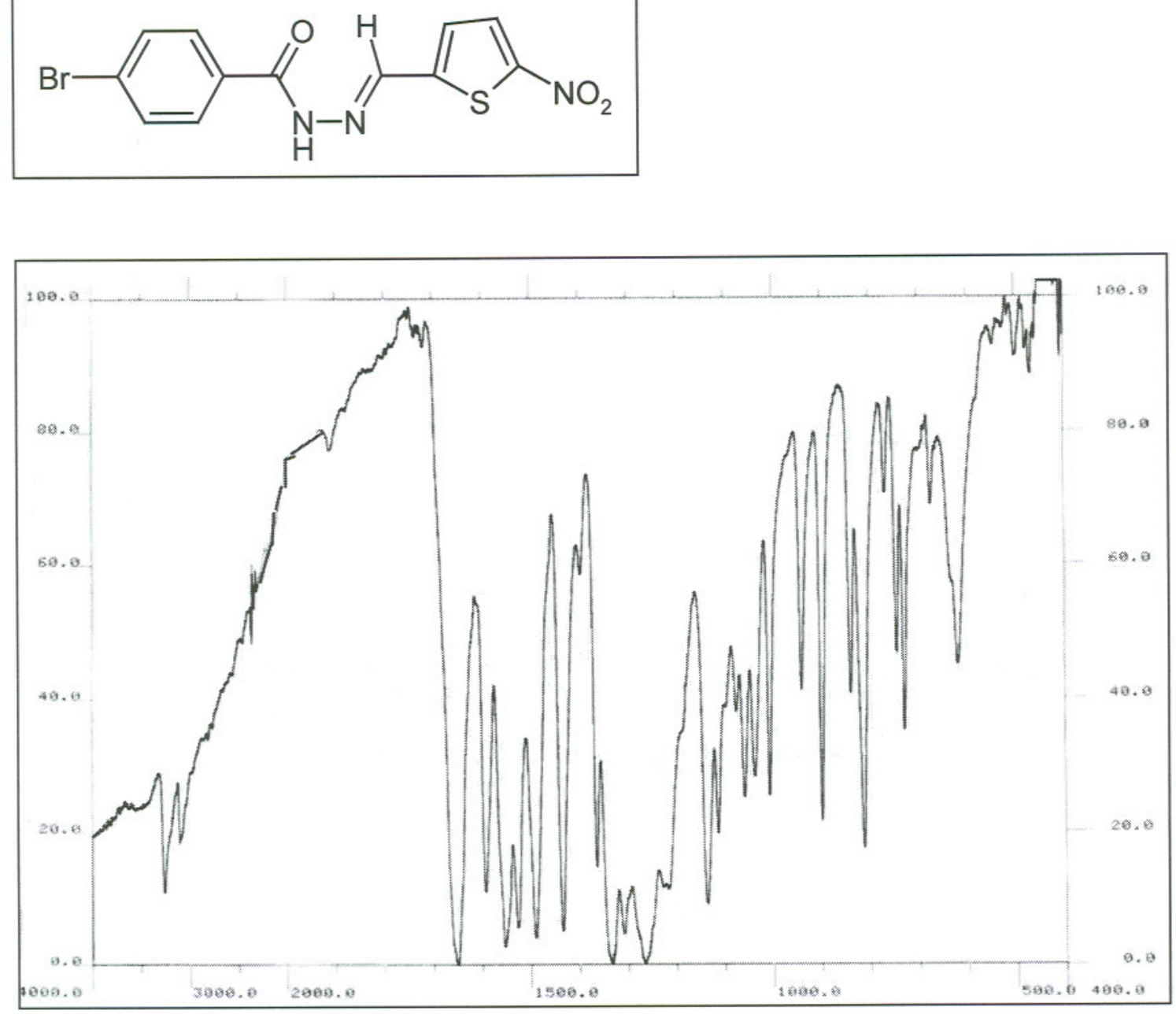

Espectro de absorção na região do IV da 5-nitro-2-tiofilideno 4-bromobenzidrazida. 


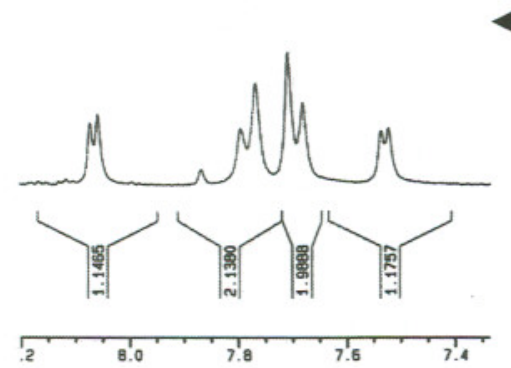

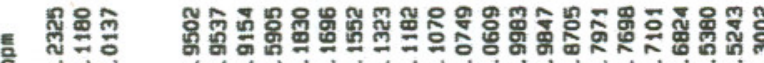

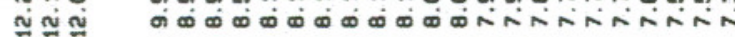
11

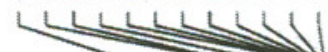

Min

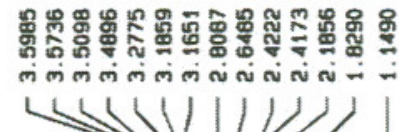

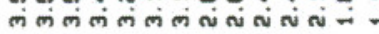

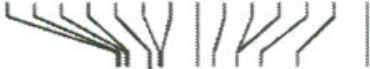

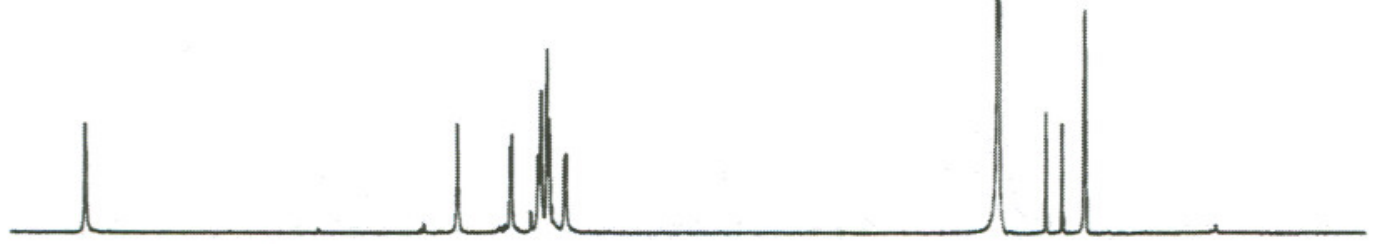
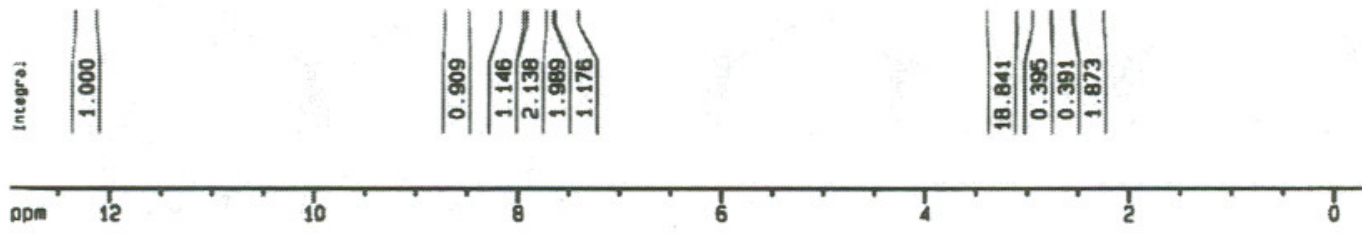

Espectro de $\mathrm{RMN}^{-1} \mathrm{H}$ da 5-nitro-2-tiofilideno 4-bromobenzidrazida. 


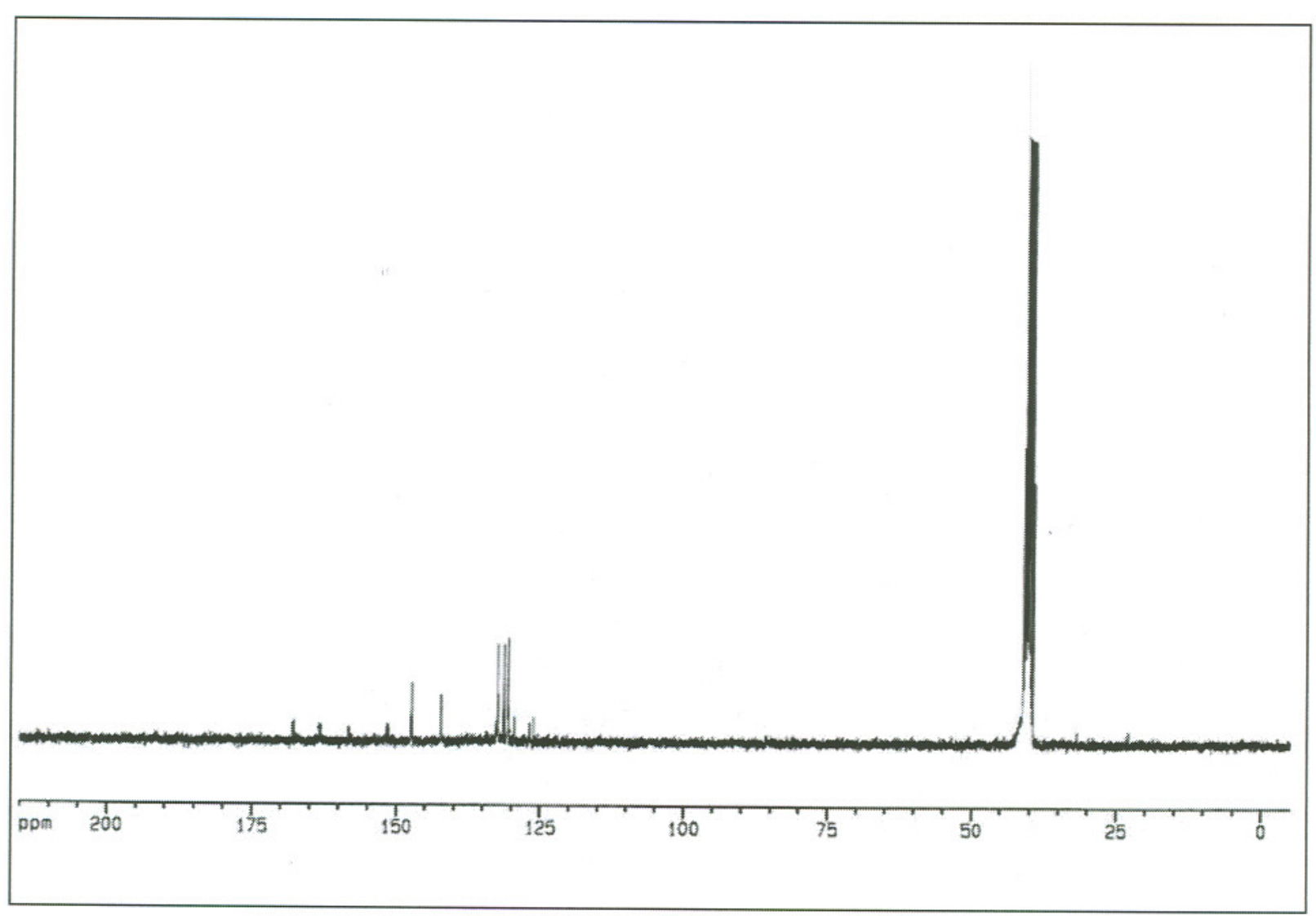

Espectro de RMN $-{ }^{13} \mathrm{C}$ da 5-nitro-2-tiofilideno 4-bromobenzidrazida. 


\section{5-nitro-2-tiofilideno 4-butilbenzidrazida}
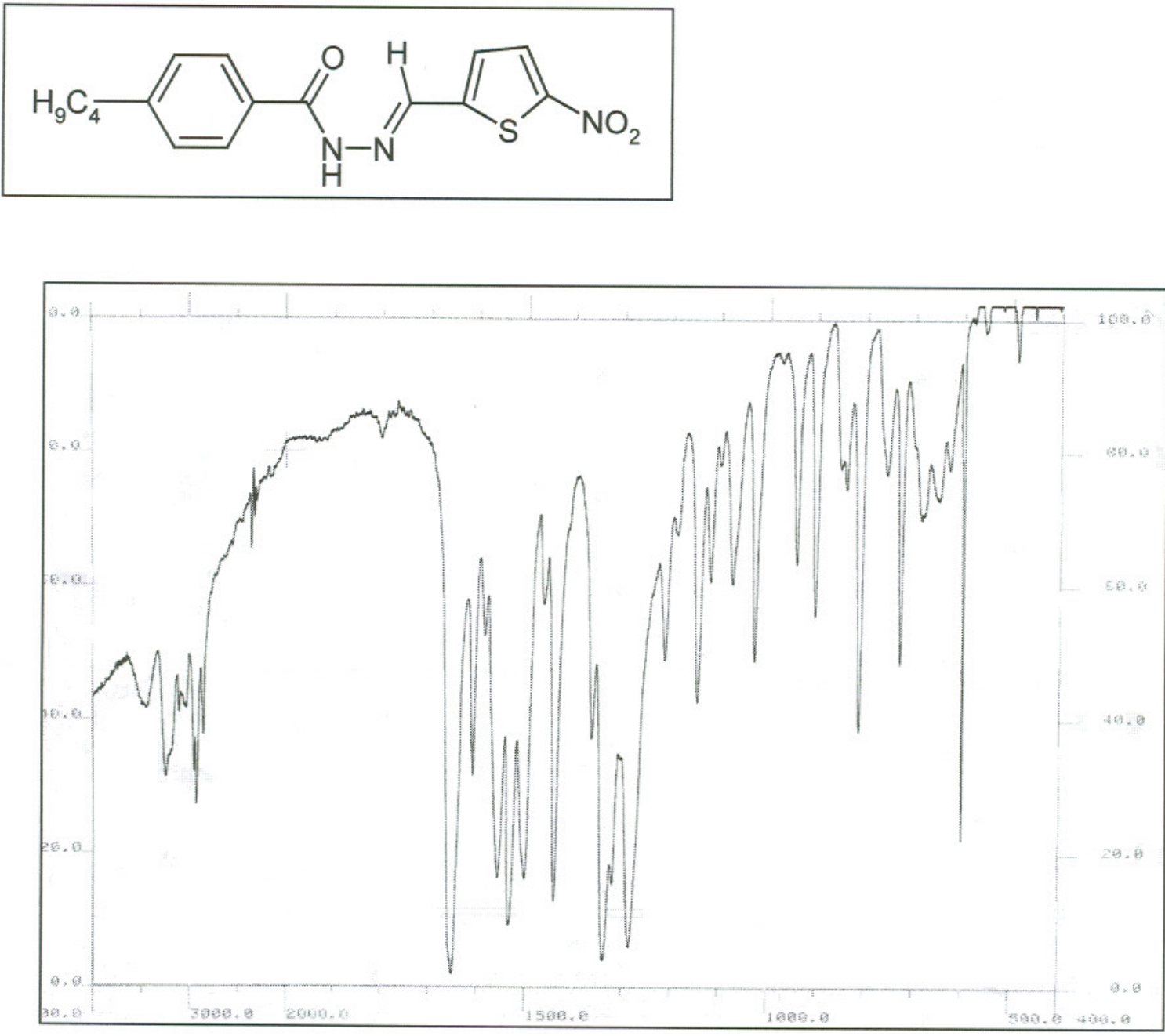

Espectro de absorção na região do IV da 5-nitro-2-tiofilideno 4-butilbenzidrazida. 

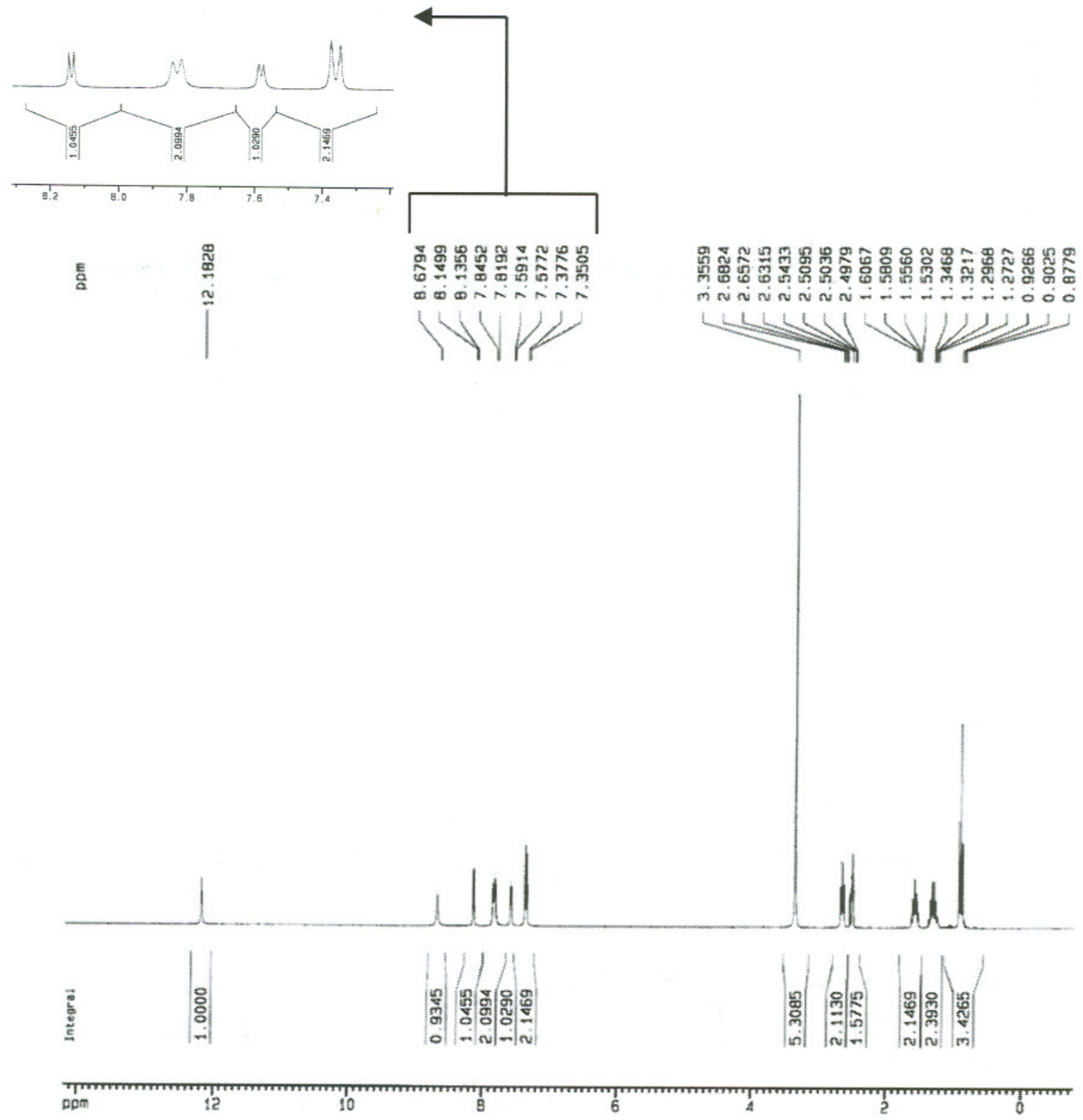

Espectro de $\mathrm{RMN}-{ }^{1} \mathrm{H}$ da 5-nitro-2-tiofilideno 4-butilbenzidrazida. 


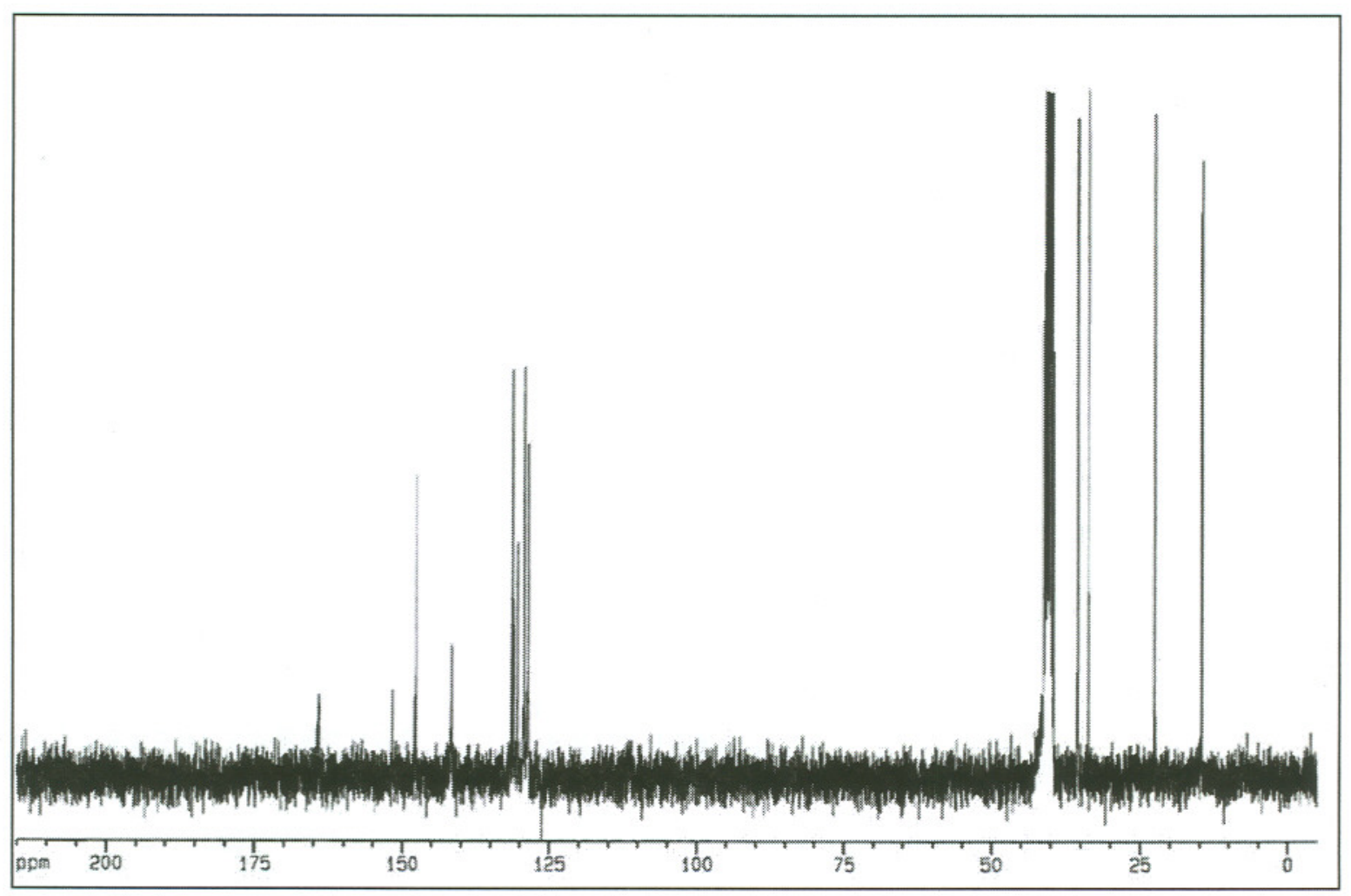

Espectro de $\mathrm{RMN}-{ }^{13} \mathrm{C}$ da 5-nitro-2-tiofilideno 4-butilbenzidrazida. 


\section{5-nitro-2-tiofilideno 3,4-diclorobenzidrazida}<smiles>O=C(N/N=C/c1ccc([N+](=O)[O-])s1)c1ccc(Cl)c(Cl)c1</smiles>

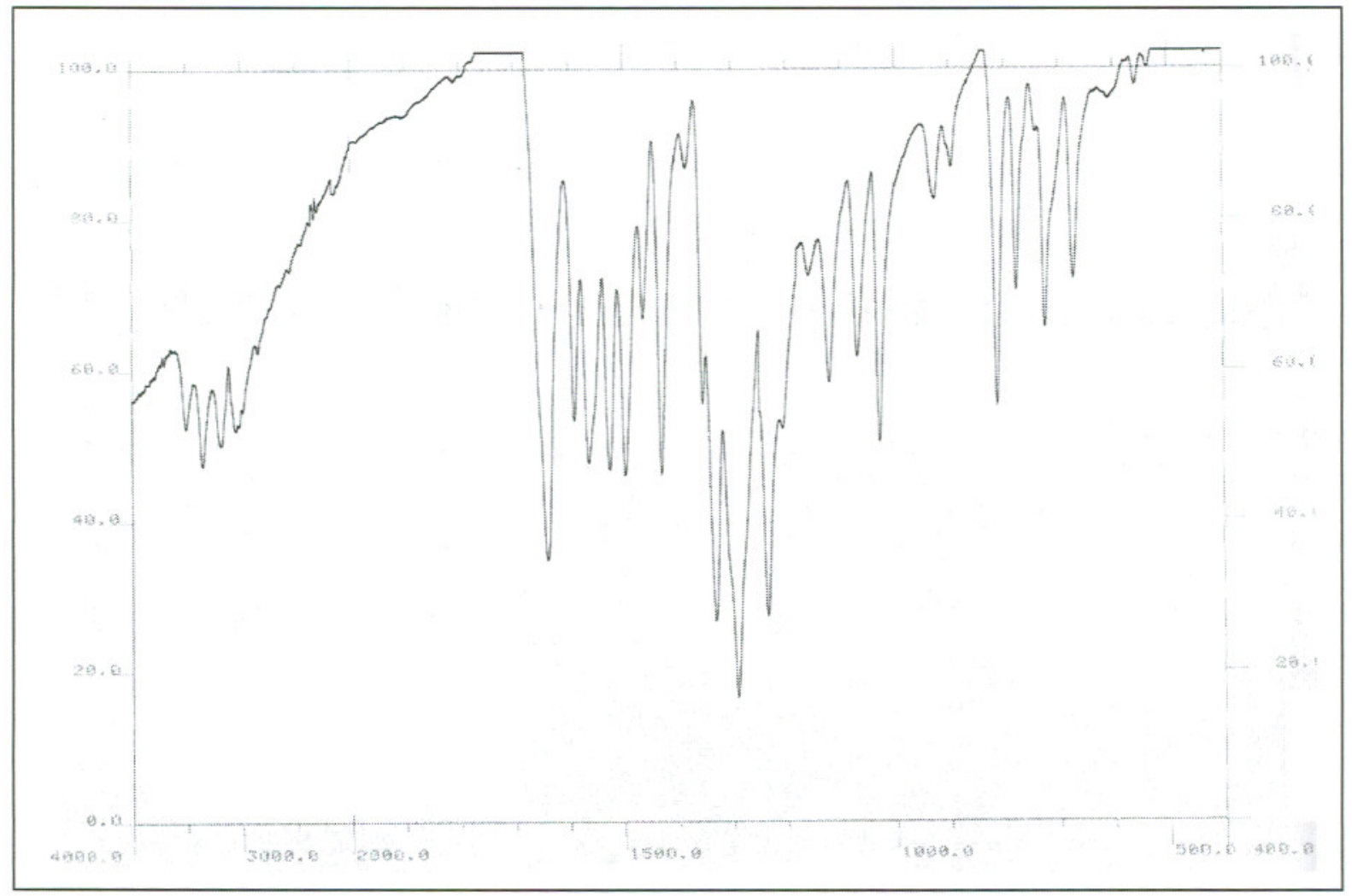

Espectro de absorção na região do IV da 5-nitro-2-tiofilideno 3,4-diclorobenzidrazida 
|
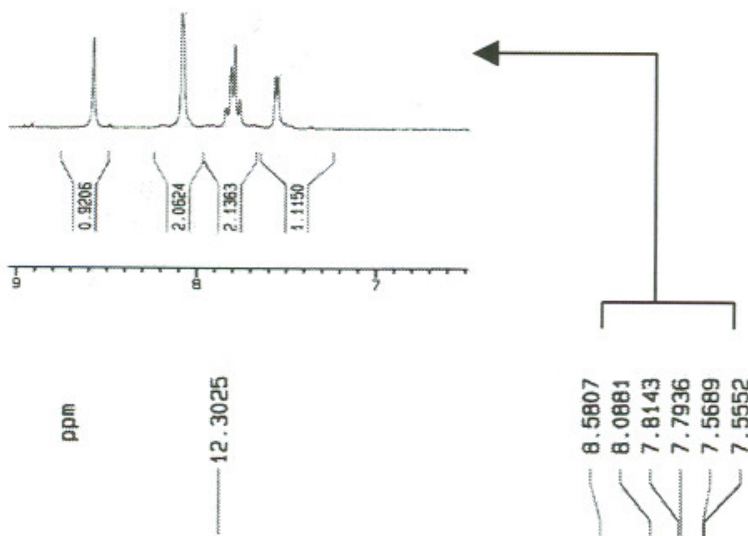

总 尔
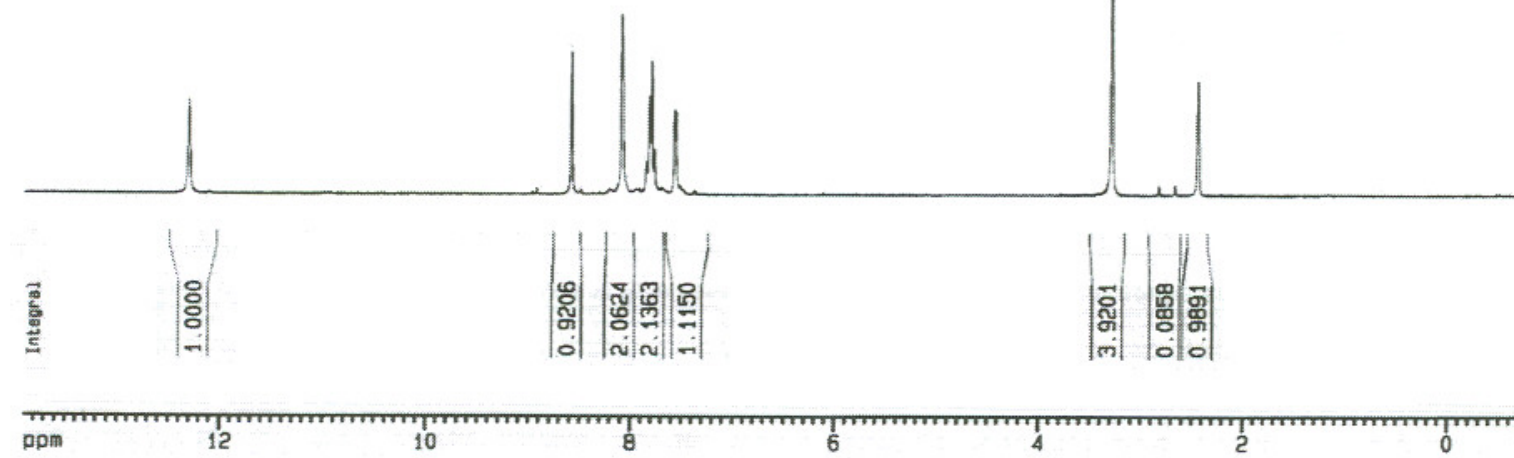

Espectro de $\mathrm{RMN}-{ }^{1} \mathrm{H}$ da 5-nitro-2-tiofilideno-3,4-diclorobenzidrazida. 


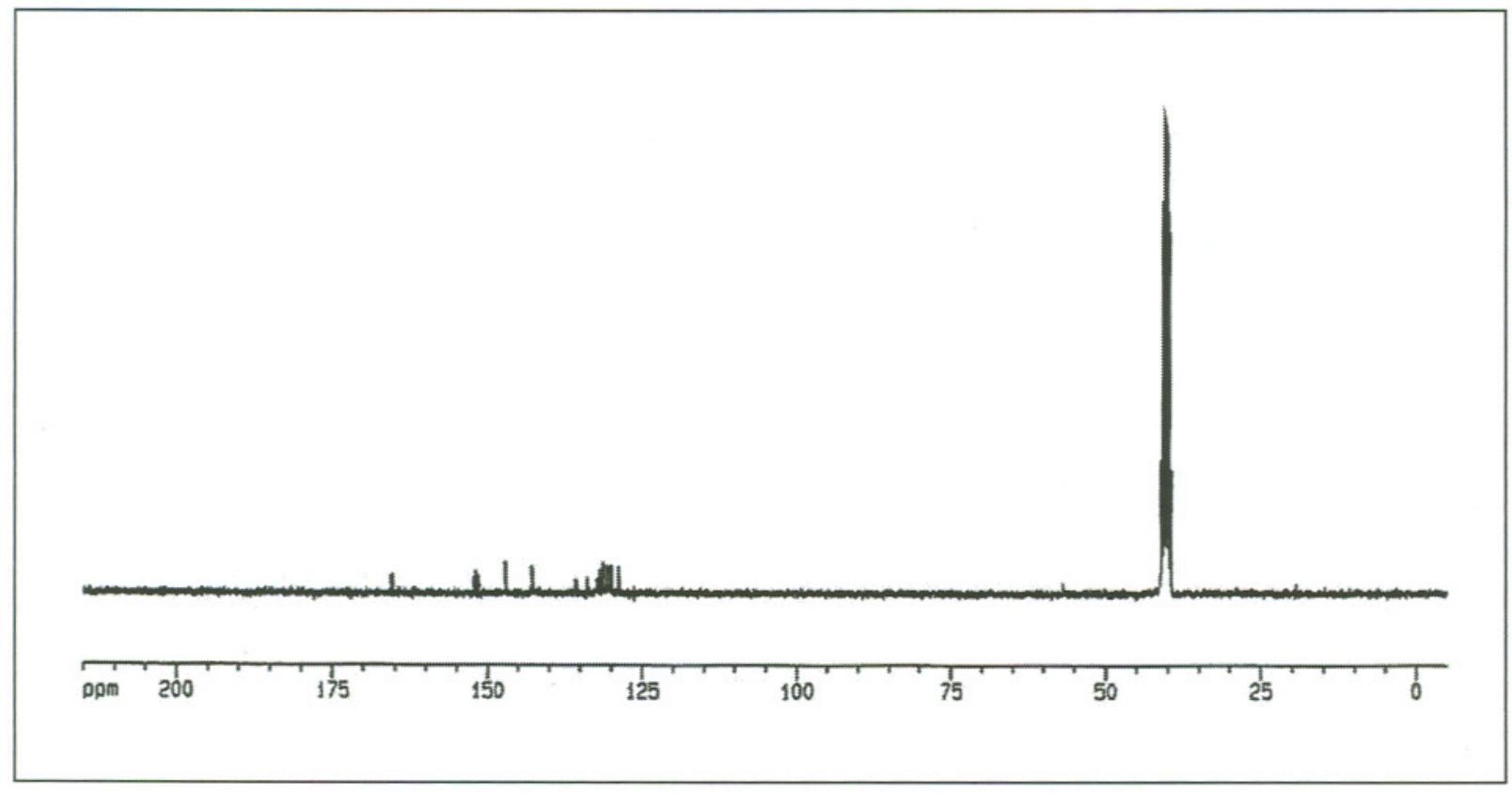

Espectro de RMN- ${ }^{1} \mathrm{H}$ da 5-nitro-2-tiofilideno-3,4-diclorobenzidrazida. 
FBT/FCF/USP

5-nitro-2-tiofilideno 4-etilbenzidrazida<smiles>CCc1ccc(C(=O)N/N=C/c2ccc([N+](=O)[O-])s2)cc1</smiles>

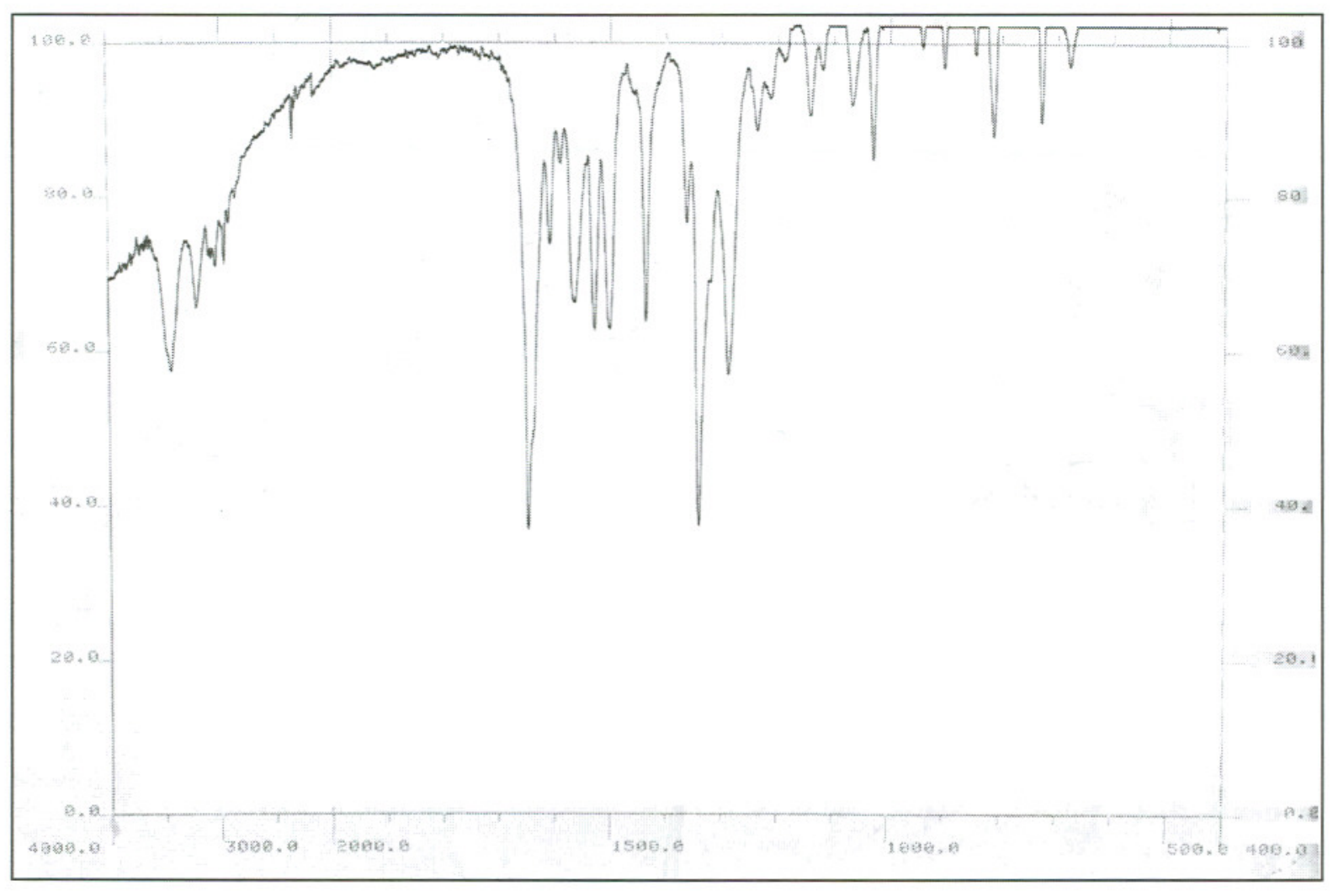

Espectro de absorção na região do IV da 5-nitro-2-tiofilideno 4-etilbenzidrazida.

Andrea Masunari 


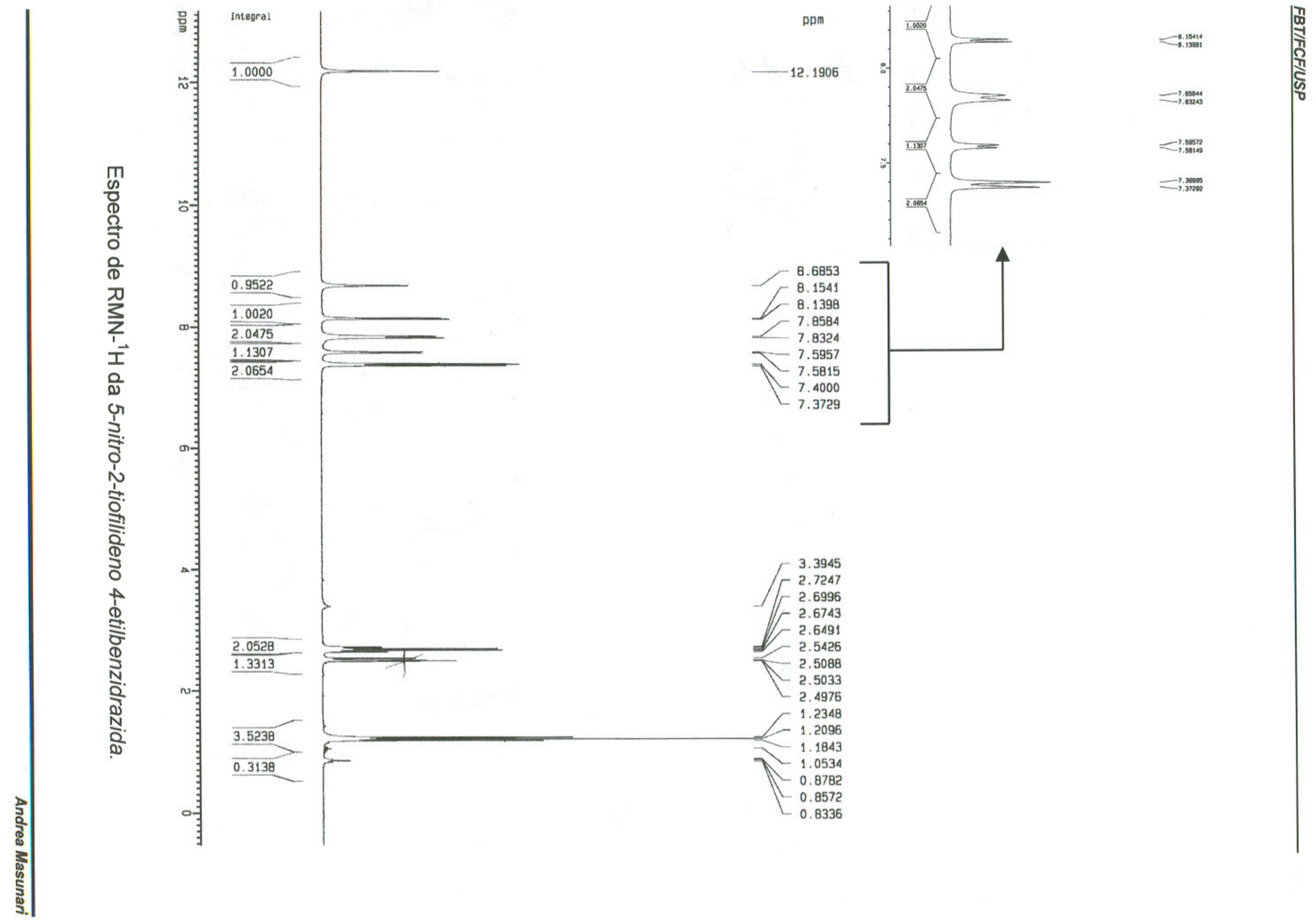




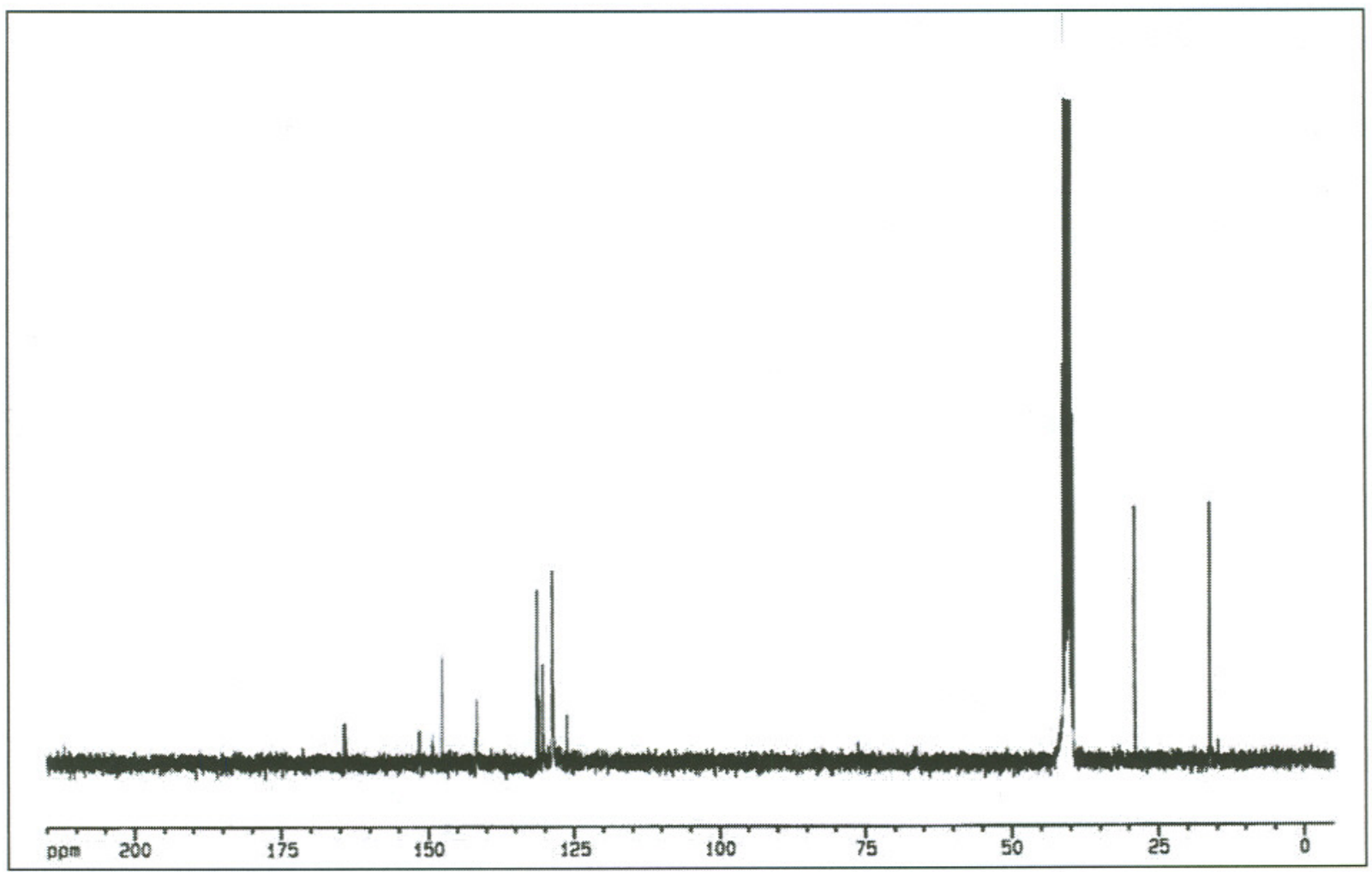

Espectro de $\mathrm{RMN}-{ }^{1} \mathrm{H}$ da 5-nitro-2-tiofilideno 4-etilbenzidrazida. 


\section{5-nitro-2-tiofilideno benzidrazida}
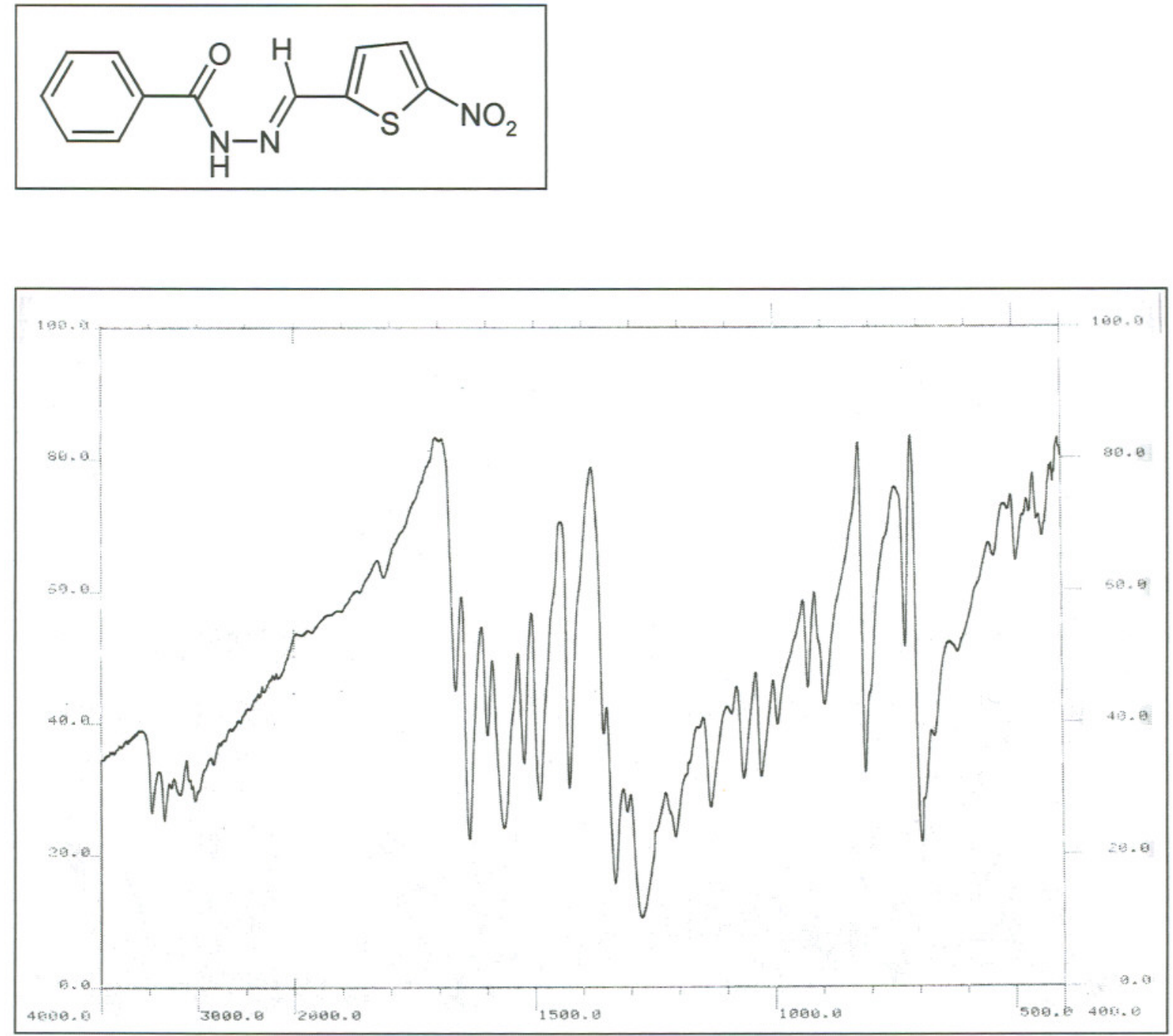

Espectro de absorção na região do IV da 5-nitro-2-tiofilideno benzidrazida. 

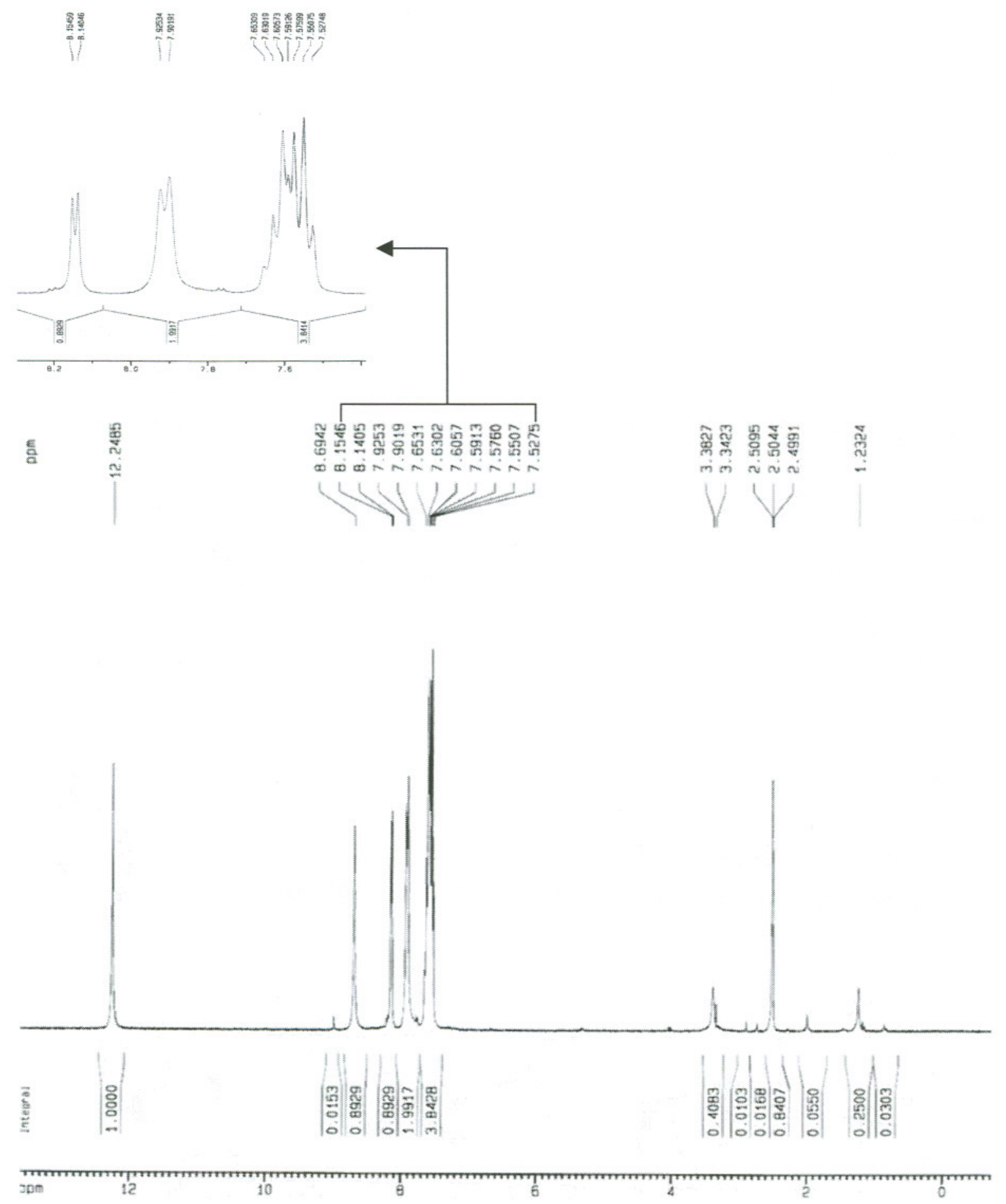

Espectro de $\mathrm{RMN}-{ }^{1} \mathrm{H}$ da 5 -nitro-2-tiofilideno benzidrazida. 


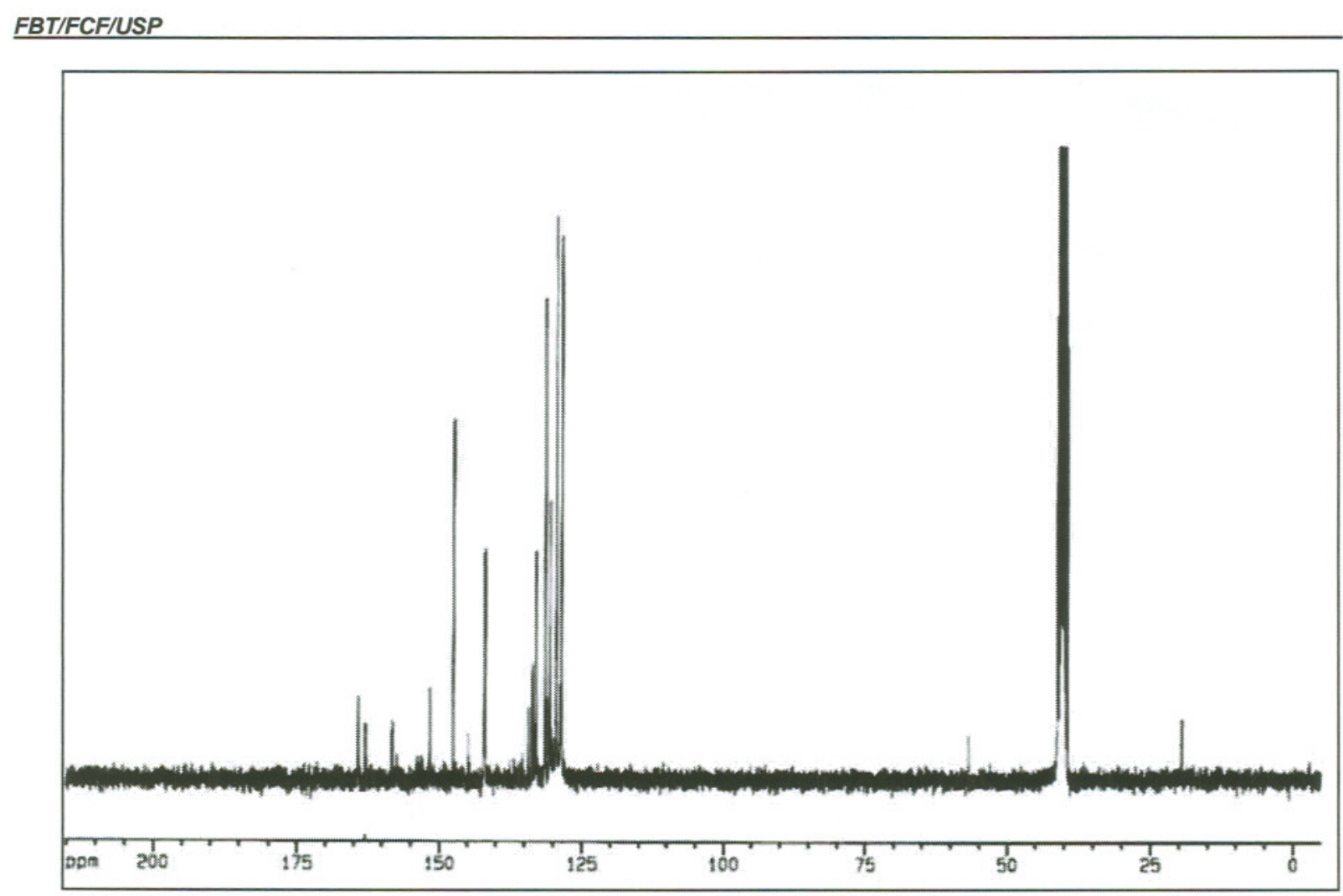

Espectro de $\mathrm{RMN}-{ }^{13} \mathrm{C}$ da 5-nitro-2-tiofilideno benzidrazida. 
FBT/FCF/USP

5-nitro-2-tiofilideno 4-isopropilbenzidrazida<smiles>CC(C)c1ccc(C(=O)N/N=C/c2ccc([N+](=O)[O-])s2)cc1</smiles>

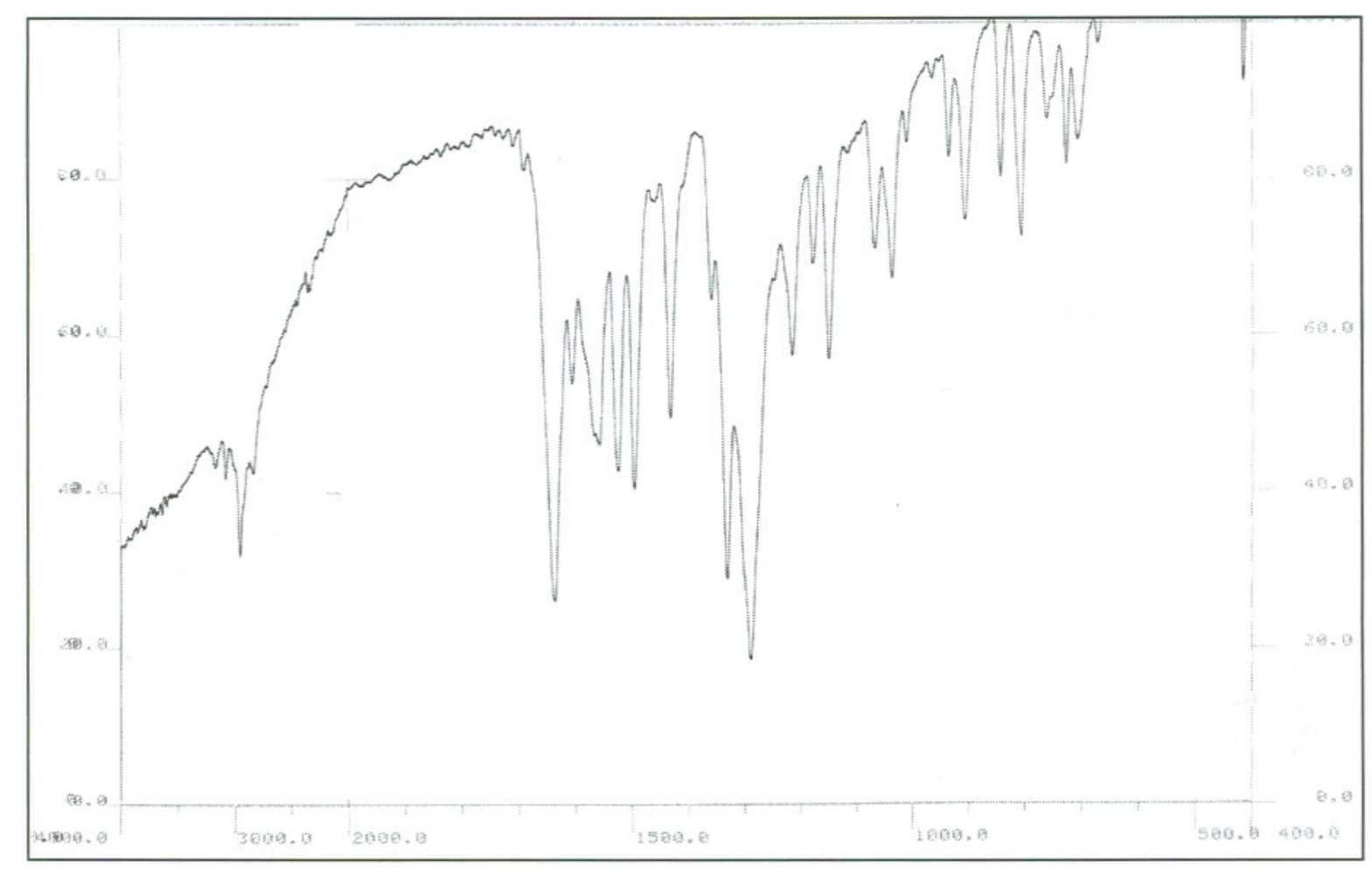

Espectro de absorção na região do IV da 5-nitro-2-tiofilideno 4-isopropilbenzidrazida.

Andrea Masunari 
$\|$ H
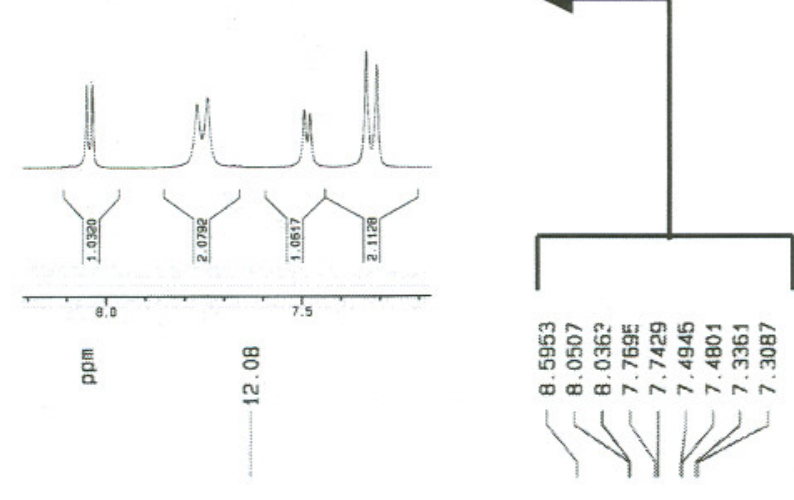

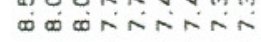

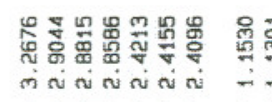

WYV

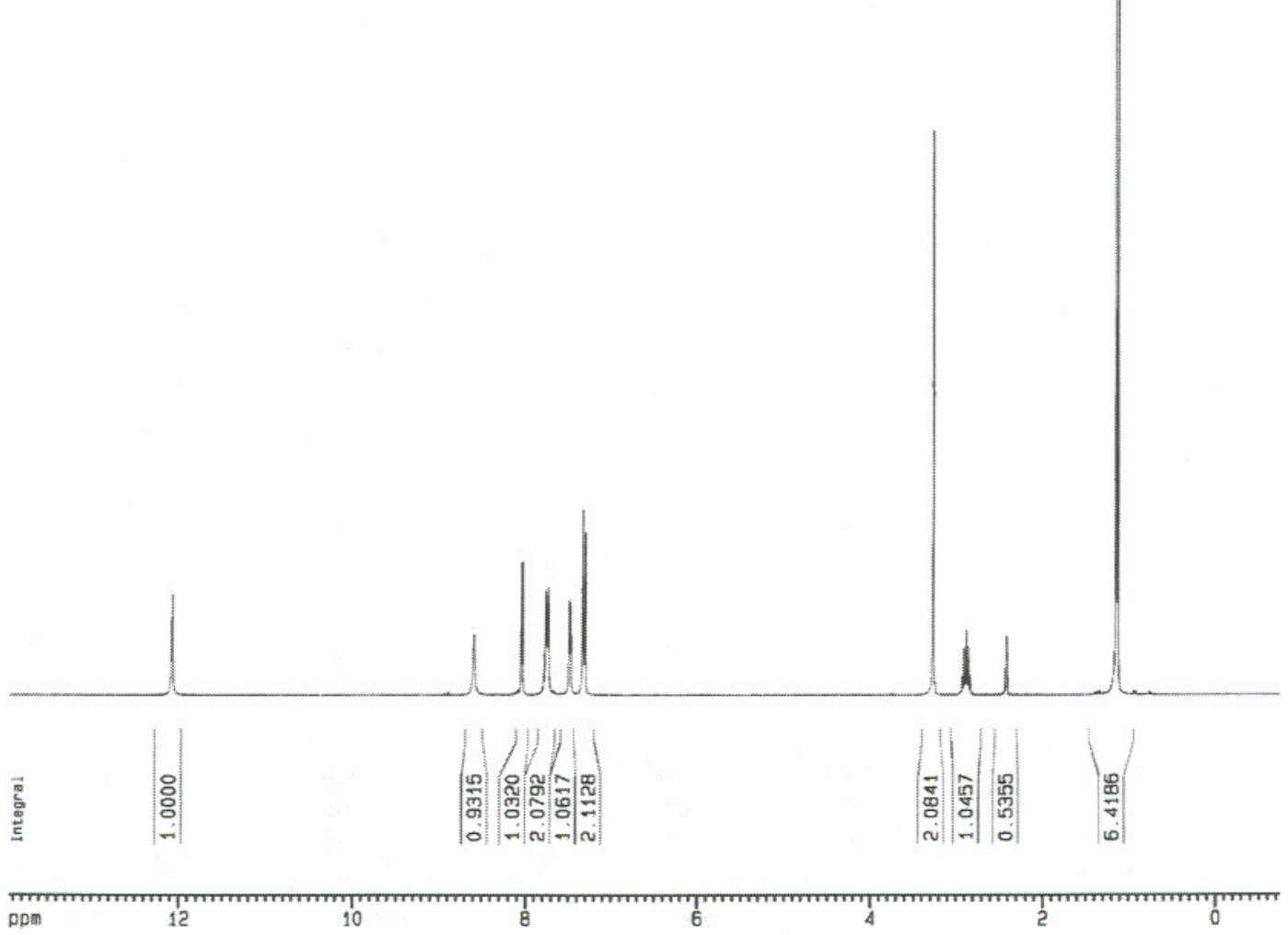

Espectro de $\mathrm{RMN}-{ }^{1} \mathrm{H}$ da 5-nitro-2-tiofilideno 4-isopropilbenzidrazida. 


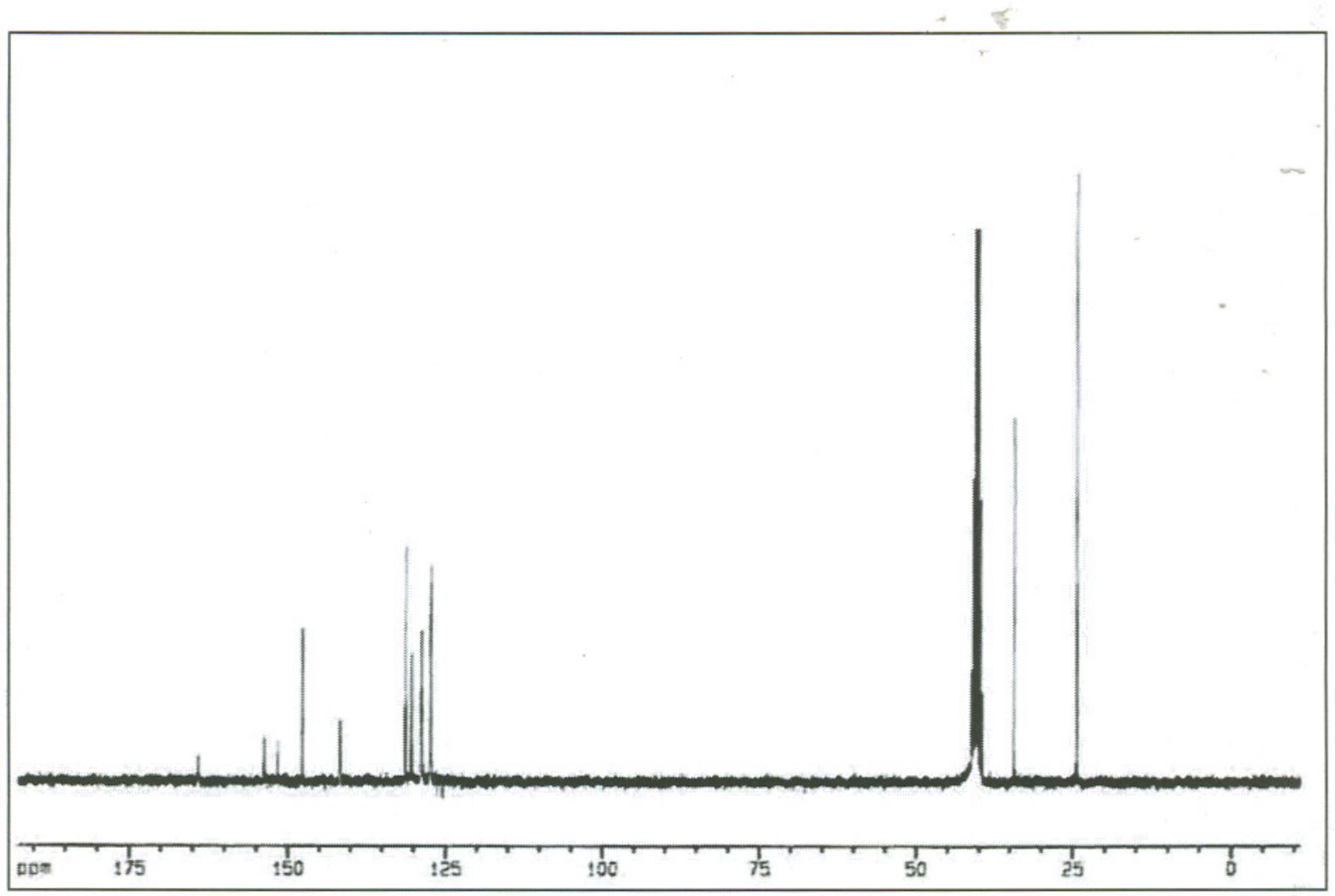

Espectro de $\mathrm{RMN}-{ }^{13} \mathrm{C}$ da 5-nitro-2-tiofilideno 4-isoproplibenzidrazida. 